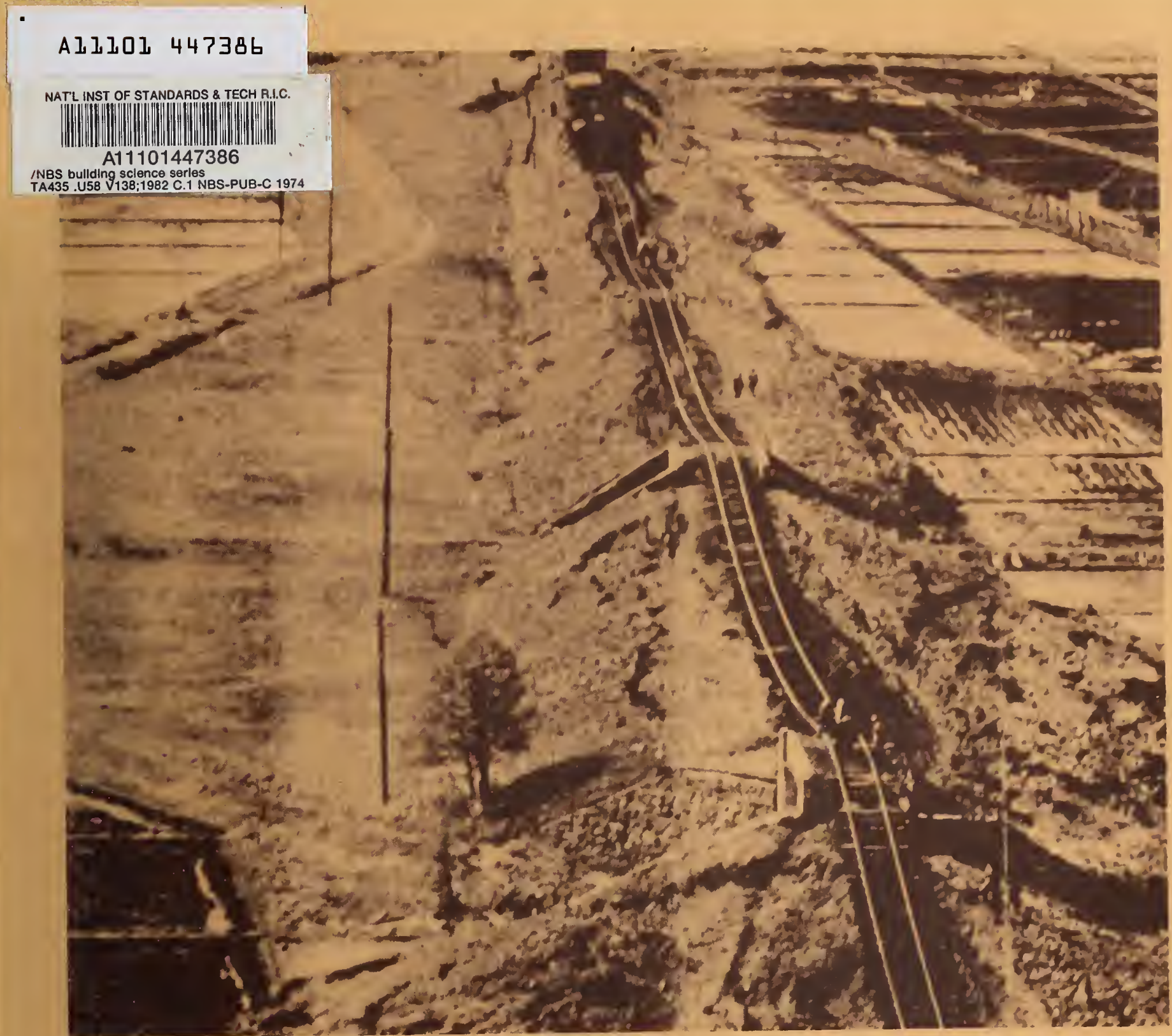

NBS BUILDING SCIENCE SERIES 138

\title{
Prediction of Pore Water Pressure Buildup and Liquefaction of Sands During Earthquakes by the Cyclic Strain Method
}

TA
435
$.453,138$
No.145
1932
$c . ?$




\section{NATIONAL BUREAU OF STANDARDS}

The National Bureau of Standards' was established by an act of Congress on March 3, 1901. The Bureau's overall goal is to strengthen and advance the Nation's science and technology and facilitate their effective application for public benetit. To this end, the Bureau conducts research and provides: (1) a basis for the Nation's physical measurement system, (2) scientific and technological services for industry and government, (3) a technical basis for equity in trade, and (4) technical services to promote public safety. The Bureau's technical work is performed by the National Measurement Laboratory, the National Engineering Laboratory, and the Institute for Computer Sciences and Technology.

THE NATIONAL MEASUREMENT LABORATORY provides the national system of physical and chemical and materials measurement; coordinates the system with measurement systems of other nations and furnishes essential services leading to accurate and uniform physical and chemical measurement throughout the Nation's scientific community, industry, and commerce; conducts materials research leading to improved methods of measurement, standards, and data on the properties of materials needed by industry, commerce, educational institutions, and Government; provides advisory and research services to other Government agencies; develops, produces, and distributes Standard Reference Materials; and provides calibration services. The Laboratory consists of the following centers:

\section{Absolute Physical Quantities ${ }^{2}$ - Radiation Research - Chemical Physics - Analytical Chemistry - Materials Science}

THE NATIONAL ENGINEERING LABORATORY provides technology and technical services to the public and private sectors to address national needs and to solve national problems; conducts research in engineering and applied science in support of these efforts; builds and maintains competence in the necessary disciplines required to carry out this research and technical service; develops engineering data and measurement capabilities; provides engineering measurement traceability services; develops test methods and proposes engineering standards and code changes; develops and proposes new engineering practices; and develops and improves mechanisms to transfer results of its research to the ultimate user. The Laboratory consists of the following centers:

Applied Mathematics - Electronics and Electrical Engineering ${ }^{2}$ - Manufacturing Engineering - Building Technology - Fire Research - Chemical Engineering ${ }^{2}$

THE INSTITUTE FOR COMPUTER SCIENCES AND TECHNOLOGY conducts research and provides scientific and technical services to aid Federal agencies in the selection, acquisition, application, and use of computer technology to improve effectiveness and economy in Government operations in accordance with Public Law 89-306 (40 U.S.C. 759), relevant Executive Orders, and other directives; carries out this mission by managing the Federal Information Processing Standards Program, developing Federal ADP standards guidelines, and managing Federal participation in ADP voluntary standardization activities; provides scientific and technological advisory services and assistance to Federal agencies; and provides the technical foundation for computer-related policies of the Federal Government. The Institute consists of the following centers:

Programming Science and Technology-Computer Systems Engineering.

'Headquarters and Laboratories at Gaithersburg, MD, unless otherwise noted;

mailing address Washington, DC 20234.

${ }^{2}$ Some divisions within the center are located at Boulder, CO 80303. 


\title{
Prediction of Pore Water Pressure Buildup and Liquefaction of Sands During Earthquakes by the Cyclic Strain Method
}

\author{
R. Dobry² \\ R.S. Ladd ${ }^{3}$ \\ F.Y. Yokel' \\ R.M. Chung' \\ D. Powell?
}

'Center for Building Technology National Engineering Laboratory

National Bureau of Standards

Washington, DC 20234

2Department of Civil Engineering

Rensselaer Polytechnic Institute

Troy, NY 12181

${ }^{3}$ Woodward-Clyde Consultants

Clifton, NJ 07012

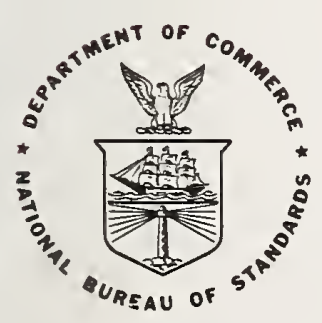

U.S. DEPARTMENT OF COMMERCE, Malcolm Baldrige, Secretary

NATIONAL BUREAU OF STANDARDS, Ernest Ambler, Director

lssued July 1982 


\section{Library of Congress Catalog Card Number: 82-600561}

National Bureau of Standards Building Science Series 138 Nat. Bur. Stand. (U.S.), Bldg. Sci. Ser. 138, 168 pages (July 1982) CODEN: BSSNBV 
PREDICTION OF PORE WATER PRESSURE BUILDUP AND LIOUEFACTION OF SANDS

DURING EARTHQUAKES BY THE CYCLIC STRAIN METHOD

\section{ABSTRACT}

A cyclic strain approach for evaluating the buildup of excess pore water pressures and the potential for liquefaction of level sandy sites during earthquakes is proposed in this report. This strain approach is based on the premise that, for undrained loading of sand, there is a predictable correlation between cyclic shear strain and excess pore water pressure; also, that there is a threshold shear strain below which there is no sliding at the contacts between sand particles and no pore water pressure buildup can occur. As the result, a sand deposit will not develop excess pore pressures if the induced seismic shear strain is less than the threshold strain. Both theoretical evidence and experimental verification supporting the cyclic strain approach and the existence of the threshold, are presented in the report. Based on all these findings, a specific design method is proposed for predicting if excess pore pressures will develop at a specific site during a design earthquake.

Key words: cyclic strain; damping ratio; earthquake engineering; laboratory testing; liquefaction; particulate mechanics; particulate model; pore water pressure; sand; seismic loading; shear modulus; shear strain; site stability.

COVER: A railroad embankment which was totally destroyed during an earthquake in Japan by liquefaction of the underlying loose saturated sands. 



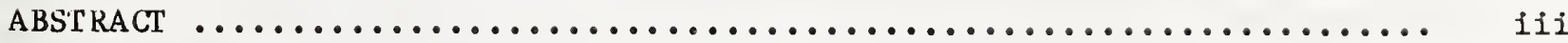

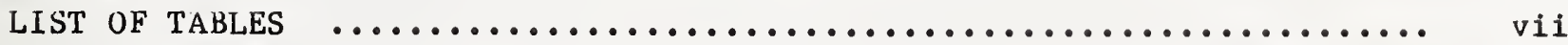

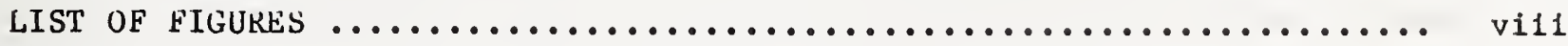

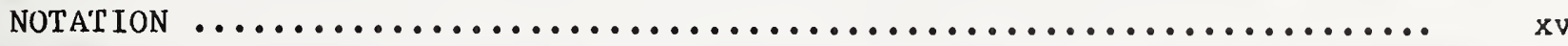

1. IntRoduction $\ldots \ldots \ldots \ldots \ldots \ldots \ldots \ldots \ldots \ldots \ldots \ldots \ldots \ldots \ldots \ldots \ldots \ldots \ldots \ldots \ldots$

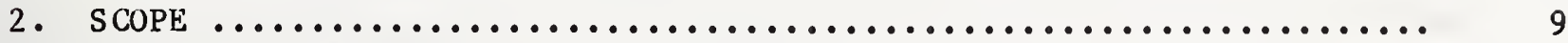

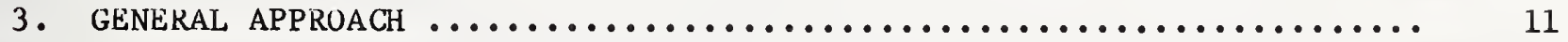

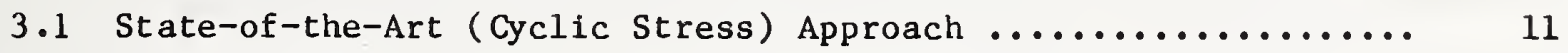

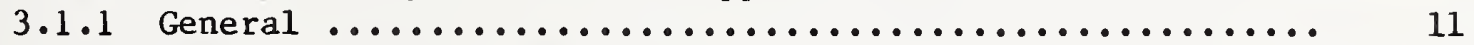

3.1 .2 The Simplified (Seed and Idriss) Procedure ........... 13

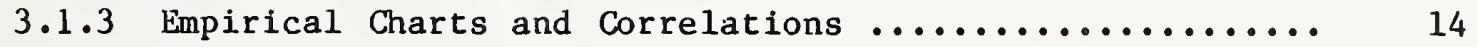

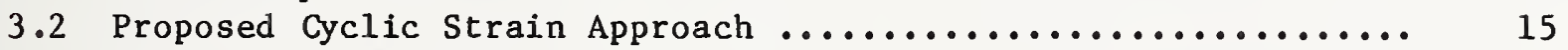

3.2 .1 Problems with the Stress Approach................. 15

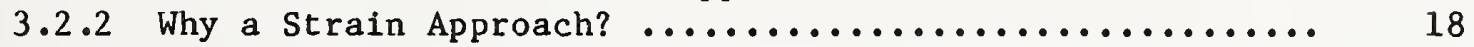

3.2.3 Analysis of Available Cyclic Test Results ............. 19

3.2 .4 Proposed Cyclic Strain Method ................... 22

4. A MODEL OF SPHERES FOR THE THRESHOLd STRAIN ................. 49

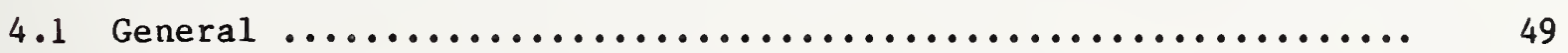

4.2 Contact Between Elastic Spheres ...................... 50

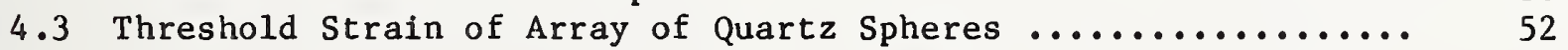

4.4 Cyclic Stress-Strain Behavior at Very Small Strains ......... 53

5. CYCli L LABORATORY MEASUREMENTS .......................... 65

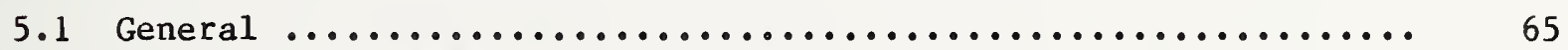

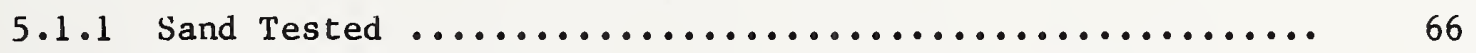

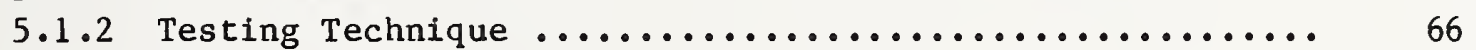

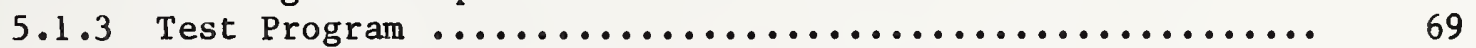

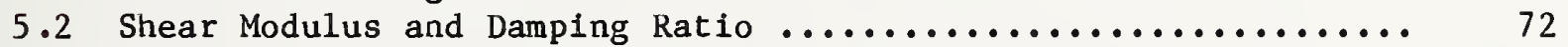

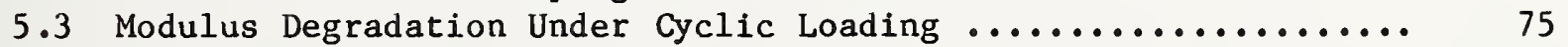

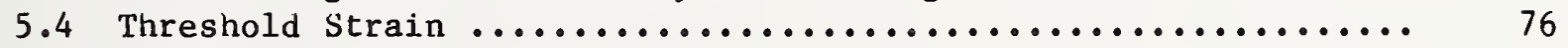

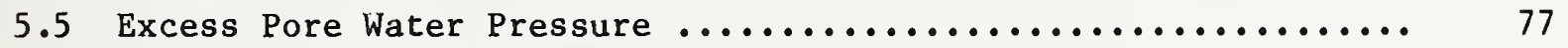

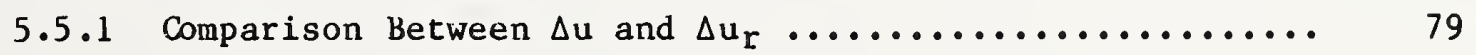

5.6 Pore Water Pressure and Modulus Degradation ............... 80

6. EAKTHQUAKE ACCELERATION AND THRESHOLD STRAIN ................ 117

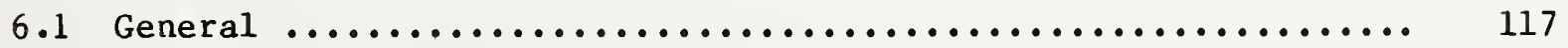

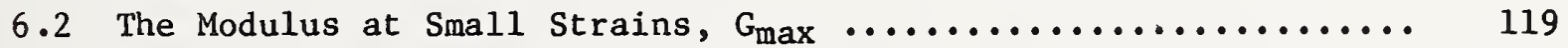

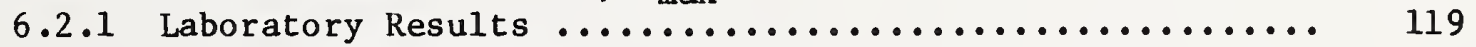

6.2 .2 In Situ Measurements ......................... 120 
TABLE OF CONTENTS (continued)

$\underline{\text { Page }}$

6.3 The Modulus Reduction Factor, $G / G_{\max } \ldots \ldots \ldots \ldots \ldots \ldots \ldots \ldots \ldots \ldots \ldots 123$

6.4 Parametric study ................................. 124

7. SUMMARY AND FINDINGS .............................. 137

8. ACKNOWLEDGEMENTS $\ldots \ldots \ldots \ldots \ldots \ldots \ldots \ldots \ldots \ldots \ldots \ldots \ldots \ldots \ldots \ldots \ldots \ldots \ldots \ldots \ldots$

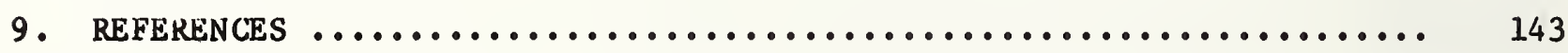

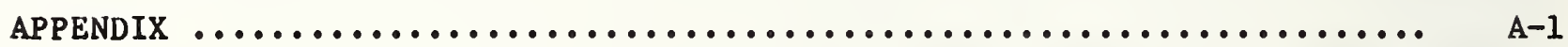


LIST OF TABLES

Page

Table 1.1 Some Modern Non-Japanese Earthquakes Which Have Induced Liquefaction

3

Table 3.1 Some Factors Influencing the Cyclic Strength of Sands ....

17

Table 5.1 Index Properties for Monterey No. 0 Sand (Mulilis et al., 1975)

67

Table 5.2 List of Cyclic Triaxial Tests

70

Table 5.3 Cyclic Triaxial Tests with $\sigma_{3}^{\prime}=2,000$ psf

71

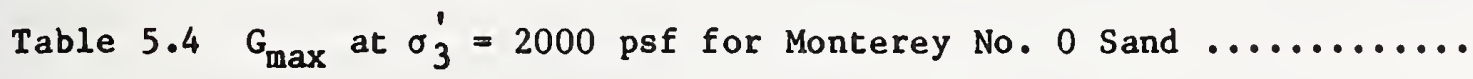

73

vii 


\section{LIST OF FIGURES}

Page

Figure 1.1. Tilted Nilgata buildings after earthquake .............. 6

Figure 1.2. Settlement of a dry sand in cyclic strain controlled simple shear tests (Silver and Seed, 1971) ...............

Figure 3.1. Cyclic shear stresses on a soil element during ground

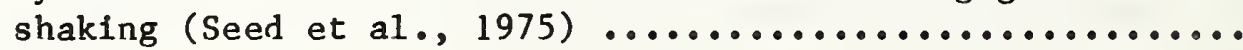

Figure 3.2. Typical form of the relationship between pulsating shear stress and the number of cycles to cause failure - simple shear conditions (Peacock and Seed,

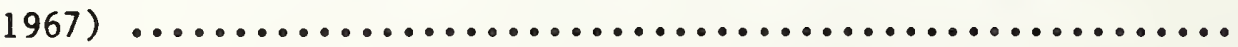

Figure 3.3. Cyclic stress method for evaluating liquefaction potential

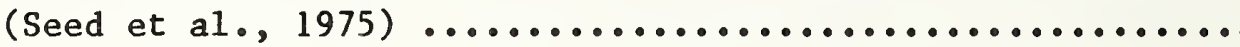

Figure 3.4. Range of values of stress reduction ratio, $r_{d}$, for different soil profiles (Seed and Idriss, 1971)

Figure 3.5. Equivalent number of uniform stress cycles based on strongest components of ground motion (Seed et al., 1975a)

Figure 3.6. Analysis of liquefaction potential at Nigata for earthquake of June 16, 1964. (Seed et al., 1975) .........

Figure 3.7. Performance of saturated sands at earthquake sites (Castro, 1975)

Figure 3.8. Correlation between stress ratio causing liquefaction in the fleld and modifled penetration resistance of sand, $N_{1}$ (Seed et al., 1975)

Figure 3.9. Correlation between field liquefaction behavior of sands for level ground conditions and modified penetration resistance (supplemented by data from large scale tests, Seed, 1979)

Figure 3.10. Cyclic stresses required to cause liquefaction and 20 percent strain in Sacramento river sand at different densities $-\sigma\} ;=1.0 \mathrm{~kg}$ per sq $\mathrm{cm}$ (Seed and Lee, 1965) ...

Figure 3.11. Cyclic stress ratio versus number of cycles for different compaction procedures (after Mulilis et al., 1975) 
Figure 3.12 Effect of seismic history on cyclic strength of sand

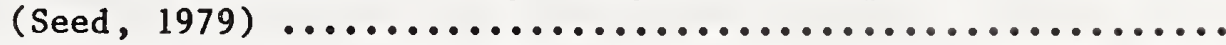

Figure 3.13 Influence of overconsolidation on stress causing pore water pressure ratio of 100 percent in simple shear tests

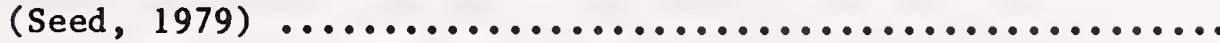

Figure 3.14 Influence of period of sustained pressure on stress causing peak cyclic pore pressure ratio of 100 percent

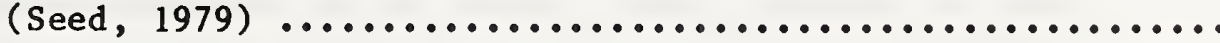

Figure 3.15 Vold ratio change for a sand as a function of cyclic shear strain and number of cycles (Youd, 1972) ..............

Figure 3.16 Grain size curves of sands used in testing ........... 40

Figure 3.17 Effect of fabric on cyclic strength, stress-controlled

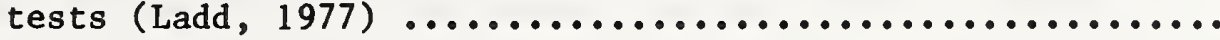

Figure 3.18 Stress-strain curves for first compression and extension excursions, stress-controlled cyclic triaxial tests, Sand No. 2 (modified after Ladd, 1977) ...............

Figure 3.19 Effect of fabric on cyclic strength after accounting for sample stiffness, stress-controlled tests (modified

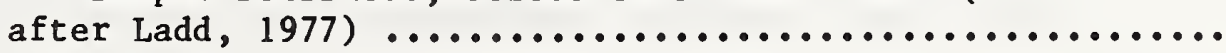

Figure 3.20 Effect of fabric on cyclic strength, stress-controlled

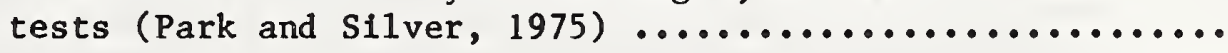

Figure 3.21 Stress-controlled cyclic triaxial tests of saturated Crystal Silica sand (modified after Park and Silver, 1975)

Figure 3.22 Stress-strain curve for first cycle, cyclic triaxial tests of saturated Crystal Silica sand (modified after

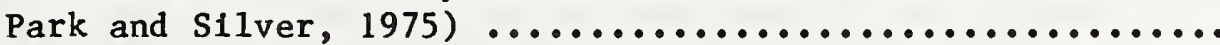

Figure 3.23 Strain-controlled cyclic triaxial tests of saturated Crystal Silica sand (modified after Park and Silver, 1975)

Figure 3.24 Measured pore water pressure in saturated sands after ten loading cycles, strain-controlled cyclic triaxial

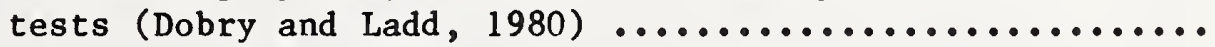

Figure 4.1 Simple cubic array of equal spheres $\ldots \ldots \ldots \ldots \ldots \ldots \ldots \ldots$ 
Figure 4.2 Elast1c spheres under normal and tangent1al loads ........

Figure 4.3 Normal $\left(\sigma_{c}\right)$ and tangent1al $\left(\tau_{c}\right)$ components of traction on contact region between two spheres subjected to normal force followed by a monotonic tangential force

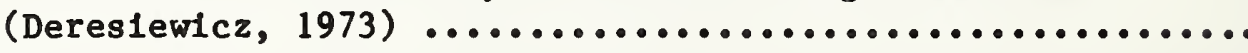

Figure 4.4 Theoretical hysteresis loop due to oscillating tangential force at constant normal force for two spheres in contact (Dereslew1cz, 1973)

Figure 4.5 Experimental hysteresis loops obtalned from cyclic tests of bodies in contact (Johnson, 1955) ...................

Figure 4.6 Tangential force - displacement relation for two elastic spheres under constant normal force, $N$ (Dobry and Grivas, 1978)

Figure 4.7 Calculated threshold shear strain as a function of Isotroplc confining stress for a simple cublc array of quartz spheres ...................................

Figure 4.8 Reduction of shear modulus as a function of shear strain - comparison between calculated $G / G_{\max }$ for a simple cublc array and experimental range for sand .........

Figure 4.9 Dampling ratio as a function of shear strain - comparison between calculated $\lambda$ for a simple cublc array and experimental range for sand

Figure 5.1 Grain size distribution of Monterey No. 0 sand ...........

Figure 5.2 Typical correction factor for equipment compliance, cycllc triaxial tests .............................

Figure 5.3 Reduction of shear modulus as a function of cyclic shear strain for Monterey No. 0 sand at $\sigma \xi=2000$ psf and $D_{r}=45$ percent ................................

Figure 5.4 Reduction of shear modulus as a function of cycllc shear strains for Monterey No. 0 sand at $\sigma \xi=2000$ psf and

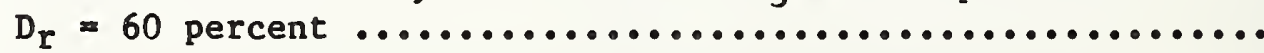


Figure 5.5 Reduction of shear modulus as a function of cyclic shear strain for Monterey No. 0 sand at $\sigma \xi=2000$ psf and

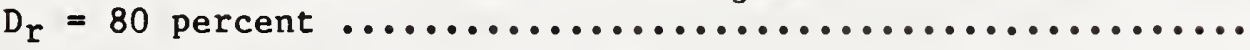

Figure 5.6 Reduction of shear modulus as a function of cyclic shear strain for Monterey No. 0 sand at $\sigma\}=2000$ psf and $D_{r}=45,60$, and 80 percent $\ldots \ldots \ldots \ldots \ldots \ldots \ldots \ldots \ldots$

Figure 5.7 Damping ratio as a function of cyclic shear strain for Monterey No. 0 sand at $\sigma \xi=2000$ psf and $D_{r}=45,60$,

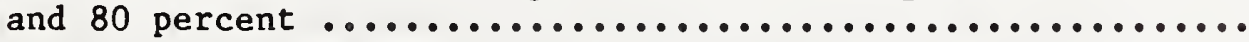

Figure 5.8 Reduction of shear modulus as a function of cyclic shear strain for Monterey No. 0 sand at $D_{r}=60$ percent and

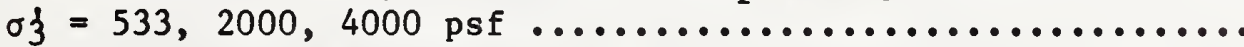

Figure 5.9 Shear modulus at very small shear strains $\left(G_{\max }\right.$ ) as a function of effective confining pressure $(\sigma \xi)$ for Monterey No. 0 sand at $\mathrm{D}_{\mathrm{r}}=60$ percent

Figure 5.10 Normalized stiffness parameter as a function of cyclic shear strain for Monterey No. 0 sand at $D_{r}=60$ percent, $\sigma_{3}=2000$ psf and various effective confining pressures ....

Figure 5.11 Degradation of shear modulus as a function of number of cycles for Monterey No. 0 sand at $D_{r}=45$ percent, of $=2000$ psf and varlous cyclic shear stralns ...........

Figure 5.12 Degradation of shear modulus as a function of number of cycles for Monterey No. 0 sand at $D_{r}=60$ percent $\sigma\}=2000$ psf and various cyclic shear strains ...........

Figure 5.13 Degradation of shear modulus as a function of number of cycles for Monterey No. 0 sand at $D_{r}=80$ percent, $\left.\sigma\right\}=$

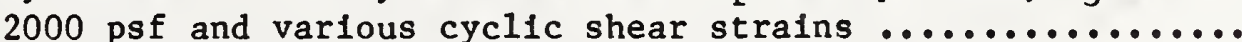

Figure 5.14 Degradation of shear modulus as a function of number of cycles for Monterey No. 0 sand at 0$\}=2000$ psf, $\gamma=3 \times 10^{-2}$ percent and $D_{r}=45$ and 60 percent $\ldots \ldots \ldots \ldots$

Figure 5.15 Degradation of shear modulus as a function of number of cycles for Monterey No. 0 sand at $\sigma\}=2000$ psf, $\gamma=1 \times 10^{-1}$ percent, and $D_{r}=45,60$, and 80 percent ......

Figure 5.16 Degradation of shear modulus as a function of number of cycles for Monterey No. 0 sand at $\sigma \xi=2000 \mathrm{psf}$, $\gamma=3 \times 10^{-1}$ percent, and $D_{r}=45,60$, and 80 percent ..... 
LIST OF FIGURES (continued)

Page

Figure 5.17 Degradation of shear modulus as a function of number of cycles for Monterey No. 0 sand at $D_{r}=60$ percent, $\gamma=3 \times 10^{-2}$ percent, and $\sigma_{3}^{\prime}=533,2000$, and 4000 psf $\ldots . .97$

Figure 5.18 Residual pore water pressure bulldup after ten loading cycles, as a function of cyclic shear strain for Monterey No. 0 sand at $\sigma\}=2000$ psf and $D_{r}=45,60$, and 80

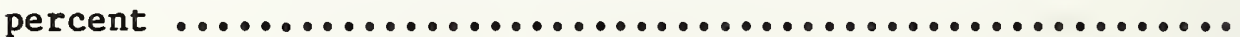

Figure 5.19 Residual pore water pressure buildup after ten loading cycles, as a function of cyclic shear strain for Monterey No. 0 sand at $\sigma\}=533,2000$, and 4000 psf and $D_{r}=45$,

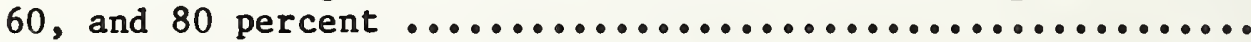

Figure 5.20 Settlement in the first loading cycle as a function of cyclic shear strain for dry Monterey No. 0 sand at various relative densities and confining pressures, simple shear

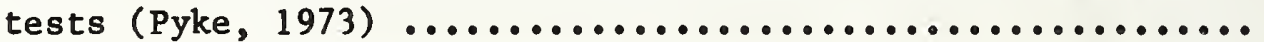

Figure 5.21 Pore water pressure bulldup as a function of number of cycles for Monterey No. 0 sand at $\sigma\}=2000$ psf, $D_{r}=45$ percent and various cyclic shear strains ............... 101

Figure 5.22 Pore water pressure bulldup as a function of number of cycles for Monterey No. 0 sand at of $=2000 \mathrm{psf}, \mathrm{D}_{\mathrm{r}}=60$ percent and various cyclic shear strains ............... 102

Figure 5.23 Pore water pressure bulldup as a function of number of cycles for Monterey No. 0 sand at $\sigma\}=2000 \mathrm{psf}, \mathrm{D}_{\mathrm{r}}=80$ percent and various cyclic shear strains ............... 103

Figure 5.24 Pore water pressure bulldup as a function of number of cycles for Monterey No. 0 sand at $\sigma\}=2000$ psf, $\gamma=$ $3 \times 10^{-2}$ percent, and $D_{r}=45$ and 60 percent $\ldots \ldots \ldots \ldots \ldots . . .104$

Figure 5.25 Pore water pressure bulldup as a function of number of cycles for Monterey No. 0 sand at $\sigma\}=2000$ psf, $\gamma=$ $1 \times 10^{-1}$ percent, and $D_{r}=45,60$, and 80 percent $\ldots \ldots \ldots \ldots 105$

Figure 5.26 Pore water pressure bulldup as a function of number of cycles for Monterey No. 0 sand at of $=2000$ psf, $\gamma=$ $3 \times 10^{-1}$ percent, and $D_{r}=45,60$, and 80 percent $\ldots \ldots \ldots . .106$

Figure 5.27 Pore water pressure bulldup as a function of number of cycles for Monterey No. 0 sand at $D_{r}=60$ percent, $\gamma=3 \times 10^{-2}$ percent, and various effective confining pressures ..................................... 
Figure 5.28 Pore water pressure buildup as a function of cyclic shear strain for Monterey No. 0 sand at $D_{r}=45$ percent, $\left.\sigma\right\}=$ 2000 psf and various numbers of cycles ................. 108

Figure 5.29 Pore water pressure buildup as a function of cyclic shear strain for Monterey No. 0 sand at $D_{r}=60$ percent, of $=$ 2000 psf and various numbers of cycles ................ 109

Figure 5.30 Pore water pressure bulldup as a function of cyclic shear strain for Monterey No. 0 sand at $D_{r}=80$ percent, $\left.\sigma\right\}=$ 2000 psf and various numbers of cycles ................

Figure 5.31 Pore water pressure buildup after ten loading cycles, as a function of cyclic shear strain for Monterey No. 0 sand at $\sigma\}=2000 \mathrm{psf}$, and $\mathrm{D}_{\mathrm{r}}=45,60$, and 80 percent $\ldots \ldots \ldots \ldots$

Figure 5.32 Pore water pressure buildup after thirty loading cycles, as a function of cyclic shear strain for Monterey No. 0 sand at $\sigma \xi=2000$ psf, and $D_{r}=45,60$, and 80 percent .....

Figure 5.33 Pore water pressure buildup in cyclic triaxial straincontrolled tests after ten loading cycles, as a function of cyclic shear strain, for various NC saturated sands, $D_{r}=60$ percent and for various confining pressures ..............

Figure 5.34 Comparison between $\Delta u$ and $\Delta u_{r}$ as a function of pore water pressure ratio for Monterey No. 0 sand at $D_{r}=45,60$ and

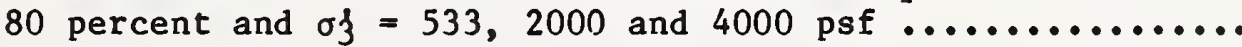

Figure 5.35 Degradation of shear modulus as a function of pore water pressure buildup for Monterey No. 0 sand ................

Figure 6.

Simplified soil profile

Figure 6.2 Modulus reduction curves for sands (Iwasaki et al., 1978)

Figure 6.3 Relation between normalized stiffness parameter, $K_{2 \max }$, and relative density (modified from Seed and Idris8, 1970) .....

Figure 6.4 Crosshole geophysical method (Hoar and Stokoe, 1977) .......

Figure 6.5 Normalized shear modulus parameter, A, measured for sands in the field using geophysical techniques (Powel1, 1979)... 


\section{LIST OF FIGURES (continued)}

Page

Figure 6.6 Coefficient of earth pressure at rest, $\mathrm{K}_{0}$, as a function of overconsolidation ratio, OCR (Hendron, 1963) ........... 131

Figure 6.7 Influence of the coefficient of earth pressure at rest,

$\mathrm{K}_{\mathrm{O}}$, on the normalized shear modulus parameter, $\mathrm{A} \ldots \ldots \ldots \ldots . . .132$

Figure 6.8 Reduction of shear modulus at different cyclic shear

strains, $\gamma$, for sands (data from Iwasaki et al., 1978) ..... 133

Figure 6.9 Liquefaction chart for threshold peak ground surface

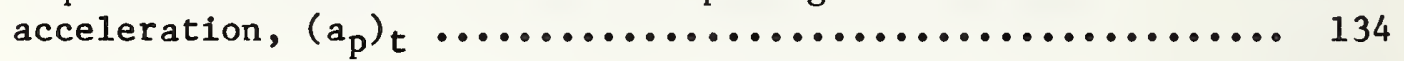

Figure 6.10 Liquefaction chart for threshold peak ground surface

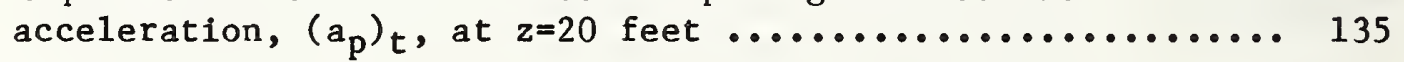

Figure 6.11 Lower and upper values of $\left(a_{p}\right)_{t}$ to account for scatter

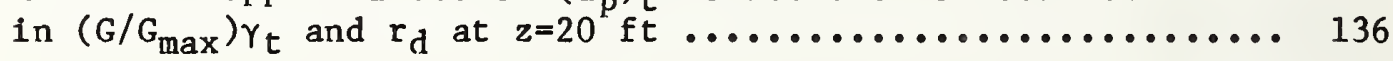



A
Normalized shear modulus parameter
a
Radius of contact area between two spheres
$a_{p}$
Horfzontal peak acceleration at the ground surface
$\left(a_{p}\right)_{t}$
c
$\mathrm{C}_{\text {r }}$
$D_{r}$
e
E
f
G
$G_{\max }$
g
K
$K_{0}$
$\mathrm{K}_{2}$
M
N
N
$\mathrm{N}^{\prime}, \mathrm{N}_{1}$
Threshold peak ground surface acceleration
Propagation velocity of the relevant selsmic waves
Correction factor relating the cyclic shear strength obtalned in a triaxial test to that anticlpated under typical field conditions
Relative density
Vold ratio
Young 's modulus
Friction coefficient
Secant or effective shear modulus of soll
Shear modulus of soll at small strains $\left(\gamma_{c} \approx 10^{-4}\right.$ percent $)$
Acceleration of gravity
Lateral earth pressure coefficlent
Coefficlent of lateral earth pressure at rest
Normal1zed stiffness parameter $=G /\left(\sigma_{3}\right)^{1 / 2}$
Magnitude of earthquake, Richter Scale
Normal force
Standard penetration resistance
Corrected or modifled standard penetration resistance for the effect of overburden pressure 
n

$\mathbf{R}$

$R\left(=\sigma_{\mathrm{dc}} / 2 \sigma \xi\right)$

$r_{d}, r_{d}(z)$

$\mathbf{T}$

$\mathbf{u}$

v

$\mathrm{V}_{\mathrm{s}}$

$\Delta W$

$z$

$\mathbf{z}_{\mathbf{w}}$

$\gamma$

$r_{c}$

$\gamma_{t}$

$\delta$

$\Delta e$

$\Delta u, \Delta u(t)$

$\Delta u_{r}$

$\varepsilon_{\mathrm{v}}$

$\lambda$

$v$
Number of cycles of a sinusoidal (cyclic) shear stress or strain of uniform magnitude applied to the the test specimen

Radius of a sphere

Cyclic shear stress ratio in stress-controlled cyclic triaxial test

Stress reduction factor varying from a value of one at $z$ (depth) $=0$ to values below 0.7 at $z=100 \mathrm{ft}$.

Tangential force

Initial pore water pressure

Seismic ground particle velocity

Shear wave velocity

Area enclosed by $\tau-\gamma$ hysteresis loop

Depth of soil element below the ground surface

Depth of groundwater table

Shear strain, cyclic shear strain

Seismic (Cyclic) shear strain

Threshold cyclic shear strain

Tangential displacement between centers of spheres

Change of void ratio

Excess pore water pressure; excess peak pore water pressure

Residual pore water pressure

Axial strain corresponding to the first compression excursion (i.e., $\mathrm{n}=1 / 4$ cycle).

Damping ratio

Poisson's ratio

xvi 
$\rho$

$\sigma_{\mathrm{C}}$

$\sigma_{\mathrm{v}}$

$\sigma_{0}$

$\sigma_{0}^{\prime}$

$\sigma_{3}$

o3

$\sigma_{\mathrm{m}}^{\prime}$

$\sigma_{\mathrm{dc}}$

$\sigma_{\mathrm{dp}}$

$\tau, \tau(t)$

$\tau_{c}$

$\tau_{\mathrm{p}}$

$\tau^{D_{r}}$

OCR

$\left(\frac{\sigma_{d c}}{2 \sigma_{0}^{\prime}} 50\right.$

$\left(\frac{G}{G_{\max } \gamma}\right)$
Mass density of soil

Normal contact stress

Initial vertical pressure

Initial vertical pressure

Initial effective vertical pressure

Initial total confining pressure; in triaxial testing, $\sigma_{3}=\sigma_{2}=$ confining pressure in the chamber.

Initial effective confining pressure

Average effective stress $=1 / 3(\sigma 1+\sigma 2+$ $\sigma\})$

Cyclic deviator stress

Peak cyclic deviator stress

Cyclic shear stress

Uniform magnitude of a sinusoidal (cyclic) shear stress applied to the test specimen, usually taken as a fraction of the peak

value, $\tau_{p}$.

Peak seismic shear stress associated with peak ground acceleration

Cyclic shear strength for a given relative density, $D_{r}$.

Overconsolidation ratio

Cyclic shear stress ratio causing 1 iquefaction in the laboratory, for $D_{r}$ of 50 percent.

Modulus reduction factor of the soll at shear strain $\gamma$ 
FACING PAGE: This partial failure of the lower San Fernando Dam, which occurred during the February 1971 earthquake was the result of liquefaction of the hydraulically-filled embankment material. Eighty thousand people had to be temporarily evacuated and could have lost their lives in a total embankment collapse. 


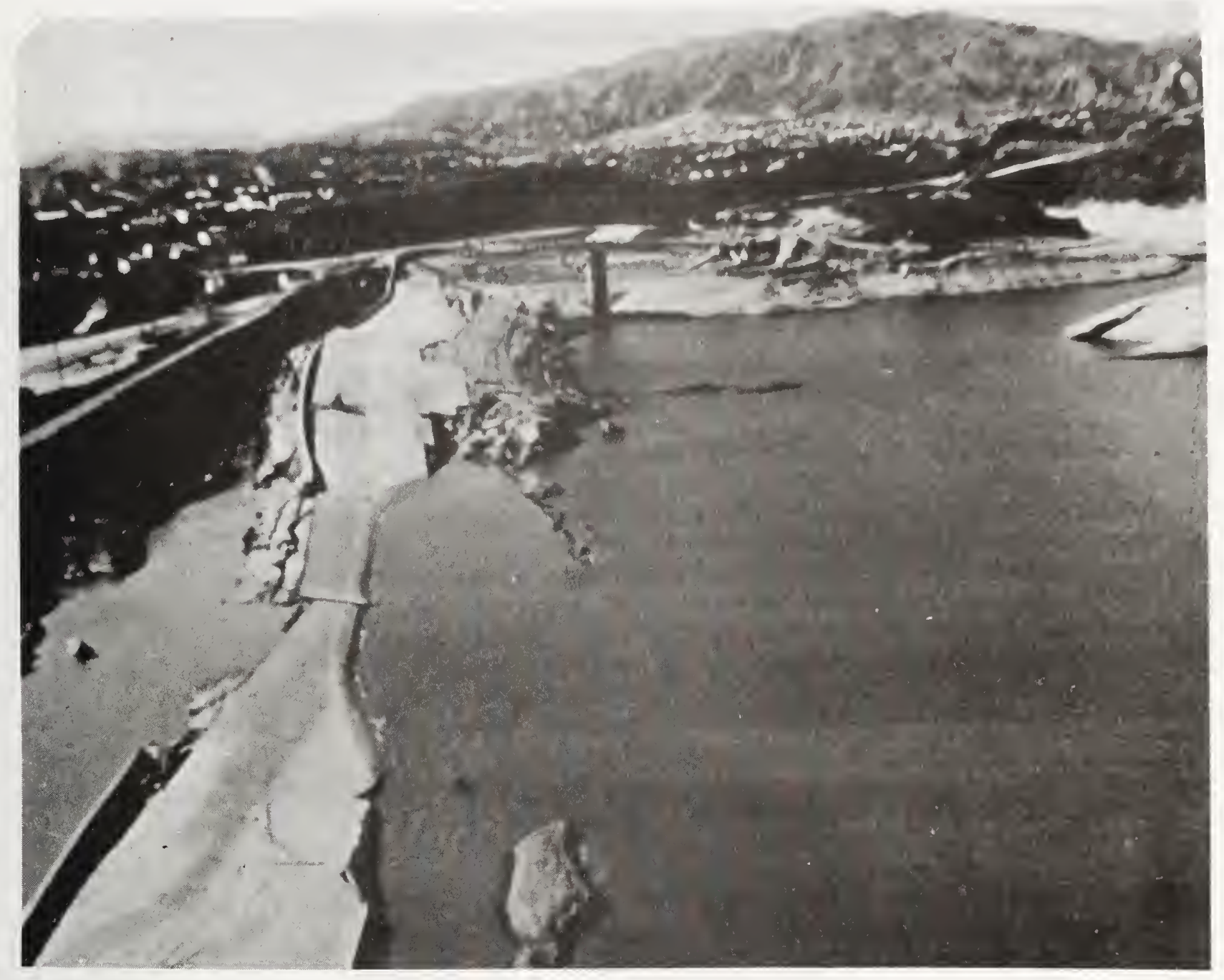

\section{INTRODUCTION}

The liquefaction of saturated cohesionless soils during earthquakes is one of the most important problems facing earthquake engineers. There has scarcely been a major earthquake without at least some reported cases of liquefaction. Sand boils, flotation to the ground surface of buried concrete tanks, cracking of pavements, settlement and tilting of buildings and bridge supports, collapse of waterfront structures, lateral spreading and cracking of slopes and embankments, and flow failures of natural slopes and earth dams have been some of i.ts manifestations.

Kuribayashi and Tasuoka, 1975 [42]1/ 1ist 44 Japanese earthquakes between 1872 and 1968 for which liquefaction of sandy sites occurred. Of these, the best

1 Numbers in brackets refer to literature references in section 9 . 
known is the Niigata earthquake of 1964, where tilting and failure of multistory buildings due to liquefaction of the foundation sand was widespread (see fig. l.1) (Kishida, 1966 [36] ; Koizumi, 1966 [38]; Ohsaki, 1966 [56]; Seed and Idriss, 1967 [76]). A more recent Japanese earthquake which also caused extensive liquefaction occurred on June 12, 1978 in Miyagi-Ken-Oki (Kobayashi et al., 1978 [37]; Yamamura et al., 1979 [89]).

Table 1.1 is a partial list of 14 other earthquakes outside Japan which have occurred during this century and which induced liquefaction.

The high incidence of liquefaction during earthquakes, together with its potential for damage, has made the phenomenon a prime subject of concern in earthquake engineering. The seismic design of nuclear power plants and other critical facilities routinely includes evaluation of the liquefaction potential of saturated sandy or silty cohesionless soil layers. The design of new and the inspection of old earth dams in seismic areas is carried out considering the possibility of liquefaction of the dam and/or its foundation when sandy or silty cohesionless soils are involved. Due to its complexity, the mechanism of the liquefaction phenomenon is not yet completely understood and a large amount of liquefaction research is still being done, especially in the U.S. and Japan. The recent upsurge in the construction of fixed offshore oil platforms throughout the world, where potential failure of the foundation due to ocean wave induced liquefaction of the ocean bottom must be considered in the design, has reinforced the interest in clarifying the liquefaction phenomenon.

Most research on liquefaction has taken place in the 1 ast 10 to 15 years. Some significant publications, including recent summaries and discussions of the state-of-the-art, are: Lee and Seed, 1967 [47]; Seed, 1968 [72]; Seed and Idriss, 1971 [78]; Castro, 1975 [9]; Youd, 1975 [93]; Seed et al., 1975 [80]; Castro and Poulos, 1977 [10]; Seed, 1979 [74]; and Peck, 1979 [61]. Some of these papers were presented at the ASCE Specialty Session on "Liquefaction Problems in Geotechnical Engineering" (ASCE, 1976 [4]).

In the last few years, two aspects of the liquefaction problem have generated a great deal of discussion and motivated significant research. The first aspect relates to the conditions necessary to produce unlimited flow of the liquefied soil in the field under the action of gravity loads such as those occurring in a slope or beneath a structure. There is now general consensus that, while loose or very loose cohesionless soils can experience unlimited flow, dense soils at usual confining pressures cannot, because of their dilative behavior at large shear strains (Castro and Poulos, 1977 [10]; Seed, 1979 [74]).

The second aspect of the problen is related to the importance of relative density on the rate at which excess pore water pressure builds up during an earthquake. Early work suggested that relative density is the key soil parameter controlling pore water pressure increases (Seed and Idriss, 1971 [78]). Many engineering decisions have been based on the assumption that relative density is the key parameter, and pore water pressures measured on reconstituted samples in cyclic laboratory tests have been taken to be representative of pore 
Table 1.1 Some Modern Non-Japanese Earthquakes Which Have Induced Liquefaction

\begin{tabular}{|c|c|c|}
\hline Earthquake & Year & Reference \\
\hline San Francisco, California & 1906 & $\begin{array}{l}\text { Lawson et al., } 1908 \text { [46] } \\
\text { Youd and Hoose, } 1976 \text { [97] }\end{array}$ \\
\hline Bihar-Nepal, India & 1934 & $\begin{array}{l}\text { Geological Survey of } \\
\text { India, } 1939 \text { [25] }\end{array}$ \\
\hline E1 Centro, California & 1940 & Ross, 1968 [67] \\
\hline San Francisco, California & 1957 & Ross, 1968 [67] \\
\hline $\begin{array}{l}\text { Coatzacoalcos, Mexico } \\
\text { Southern Chile }\end{array}$ & $\begin{array}{l}1959 \\
1960\end{array}$ & $\begin{array}{l}\text { Diaz de Cossio, } 1960 \text { [17] } \\
\text { BSSA, } 1963 \text { [7] }\end{array}$ \\
\hline Alaska & 1964 & Ross et al., 1969 [68] \\
\hline $\begin{array}{l}\text { Caracas, Venezuela } \\
\text { Borrego Mounta1n, California }\end{array}$ & $\begin{array}{l}1967 \\
1968\end{array}$ & $\begin{array}{l}\text { Cluff et al., 1973 [13] } \\
\text { Youd and Castle, 1970 [96] }\end{array}$ \\
\hline San Fernando, California & 1971 & $\begin{array}{l}\text { D1xon and Burke, 1973 [18] } \\
\text { Seed et a1, 1975 [80] }\end{array}$ \\
\hline $\begin{array}{l}\text { Halcheng, China } \\
\text { Guatemala }\end{array}$ & $\begin{array}{l}1974 \\
1976\end{array}$ & $\begin{array}{l}\text { Xie Junfei, } 1979 \text { [88] } \\
\text { Hoose, } 1976[32] \text { cited by } \\
\text { Youd, } 1977 \text { [94] }\end{array}$ \\
\hline $\begin{array}{l}\text { Tangshan, China } \\
\text { San Juan, Argentina }\end{array}$ & $\begin{array}{l}1976 \\
1977\end{array}$ & $\begin{array}{l}\text { Xie Junfe1, } 1979[88] \\
\text { Bruschi, } 1978[6]\end{array}$ \\
\hline
\end{tabular}


water pressures in the field during earthquakes. However, more recent research has conclusively demonstrated that relative density is only one of several factors involved (Seed, 1976 [73], 1979 [74]). Based on these findings, Peck, ( 1979 [61]) has questioned the validity of laboratory cyclic tests as presently performed for predicting liquefaction potential, and has instead suggested reliance on empirical methods based on field exploration by standard penetration tests.

This report addresses the problem of pore water pressure buildup and liquefaction during earthquakes at level sites. It is generally agreed that the cause of pore water pressure buildup in saturated sands or cohesionless silts is the cyclic loading of the soil associated with the passage of seismic waves. Both loose and dense dry sands compact and settle when subject to cyclic shear loading, as illustrated in figure 1.2 (Silver and Seed, 1971 [83]). If the soil is saturated and the loading takes place in an undrained condition, the relative incompressibility of the pore water makes the rapid compaction of the sand impossible. Instead, an excess pore water pressure develops whose value increases with the duration of cyclic loading, and in many fine sands and silts these pressures only start dissipating after the ground shaking has ended. Some manifestations of liquefaction in the field, such as the occurrence of sand boils, and the differential settlement of structures due to uneven post-earthquake compaction of the foundation soil, can be explained by the presence of excess pore water pressures and associated water flow. Other manifestations of seismically-induced liquefaction, which are associated with large or unlimited shear straining of the soil, can be explained by the decrease in shear strength associated with these excess pore water pressures. This shear strength decrease, while obviously a very important aspect of the liquefaction problem, is outside the scope of this work. This report focuses on the pore water pressure buildup common to all manifestations of liquefaction at level sites during earthquakes.

The approach to the liquefaction problem presented in this report is based on the premise that pore water pressure buildup during cyclic shear loading of sand is controlled mainly by the magnitude of the cyclic shear strain. This premise leads to the conclusion that shear modulus, rather than relative density, is the main parameter controlling pore water pressure buildup in the field. An important practical consequence is that measurements of in situ modulus at small strains, which can be obtained from geophysical measurements of shear wave velocity, should be used for predicting pore pressures. This is in contrast with the present use of in situ relative density which: a) is not a clearly valid concept when applied to natural sand deposits because of their stratification (Castro, 1975 [9]); and b) cannot be measured directly in the field, but instead must be inferred from penetration tests. Therefore, the proposed strain approach, based on seismic shear strains, in situ measurements of shear modulus, and cyclic strain-controlled tests, is different from current practice, which is based on seismic shear stresses, in situ penetration measurements for relative density determinations, and stress-controlled tests.

Chapter 3 of this report describes the main features of the present state-of-the-art and discusses the need for the new cyclic strain approach. Chapters 4, 5 and 6 present results of studies performed to develop the cyclic 
strain method, including a theoretical analysis using a particulate model of the sand, laboratory measurements, additional studles of the most 1mportant parameters used in the method, and a proposed engineering procedure to eliminate the potential for liquefaction at level sites during earthquakes. 


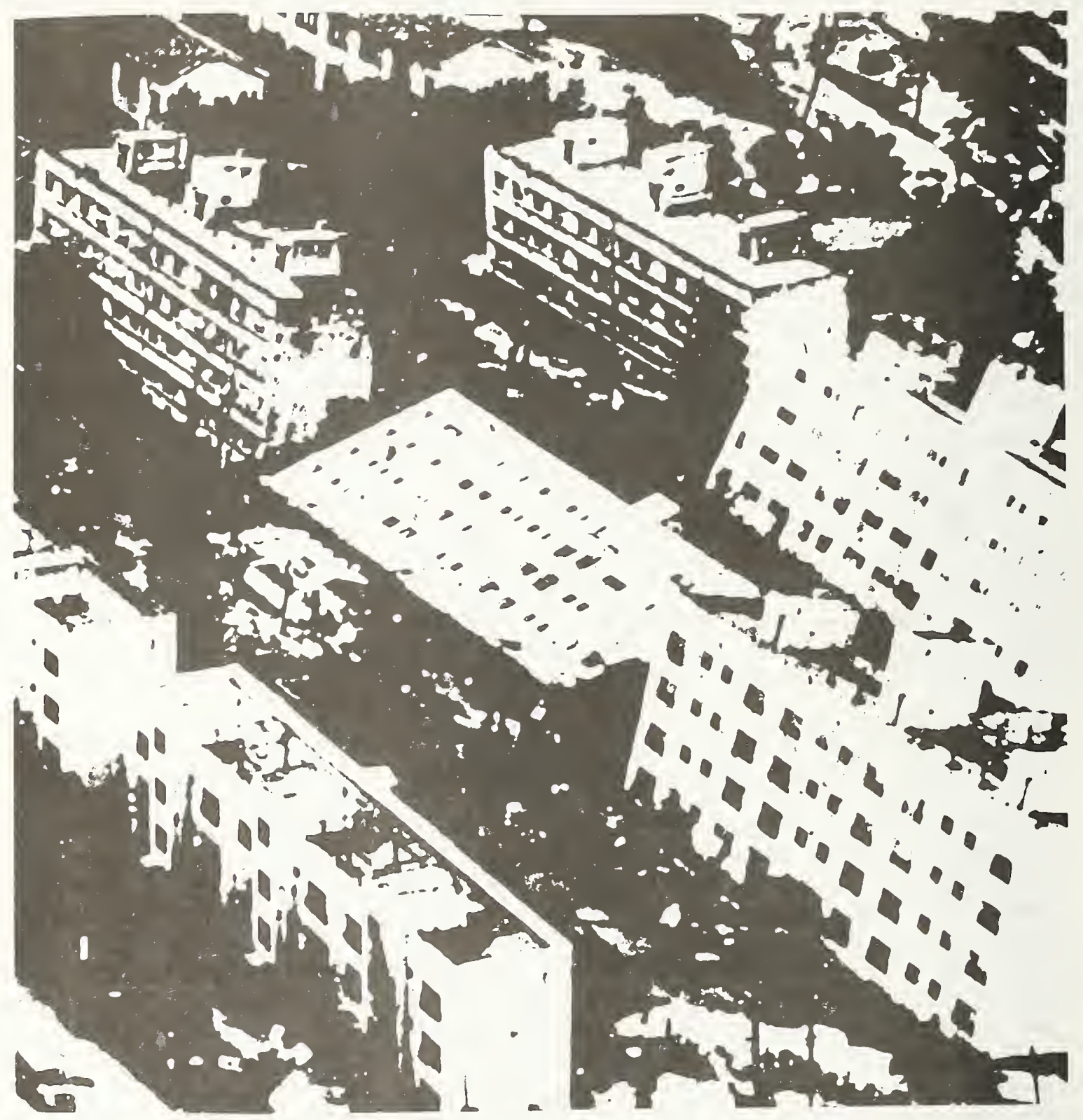

Figure 1.1 Tilted Niigata buildings after earthquake 


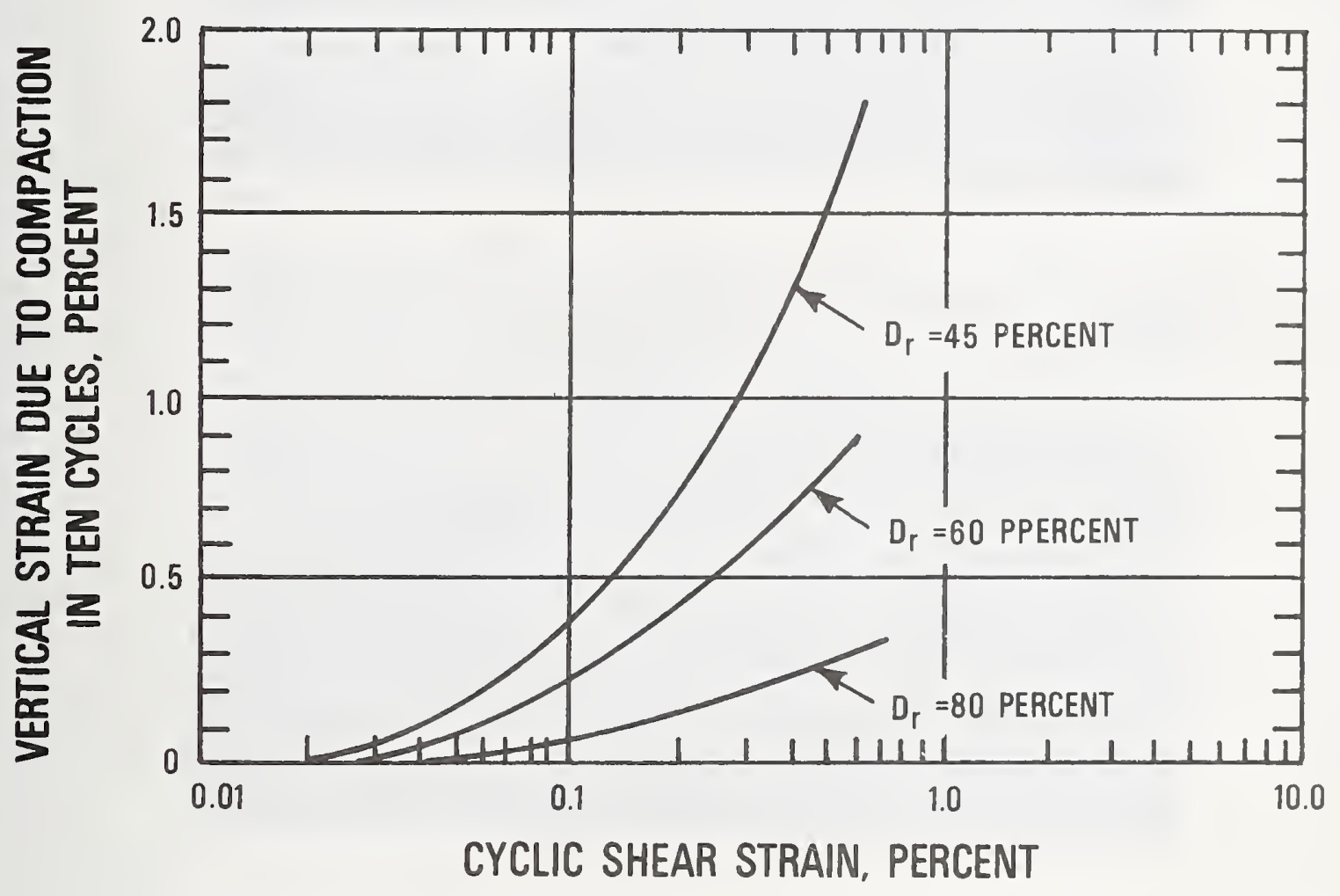

Figure 1.2 Settlement of a dry sand in cyclic strain controlled simple shear tests (Silver and Seed, 1971) 
FACING PAGE: Detailed view of the fissures induced by liquefaction of the hydraulic fill in the San Fernando Dam during the February 1971 earthquake. The remaining embankment downstream of the failure had only a 4-ft. freeboard of highly fractured soil which was on the verge of failure and could have failed if the earthquake had lasted a few more seconds. 

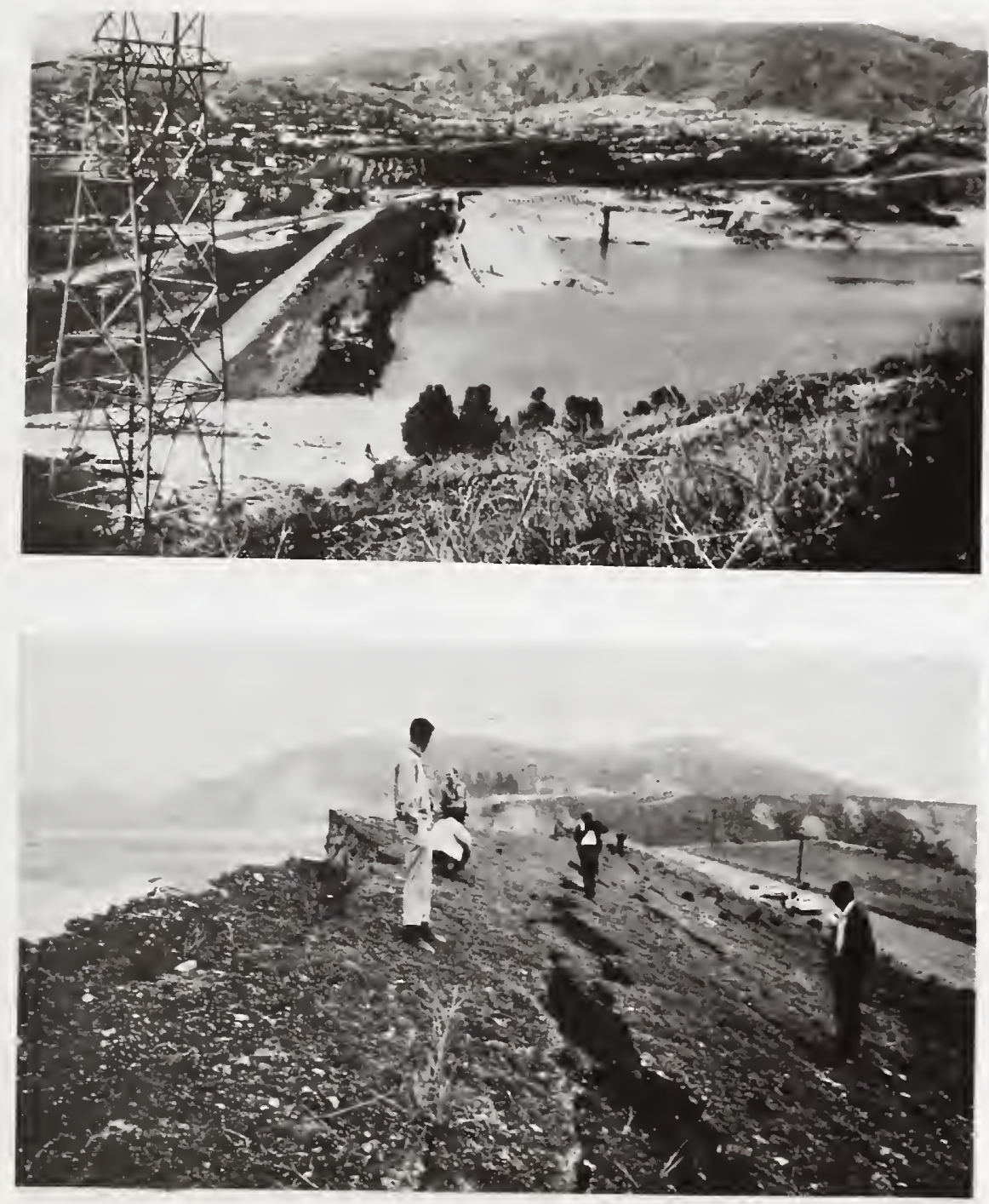

2. $\mathrm{SCOPE}$

This report contains:

(1) A review of present cyclic stress methods for predicting liquefaction potential of level sandy sites;

(2) A proposed new approach to predicting liquefaction potential based on the correlation between cyclic strain and excess pore water pressure buildup;

(3) The documentation for the existence of a threshold cyclic shear strain $\left(\gamma_{t}\right)$, below which there is no excess pore water pressure buildup, and an explanation for the existence of $\gamma_{t}$ by a particulate soil model; 
(4) The results of 12 undrained strain-controlled cyclic triaxial tests on Monterey No. 0 sand which are aimed at developing the basic parameters needed for the proposed strain approach to liquefaction, and a comparison of these results with measurements performed by others; and

(5) A proposed design method for predicting the threshold peak ground surface acceleration, $\left(a_{p}\right)_{t}$, below which a site does not build up pore pressures and cannot liquefy.

Chapter 3 contains a review of the existing stress approach and a discussion of problems associated with its application. It also discusses the rationale for the proposed strain approach, as well as experimental evidence from prior work documenting the existence of the cyclic threshold strain, $\gamma_{t}$, and of a consistent correlation between cyclic strain and excess pore water pressure.

Chapter 4 contains a particulate model where the sand is represented by a simple cubic array of quartz spheres, and which predicts values of $\gamma_{t}$ close to those observed experimentally.

Chapter 5 contains the results of 12 undrained strain controlled cyclic triaxial tests on Monterey No. 0 sand, performed under the direction of the second author of this report (Ladd). The tests include measurements at very small cyclic strains $\left(\gamma \approx 10^{-3}\right.$ percent) and precise measurements of the threshold strain. Comparisons are also presented between the results of these tests and measurements performed by others.

Chapter 6 contains the derivation of a proposed design method based on the threshold strain, and on the derived concept of a "threshold peak ground surface acceleration," $\left(a_{p}\right)_{t}$, needed to start pore pressure buildup at a given site and saturated sand layer.

FACING PAGE: Liquejaction-induced fissures and embankment bailure observed after the Miyagi-ken-oki June 1978 earthquake. 


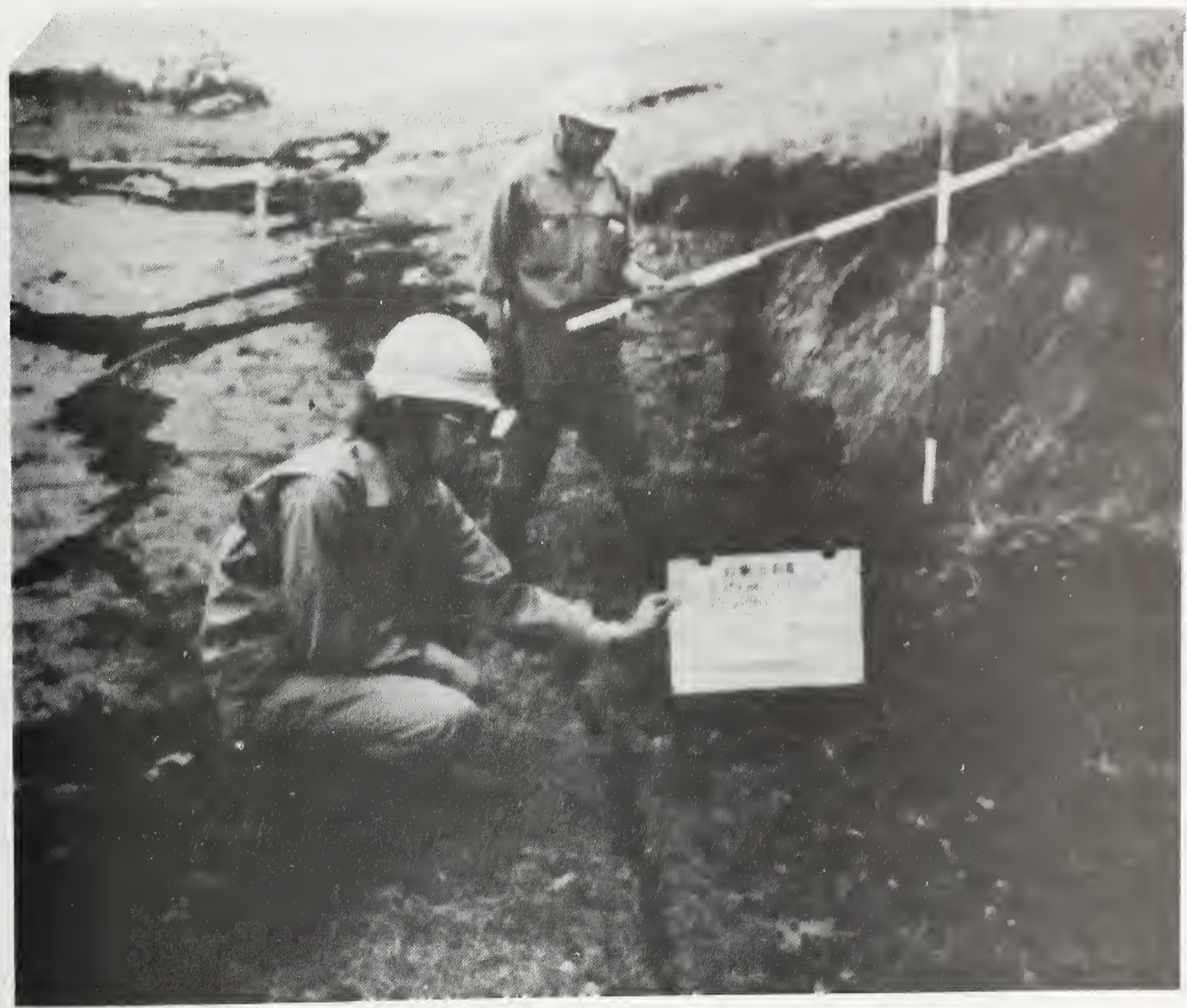

3. GENERAL APPROACH

\subsection{STATE-OF-THE-ART (CYCLIC STRESS) APPROACH}

\subsubsection{Genera1}

The current state-of-the-art method to predict pore water pressure buildup and liquefaction potential during earthquakes in level sites has been developed to a large extent by Seed and his coworkers (Seed and Idriss, 1971 [78]; Seed et al., 1975 [80]; Seed, 1979 [74]). The following two main assumptions are made in this method:

1) The pore pressure developed at any saturated cohesionless soil element such as the one shown in figure 3.1 (a) is caused by the cyclic shear stress, $\tau$. This shear stress acts in the horizontal and vertical planes and is caused 
by the passage of vertically propagating seismic shear waves. Figure 3.1(b) shows a typical variation of $\tau$ with time, $\tau(t)$, during ground shaking.

2) The loading of the soil by $\tau(t)$ is undrained (the pore water pressure dissipation and redistribution within the soil mass are disregarded within the time frame of the event). Therefore, the pore water pressure in the element in excess of the hydrostatic pressure, $\Delta u(t)$, increases with duration of shaking and is a maximum at the end of the shaking $(t=30$ seconds in figure $3.1(\mathrm{~b}))$. Thus, the minimum value of the effective overburden pressure occurs also at the end of the shaking, and is $\sigma_{0}^{\prime}-\Delta u(30)$ where $\sigma_{0}^{\prime}=$ initial effective overburden pressure. If $\Delta u(30)=\sigma_{0}^{\prime}$, there is no effective stress in the soil and, by definition, "initial liquefaction" of the soil has occurred. If $\Delta \mathrm{u}(30)<\sigma_{0}^{\prime}$ "initial liquefaction" did not occur during the shaking.

Initial liquefaction has been extensively used as a criterion defining failure. other criteria, based on the strain developed during stress-controlled tests, have also been used; however, the discussion herein is mainly restricted to the initial liquefaction concept. The ideal way to obtain the value of $\Delta u(30)$ would be: (i) to retrieve a perfectly undisturbed soil sample from the given depth, (ii) to consolidate a specimen in the laboratory to the effective field static pressures, $\sigma_{0}^{\prime}$ and $\mathrm{K}_{\mathrm{O}} \sigma_{0}^{\prime}$, and (iii) to subject the saturated specimen to the seismic shear stress history, $\tau(t)$, in undrained condition, and monitor the development of the excess pore water pressure, $\Delta u(t)$. In practice this 3-step method cannot be implemented, and is replaced instead by the following, more manageable procedure:

a) $\tau(t)$ is replaced by $n$ cycles of a sinusoidal shear stress of uniform amplitude, $\tau_{c}$. This cyclic stress, $\tau_{c}$ is taken as a fraction of the peak value, $\tau_{p}$ of $\tau(t)$. Usually, $\tau_{c}=0.65 \tau_{p}$ is used. Therefore, $\tau(t)$ is replaced by $n$ cycles of $\tau_{c}$, and the value of $n$ is selected so that $\Delta u$ at the end of the $n$ cycles is approximately equal to $\Delta u$ at the end of $\tau(t)$.

b) A disturbed soil sample is retrieved from the depth of interest, and is reconstituted in the laboratory to the same relative density, $\mathrm{D}_{\mathrm{r}}$, it had in the field. Field $D_{r}$ is usually estimated from the measured standard penetration resistance, $N$, using available correlations between $N, \sigma_{0}^{\prime}$, and $D_{r}$ such as that of Gibbs and Holtz, (1957 [26]).

c) The reconstituted sample is consolidated under stresses approximating the free field effective pressures (usually this means isotropic consolidation under $\left.\sigma_{0}^{\prime}\right)$.

Then, an undrained stress controlled test is performed where $\mathrm{n}$ cycles of the uniform cyclic shear stress, $\tau_{c}$, are applied to the sample in an undrained condition, while monitoring the excess pore water pressure buildup, $\Delta \mathrm{u}$. If $\Delta \mathrm{u}=\sigma_{0}^{\prime}$ at the end of the $\mathrm{n}$ cycles, the sample has experienced initial liquefaction. This result is then used to predict the occurrence of the initial liquefaction in the field. 
Usually, several stress-controlled, cyclic laboratory tests such as described in (c) are performed on identical reconstituted samples having equal $D_{r}$ and consolidated under the same $\sigma_{o}^{\prime}$. The cyclic stress, $\tau_{c}$, is varied between tests, and the number of cycles, $n$, needed to produce initial liquefaction is obtalned from each test. The curve of $\tau_{c}$ versus $n$ is used for the prediction of liquefaction in the field. Figure 3.2 shows an example of such a curve obtained from cyclic simple shear tests. The value of $\tau_{c}$ from the curve for a given $\mathrm{n}$ (also called the cyclic strength of the soil) is compared with the average $\tau_{c}$ developed by the earthquake, and the liquefaction potential in the field is evaluated from this comparison. This comparison is illustrated in figure 3.3.

The shear stress history, $\tau(t)$, and the derived $\tau_{c}$ value shown in figure 3.1(b) are sometimes obtained from site response analyses. In those analyses, assumed ground motions are input at rock or at some depth within the soil, and a shear beam model of the soll profile is used for the computations of selsmic shear stresses, strains and accelerations at different depths within the soll (1.e., Schnabel et al., 1972 [71]). In this case, the calculated $\tau(t)$ is a function of the input motions and of the geometry and stress-strain properties of the soll model.

\subsubsection{The Simplified (Seed and Idriss) Procedure}

A further simplification of the cyclic stress approach described in section 3.1.1 has been proposed by Seed and Idriss (1971 [78]). This simplified procedure is widely used in engineering practice. It has the advantage of using a limited number of parameters which are usually available, and not requiring the use of a computer.

In this simplified procedure, the liquefaction potential of a soil element at a depth $z$ is evaluated in three steps as follows:

Step 1. Determination of $\tau_{c}$ and $n$. This is done by computing the stress rat1o, $\tau_{c} / \sigma_{0}^{\prime}$ caused by earthquake by means of equation 3.1 :

$$
\frac{\tau_{c}}{\sigma_{0}^{l}}=0.65 \frac{a_{p}}{g} \frac{\sigma_{o}}{\sigma_{o}^{\prime}} r_{d}
$$

where: $\quad a_{p}=$ horizontal peak acceleration at the ground surface

$\mathrm{g}=$ acceleration of gravity $=32.2 \mathrm{ft} / \mathrm{sec}^{2}$

$\sigma_{0}, \sigma_{0}^{\prime}=$ total and effective overburden pressures at depth $z$

$r_{d}=r_{d}(z)=$ stress reduction factor varying from a value of one at $z=0$ to values below 0.7 at $z=100 \mathrm{ft}$. (see fig. 3.4)

The earthquake is assumed to induce in the soil $\mathrm{n}$ cycles of uniform cyclic stress, $\tau_{c}$. The value of $n$ is related to the magnitude, $M$ of the earthquake, and is equal to about 10 cycles for $M=7$. Figure 3.5 presents the most recent relationship between $M$ and $n$ proposed by Seed et al., (1975a [81]). 
Step 2. Determination of $(\tau)$ Dr causing initial liquefaction (cyclic strength of soil). The value of uniform cyclic stress causing initial liquefaction in $n$ cycles, $(\tau) \mathrm{Dr}$ is assumed to be a function of $n$, and of the relative density and grain size of the soll. $(\tau) \mathrm{Dr}$ is obtained from equation 3.2:

$$
\frac{(\tau)_{D r}}{\sigma_{0}^{!}}=\frac{\sigma d c}{2 \sigma_{0}^{\prime}} 50 \cdot C_{r} \cdot \frac{D_{r}}{50} \quad 3.2
$$

where: $(\tau)_{D_{r}} / \sigma_{0}^{\prime}=$ the cyclic shear strength ratio for a given relative

$$
\begin{aligned}
\sigma_{\mathrm{dc}}= & \text { the cyclic deviator stress } \\
50= & \text { signifies a relative density of } 50 \text { percent } \\
\mathrm{D}_{\mathrm{r}}= & \text { field relative density in percent } \\
\left(\frac{\sigma_{\mathrm{dc}}}{2 \sigma_{0}^{\prime}}\right)_{50} & \text { the shear stress ratio causing liquefaction in the laboratory } \\
& \text { in a stress-controlled cyclic triaxial test, for } \mathrm{D}_{\mathrm{r}}=50 \\
& \text { percent } \\
\mathrm{C}_{\mathrm{r}}= & \text { a correction factor relating the cyclic shear strength obtained } \\
& \text { in a triaxial test to that anticipated under typical field } \\
& \text { conditions. }
\end{aligned}
$$

$\left(\sigma_{\mathrm{dc}} / 2 \sigma_{0}^{\prime}\right)_{50}$ and $\mathrm{C}_{\mathrm{r}}$ are obtained from appropriate charts once $\mathrm{n}, \mathrm{D}_{\mathrm{r}}$, and the grain size of the sand are known. $D_{r}$ is obtained from the standard penetration resistance, $N$, using the Gibbs and Holtz correlation.

Step 3. Comparison between $\tau_{\mathrm{C}}$ and $(\tau)_{\mathrm{Dr}}$. The values of $\tau_{\mathrm{C}}$ and $(\tau)_{\mathrm{Dr}}$ obtained from equations 3.1 and 3.2 are compared. If $\tau_{c}>(\tau)$ Dr liquefaction at depth $z$ is predicted by the method. If $\tau_{C}<(\tau)_{D r}$ no liquefaction is predicted.

The simplified procedure has all the main features of the general stress approach discussed in section 3.1.1. Note the importance given to the relative density of the soll in this method.

\subsubsection{Empirical Charts and Correlations}

After the 1964 Niigata earthquake, it was observed that the occurrence and degree of damage caused by liquefaction were well correlated with measurements of the standard penetration resistance, $N$, performed before the earthquake (Kishida, 1966 [36]; Ohsak1, 1966 [56]). Based on this observation, some empirical correlations were obtained which are summarized in figure 3.6 . Figure 3.6 is directly applicable to a site having subsoll conditions similar to those in Niigata and experiencing a ground shaking similar to that which occurred in Nilgata in 1964. More general correlations and charts, applicable to wider ranges of soll and shaking conditions, have been proposed by Whitman, 1971 [86]; Seed and Idriss, 1971, [78]; Castro, 1975 [9]; Christian and Swiger, 1975 [12]; Yegian and Whitman, 1978 [91]; and Seed, 1979 [74]. In all cases, these authors have calibrated their proposed correlations with documented case histories where liquefaction has (or has not) occurred. Tables containing the values of $\mathrm{N}$ and of other basic parameters of up to 50 case histories have been presented by Seed and Idriss, 1971 [77]; Seed et a1., 1975 [80]; and Yegian, 1976 [90]. 
Figures 3.7 through 3.9 present some of these empirical correlations. In all of these figures, the stress ratio caused by the earthquake is obtained from the peak ground surface acceleration using an expression such as equation 3.1. Other parameters needed to use the charts are $N, \sigma_{0}^{\prime}$, and the earthquake magnitude, $\mathrm{M}$ (for $\mathrm{fig}$. 3.9). In these three figures, the measured value of $\mathrm{N}$ must be corrected for the effect of overburden pressure. In figure 3.7 the corrected value, $N^{\prime}$, defined in the figure, is used. The corrected $N_{1}$ value used in figures 3.8 and 3.9 is calculated using equation 3.3 .

$$
\mathrm{N}_{1}=\left(1-1.25 \log \frac{\sigma_{0}^{\prime}}{2000}\right) \mathrm{N}
$$

where $\sigma_{0}^{\prime}$ is in psf.

It must be noted that the corrections used to calculate $N^{\prime}$ and $N_{1}$ in figures 3.7 through 3.9 are very similar except for a constant factor. For a wide range of pressures, 500 psf $<\sigma_{0}^{\prime}<4,000$ psf, $\mathrm{N}_{1} \simeq 0.5 \mathrm{~N}^{\prime}$.

The original use of $\mathrm{N}$ as a basis for the development of empirical liquefaction correlations was based on two assumptions: (i) the paramount importance attributed to relative density in controlling the rate of development of excess pore water pressures in the field, and (ii) the belief that $\mathrm{N}$ measures relative density in the field. As discussed in section 3.1.1 of this report, both assumptions (i) and (ii) have been challenged; however, this challenge does not affect the proven success of $\mathrm{N}$ and of the empirical correlations as tools to organize liquefaction case histories and to evaluate liquefaction potential. Therefore, what is needed is an improved and more basic understanding of standard penetration test (SPT) measurements in cohesionless soils, and of the relation between these measurements and the factors controlling liquefaction. The results of recent research on the SPT along these lines by Kovacs, 1975 [40], and Kovacs et al., 1981 [41]; Schmertmann, 1977 [69] and Schmertmann and Palacios, 1979 [70] represent a very promising start towards this objective.

\subsection{PROPOSED CYCLIC STRAIN APPROACH}

\subsubsection{Problems with the Stress Approach}

The current cyclic stress approach to liquefaction described above is based on the premise that the pore water pressure buildup in a saturated sand, subjected to a given cyclic shear stress history, is mainly a function of the relative density $D_{r}$ and the initial effective stresses acting on the sand. The influence of the density on cyclic strength of reconstituted sand was first observed in 1965 (see fig. 3.10). Therefore, this parameter was incorporated by specifying that the cyclic tests should be done on reconstituted samples compacted to the estimated field density. The assumption that cyclic strength is mainly a function of relative density, is also used in the simplified procedure described in section 3.1 .2 .

However, cyclic tests performed in the last few years have revealed that a number of other factors besides $D_{r}$ also influence significantly the results of 
stress-controlled tests. Some of these factors, which were recently discussed in detall by Seed, 1979 [74], are listed in table 3.1.

Experimental results showing the significance of the last four factors of table 3.1 on the cyclic strength of reconstituted sands are plotted in figures 3.11 through 3.14. These figures show that the effect of these factors can be even more significant than that caused by large variations in density. Most of the evidence showing the influence of time under pressure, overconsolidation, prestraining and fabric on cyclic strength is from laboratory tests. However, some limited evidence from the field suggest that the geological age of the soil deposit influences liquefaction potential and should be considered (Ohsak1, 1969 [57]; Youd et al., 1978 [98]; Finn, 1979 [24]). Seed, 1976 [73] has pointed out that "...the liquefaction characteristics of in situ sand deposits are determined by a number of complex factors, of which relative density is only one, and careful evaluation of all these factors is required in selecting soil characteristics for use in design."

The influence of all these factors on the cyclic strength of sands certainly complicates the state-of-the-art and makes its practical use more difficult. Efforts can be made to simulate as closely as possible the geological and seismic history of the soll when testing reconsolidated samples in the laboratory. The specimens can be reconsolidated, prestrained, and aged under pressure prior to cyclic loading. However, this complicates the tests and requires information that may not be avallable. Besides, there are limits to what can be done on a reconstituted sample. Laboratory aging under pressure cannot possibly. simulate the hundreds or thousands of years of history of many soil deposits. The fabric effect introduces an additional and serious problem, since there is yet no reliable method to measure sand fabric in the field.

Testing undisturbed samples of cohesionless soils and performing the cyclic tests on them rather than using reconstituted specimens would solve this dilemma. Unfortunately, the factors included in table 3.1 appear to be very sensitive to sampling and handling of sands prior to testing (Seed, 1979 [74]).

Peck, 1979 [61], has tentatively concluded that: "(1) unless the cyclic loading tests used to evaluate liquefaction potential can be performed on absolutely undisturbed samples, which is manifestly impossible, the results will probably indicate too great a likelihood of liquefaction; and (2) in many instances the resistance to liquefaction in the field may be appreciably, even spectacularly, greater than that determined on the basis of conventional cyclic laboratory tests on reconstituted or even "undisturbed" samples if no allowances are made for various possible beneficial effects such as time, repeated small shearing forces, and stress history." Based on these conclusions, Peck proposes at this time to rely more on empirical correlations based on field standard penetration measurements, rather than using cyclic laboratory tests. 
Table 3.1. Some Factors Influencing the Cyclic Strength of Sands

- Relative Density

- Method of Sample Preparation (Fabric Effect)

- Prior Seismic Straining (Prestraining or Preshaking Effect)

- Lateral Earth Pressure Coefficient $\left(\mathrm{K}_{0}\right)$ and Overconsolidation Ratio (OCR)

- Increased Time Under Pressure (Aging Effect) 


\subsubsection{Why a Strain Approach?}

The main premise of this report is that a cyclic strain approach to the problem of predicting pore water pressure buildup and liquefaction of saturated cohesionless soils would have significant advantages over the current cyclic stress approach. Evidence substantiating this statement, which was available at the outset of this research, is discussed in this and the following sections.

Silver and Seed, 1971 [83] showed experimentally that cyclic shear strain, $\gamma_{c}=\tau_{c} / G\left(G=\right.$ secant shear modulus) rather than cyclic shear stress, $\tau_{c}$, controls the densification of dry sands. Strain-controlled cyclic simple shear tests were performed by Silver and Seed on Dry Crystal Silica No. 20 sand using a range of relative densities, $D_{r}$, of overburden pressures, $\sigma_{o}^{\prime}$, and of cyclic shear strains, $\gamma_{c}$. It was found that the rate of settlement with number of cycles depended on $D_{r}$ and $\gamma_{c}$, but was independent of $\sigma_{o}^{\prime}$, and did not correlate with $\tau_{c}$ and $G$ taken independently. Some results of these tests are summarized in figure 1.2. Based on the Seed and Silver results, Martin et a1., 1975 [49] successfully developed a cyclic strain, effective-stress model to predict pore water pressure buildup in saturated sands during undrained stress-controlled tests. All of these findings strongly suggest that $\gamma_{c}$, rather than $\tau_{c}$, controls both densification and liquefaction in sands.

Based on cyclic test results on dry sands, Drnevich and Richart, 1970 [23] Youd, 1972 [92] and Pyke, 1973 [64] concluded that there is a threshold cyclic shear, $\gamma_{t}$, of the order of $10^{-2}$ percent, below which no densification occurs (see fig. 3.15). A value of $\gamma_{t}$ of about $10^{-2}$ percent is also consistent with the experimental results for dry sand shown in figure 1.2, and with straincontrolled tests results on saturated sands reported by Park and Silver, 1975 [59], and Dobry and Ladd, 1980 [20], and will be discussed in more detail in section 3.2.3. A theoretical study of a simple granular model of a quartz sand, originally proposed by Dobry and Swiger, 1979 [21], and presented in detail in chapter 4, predicts a range of values for this threshold strain, $1 \times 10^{-2}$ percent $<\gamma_{t}<4 \times 10^{-2}$ percent for effective confining pressure between 500 psf and 4,000 psf ( 24 and $192 \mathrm{kPa}$ ). The existence of a threshold level at which pore water pressure buildup starts is obviously very important for liquefaction prediction. The fact that this threshold has a more stable value when expressed as a strain than when expressed in terms of stress is another argument in favor of a strain approach to liquefaction.

The adoption of a cyclic strain approach should considerably simplify the interpretation of cyclic laboratory tests on saturated sands. There is experimental evidence indicating that the factors presented in table 3.1 which increase the cyclic strength of sands in stress-controlled tests, also increase the shear modulus of sands (Seed and Idriss, 1971 [78]; Drnevich and Richart, 1970 [23]; Hardin and Drnevich, 1972 [29]; Pyke, et al., 1974 [65]; Anderson and Stokoe, 1977 [3]; Dobry and Ladd, 1980 [20]). This evidence suggests that, if both $\tau$ (cyclic shear strength) and $G$ are similarly affected by the factors listed in table 3.1, the ratio $\gamma=\tau / G$ should be less affected by these same factors. Therefore, the pore water pressure buildup in strain-controlled tests should be less sensitive to those factors than in stress-controlled tests. A more detailed discussion of this premise is presented in section 3.2.3. 
The advantage gained by adopting a strain approach to liquefaction would be the total or partial replacement of the parameters listed in table 3.1 by the shear modulus, G. Unlike relative density or sand fabric, the shear modulus at small strains, $G_{\max }$, can be directly measured in the field by means of the shear wave propagation velocity. Field measurements of $G_{\max }$ would automatically incorporate many of the characteristics of the soil deposits which are important for pore water pressure buildup and liquefaction during earthquakes. This approach should, therefore, decrease the need for a detailed knowledge of the geological and seismic history of the site which is presently required in the stress approach.

There is still another argument in favor of the strain approach, which relates to the advantages of running cyclic strain - instead of stress-controlled tests of dense (dilative) sands. Castro (1975 [9]) has shown that, for cyclic triaxial stress-controlled tests on these solls, there is a substantial redistribution of water content within the specimen, most of which probably occurs near the end of the test, when the cyclic strain becomes large. This redistribution affects the cyclic behavior of the dense sand specimen in such a way that it ceases to represent the field situation; in particular, the "strains measured in the laboratory in such a case are so conservatively large as to make the test unusuable as a design tool," Castro and Poulos, 1980 [11]. Strain-controlled tests of dense sands, performed at smaller cyclic strains, which are more representative of those in situ, should decrease the redistribution problem. Although more research is needed on the subject, it seems reasonable to expect that running strain-controlled tests of dense sands, at those smaller representative strains will: (a) cause less water content redistribution before initial liquefaction occurs, and (b) provide more realistic predictions of in situ pore pressures than those obtained from stress-controlled tests (see also Peck, 1980 [62]).

\subsubsection{Analysis of Available Cyclic Test Results}

This section analyzes and discusses some available stress- and strain-controlled cyclic triaxial test results on saturated sands from the viewpoint of the proposed cyclic strain approach. These results relate mainly to the fabric effect listed in table 3.1 , and were obtained from the files of one of the authors of this report (Ladd) and from Park and Silver, 1975 [59].

The first data set was obtained from Ladd's files. It corresponds to stress-controlled tests on a saturated sand compacted to $\mathrm{D}_{\mathrm{r}} \simeq 83$ percent by different sample preparation methods. The sand used is the same as the soil called "Sand No. 2" by Ladd, 1977 [43], and its grain size distribution is shown in figure 3.16. The cyclic triaxial strength data for initial liquefaction are plotted in the usual way (i.e., cyclic stress ratio versus $n$ ) in figure 3.17 for the two sample preparation methods used: Moist Vibration and Dry Tamping (see Ladd, 1977 [43] for a description of the two methods). Figure 3.17 shows again in a very dramatic way the effect of sand fabric, which was already illustrated in figure 3.11. The moist vibration specimens have much larger cyclic strengths than the dry tamping specimens. The explanation for this is that the sand compacted by moist vibration was stiffer, and therefore developed smaller cyclic strains than that compacted by dry tamping. This is 
illustrated by the data in figure 3.18, which correspond to the same stresscontrolled tests of figure 3.17. Figure 3.18 shows the maximum amplitudes of cyclic axial stress and strain, corresponding to the first compression and extension excursions, for both moist vibration and dry tamping tests. Two conclusions can be drawn from figure 3.18: (a) the specimens are stiffer in compression than in extension for both compaction methods, and (b) moist vibration specimens are stiffer than dry tamping specinens, with the difference being much larger in extension. For example, the two dry tamping tests corresponding to cyclic stress ratios, $R=0.36$ and 0.37 , developed in their first extension excursion axial strains of almost one percent and failed in only 8 to 12 cycles (see fig. 3.17); on the other hand, a moist vibration specimen tested at a similar stress, $\mathrm{R}=0.41$, developed in its first extension excursion a lower strain ( $\approx 0.4$ percent) and failed in 24 cycles. In figure 3.19 , the same results of figure 3.17 have been replotted using the axial strain in the first extension excursion, $\varepsilon_{\mathrm{V}}$, as a parameter, instead of the cyclic stress ratio of the test, $k$. The difference between dry tamping and moist vibration data points is much less in figure 3.19 than in figure 3.17. Although there is still considerable scatter in figure 3.19 , it was possible to define a single curve representing all the data points. Therefore, an important reason for the lower cyclic strength exhibited in figure 3.17 by the dry tamping specimens is that they were less stiff, especially in extension, and were thus subjected to larger cyclic strains starting from the very beginning of cyclic loading.

Figures 3.20 through 3.23 present results from stress-controlled and strain-controlled cyclic triaxial tests on saturated Crystal Silica No. 20 sand, performed by Park and Silver, 1975 [59]. The grain size distribution of the sand used is shown in figure 3.16. All tests were conducted on specimens compacted at $D_{r}=60$ percent using two preparation methods: Dry Vibration and Wet Rodding. The effective confining pressure in all tests was $\sigma \xi=2,000$ psf $(96 \mathrm{kPa})$.

The cyclic strength results from the stress-controlled tests are presented in the usual way in figure 3.20. Again, the effect of fabric is apparent with the Dry Vibration specimens being significantly weaker. For a given stress ratio, the Wet Rodding specimens needed 15 to 20 times more cycles to fail than the Dry Vibration specimens (e.g, at $\mathrm{R}=0.30, \mathrm{n}=30$ cycles and 2 cycles, respectively). Figure 3.21 gives additional information on pore water pressure buildup during the same stress-controlled tests. Figure 3.21 again shows that the rate at which pore water pressure built up was much slower for the Wet Rodding specimens.

The reason for the differences in stress-controlled test results shown in figures 3.20 and 3.21 is, again, that wet Rodding specimens were stiffer, and therefore developed smaller cyclic strains than the Dry Vibration specimens.

This difference is illustrated by the comparison of the stress-strain curves in the first cycle plotted in figure 3.22. For this case, no information was available to plot separately the first compression and extension excursions, as was done in figure 3.18 for sand No. 2. The difference between the curves in figure 3.22 is similar to that between the curves in figure 3.18 . 
Therefore, for both Crystal Silica sand and sand No. 2, the effect of fabric on cyclic strength, as measured in stress-controlled tests, seems to be largely a stiffness effect. A stiffer fabric, which develops lower cyclic strains from the beginning of cyclic loading, also develops less pore water pressures and, thus, liquefles in a larger number of cycles.

The results of strain-controlled cyclic triaxial tests, performed by Park and Silver on the same Crystal Silica sand, compacted to the same relative density, using the same specimen preparation procedures and under the same confining pressures as those used for the above-mentioned stress-controlled tests are shown in figure 3.23. This figure shows the rate of pore water pressure buildup at different cyclic axial strains, $\varepsilon_{\mathrm{V}}$, during the strain-controlled tests, and here also, the effect of fabric is minor and has been reduced to a scatter measured by the width of the hatched areas in the figure. Figure 3.23 demonstrates quite clearly that the rate of pore water pressure bulldup with number of loading cycles is essentially the same for both Dry Vibration and Wet Rodding specimens, provided that the same cyclic strains are used. A comparison between figures 3.21 and 3.23 shows again that the fabric effect on pore pressure bulldup is very pronounced for stress-controlled tests (figure 3.21 ), while it is practically nonexistent if strain-controlled tests are performed (figure 3.23 ).

The lowest value of cyclic axial strain, $\varepsilon_{\mathrm{v}}$, used by Park and Silver in their strain-controlled tests was $3 \times 10^{-2}$ percent. Using a Poisson's Ratio for the saturated sand, $v=0.5$, it ylelds a cyclic shear strain, $\gamma_{c}$ of:

$$
\gamma_{c}=1.5 \varepsilon_{\mathrm{v}}
$$

or, the lowest shear strain was $\gamma_{c}=4.5 \times 10^{-2}$ percent. For this value of cyclic shear strain, the rate of pore water pressure buildup was very slow. As shown in figure 3.23, for $\varepsilon_{v}=3 \times 10^{-2}$ percent, $\Delta_{u} / \sigma_{3} \leq 0.20$ even after 100 cycles. This, added to the shapes of the curves in fitgure 3.23 , again suggests the existence of a threshold strain, $\gamma_{t}$ near $10^{-2}$ percent as discussed in section 3.2 .2 .

Al1 results presented in figures 3.20 through 3.23 were performed by Park and Silver on fresh specimens, 1.e., each cyclic test was conducted on a new sample. They also performed strain-controlled staged tests on specimens compacted using the Dry Vibration procedure. In each stage, 300 cycles of a given cyclic strain were applied undrained, with the pore water pressure bulldup being monitored. After this cyclic loading, the drainage valves were opened and the sample was reconsolidated under the same confining pressure, $\sigma\}=2,000$ psf $(96 \mathrm{kPa})$. The valves were then closed, and in this new undrained stage, 300 cycles of a larger cyclic strain were applied. The process was repeated at several cyclic strains. A comparison between the results of the staged tests and those on fresh specimens indicates that the pore water pressure buildup versus number of cycles, $n$, was essentially identical if pore pressure in the previous stages had been kept small, $\Delta u / \sigma\} \leqslant 0.4$. Therefore, the values of $\Delta u / \sigma\}$ after $n=$ 10 cycles for fresh specimens obtained from figure 3.23 have been plotted in figure 3.24, together with those from staged specimens for which $\Delta \mathrm{u} / \sigma\} \leq 0.4$. In figure 3.24 , shear strain $\gamma_{c}$ rather than axial strain, $\varepsilon_{v}$, has been plotted, with 
equation 3.4 used to compute $\gamma_{c}$. Similar results from staged strain-controlled cyclic triaxial tests on sand No. 1, obtained from the files of one of the authors of this report (Ladd) have also been superimposed on figure 3.24. The grain size distribution of sand No. 1 is shown in figure 3.16. The specimens of sand No. 1 were compacted to $\mathrm{D}_{\mathrm{r}} \simeq 60$ percent using the Moist Tamping technique, and isotropically consolidated to effective confining pressures of of = $10 \mathrm{psi}(69 \mathrm{kPa})$ and $\sigma \xi=20 \mathrm{psi}(138 \mathrm{kPa})$. Figure 3.24 includes results of strain-controlled tests on sand No. 1 using cyclic shear strains, $\gamma_{c}<10^{-2}$ percent. These small strain measurements were done by the use of the technique described in section 5.1 .2 of this report. At these small strains, $\Delta u / \sigma \xi_{2}=0$ after $n=10$ cycles, and figure 3.24 again suggests a threshold, $\gamma_{t} \simeq 10^{-2}$ percent.

Figure 3.24, which was included in a recent publication by Dobry and Ladd, 1980 [20], is remarkably consistent. Although it includes results of cyclic tests conducted on two different sands, on normally consolidated specimens prepared at two different laboratories using different techniques, and for a range of confining pressures between 1,400 and 2,800 psf (69 to $138 \mathrm{kPa}$ ), one single curve fits all results reasonably well. The threshold strain, $\gamma_{t} \simeq 10^{-2}$ percent is one important feature of this curve. The clear and consistent picture of pore water pressure buildup provided by figure 3.24 is simpler than data that can be obtained from stress-controlled tests on the same sands. Figure 3.24 gives a clear indication of the potential usefulness of the cyclic strain method.

\subsubsection{Proposed Cyclic Strain Method}

Instead of using the seismic (cyclic) shear stress, $\tau_{c}$ (or the stress ratio $\tau_{c} / \sigma_{o}^{\prime}$ ), it is suggested to use the seismic (cyclic) shear strain, $\gamma_{c}$, for the purpose of evaluating liquefaction potential. There seems to be three possible ways of obtaining $\gamma_{c}$ at a given depth $z$ of a soil profile and for a given seismic excitation:

a) From the equation $\gamma_{c}=\tau_{c} / G$. This equation assumes that the seismic shear stress $\tau_{c}$ at depth $z$ is known. The value of $\tau_{c}$ can be computed from an expression such as equation 3.1 if the ground surface acceleration is known.

b) From site response studies where a model of the soil is subjected to an input earthquake motion, and the strains, stresses and motions within the model are calculated (e.g., Schnabel et al., 1972 [71].

c) From the ground particle velocity, V, and using the expression $\gamma=V / c$, where $c$ is the propagation velocity of the relevant seismic wave, and which is often (although not always) taken as $c=(G / \rho) 1 / 2(\rho=$ mass density of the soil). This method has been used extensively to predict ground shear distortions near pipelines during earthquakes (e.g•, see Newmark, 1967 [55]).

A common feature of procedures (a) through (c) is that they all explicitly include the stress-strain or stiffness properties of the soil in the calculation. This is in contrast with the cyclic stress approach to liquefaction, where the stiffness of the soil is not explicitly considered. Generally speaking, a stiffer soil having a larger value of $G$ will experience a smaller cyclic strain and will develop less pore pressures. 
The present report will focus on procedure (a) to calculate $\gamma_{c}$. The use of procedure (a) permits the formulation of a cyclic strain method for evaluating liquefaction potential. along the lines of the original seed and Idriss (stress) method, described in section 3.1.2. The steps of the proposed strain method to evaluate the liquefaction potential of a sand layer at a depth $z$ are the following:

Step 1. Determination of $\gamma_{c}$ and $n \cdot \gamma_{c}$ is calculated using equation 3.5

$$
\gamma_{c}=0.65 \frac{a_{p}}{g} \frac{\sigma_{o} r_{d}}{G_{\max }\left(G / G_{\max }\right)_{\gamma_{c}}}
$$

Equation 3.5 is similar to equation 3.1 , however; equation 3.5 considers the stiffness of the soil, $G$, while equation 3.1 does not.

The meaning of each symbol in equation 3.5 is given below:

$a_{p}=$ peak horizontal acceleration at the ground surface

$\mathrm{g}=$ acceleration of gravity

$\sigma_{0}=$ total overburden pressure at depth $z$

$r_{d}=r_{d}(z)=$ stress reduction factor with depth plotted in figure 3.4

$G_{\max }=$ shear modulus of the soil at very small cyclic strain, $\gamma_{c} \simeq 10^{-4}$ percent to the cyclic strain, $\gamma_{c}$.

The equivalent number of cycles $\mathrm{n}$ is obtained from the magnitude of the earthquake, M.

Step 2. Comparison between $\gamma_{c}$ and the threshold strain of the soil, $\gamma_{t}$. If $\gamma_{c}<\gamma_{t}$, neither pore pressure buildup nor liquefaction will occur and the evaluation ends here.

Step 3. If $\gamma_{c}>\gamma_{t}$, the values of $\gamma_{c}$ and $n$ should be used in conjunction with experimental curves similar to that shown in figure 3.24 , to estimate the value of the pore pressure buildup at the end of the earthquake, $\Delta u / \sigma_{0}^{\prime}$, where $\sigma_{0}^{\prime}=$ initial effective overburden pressure at depth $z$.

Step 4. The value of $\Delta u / \sigma_{0}^{\prime}$ estimated in step 3 is used to decide if the site will experience initial liquefaction $\left(\Delta u / \sigma_{0}^{\prime}=1.0\right)$ or not $\left(\Delta \mathrm{u} / \sigma_{\mathrm{o}}^{\prime}<1.0\right)$.

For the case of $\gamma_{c}>\gamma_{t}$ in steps 3 and 4 above, $\left(G / G_{\max }\right) \gamma_{c}$ in equation 3.5 is a function of both $\gamma_{c}$ and the current pore presure buildup, $\Delta u / \sigma_{0}^{\prime}$. Therefore, the relation $\left(G / G_{\max }\right) \gamma_{c}$ and $\gamma_{c}$ keeps changing during the earthquake. Obviously, some additional research is needed to develop definite rules for computing $\gamma_{C}$, as well as to refine other aspects of the proposed cyclic strain method, for the case of $\gamma_{c}>\gamma_{t}$. 
The rest of this report presents results of studies and laboratory tests conducted to develop the necessary information for the use of the proposed cyclic strain method. 
a. IDEALIZED FIELD LOADING CONDITIONS

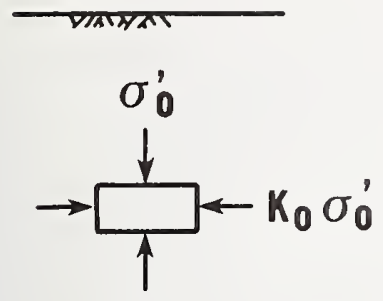

Initial stresses
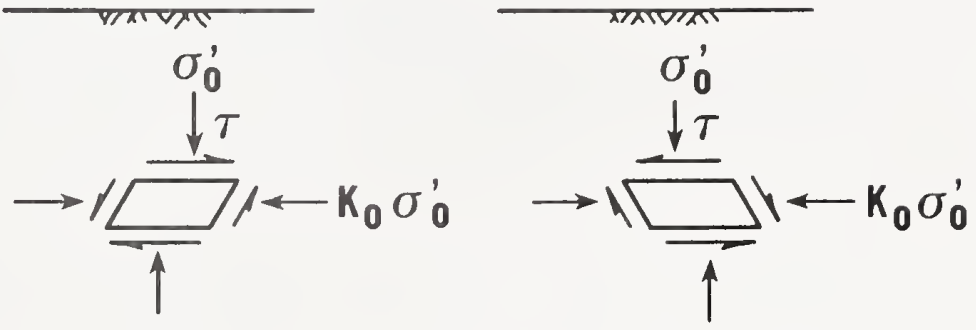

Cyclic load sequence

\section{b. SHEAR STRESS VARIATION DETERMINED BY RESPONSE ANALYSIS}

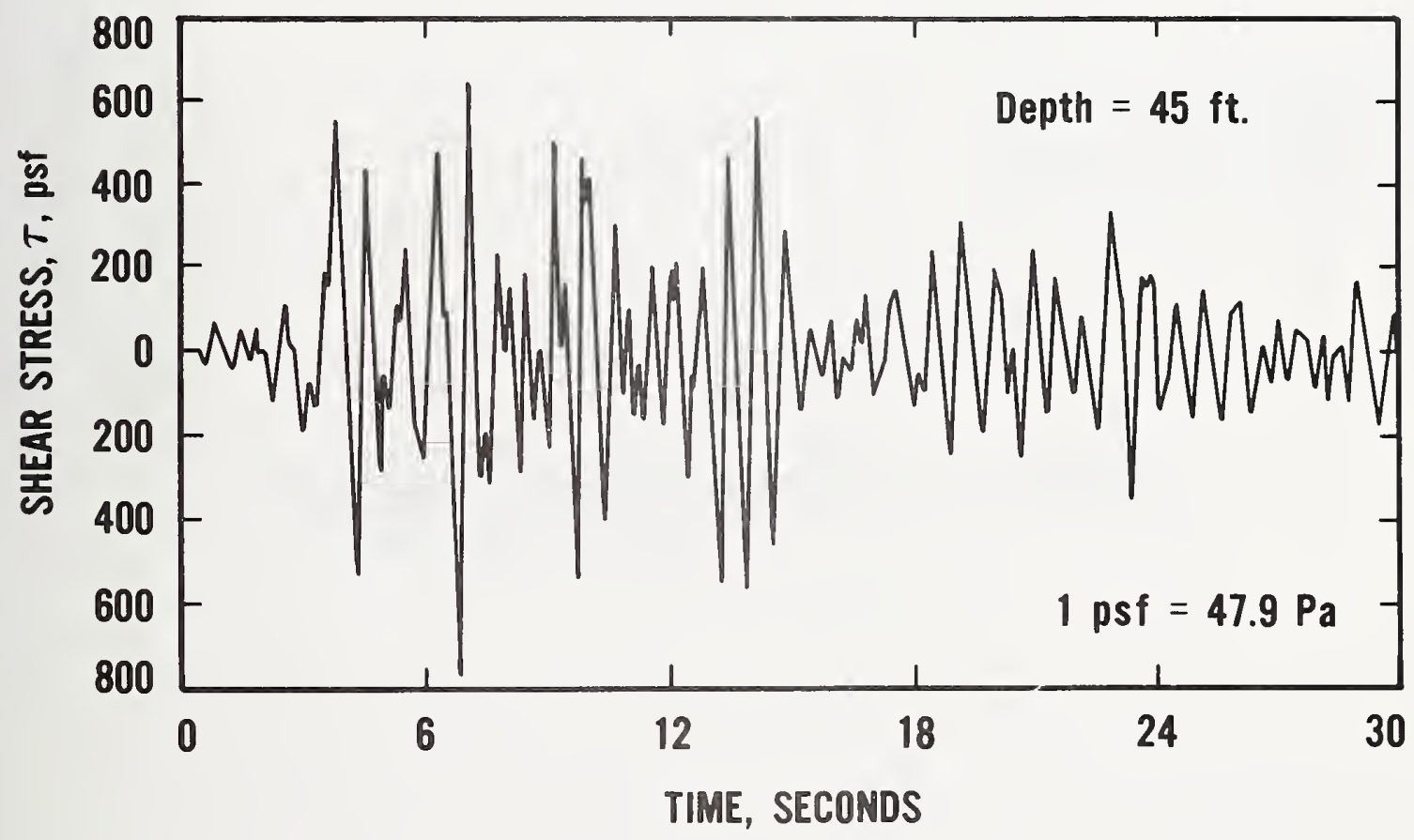

Figure 3.1 Cyclic shear stresses on a soil element during ground shaking (Seed et al., 1975) 


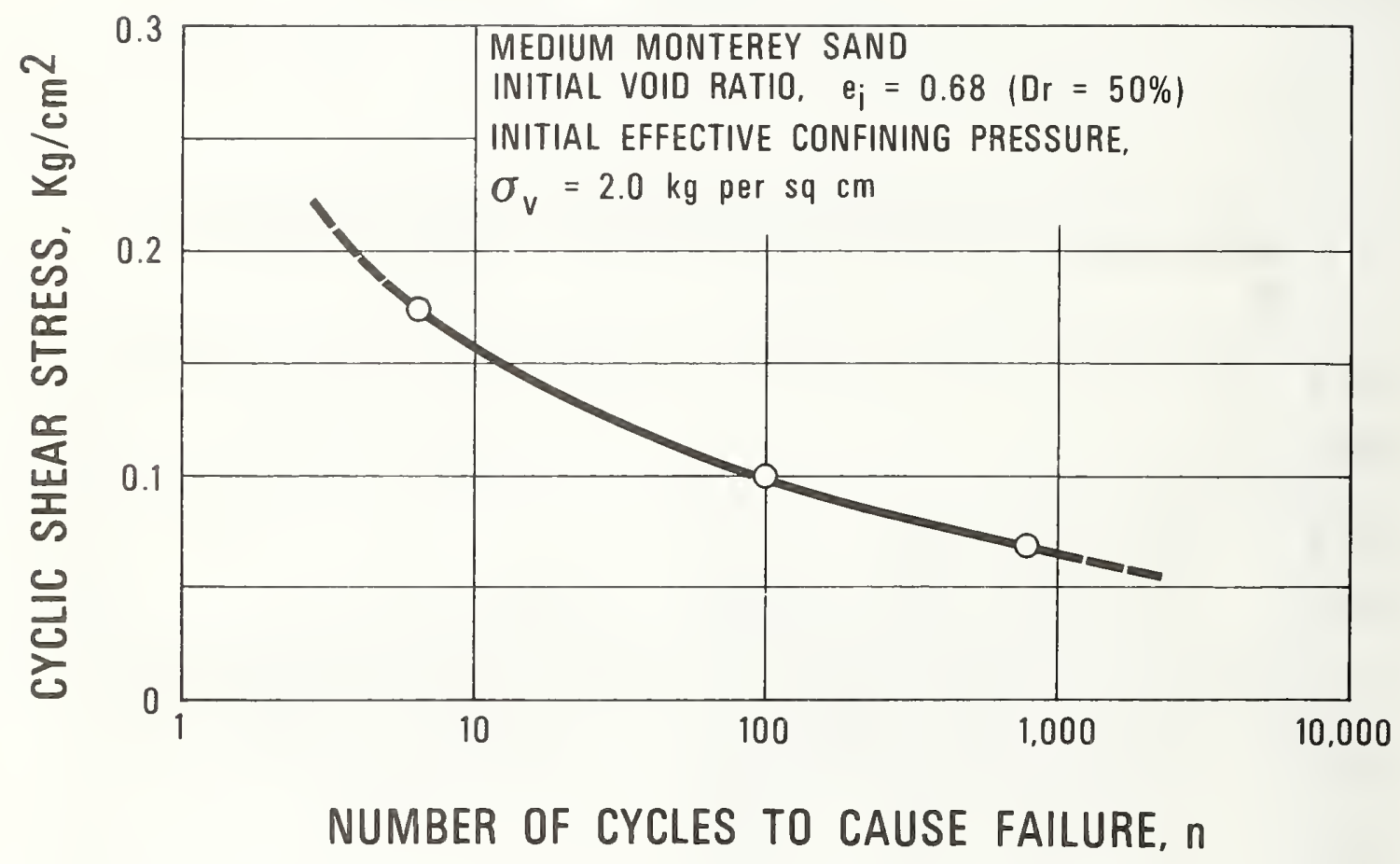

Figure 3.2 Typical form of the relationship between pulsating shear stress and the number of cycles to cause failure - simple shear conditions (Peacock and Seed, 1967) 


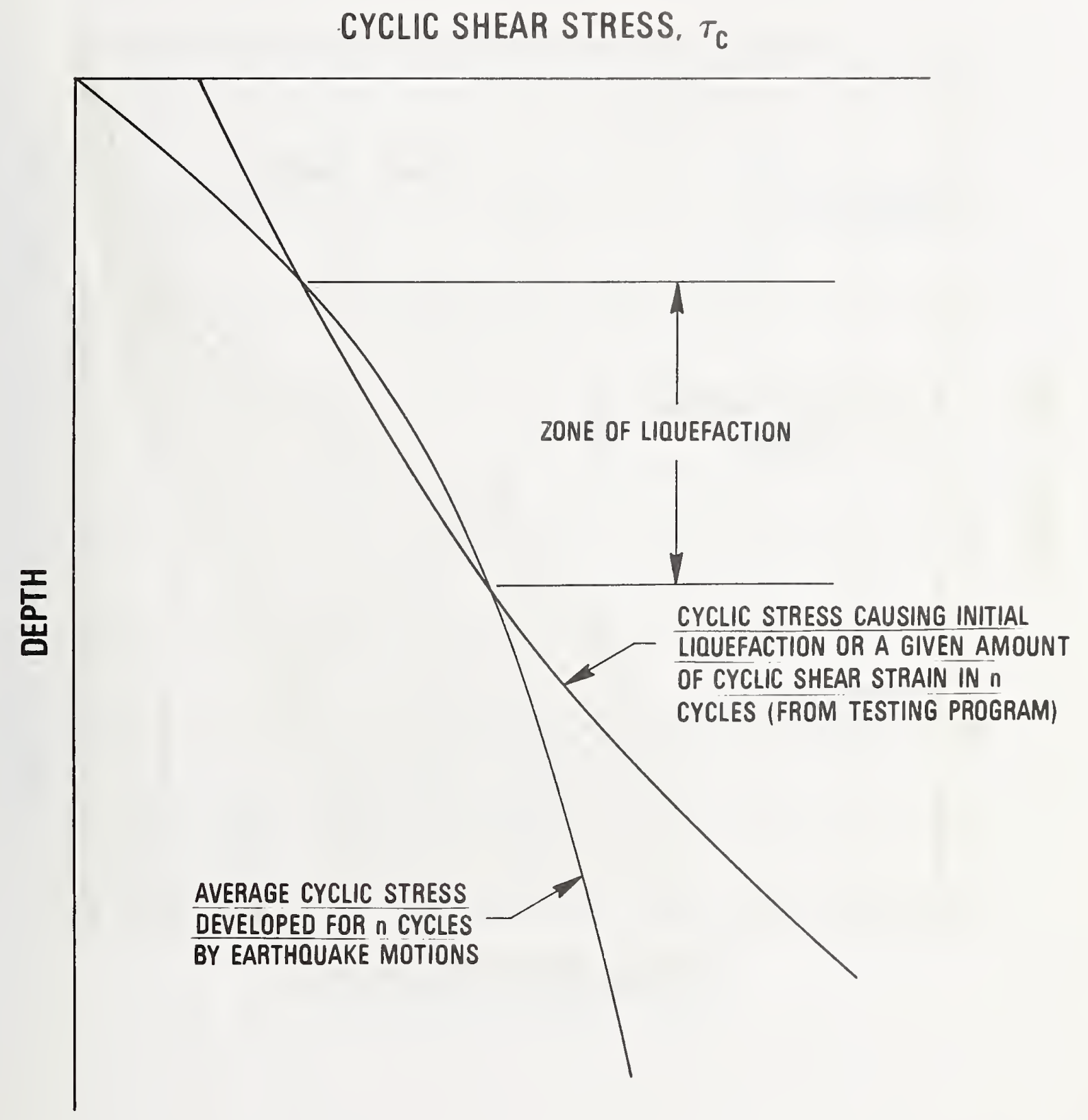

Figure 3.3 Cyclic stress method for evaluating liquefaction potential (Seed et al., 1975) 


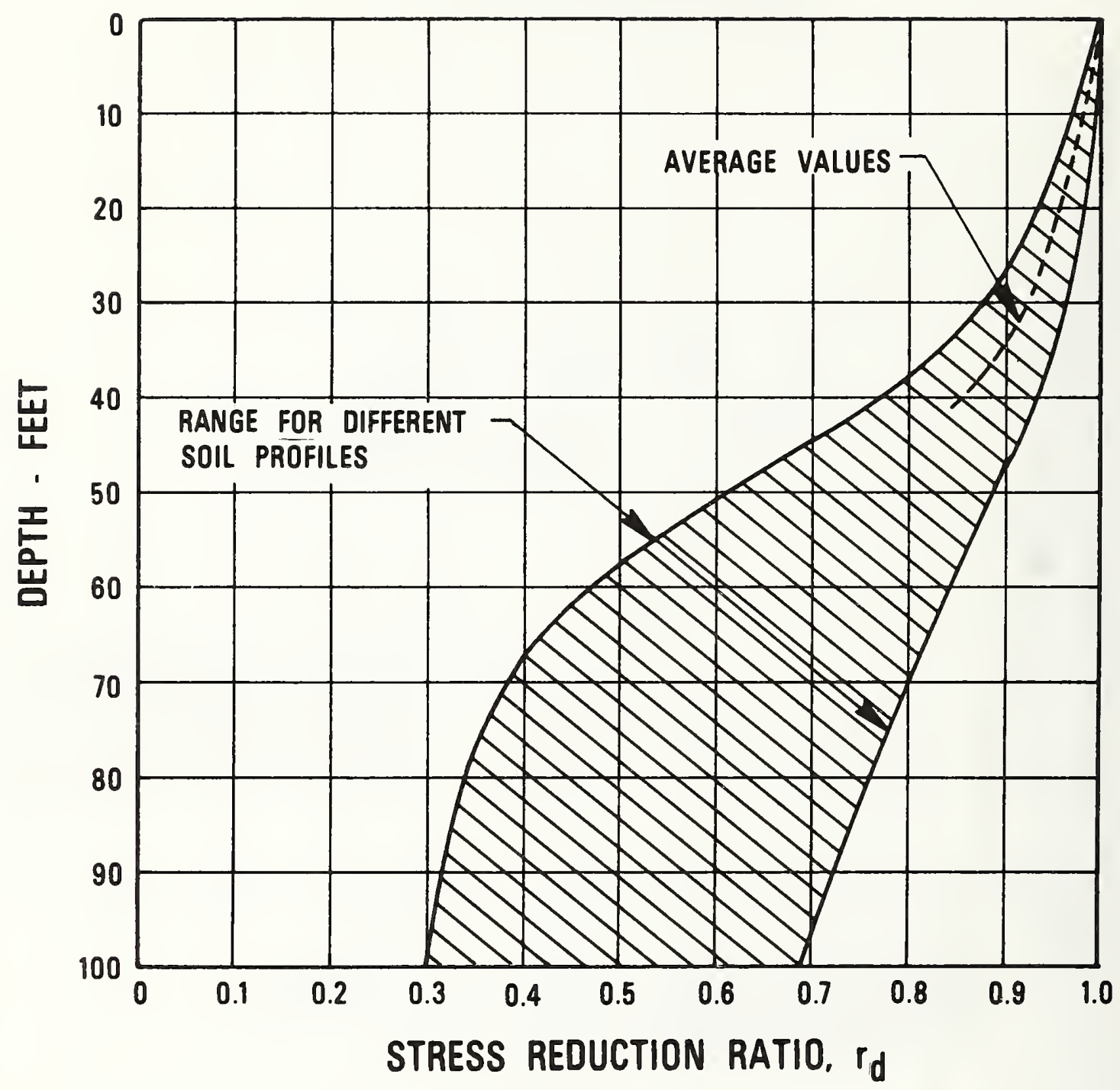

Figure 3.4 Range of values of stress reduction ratio, $r_{d}$, for different soll profiles (Seed and Idriss, 1971) 


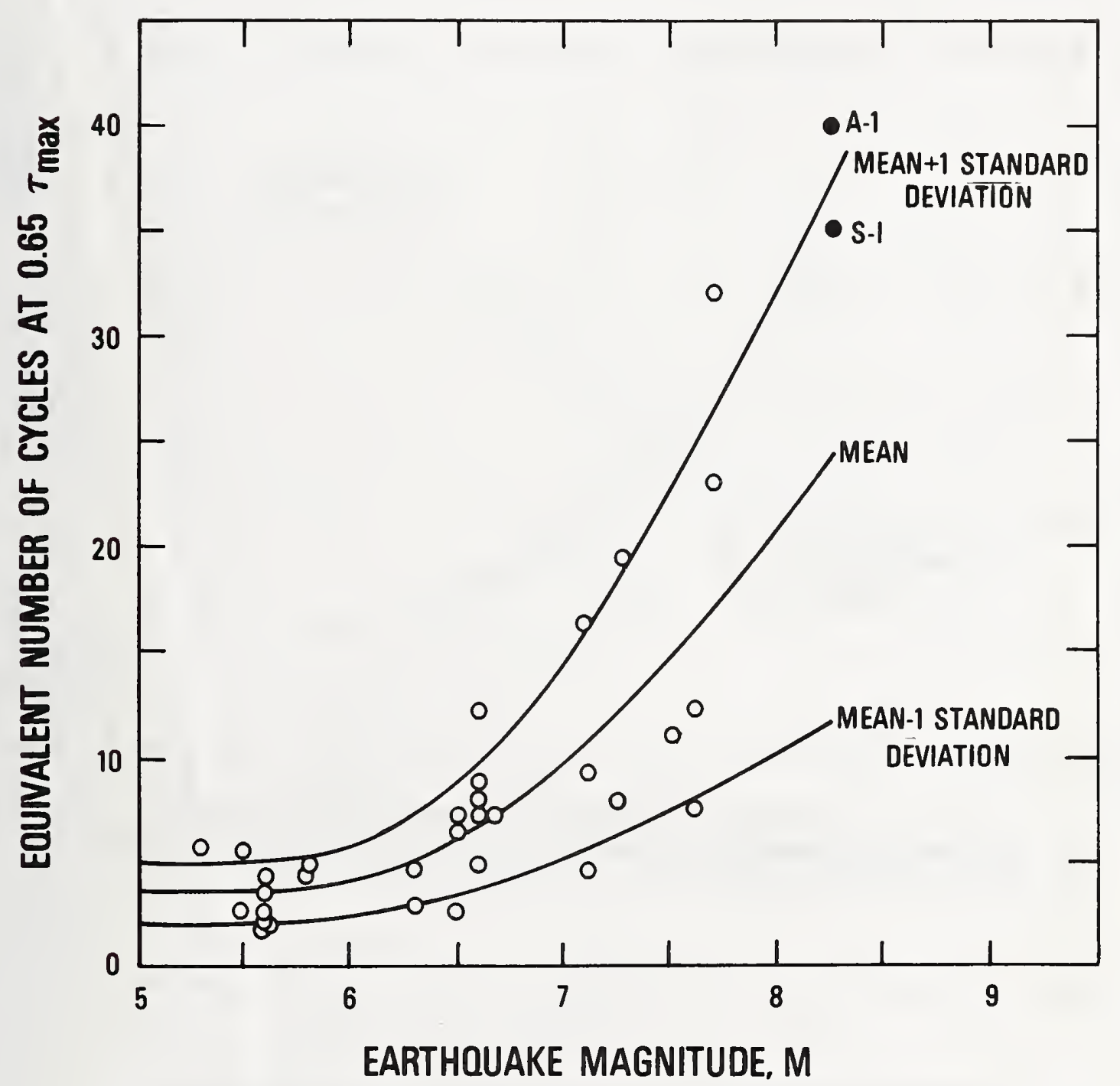

Figure 3.5 Equivalent numbers of uniform stress cycles based on strongest components of ground motion (Seed et al., 1975a) 


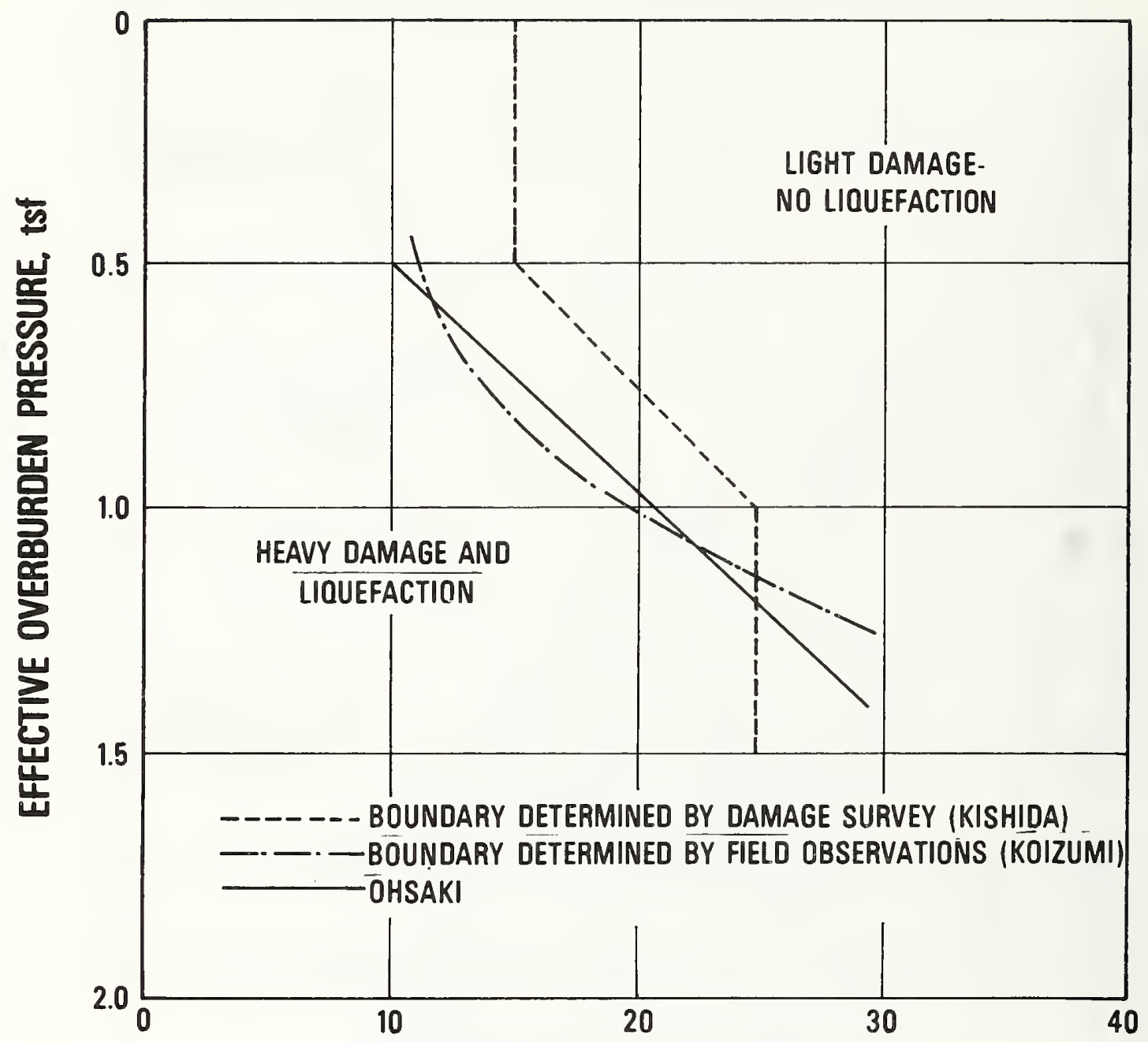

STANDARD PENETRATION RESISTANCE, N-BLOWS/FOOT

Figure 3.6 Analysis of liquefaction potential at Niigata for earthquake of June 16, 1964 (Seed et al., 1975) 


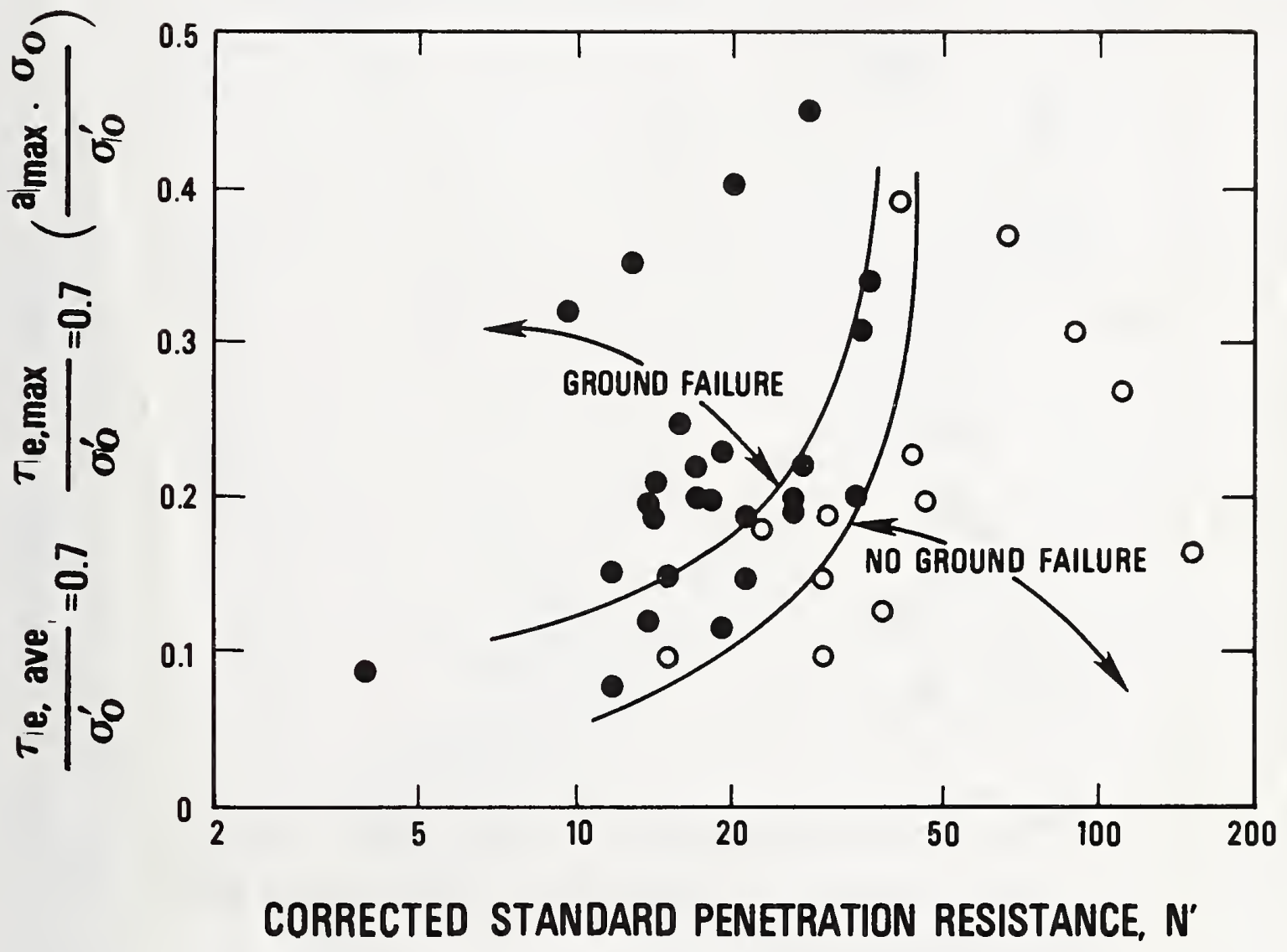

$\underline{\text { Leg end }}$

- Cyclic mobility or liquefaction

- No ground failure

$N^{\prime}=\frac{50 N}{\sigma_{0}^{\prime}+10}$

$\sigma_{0}^{\prime}=$ Effective overburden pressure, psi

Figure 3.7 Performance of saturated sands at earthquake sites (Castro, 1975) 


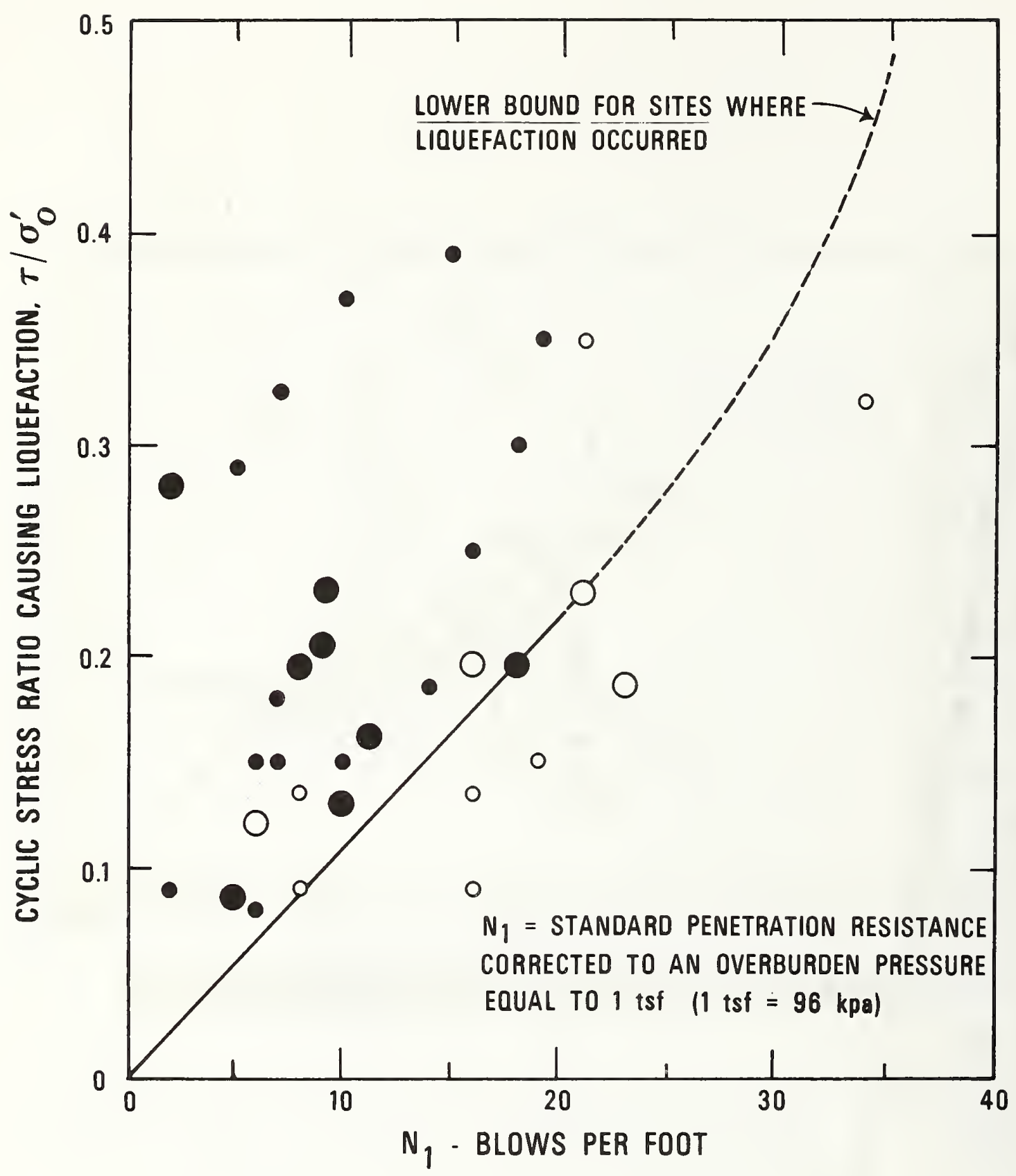

- LIquefaction; StREsS ratio based ON eStimated acceleration - LIQUEFACTION, STRESS RATIO BASED ON GOOD ACCELERATION DATA - NO LIQUEFACTION; STRESS RATIO BASED ON ESTIMATED ACCELERATION O NO LIQUEFACTION; STRESS RATIO BASED ON GOOD ACCELERATION DATA

Figure 3.8 Correlation between stress ratio causing liquefaction in the field and modified penetration resistance of sand, $\mathrm{N}_{1}$, (Seed et al., 1975) 


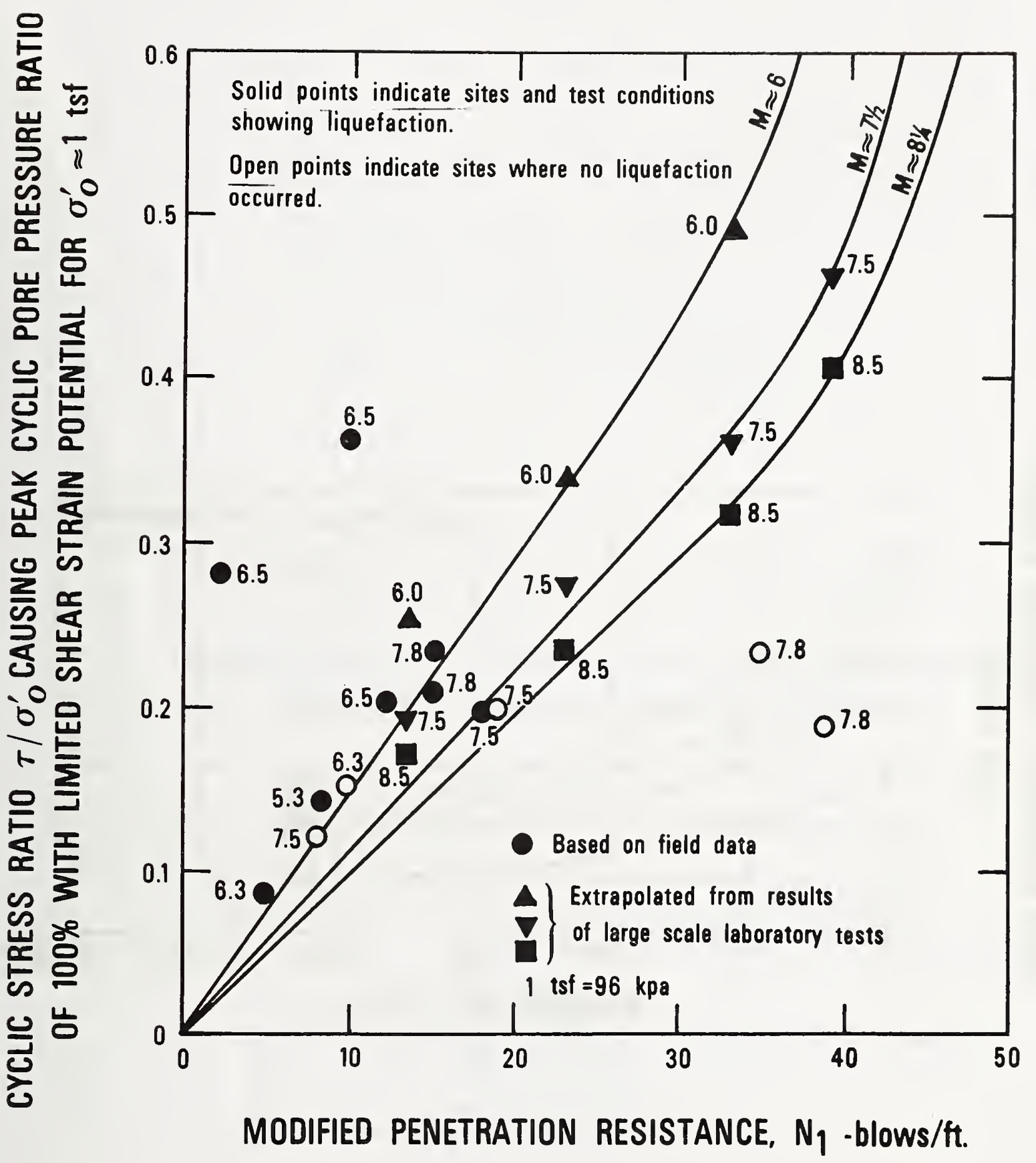

Figure 3.9 Correlation between field liquefaction behavior of sands for level ground conditions and modified penetration resistance (supplemented by data from large scale tests) (Seed, 1979) 


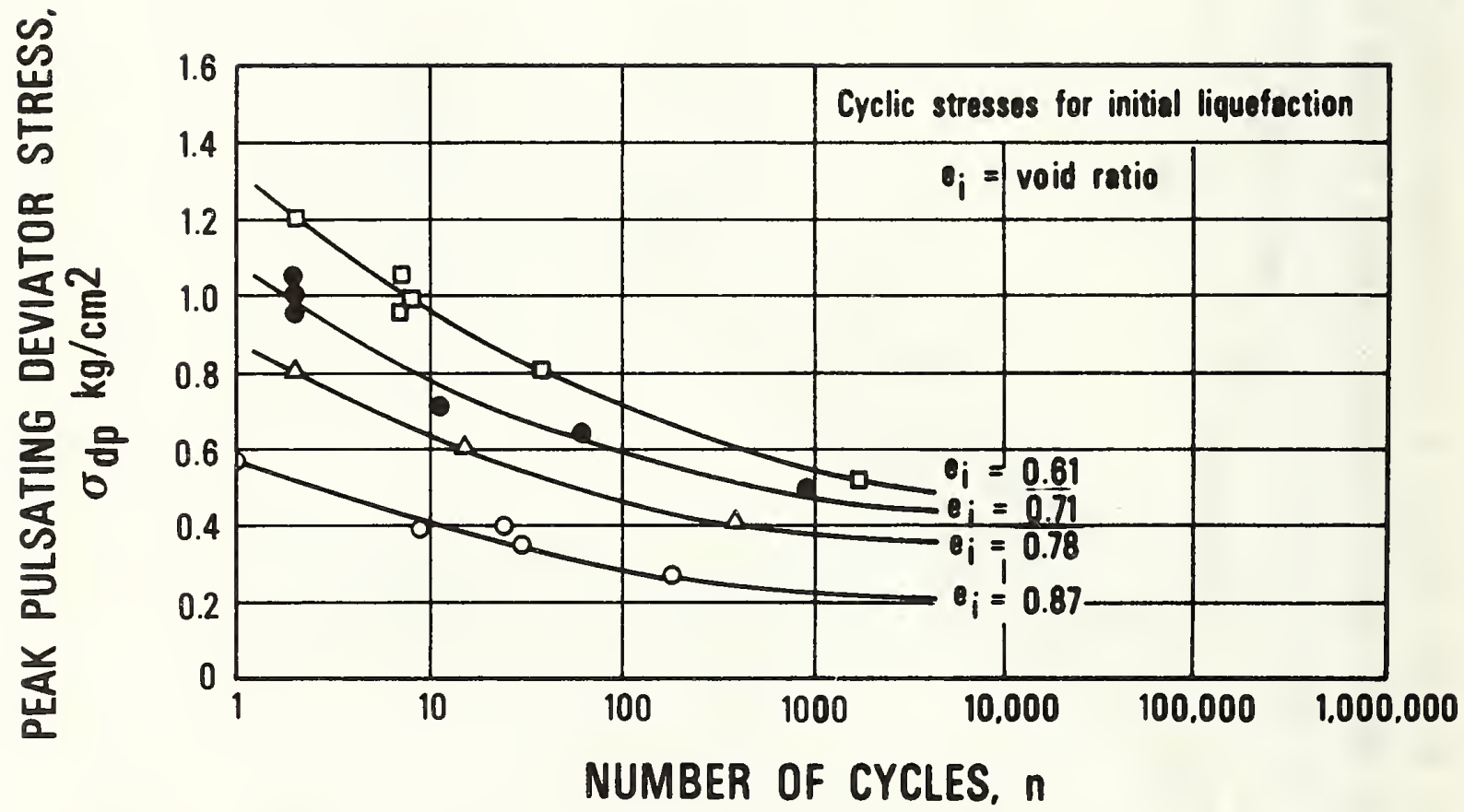

Figure 3.10 Cyclic stresses required to cause liquefaction and 20 percent strain in Sacramento River sand at different densities $\sigma\}=1.0 \mathrm{~kg}$ per sq $\mathrm{cm}$ (Seed and Lee, 1965) 


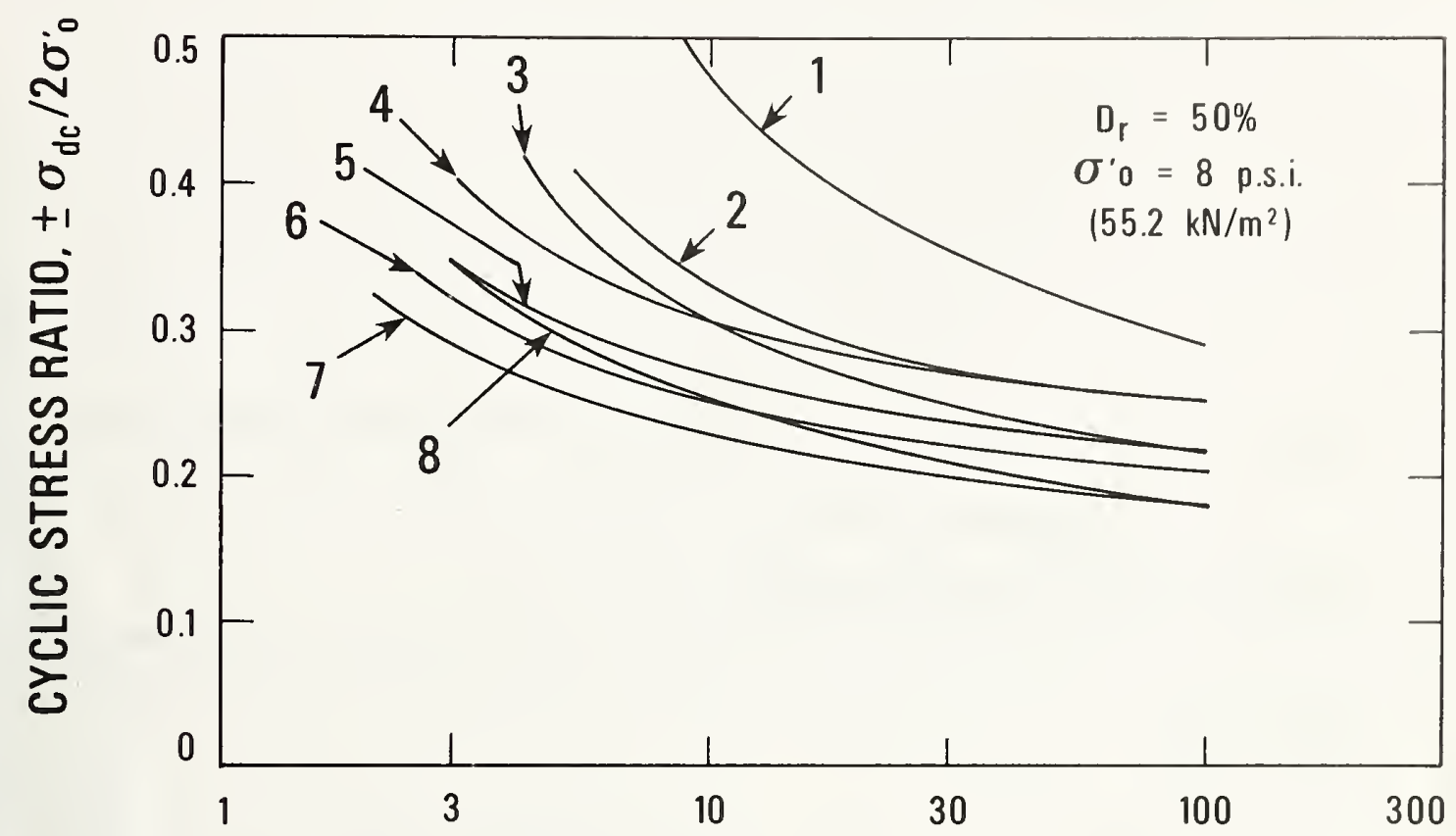

\section{NUMBER OF CYCLES TO CAUSE PEAK CYCLIC PORE PRESSURE RATIO OF $100 \%$ and $\pm 2.5 \%$ AXIAL STRAIN, $n$}

Curve No.

1
2
3
4
5
6
7
8

Method of Compaction

High frequency vibrations on moist samples Moist tamping Moist rodding Low frequency vibrations on dry samples High frequency vibrations on dry samples Pluviated-water Pluviated-air Dry rodding

Figure 3.11 Cyclic stress ratio versus number of cycles for different compaction procedures (after Mililis et a1, 1975) 


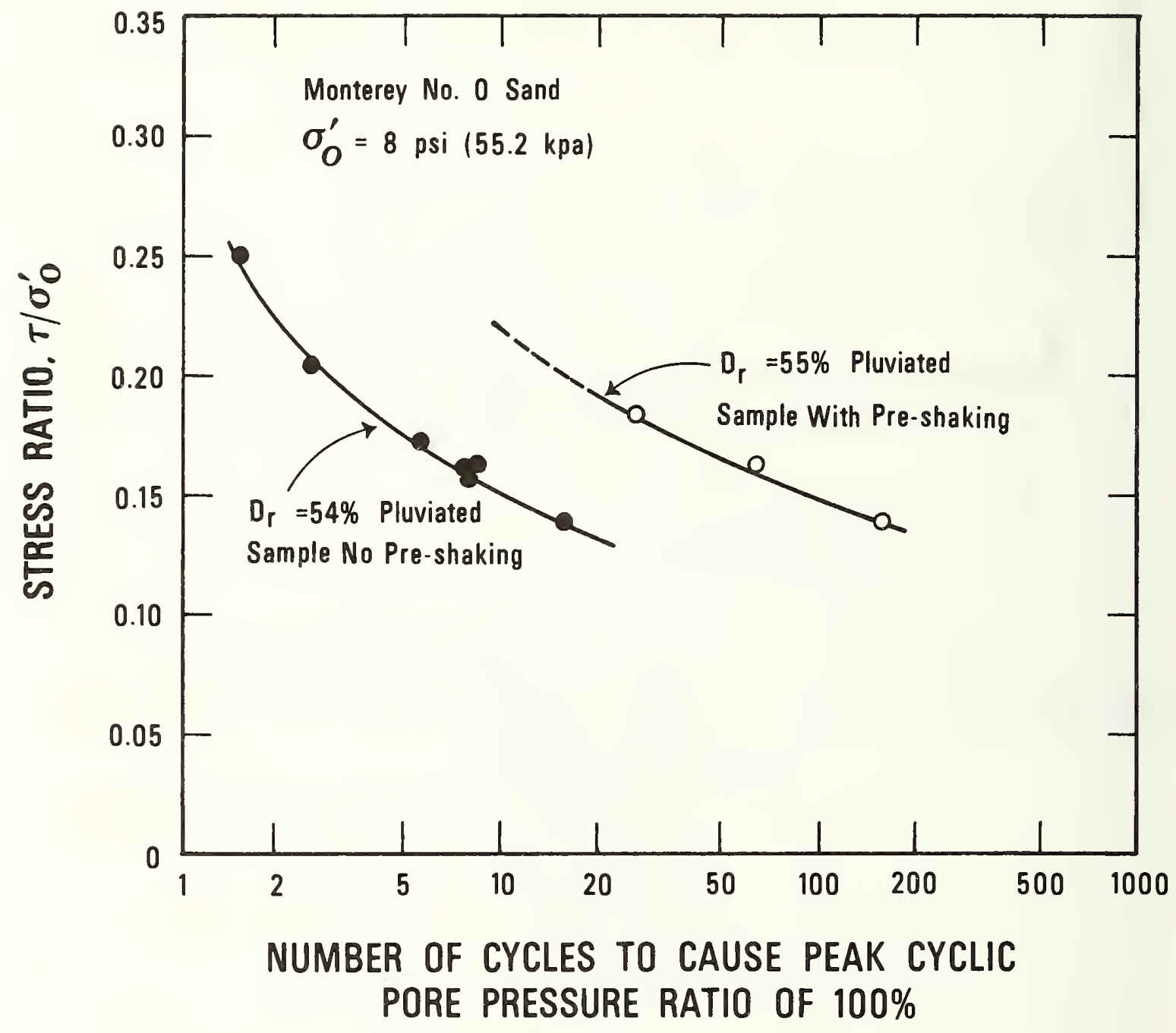

Figure 3.12 Effect of seismic history on cyclic strength of sand (Seed, 1979) 


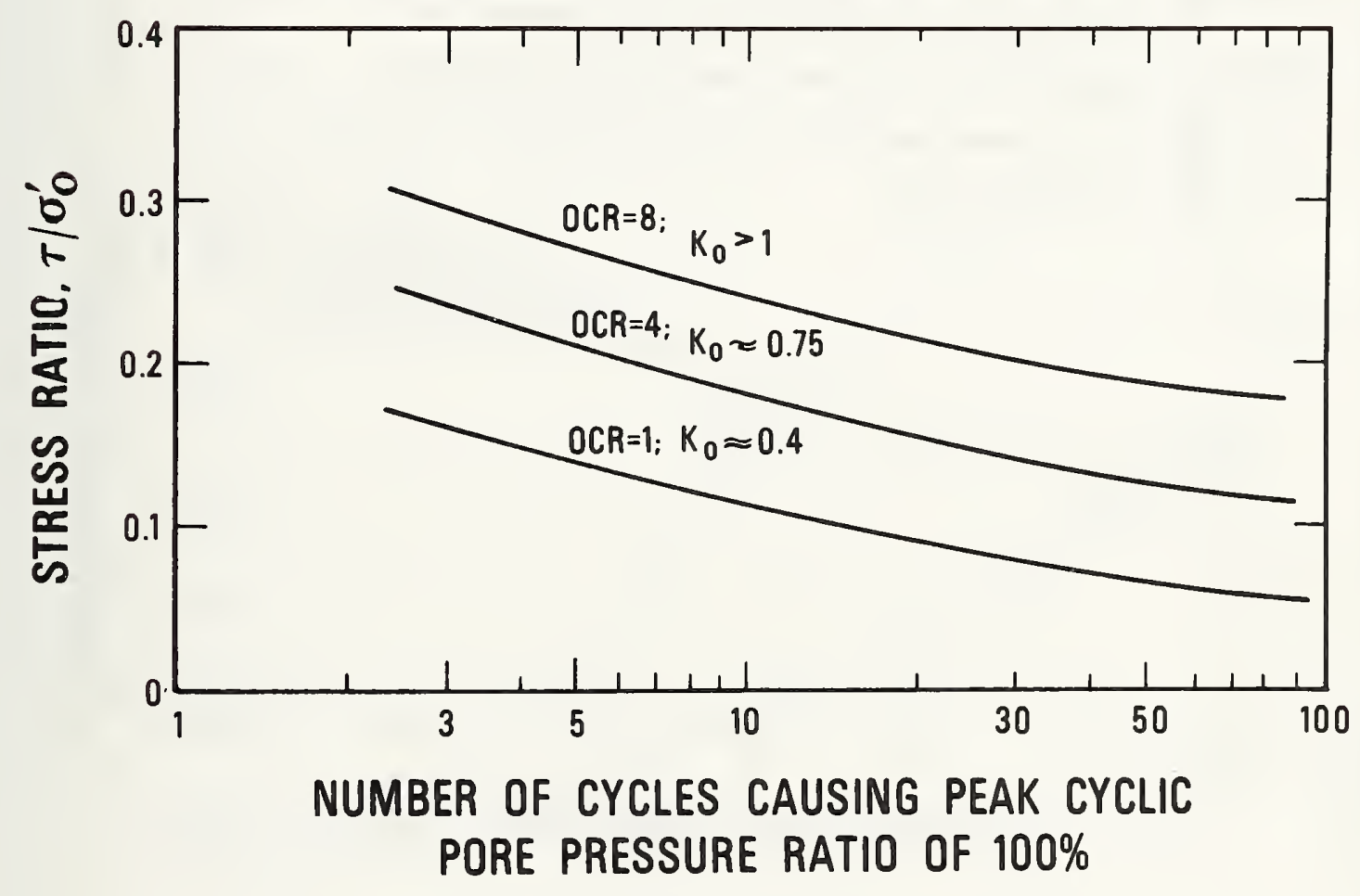

Figure 3.13 Influence of overconsolidation on stress causing pore water pressure ratio of 100 percent in simple shear tests (Seed, 1979) 


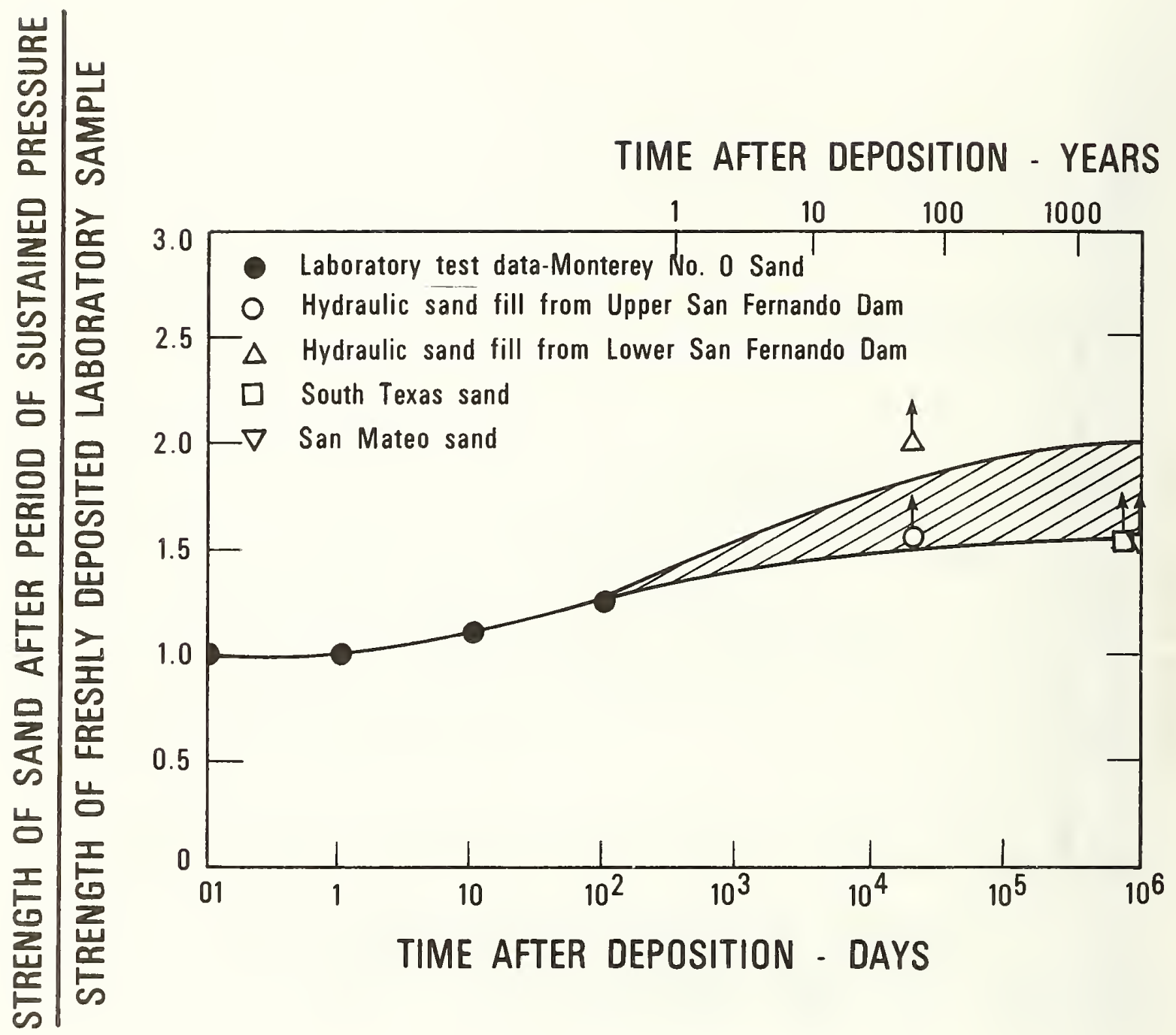

Figure 3.14 Influence of period of sustained pressure on stress causing peak cyclic pore pressure ratio of 100 percent (Seed, 1979) 


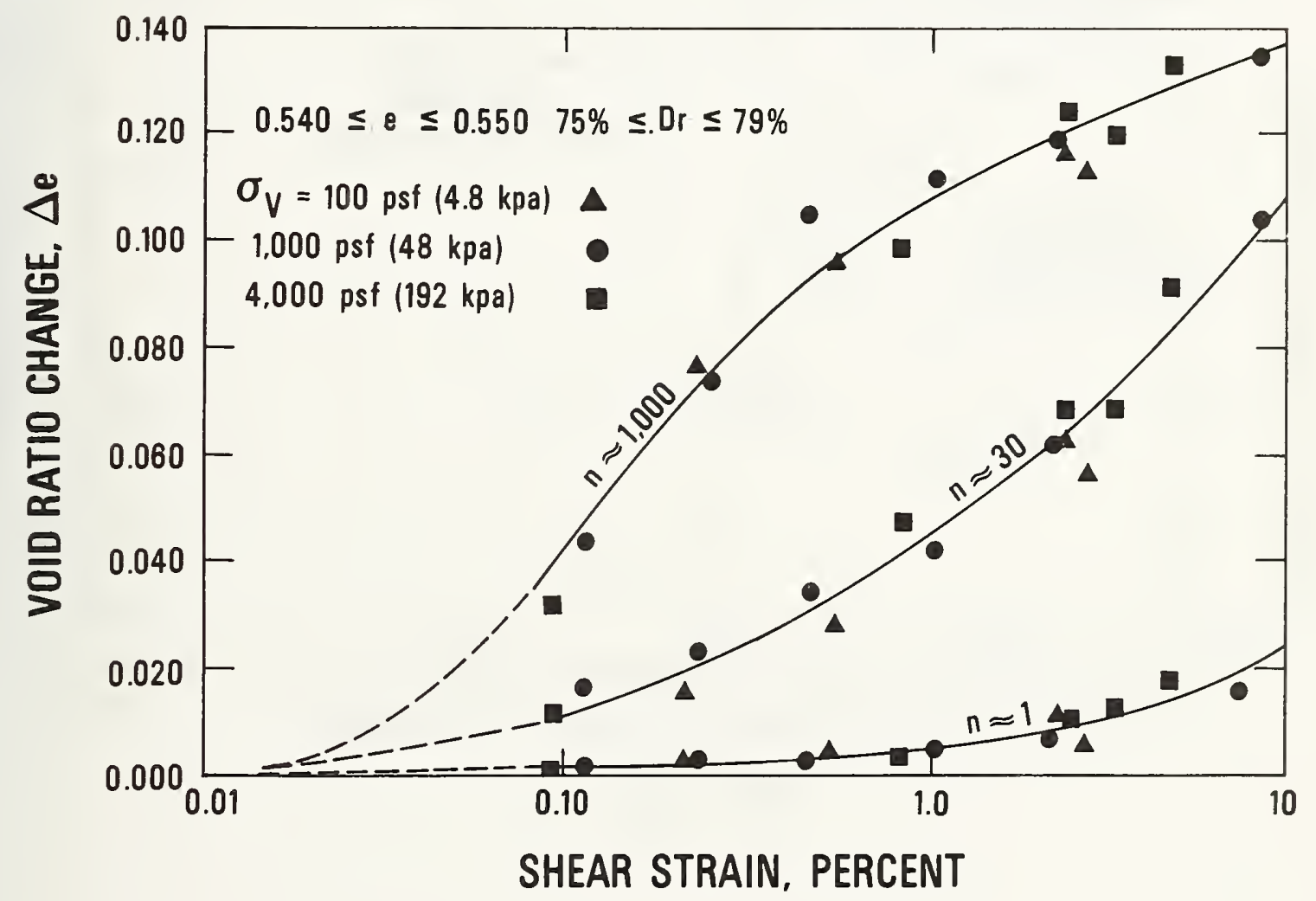

Figure 3.15 Void ratio change for a sand as a function of cyclic shear strain and number of cycles (Youd, 1972) 


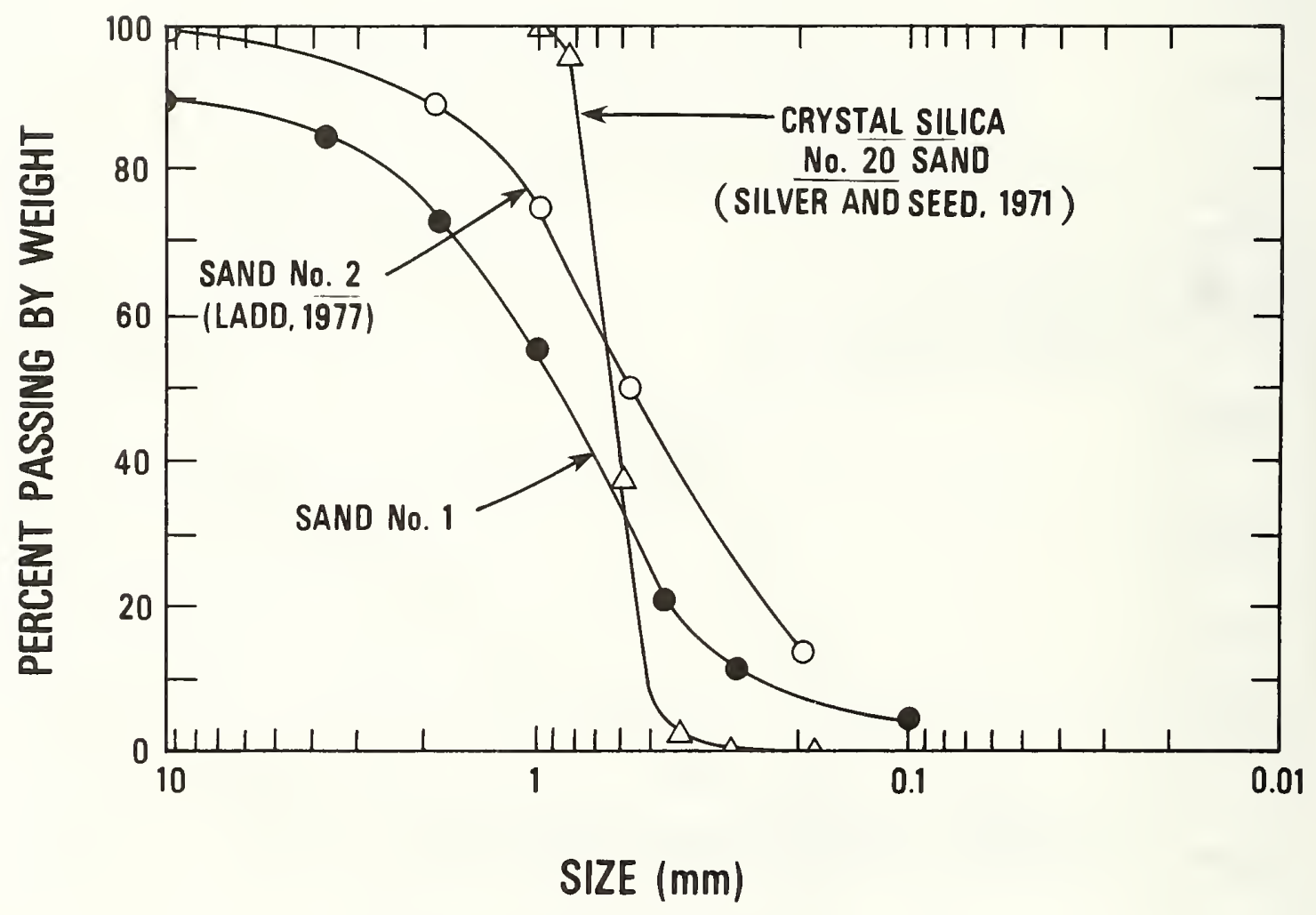

Figure 3.16 Grain size curves of sands used in testing 


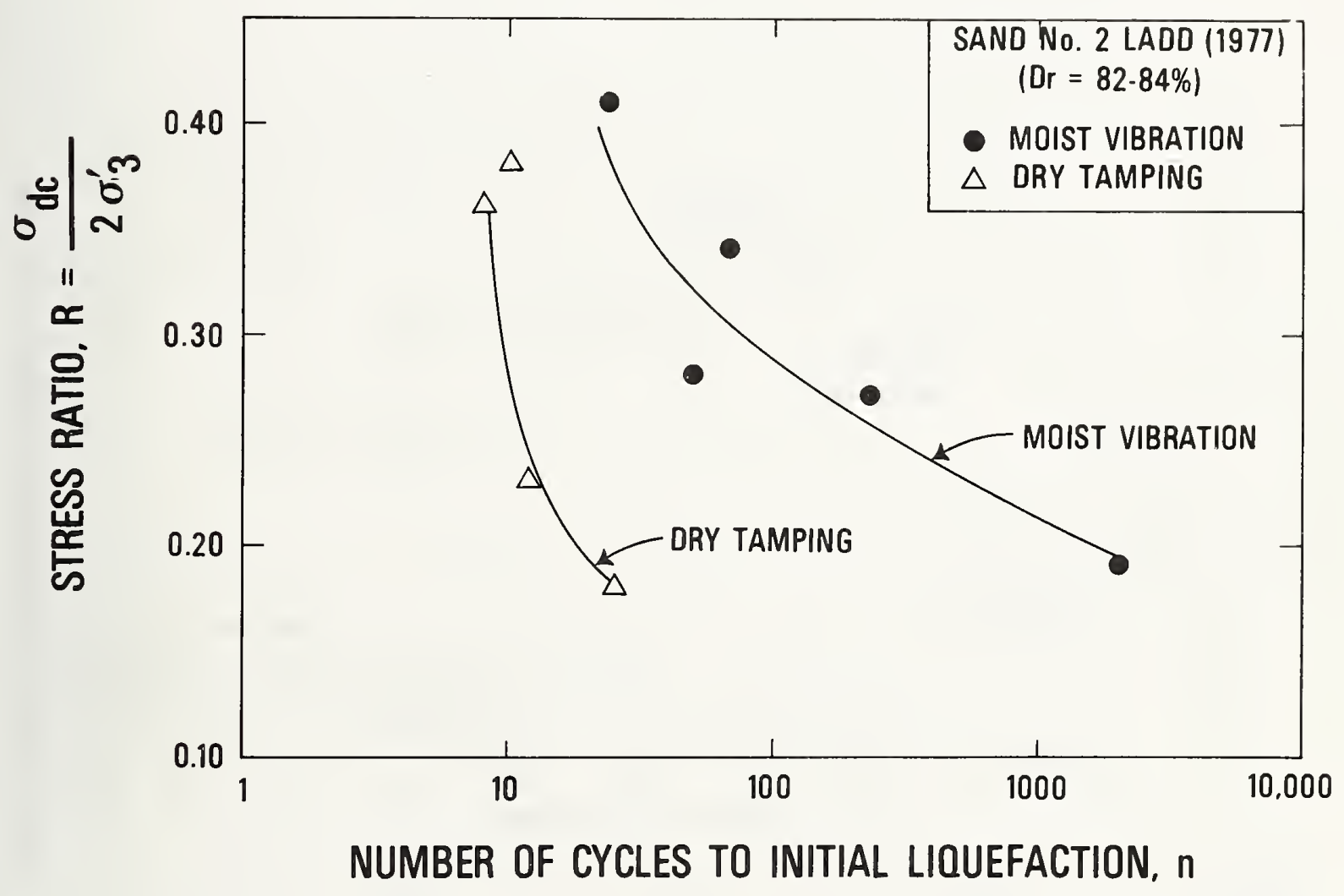

Figure 3.17 Effect of fabric on cyclic strength, stress-controlled tests (Ladd, 1977) 


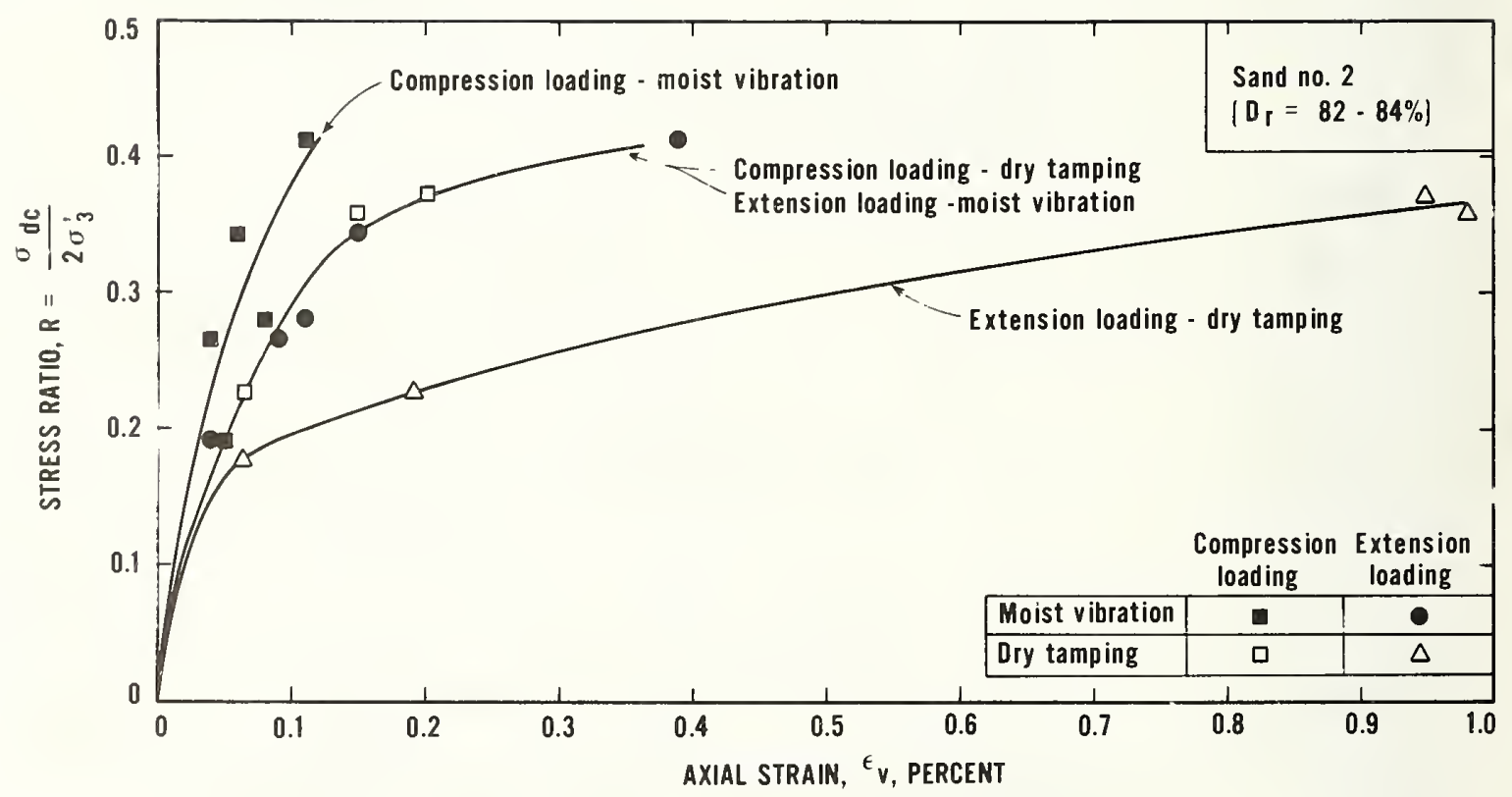

Figure 3.18 Stress-strain curves for first compression and extension excursions, stress-controlled cyclic triaxial tests, Sand No. 2 (modified after Ladd, 1977) 


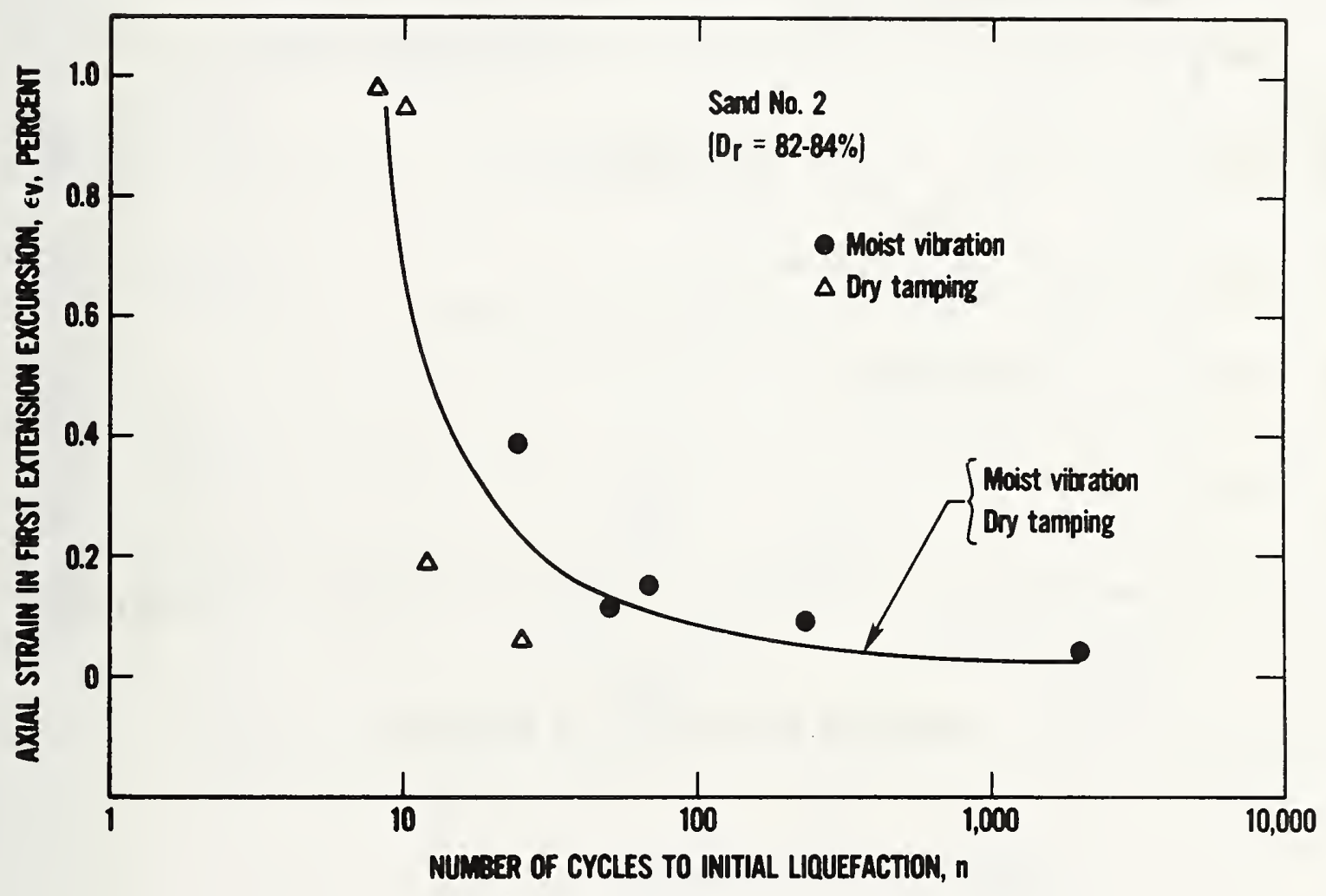

Figure 3.19 Effect of fabric on cyclic strength after accounting for sample stiffness, stress-controlled tests (modified after Ladd, 1977) 
CRYSTAL SILICA No. 20 SAND $\mathrm{Dr}=60 \%$ (PARK AND SILVER, 1975)

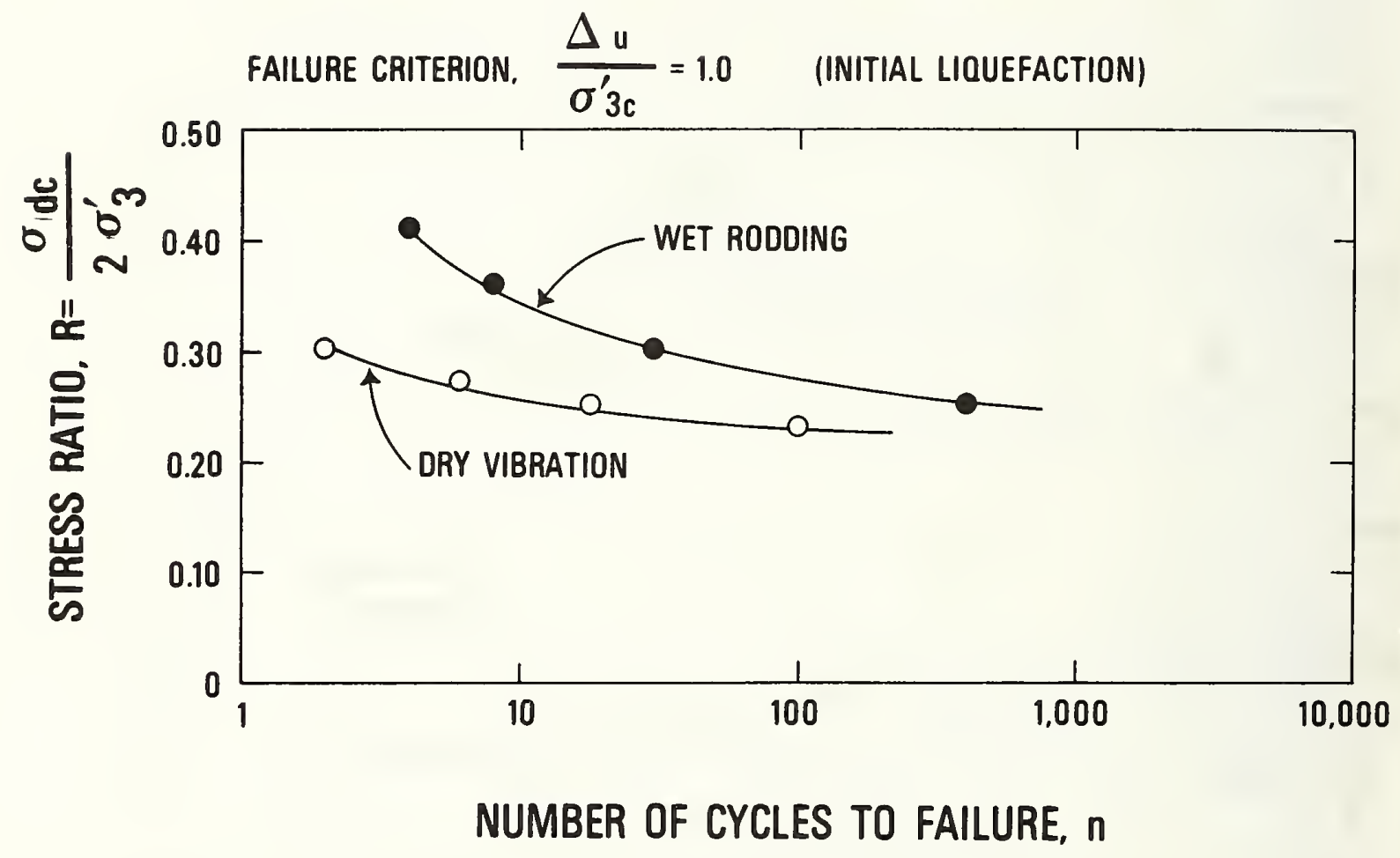

Figure 3.20 Effect of fabric on cyclic strength, stress-controlled tests (Park and Silver, 1975) 


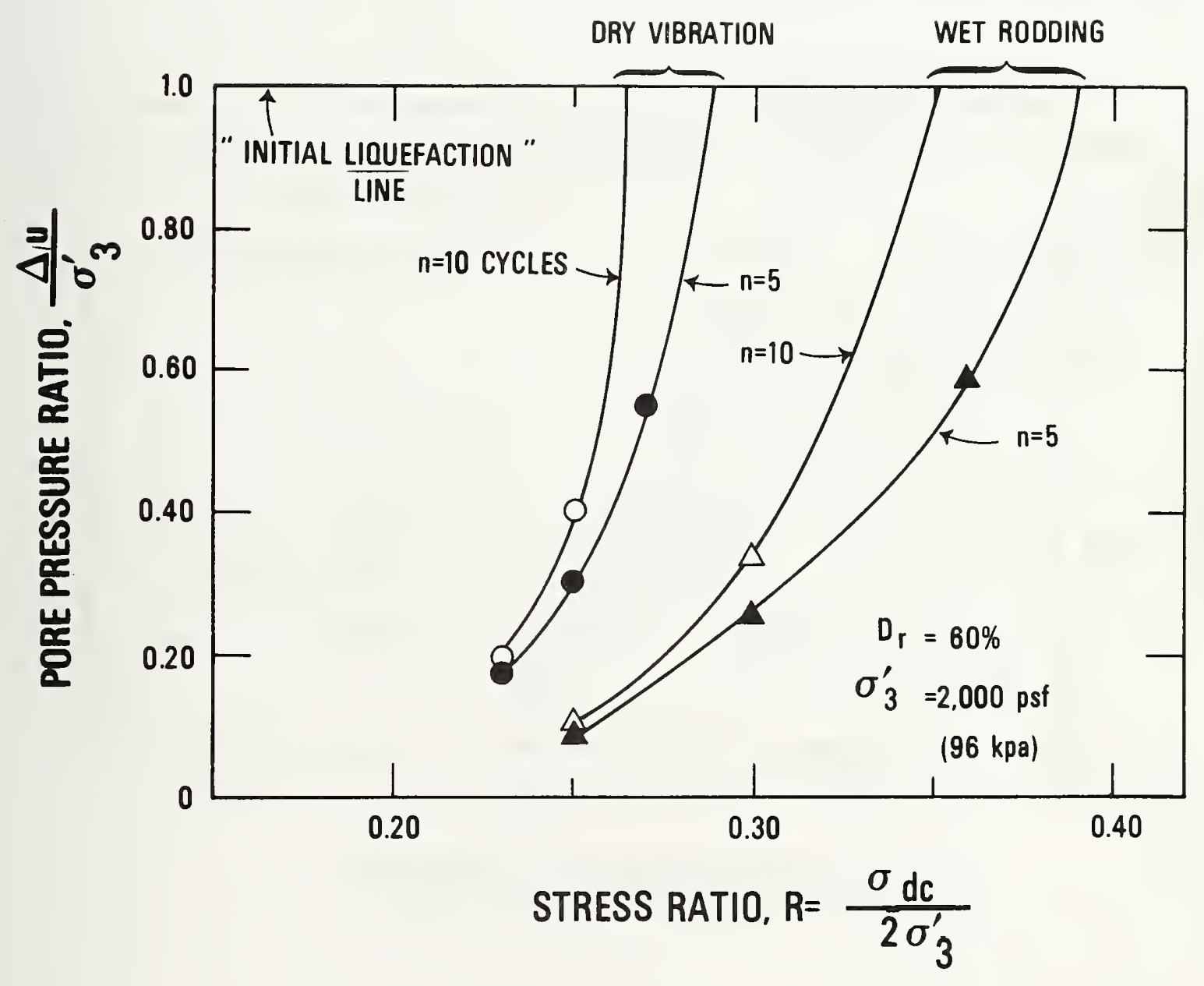

Figure 3.21 Stress-controlled cyclic triaxial tests of saturated Crystal Silica sand (modified after Park and Silver, 1975) 


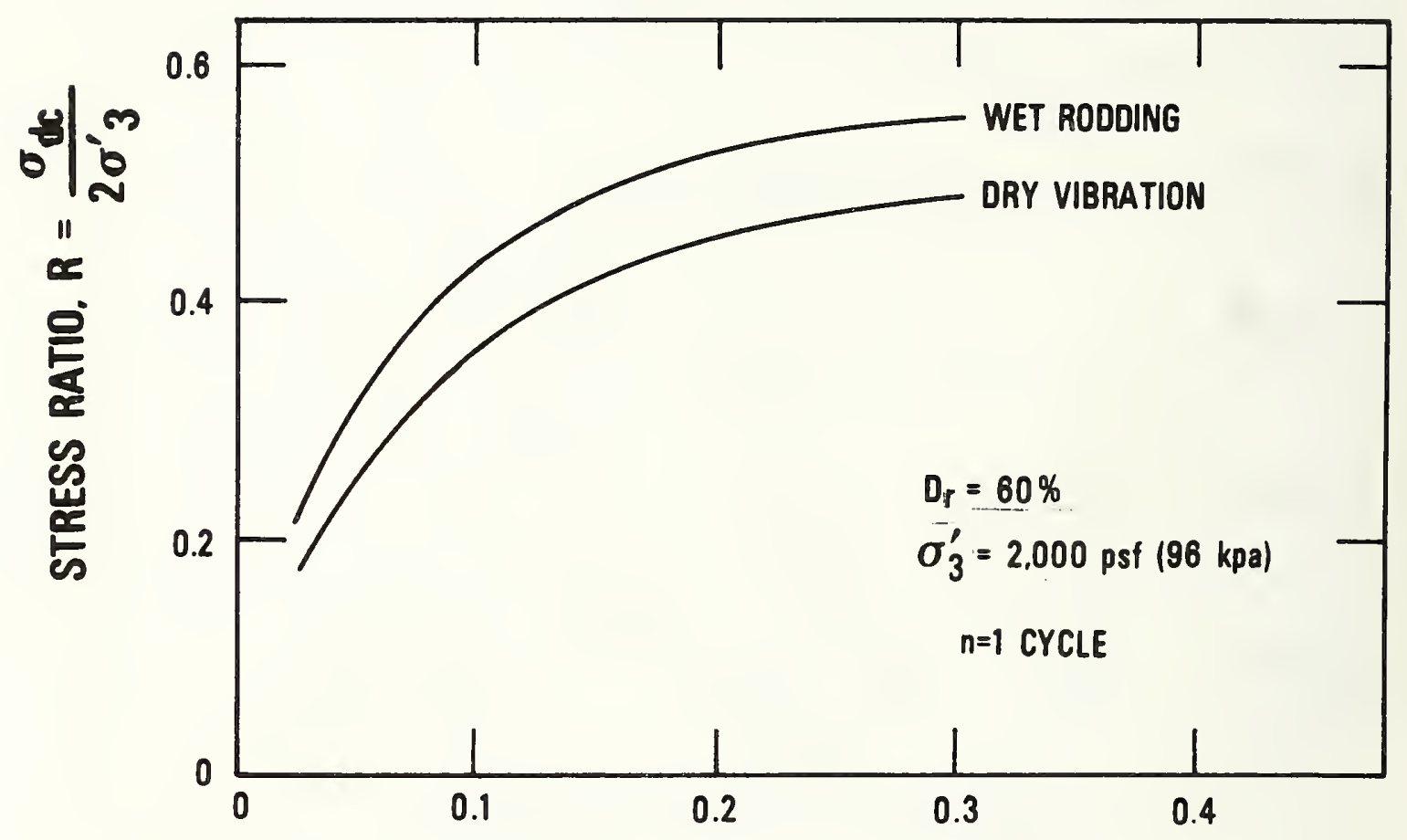

AXIAL STRAIN, $\epsilon_{\mathrm{V}}$, PERCENT

F1gure 3.22 Stress-strain curve for first cycle, cyclic triaxial tests of saturated Crystal Silica sand (modified after Park and S11ver, 1975) 


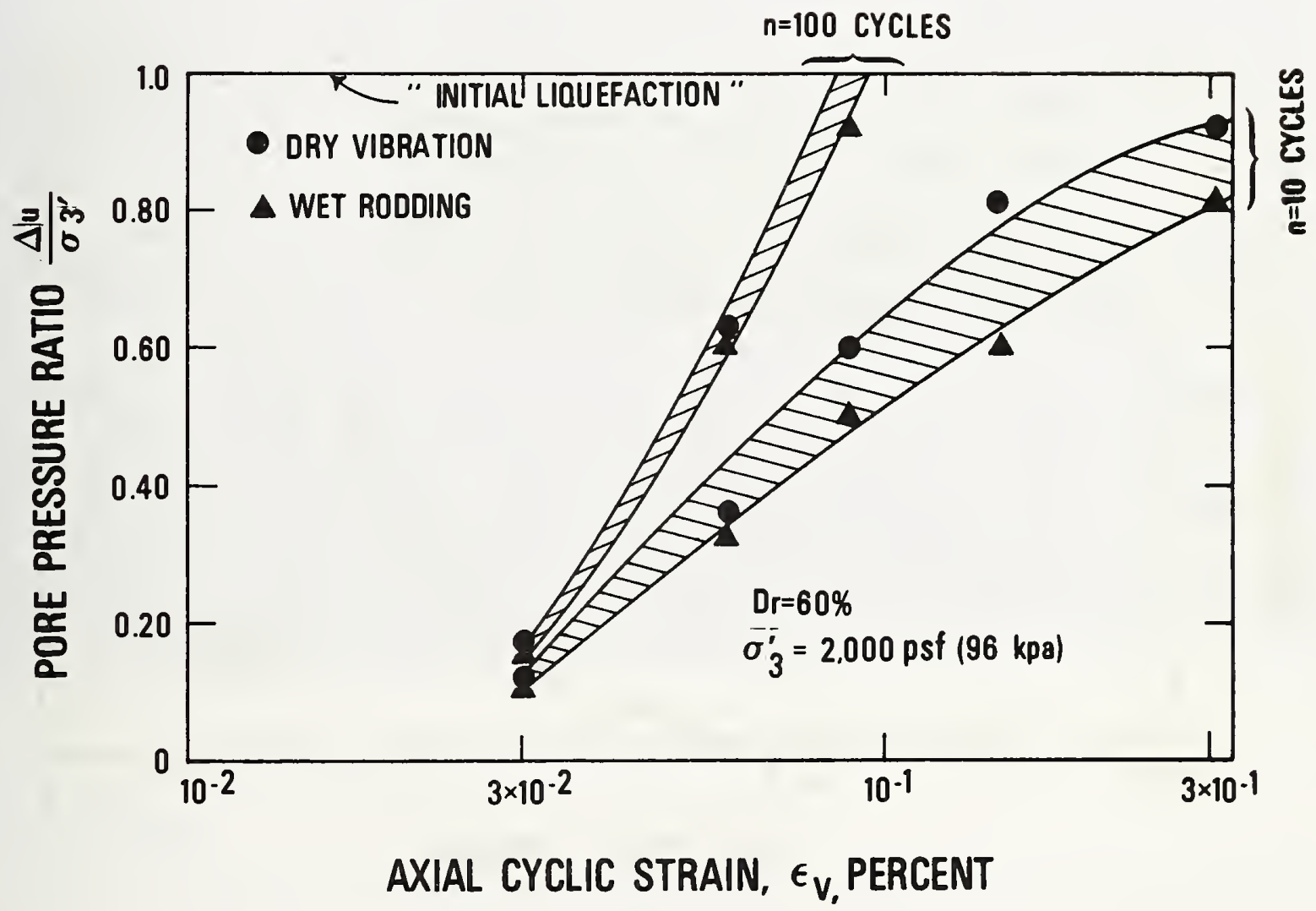

Figure 3.23 Strain-controlled cyclic triaxial tests of saturated Crystal Silica sand (modified after Park and Silver, 1975) 
FACING PAGE: Sand boils observed after the Imperial Valley, CA, October 1979 earthquake. Liquified bine sands were pushed up through the ground surface of dry coarse soils by excess pore water pressure.

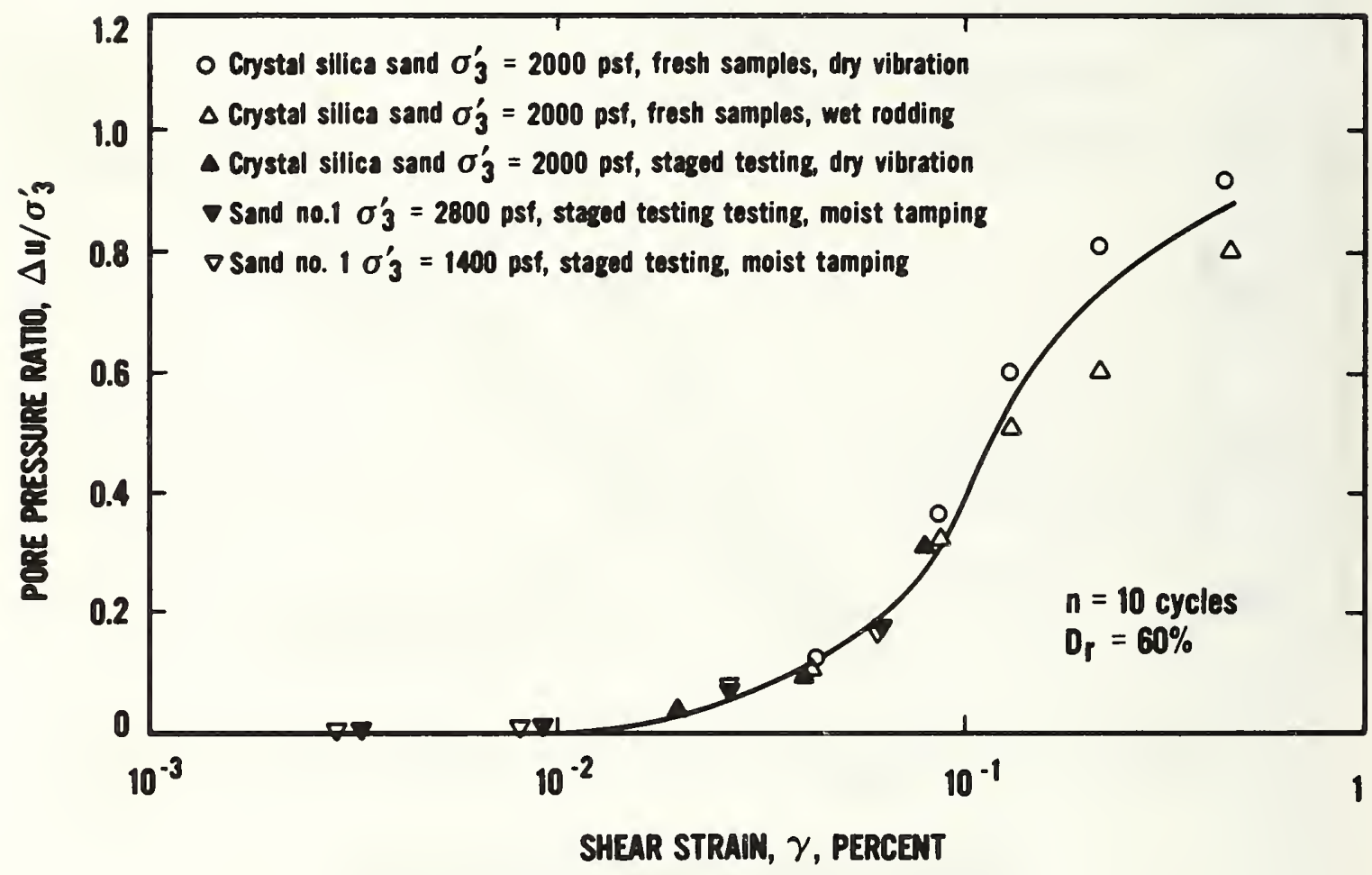

Figure 3.24 Measured pore water pressure in saturated sands after ten loading cycles, strain-controlled cyclic triaxial tests (Dobry and Ladd, 1980) 


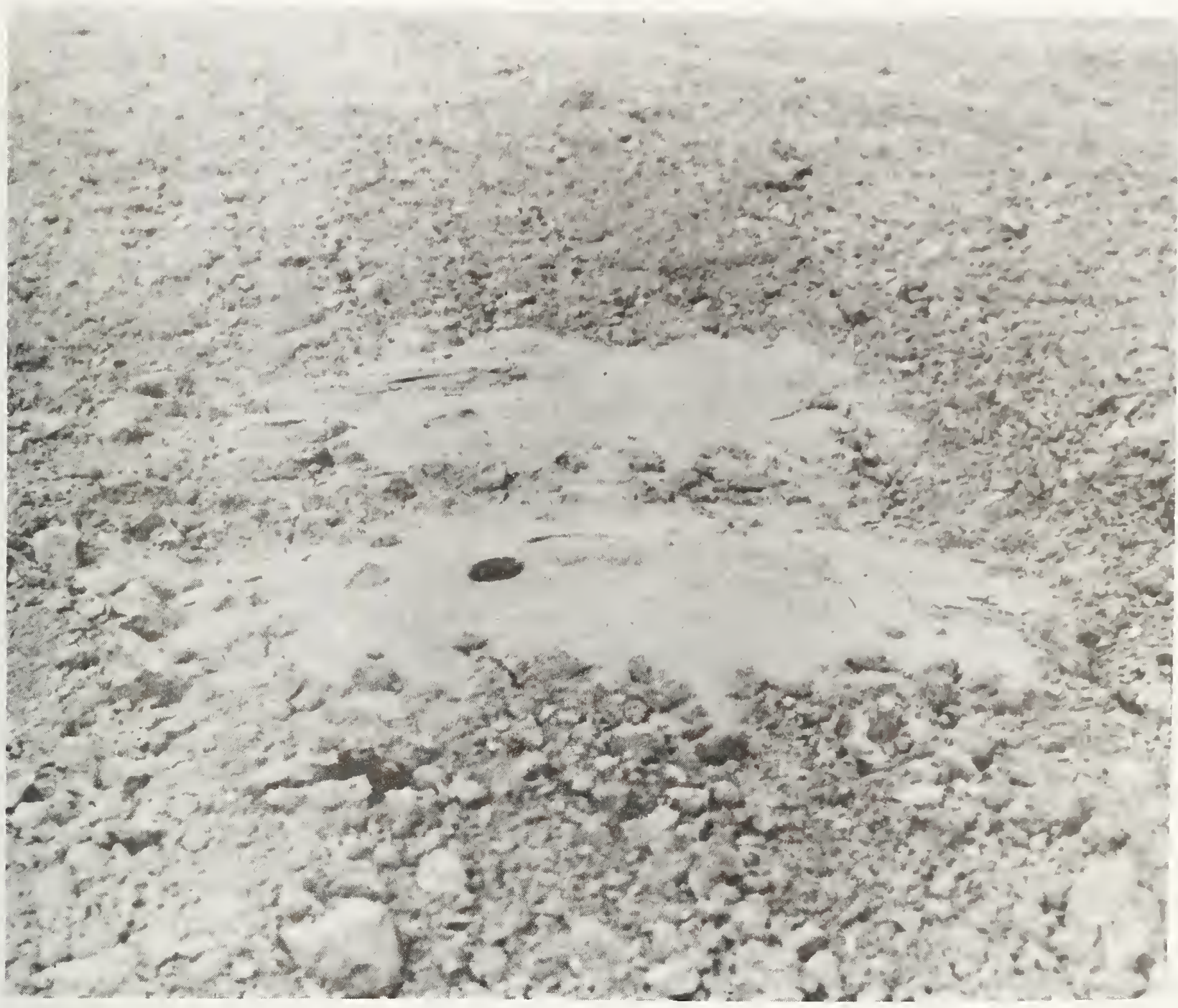

4. A MODEL OF SPHERES FOR THE THRESHOLD STRAIN

\subsection{GENERAL}

An important aspect of the relationship between cyclic strain and excess pore water pressure buildup is the existence of a threshold shear strain, $\gamma_{t}$, in sands, below which no densification and, therefore, no excess pore water pressure buildup occurs. Section 3.2.2 summarized experimental evidence suggesting that in sands this parameter seems to have a remarkably constant value, of the order of $10^{-2}$ percent. The origin of $\gamma_{t}$ and the parameters controlling it are investigated in this section by means of a theoretical model of spheres.

The model selected is that of a simple cubic array of identical quartz spheres. Some of the results using this model have been presented elsewhere (Dobry and Swiger, 1979 [21]). Even though the simple cubic array is a very simplified 
model of a real sand, it is shown in the rest of this chapter that the study of this model provides: (a) an explanation of the physical origin of $\gamma_{t}$; (b) a reasonably good prediction of the value $\gamma_{t} \simeq 10^{-2}$ percent which has been measured in actual sands; (c) insight into the influence of parameters such as confining pressure and grain size on $\gamma_{t}$; and (d) a reasonable prediction of the measured cyclic stress-strain behavior of actual sands at strains below the threshold, $\gamma<\gamma_{t}$.

Figure 4.1 shows the model. The simple cubic array of elastic quartz spheres is subjected first to an isotropic confining pressure, $\sigma$, and then to a cyclic shear stress, $\pm \tau$ (only the stresses corresponding to the positive $\tau$ are shown in the figure): Associated with the cyclic stress there is a cyclic strain of the array, $\pm \gamma$. It is assumed that $\gamma$ is smaller or at most equal to the threshold value, $\gamma \leq \gamma_{t}$. It will be seen that this is equivalent to assuming that no sliding occurs at any of the contact points between the spheres. The following elastic constants and friction coefficient for the quartz spheres were obtained from Lambe and Whitman (1969 [45]) and are used for the calculations:

$$
\begin{array}{ll}
\text { Young's Modulus } & E=11 \times 10^{6} \mathrm{psi} \\
\text { Poisson's Ratio } & \nu=0.31 \\
\text { Friction Coefficient } & \mathrm{f}=0.50
\end{array}
$$

Section 4.2 presents a study of the shear force-displacement relation at the contact points between the spheres, using the results of the Mindlin-Deresiewicz theory. In section 4.3 this information is used to calculate the value of $\gamma_{t}$. In section 4.4 the stress-strain behavior calculated for the model at small strains, $\gamma<\gamma_{t}$, is compared with that of actual sands.

\subsection{CONTACT BETWEEN ELASTIC SPHERES}

Figure 4.2 shows the situation at any one of the four contact points around the representative central sphere of figure 4.1. A normal force $\mathrm{N}$ and a tangential force $T$ must be transmitted through the contact. The relations between these forces and the overall stresses $\sigma$ and $\tau$ acting on the array shown in figure 4.1 are:

$$
\begin{aligned}
& \sigma=\frac{N}{4 R^{2}} \\
& \tau=\frac{T}{4 R^{2}}
\end{aligned}
$$

The normal force $\mathrm{N}$ produces an elastic shortening of the distance between the centers of the neighboring spheres. This shortening, which translates into normal and volumetric strains for the whole array, is of no interest for the present calculations. On the other hand, the tangential force, $T$, produces a tangential displacement, $\delta$, between the centers of the spheres. This tangential displacement is the direct cause of the shear strain of the whole array: 


$$
\gamma=\frac{\delta}{2 R}+\frac{\delta}{2 R}=\frac{\delta}{R}
$$

where the two terms represent, respectively, the contributions to $\gamma$ of the two spheres at left and right of, and above and below of, the representative central sphere of figure 4.1 .

Therefore, an understanding of the physical origin of $\delta$ and a calculating of its value are the key to understanding and calculating $\gamma$ and $\gamma_{t}$.

The following calculation of $\delta$ is based on the work by Mindlin (1949 [51]), Mindlin et al., (1951 [52]) and Mindlin and Deresiewicz (1953 [53]), as summarized in a previous report by Dobry and Grivas (1978 [19]).

The contact point between the spheres in figure 4.2 is really a small circular area of radius $a<<R$. The value of a is:

$$
a=\left(\frac{3}{4} \frac{1-v^{2}}{E} N R\right)^{1 / 3}
$$

The normal force, $\mathrm{N}$, is distributed over this circular area. The corresponding normal contact stress, $\sigma_{c}$, has the parabolic distribution shown in figure 4.3, where $\sigma_{c}$ is a maximum at the center of the contact area and zero at the edge of the area.

The distribution of the tangential force, $T$, over the same contact area is of special interest. If the tangential force has been monotonically increased while keeping $N$ constant, the elastic solution for the shear stresses, $\tau_{C}$, within the contact area gives $\tau_{c}=\infty$ at the edge of the contact area.

If the solid friction condition, $\tau_{c} \leq f \sigma_{c}$, is imposed at all points within the contact area, it is found that there is an annulus of inside radius $c$ and outside radius a (see fig. 4.3), where $\tau_{c}=f \sigma_{c}$ and where slip occurs between the two surfaces and energy is lost by friction. As $T$ increases, $C$ decreases, until, for $T=f N, c=0$, the condition $\tau_{c}=f \sigma_{c}$ prevails over the entire contact area, and there is gross sliding of the two spheres along their contact. If $\delta=$ horizontal displacement between the centers of the spheres, the force-displacement curve, T vs. $\delta$, is of the yielding type, as shown by curve $O P$ in figure 4.4 .

If the tangential load $T$ is cycled between two fixed values, $T^{*}$ and $-\mathrm{T}^{*},\left(\mathrm{~T}^{*}<\right.$ $\mathrm{f} N$ ), while maintaining $\mathrm{N}$ constant, a hysteresis loop is formed, as shown in figure 4.4. This hysteresis $100 \mathrm{p}$ is similar to the experimental loops measured in sands subjected to cyclic shear loading (e.g., see Seed and Idriss, 1970 [77]). The area enclosed by the loop measures the energy spent by friction in the annulus of slip, and for the case considered here ( $\mathrm{T}^{*}<\mathrm{f} \mathrm{N}$ ), the loop is stable (i.e., it repeats itself cycle after cycle).

Mindlin et al., (1951 [52]), Johnson (1955 [34] and 1961 [35]) and Goodman and Brown (1962 [27]) verified experimentally the predictions of the Mindlin- 
Deresiewicz theory, by pressing together glass and metallic bodies and then applying cyclic tangential forces at the contact between them. All predictions were verified, including the existence of the annulus of slip, as well as the location of the tangential force-displacement curves for monotonic (curve oP in fig. 4.4) and cyclic (hysteretic loops in figs. 4.4 and 4.5) loadings.

\subsection{THRESHOLD STRAIN OF ARRAY OF QUARTZ SPHERES}

The equation of the monotonic "backbone" curve (OP in fig. 4.4) predicted by the Mindlin-Deresiewicz theory is:

$$
\frac{\delta}{\delta_{1}}=1-\left(1-\frac{T}{\mathrm{fN}}\right)^{2 / 3}
$$

where

$$
\delta_{1}=\frac{3(2-v)(1+v) \mathrm{f} \mathrm{N}}{4 \mathrm{Ea}}
$$

Equation 4.5 has been plotted in figure 4.6. When the tangential displacement $\delta=\delta_{1}$, the tangentlal force $T=f N$ and gross sliding of the contact occurs. Therefore, $\delta_{1}$ is the threshold displacement at which there is a tendency for an overall change of the geometric arrangement of the spheres to occur. The threshold strain, $\gamma_{t}$, is related to $\delta_{1}$ by equation 4.3:

$$
\gamma_{t}=\frac{\delta_{1}}{R}
$$

If the value of $\delta_{1}$ from equation 4.6 is substituted into equation 4.7 , and the resultant expression is combined with equations 4.1 and 4.4 , the following equation is obtained for $\gamma_{t}$ :

$$
\gamma_{t}=2.08 \frac{(2-\nu)(1+\nu) f}{\left(1-\nu^{2}\right)^{1 / 2}(E)^{2 / 3}}(\sigma)^{2 / 3}
$$

Finally, if the numerical values of the constants for quartz listed in section 4.1 are used, the following simple expression is derived,

$$
\gamma_{t}(\%)=1.75 \times 10^{-4}(\sigma)^{2 / 3} \text {, }
$$

$\sigma$ in psf

Equation 4.9 gives the threshold strain, $\gamma_{t}$, as a function of the confining pressure, $\sigma$ for a simple cubic array of quartz spheres. This equation is plotted in figure 4.7. The result is extremely interesting. It suggests that: (a) for the range of confining pressures of most practical interest (500 psf $<\sigma<4,000 \mathrm{psf}), \gamma_{t}$ is in the range between about $1 \times 10^{-2}$ percent and $4 \times 10^{-2}$ percent, which is close to the experimental values reported for actual sands; and (b) $\gamma_{t}$ is independent of grain size (the radius of the spheres, $R$ is not present in equations 4.8 and 4.9 . Finally, equation 4.8 offers a means to study the influence of the material constants $E, \nu$, and $f$ for sands other than quartz sands. 


\subsection{CYCLIC STRESS-STRAIN BEHAVIOR AT VERY SMALL STRAINS}

The simple cubic model of quartz spheres can also be used to predict the cyclic stress-strain behavior of sands at very small strains, $\gamma<\gamma_{t}$. Measurements during cyclic shear loading of sands have produced experimental hysteresis loops such as those shown in figure 4.4, except that, for actual sands, stress $(\tau)$ is plotted versus strain $(\gamma)$, instead of $T$ versus $\delta$ used in the figure. However, the curves in figures 4.4 and 4.6 can be readily converted into $\tau-\gamma$ plots valid for the simple cubic array and loading system of figure 4.1 . Specifically, equation 4.5 , representing the backbone curve in figures 4.4 and 4.6, becomes:

$$
\frac{Y}{\gamma_{t}}=1-\left(1-\frac{\tau}{f \sigma}\right)^{2 / 3}
$$

It 1 s of interest to compute two normalized parameters for the simple cubic array of quartz spheres at very small strains, $\gamma<\gamma_{t}$, and to compare these parameters with the values measured in actual sands. These parameters are: (a) the modulus reduction curve, $G / G_{\max }$ versus $\gamma$, and $b$ ) the damping ratio, $\lambda$ versus the shear strain $\gamma$.

The expression of $G / G_{\max }$ versus $\gamma$ can be obtalned directly from equation 4.10 as follows:

$$
\begin{aligned}
& \tau=f \sigma\left[1-\left(1-\frac{\gamma}{\gamma_{t}}\right)^{3 / 2}\right] \\
& G=G_{s e c}=\frac{\tau}{\gamma}=\frac{f \sigma}{\gamma}\left[1-\left(1-\frac{\gamma}{\gamma_{t}}\right)^{3 / 2}\right] \\
& G_{\max }=\left(\frac{d \tau}{d \gamma}\right)_{\gamma=0}=\frac{3}{2} \frac{f \sigma}{\gamma_{t}} \\
& \frac{G}{G_{\max }}=\frac{2}{3} \frac{1-\left(1-\frac{\gamma}{\gamma_{t}}\right)}{\gamma / \gamma_{t}}
\end{aligned}
$$

Equation 4.13 has been plotted as a dashed curve in figure 4.8 for a representative value $\gamma_{t}=1.5 \times 10^{-2}$ percent. The experimental range for sands presented by Seed and Idriss (1970 [77]) is superimposed in the figure for comparison. The theoretical line generally colncides with the upper bound of the experimental range.

A similar calculation was performed for the hysteretic damping ratio, $\lambda$. The usual definition of $\lambda$ is:

$$
\lambda=\frac{1}{2 \pi} \frac{\Delta W}{\tau \gamma}
$$


where $\Delta W=$ area enclosed by a $\tau-\gamma$ hysteresis loop. For the simple cubic array $\lambda$ can be calculated using equation 4.14 , or alternatively directly from the theoretical $\mathrm{T}-\delta$ hysteretic loop shown in figure 4.4. If this last procedure is used, the damping ratio is:

$$
\lambda=\frac{1}{2 \pi} \frac{(\Delta W) \text { contact }}{T^{*} \delta^{*}}
$$

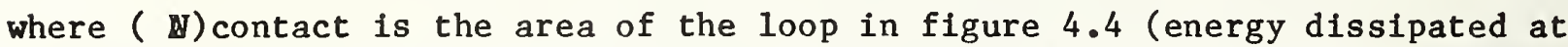
one contact during one loading cycle), and $T^{*}$ and $\delta^{*}$ are the maximum values of the tangential load and displacement, respectively, during the cycle. Equations 4.14 or 4.15 give identical results and equation 4.15 is used here for convenience.

Goodman and Brown (1962 [27]) calculated the value of ( $\Delta W$ ) contact:

$$
\begin{aligned}
(\Delta \mathrm{W}) \text { contact }= & \frac{18}{5} \frac{(2-\nu)(1+\nu)(\mathrm{fN})^{2}}{\mathrm{Ea}}\left\{1-\left(1-\frac{\mathrm{T}^{*}}{\mathrm{fN}}\right)^{5 / 3}\right. \\
& \left.-\frac{5 \mathrm{~T}^{*}}{6 \mathrm{fN}}\left[1+\left(1-\frac{\mathrm{T}^{*}}{\mathrm{fN}}\right)^{2 / 3}\right]\right\}
\end{aligned}
$$

By combining equations $4.5,4.3$ and 4.7 , equation 4.17 is obtained:

$$
\frac{T^{*}}{f N}=1-\left(1-\frac{\delta^{*}}{\delta_{1}}\right)^{3 / 2}=1-\left(1-\frac{\gamma}{\gamma_{t}}\right)^{3 / 2}
$$

where $\gamma=$ maximum shear strain during the loading cycle.

By substituting equation 4.17 into equation 4.16 , the following expression is obtained for $(\Delta W)$ contact:

$$
\begin{aligned}
(\Delta W) \text { contact }=\frac{18}{5} & \frac{(2-\nu)(1+\nu)(f N)^{2}}{E a}\left\{1-\left(1-\gamma / \gamma_{t}\right)^{5 / 2}\right. \\
& \left.-\frac{5}{6}\left(2-\frac{\gamma}{\gamma_{t}}\right)\left[1-\left(1-\gamma / \gamma_{t}\right)^{3 / 2}\right]\right\}
\end{aligned}
$$

Equation 4.18 provides the value of $(\Delta W)$ contact needed to calculate $\lambda$ in equation 4.15. The product $T^{*} \delta^{*}$ for equation 4.15 is obtained as follows:

From equation 4.17 :

$$
\mathrm{T} *=\mathrm{fN}\left[1-\left(1-\frac{\gamma}{\gamma_{t}}\right)^{3 / 2}\right]
$$

From equations 4.6 and 4.17 :

$$
\delta *=\delta_{1} \frac{\gamma}{\gamma_{t}}=\frac{3(2-v)(1+v) f N}{4 E a} \frac{\gamma}{\gamma_{t}}
$$


Finally, if equations $4.18,4.19$ and 4.20 are combined with equation 4.15 , the following expression is obtained for $\lambda$ :

$$
\lambda=\frac{12}{5 \pi}\left\{1-\frac{\left(1-\gamma / \gamma_{t}\right)^{5 / 2}}{\left(\gamma / \gamma_{t}\right)\left[1-\left(1-\gamma / \gamma_{t}\right)^{3 / 2}\right]}-\frac{5\left(2-\gamma / \gamma_{t}\right)}{6}\right\}
$$

Equation 4.21 has been plotted as a dashed curve in figure 4.9 for a value $\gamma_{t}=$ $1.5 \times 10^{-2}$ percent. The experimental range for sands given by Seed and Idriss (1970 [77]) is again included for comparison. The theoretical equation for the simple cubic array coincides approximately with the lower bound of the experimental results for most of the range of strains, $\gamma<\gamma_{t}=1.5 \times 10^{-2}$ percent. The comparisons presented in figures 4.8 and 4.9 further verify the crude simple cubic model used to compute $\gamma_{t}$. These figures show that the model predicts in a general manner the main features of the cyclic stress-strain behavior of sands at very small strains, $\gamma<\gamma_{t}$.

Another interesting feature of equations 4.13 and 4.21 is that both $G / G_{\max }$ and $\gamma$ are unique functions of the normalized strain parameter, $\gamma / \gamma_{t}$. This is similar to the hyperbolic stress-strain model for cyclic loading of solls proposed by Hardin and Drnevich (1972) [29], where $G / G_{\max }$ is a function of $\gamma / \gamma_{r}$, and $\gamma_{r}=$ reference strain. In the simple cubic array, the threshold, $\gamma_{t}$, plays the role of a reference strain, and in actual sands, perhaps $\gamma_{t}$ and $\gamma_{r}$ are also related. In that respect, it is interesting to note that measurements in sands and other soils show that, if the confining pressure, $\sigma$, is increased, both $\gamma_{r}$ and $\left(G / G_{\max }\right)_{\gamma}$ at a given $\gamma$ also increase (see also Richart, 1980 [66]). This is similar to the prediction of the cubic array model: equations 4.8 and 4.9 and figure 4.7 illustrate the increase in $\gamma_{t}$ with $\sigma$, while equation 4.13 predicts an increase in $G / G_{\max }$ as $\gamma_{t}$ (and therefore as $\sigma$ ) increases. For example, for $\gamma=10^{-2}$ percent and $\sigma=500$ psf, equations 4.9 and 4.13 predict $\left(G / G_{\max }\right)=$ $10^{-2}$ percent $=0.71$ for a cubic array of quartz spheres. If $\sigma=4,000 \mathrm{psf}$, the same trend and very similar values of $\left(G / G_{\max }\right)_{Y}=10^{-2}$ percent have been measured in several sands by Iwasak1 et al., (1978 [33]). 


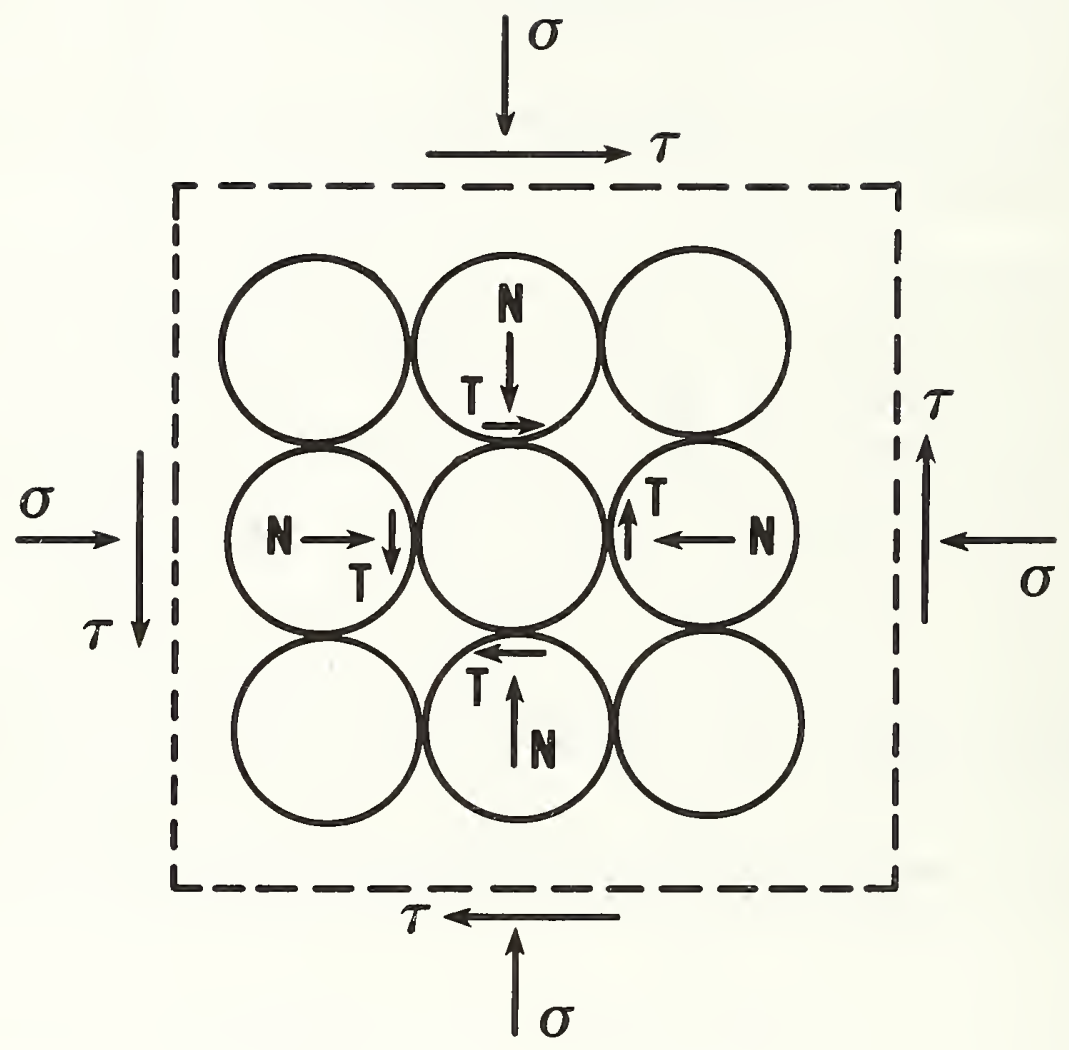

Figure 4.1 Simple cubic array of equal spheres 


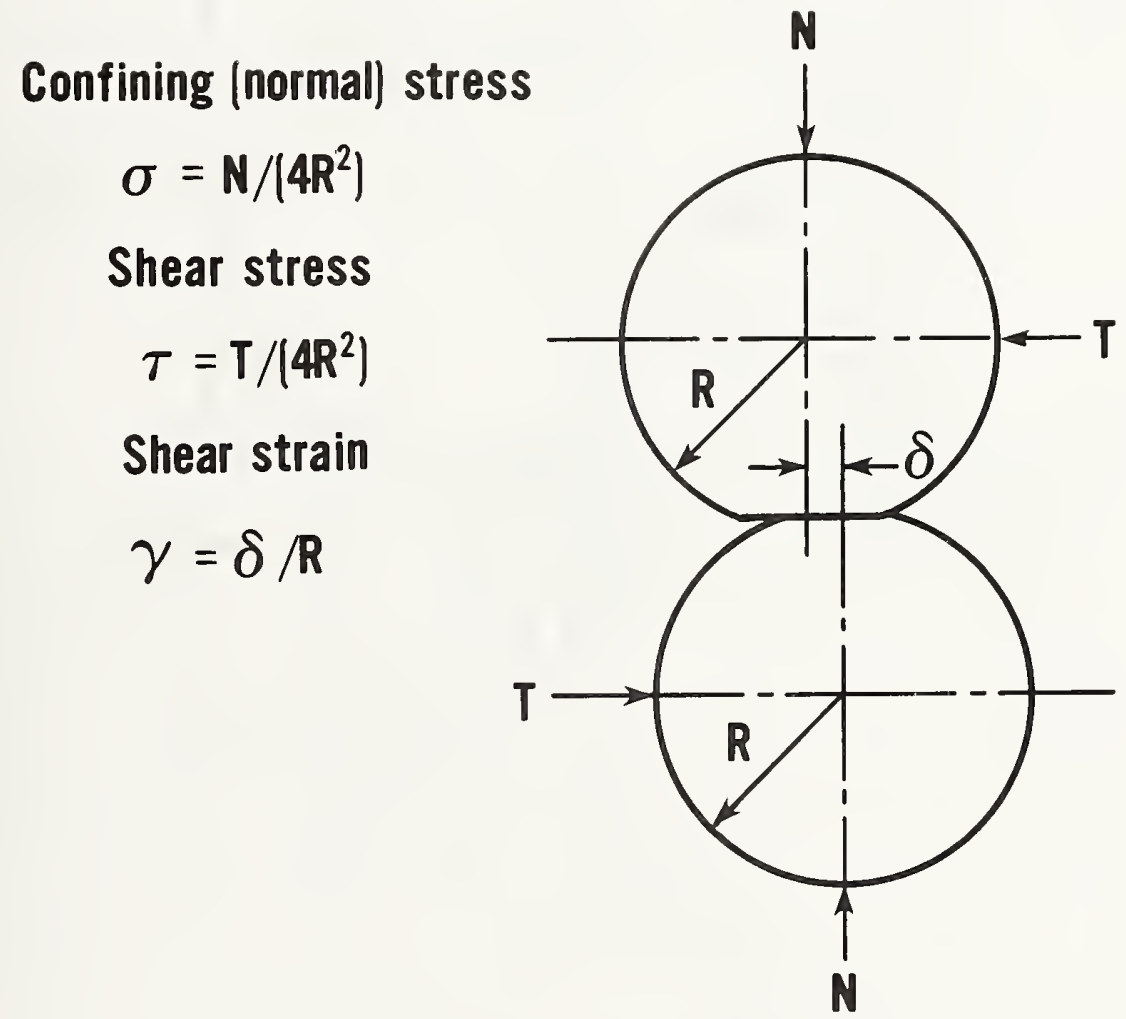

Figure 4.2 Elastic spheres under normal and tangential loads 


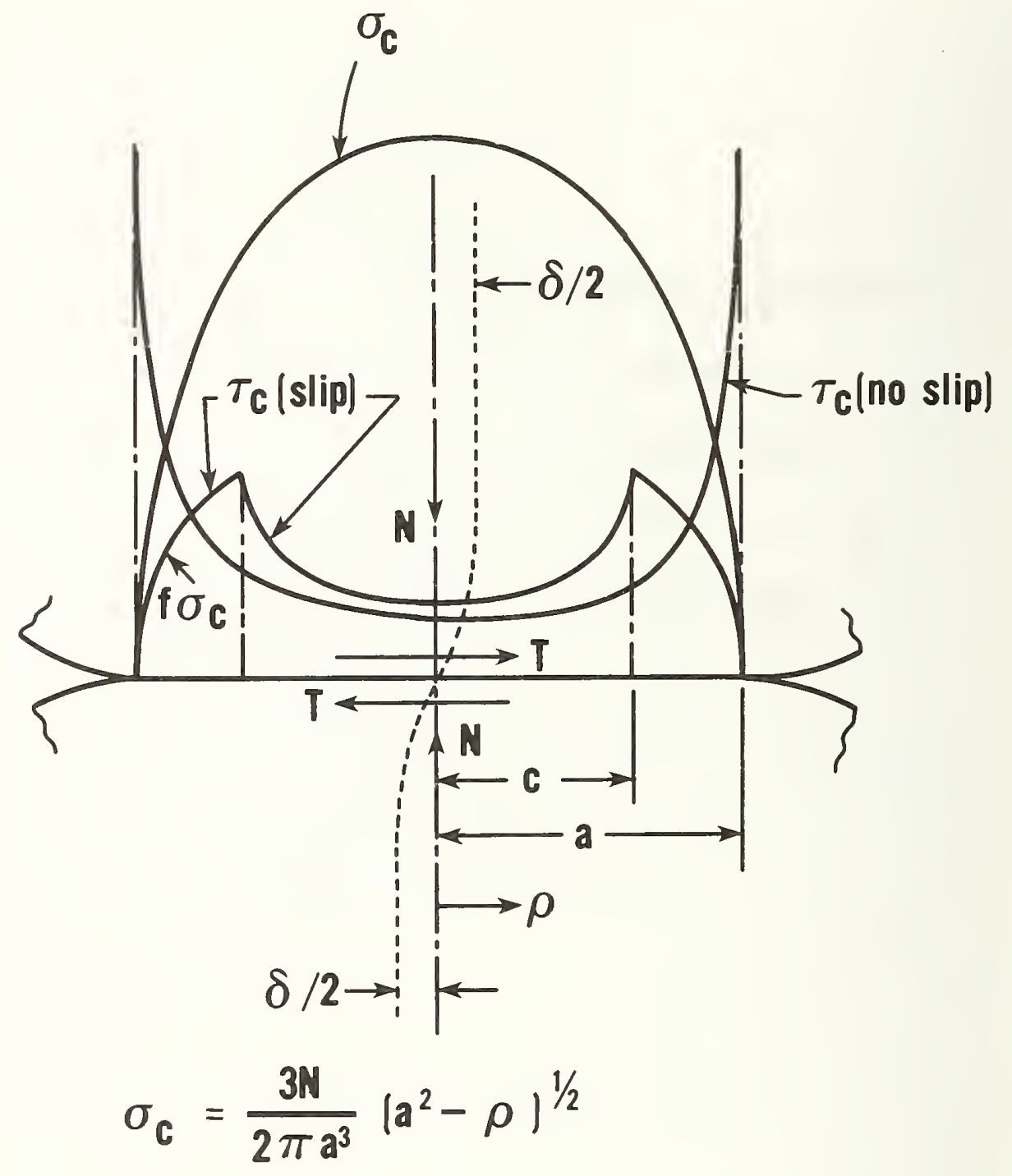

Figure 4.3 Normal $\left(\sigma_{c}\right)$ and tangential $\left(\tau_{c}\right)$ components of traction on contact region between two spheres subjected to a normal force followed by a monotonic tangential force (Deresiewicz, 1973) 


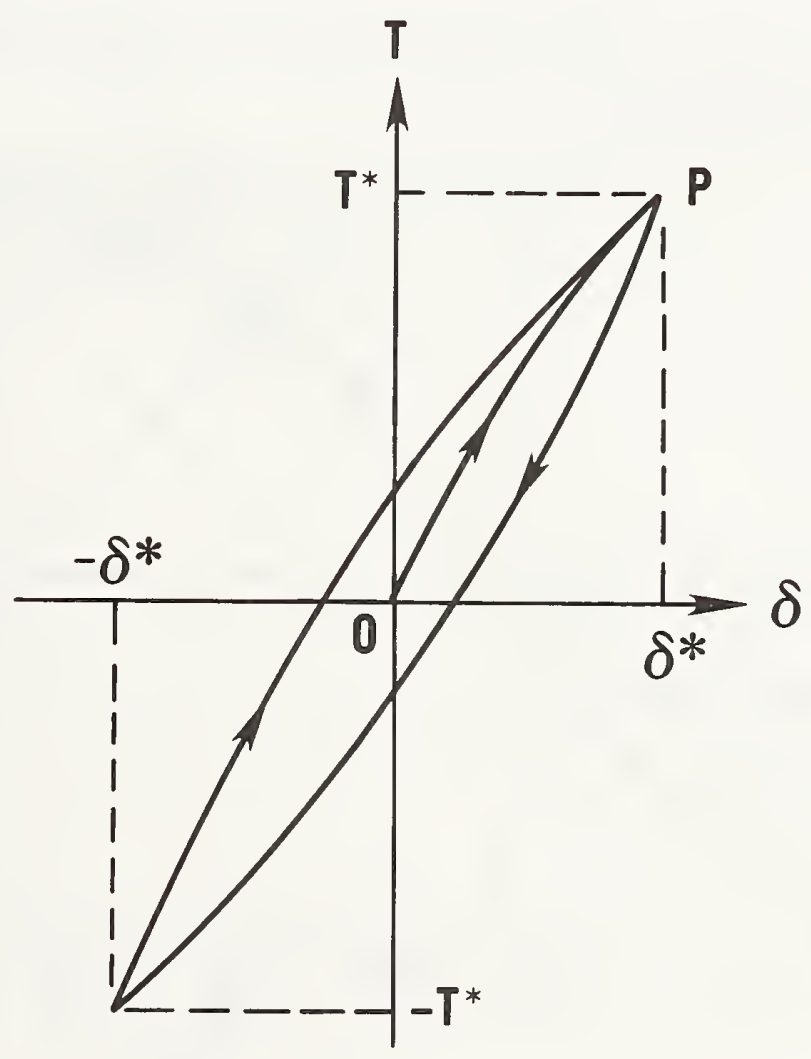

Figure 4.4 Theoretical hysteresis loop due to oscillating tangential force at constant normal force for two spheres in contact (Deresiewicz, 1973) 


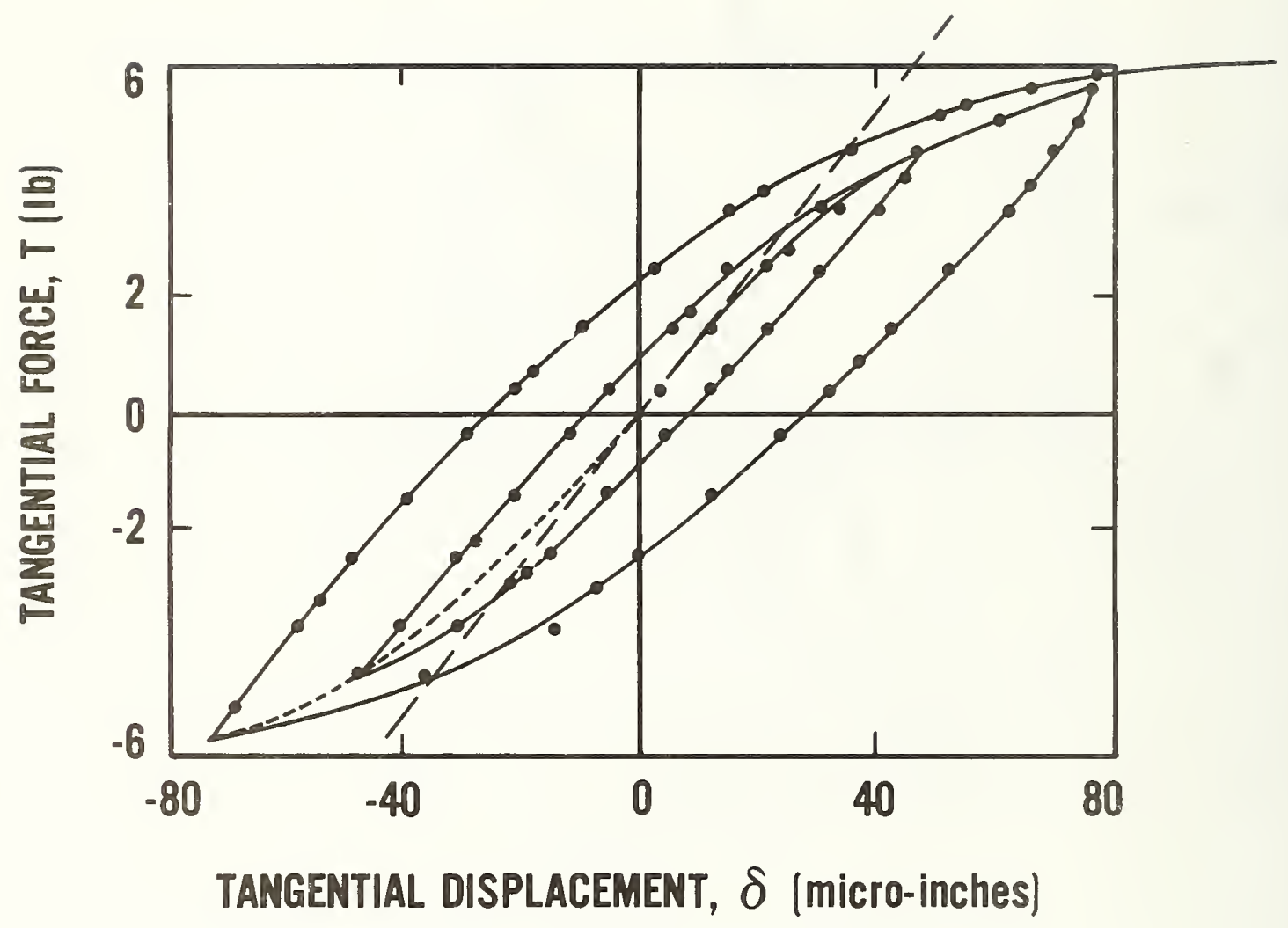

Figure 4.5 Experimental hysteresis loops obtained from cyclic tests of bodies in contact (Johnson, 1955) 


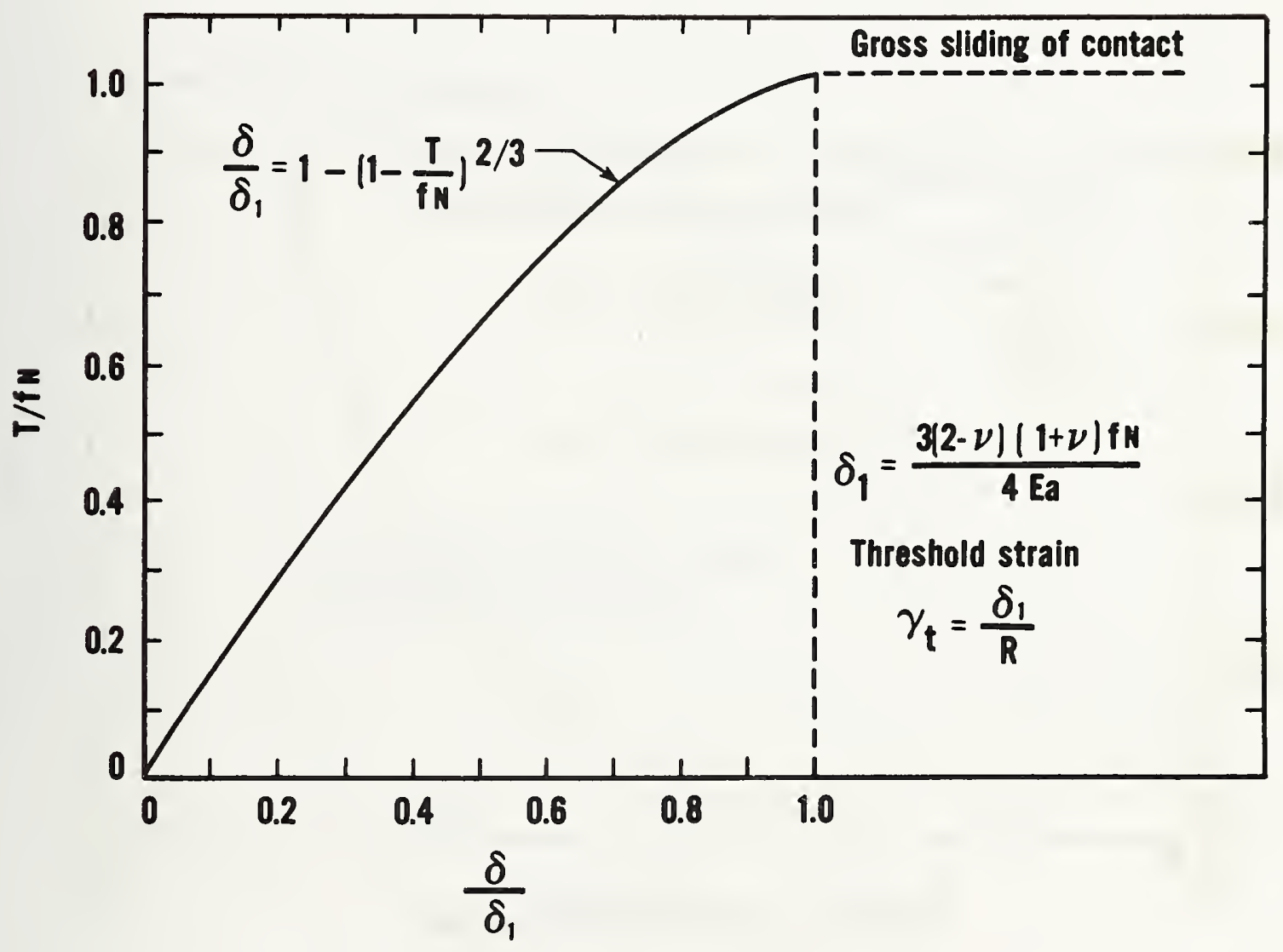

Figure 4.6 Tangential force-displacement relation for two elastic spheres under constant normal force, N (Dobry and Grivas, 1978) 


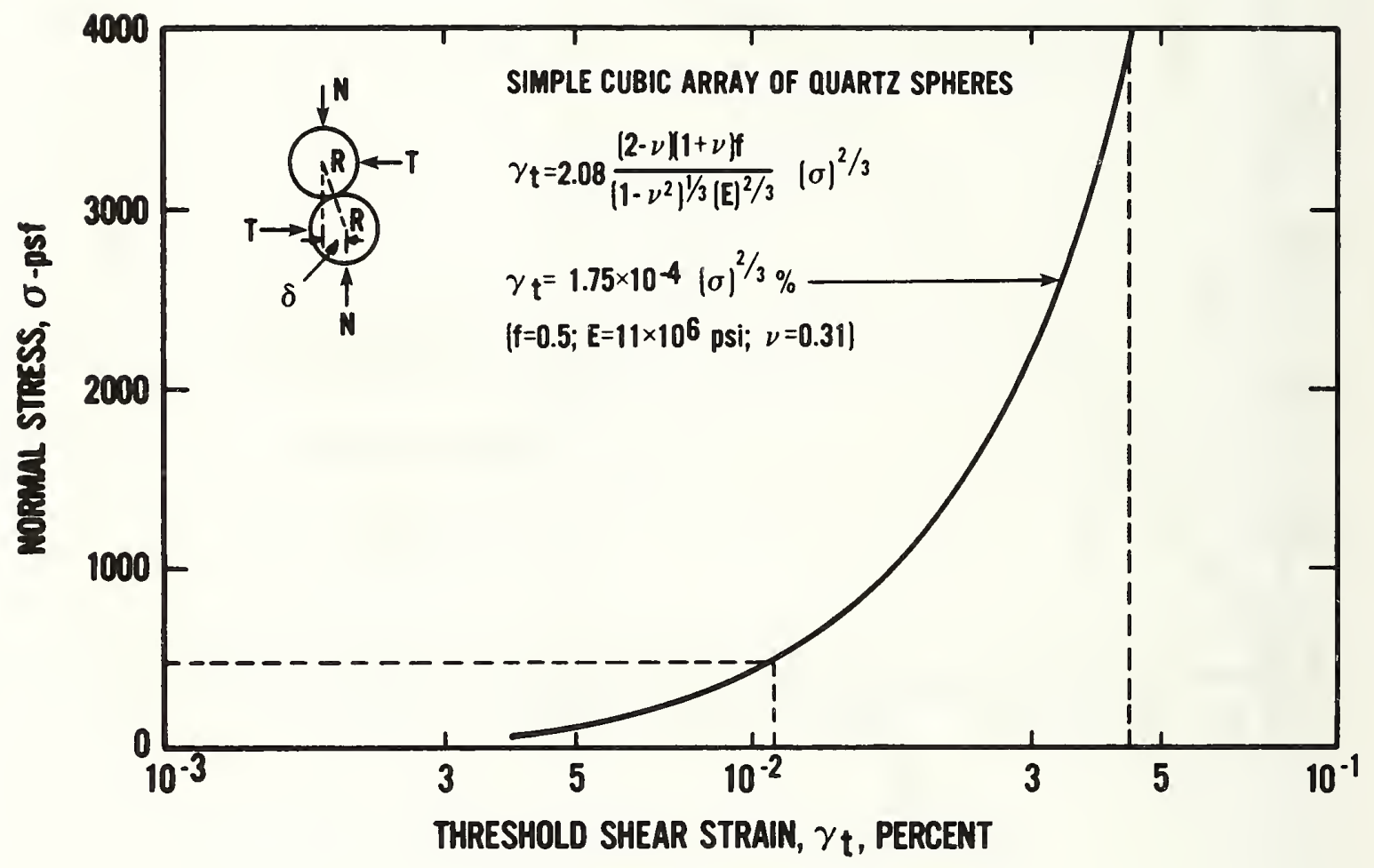

Figure 4.7 Calculated threshold shear strain as a function of isotropic confining stress for a simple cubic array of quartz spheres (Dobry and Swiger, 1979) 


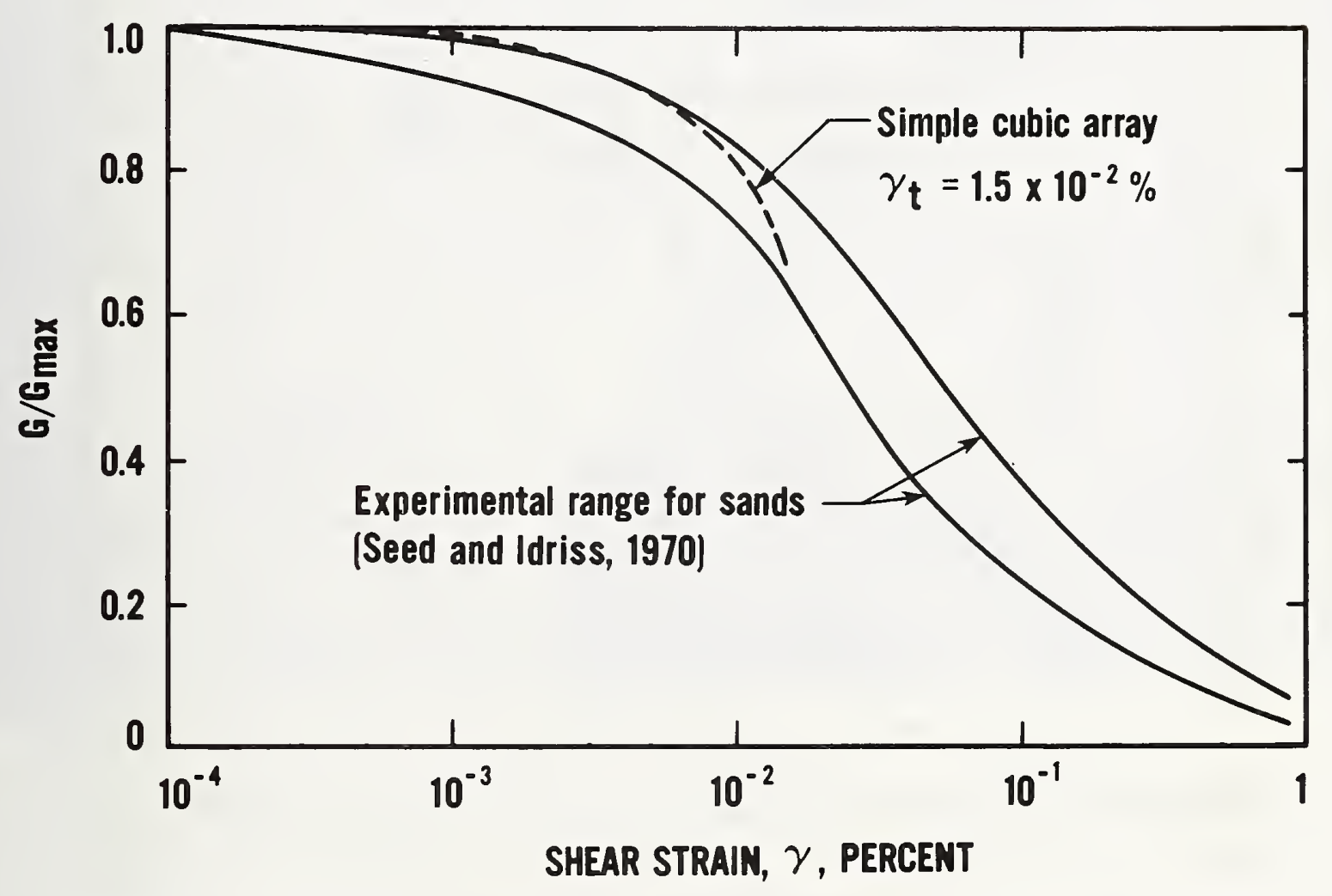

Figure 4.8 Reduction of shear modulus as a function of shear strain comparison between calculated $G / G_{\max }$ for a simple cublc array and experimental range for sand 
FACING PAGE: Ground cracks which developed during the San Fernando February 9,1971 , earthquake in compacted fill above loose saturated sand at the partially completed Jensen Filtration Plant.

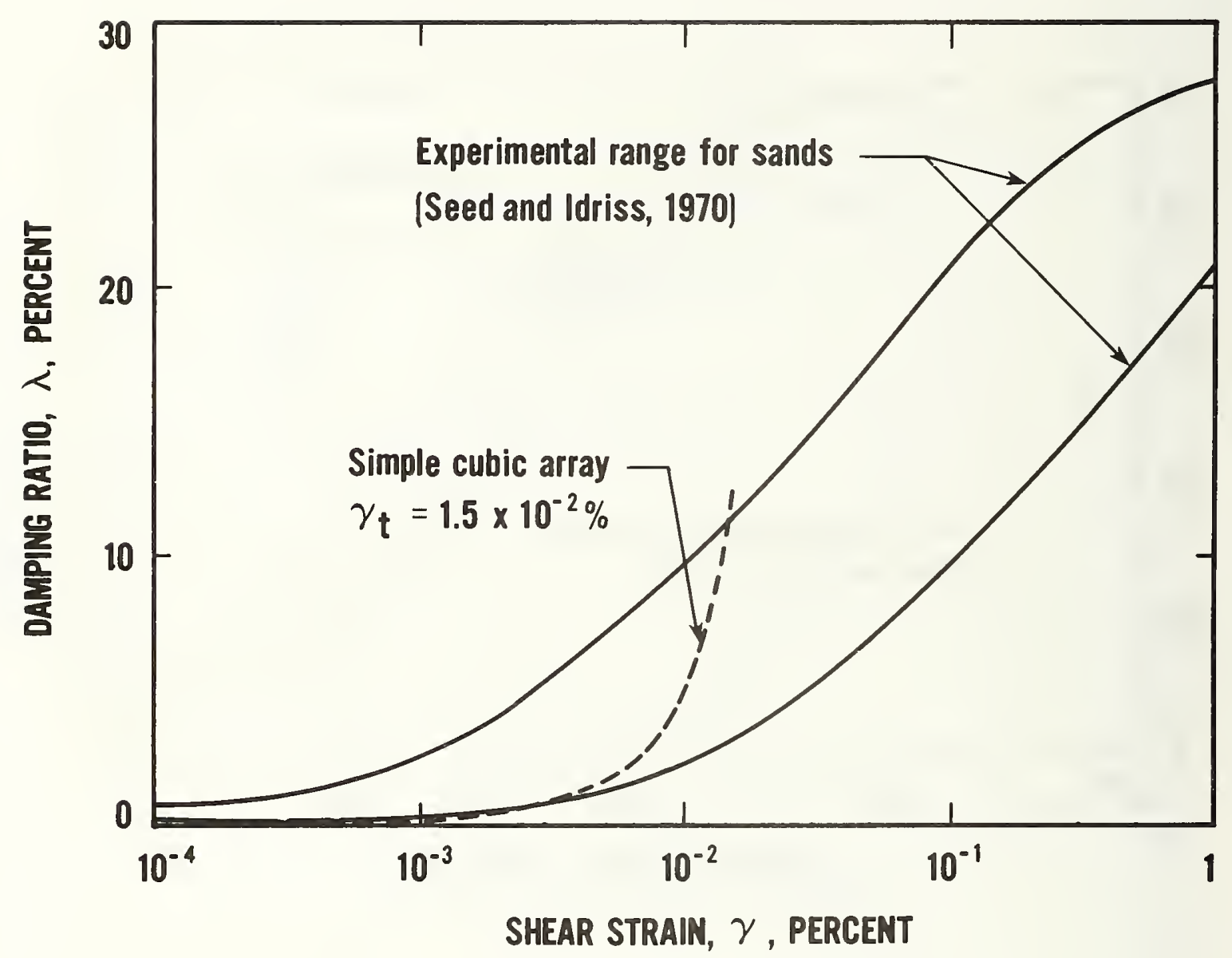

Figure 4.9 Damping ratio as a function of shear strain - comparison between calculated $\lambda$ for a simple cubic array and experimental range for sand 


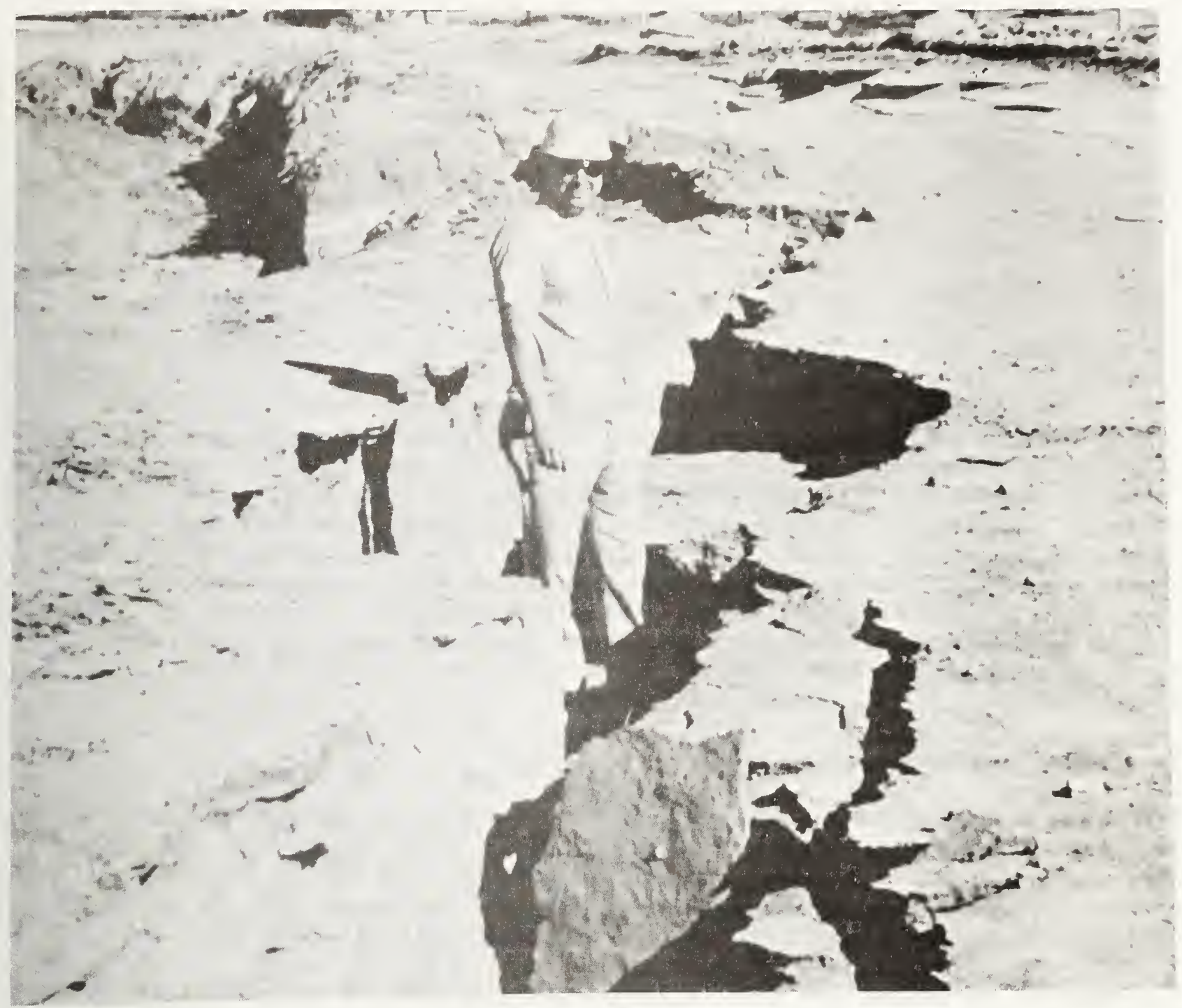

\section{CYCLIC LABORATORY MEASUREMENTS}

\subsection{GENERAL}

This chapter presents the results of a program of undrained cyclic triaxial tests performed on specimens of saturated Monterey No. 0 sand. The tests were performed during the summer of 1979, as part of the development of the cyclic strain approach to evaluate liquefaction potential, described in this report.

For the reasons discussed in chapter 3, all cyclic tests were of the straincontrolled type. A key parameter needed for the cyclic strain approach is the shear modulus of the soil, G. Therefore, a major objective of the tests was to obtain both $G$ at small strains $\left(G_{\max }\right)$, and the variation of $G$ and $G / G_{\max }$ with cyclic shear strain amplitude, $\pm \gamma$, and with number of loading cycles, $\mathrm{n}$. Another key parameter needed in the approach is the threshold strain, $\gamma_{t}$, which was also measured during the tests. The measurements of $G$ at small 
strains and of $\gamma_{t}$ involved the use of an improved experimental technique recently developed by one of the authors (Ladd). Finally, the development of excess pore water pressure, $\Delta u$, with number of cycles, $n$, of strain-controlled loading, was also measured during the tests and is reported in this chapter. In addition, the influence of relative density $\left(D_{r}\right)$ and of initial confining pressure $(\sigma \xi)$ on $G, G / G_{\max }, \gamma_{t}$ and $\Delta u$ was studied and is discussed in this chapter.

\subsubsection{Sand Tested}

The particle size distribution curve and the selected index properties of the Monterey No. 0 sand, obtained by Mulilis et al., (1975 [54]) are shown in figure 5.1 and table 5.1, respectively. The sand is a commercially available washed uniform medium-to-fine beach sand (SP), composed of quartz and feldspar particles. The maximum and minimum dry unit weight determinations were performed in accordance with the ASTM Test for Relative Density of Cohesionless Soils (D 2049-69) and Kolbuszewski's (1948 [39]) method, respectively. The specimens tested had initial relative densities, $D_{r}$, of approximately 45,60 , and 80 percent, and were prepared using the moist tamping compaction method (Ladd 1978 [44]). It should be noted that the same type of sand was used at the University of California at Berkeley to perform a number of studies on sand liquefaction and densification during earthquakes (e.g., see DeAlba, et al., 1975 [14] and Pyke et a1., 1974 [65]).

\subsubsection{Testing Technique}

The techniques used for specimen preparation and testing include unique features such as the undercompaction of the lower layers of the specimen to achieve a more uniform density, and the capability to measure modulus and pore water pressure response at very small strains $\left(\gamma \simeq 10^{-3}\right.$ percent $)$. Details of the undercompaction moist tamping technique are given by Ladd (1978 [44]).

The improved technique. which has allowed extending the testing capability of cyclic triaxial equipment from $\gamma \simeq 10^{-2}$ percent to $\gamma \simeq 10^{-3}$ percent includes:

(a) a frictionless loading system with precise axial alignment (air bushing and specially machined and ground components),

(b) precise coupling between porous stones and top and bottom plattens (Individually lapped and indexed) and test specimen and porous stones (refined compaction techniques),

(c) a correction for equipment compliance (see figure 5.2), and

(d) very sensitive recording systems (1oad to 0.01 pound and deformation to $1 \times 10^{-6}$ inch).

Additional details on the specimen preparation and testing techniques are given in the following paragraphs, while the method of performing the calculations is included in the appendix. An electrohydraulic closed-loop loading 
Table 5.1 Index Properties for Monterey No. 0 Sand Mulilis et al. (1975)

Unified Soil Classification System Group symbol

Mean Specific Gravity

Particle Size Distribution Data
$\mathrm{D}_{50}, \mathrm{~mm}$
0.36
$\mathrm{C}_{\mathrm{c}}(1)$
0.9
$\mathrm{C}_{\mathrm{u}}$ (2)
1.5

Dry Unit Weight Data
Maximum, pcf
105.7
Minimum, pcf
89.3

(1) $\mathrm{C}_{\mathrm{c}}=\left(\mathrm{D}_{30}\right)^{2} /\left(\mathrm{D}_{60} \times \mathrm{D}_{10}\right)$

(2) $\mathrm{C}_{\mathrm{u}}=\mathrm{D}_{60} / \mathrm{D}_{10}$ 
system and specially designed and manufactured triaxial cells, were used in all tests.

The strain-controlled cyclic triaxial tests were performed in general accordance with the procedures outlined by Silver (1975 [82]) and Park and Silver (1975 [59]).

The key points followed in performing the tests are:

1) Each specimen was reconstituted using the moist tamping method as outlined by Ladd (1978 [44]), using a compaction mold attached to the base of the triaxial cell. This method ensures a "perfect" contact between the specimen and the loading platens. In addition, in these tests, some of which involved low relative densities, it was found that, to obtain a "perfect" contact: a) the bottom layer had to be placed and compacted in two parts, and $b)$ the top layer had to be partially compacted, then scarified, the top stone inserted and twisted to get it seated properly and then compacted to the prescribed density, with all equipment in place, by striking the top of the loading piston.

2) Each specimen was saturated by backpressuring (backpressuring is done by gradually increasing the backpressure and cell pressure simultaneously) at an effective stress of $5 \mathrm{psi}(34.5 \mathrm{kPa})$. The test specimen was considered to be saturated if the pore pressure response ( $B$-parameter) was equal to or greater than 95 percent.

To assist in the saturation of the specimen, carbon dioxide $\left(\mathrm{CO}_{2}\right)$ and deaired water were percolated through the specimen prior to backpressuring. A backpressure of 70 psi ( $483 \mathrm{kPa}$ ) was applied in all tests.

3) Each specimen was isotropically consolidated in increments to the final effective confining pressure of the test, $\sigma\}$, on the day prior to performing the cyclic test.

4) During backpressuring and consolidation, the triaxial cell was completely filled with water (which had been deaired at the start of the test) and axial deformations and volume changes of the specimens were recorded. In addition, a small axial load was applied to the piston screwed into the top cap, sufficient to maintain the specimen in an isotropic state of stress.

5) Prior to cyclic loading, the triaxial cell was transferred from the consolidation area to the cyclic loading apparatus. During this stage, the applied values of cell pressure, axial load, and backpressure were maintained constant.

6) The specimen was cyclically loaded without drainage using the electrohydraulic closed-loop loading system. The system applied a sinusoidally-varying cyclic load or deformation at a frequency of $1 \mathrm{~Hz}$. Just prior to cyclic loading, an air pocket was formed at the top of the cell and the o-ring seal (which was attached to the bushing assembly) was 
removed, thereby switching over to an air bushing housed in the bushing assembly. During cyclic testing, changes in axial load, axial deformation, and pore water pressure were recorded on a 7-in. oscillograph recorder. These values were typically recorded within a resolution of two percent of the recorded maximum value. In addition, an $x-y$ recorder was used to obtain hysteresis loops of selected loading cycles.

\subsubsection{Test Program}

A total of 12 undrained strain-controlled cyclic triaxial tests were performed on saturated specimens of Monterey No. 0 sand. The list of tests is presented in table 5.2 .

With the exception of test 12, which was a staged test, all other tests used fresh specimens. These 11 tests were all very similar, with the confining pressure, $\sigma \xi$, relative density, $D_{r}$, and cyclic shear strain, $\gamma$, of the test being varied between tests. Most of the tests were conducted with $\sigma\}=2,000$ psf, except for tests 10 and 11 , where 0$\}=533$ psf and 4,000 psf, respectively. Three relative densities, 45, 60, and 80 percent and three values of $\gamma, 3 \times 10^{-2}, 1 \times 10^{-1}$ and $3 \times 10^{-1}$ percent, were used. Table 5.3 shows in a matrix form the values of $D_{r}$ and $\gamma$ corresponding to each test for of $=2,000$ psf.

The typical undrained cyclic testing sequence for each test was as follows:

a) Measurements at very small strains. Measurements of $G$ and pore water pressure response $(\Delta \mathrm{u})$ were made at very small cyclic strains, $10^{-3}$ percent $\left\langle\gamma<10^{-2}\right.$ percent. These measurements were done by applying cyclic loads. Several levels (stages) of cyclic loads were typically applied with five loading cycles being applied in each stage. In addition to measuring the pore water pressure during cyclic loading, $\Delta \mathrm{u}$, the residual pore water pressure, $\Delta u_{r}$, was also measured after cyclic loading was stopped. All these measurements were nondestructive, as verified by the fact that $\Delta u_{r}=0$, and also by the repeatability of the values of $G$ at the given $\gamma$, irrespective of the previous history of small strain cyclic loading.

b) Measurement of $\gamma_{t}$. This was done by applying 10 cycles of a value of cyclic strain, $\gamma$, slightly larger than $\gamma_{t}$, usually in the range $1 \times 10^{-2}$ percent $\left\langle\gamma<2 \times 10^{-2}\right.$ percent. Both $\Delta u$ during cyclic testing and $\Delta u_{r}$ after the 10 cycles were recorded. Invariably the measured values of $\Delta \mathrm{u}$ and $\Delta \mathrm{u}_{\mathrm{r}}$ were very small. The shear modulus, G, was also measured during these 10 cycles; it usually varied 11ttle between the first and last cycle. After measuring $\Delta u_{r}$, the drainage valves were opened and reconsolidation of the system was allowed for.

c) Measurements at very small strains. Same as in step (a) above. This was done to verify that the $G$ values at very small strains had not been significantly affected by step (b), thus, confirming the assumption that step (b) could be considered nondestructive for practical purposes. 
Table 5.2 List of Cyclic Triaxial Tests

\begin{tabular}{|c|c|c|c|}
\hline Test No. & $\begin{array}{c}\text { Confining Pressure, } \sigma\} \\
\text { psf }\end{array}$ & $\begin{array}{c}\text { Relative Density, } \\
\text { percent }\end{array}$ & $\begin{array}{c}\text { Cyclic Shear strain, } \\
\text { percent }\end{array}$ \\
\hline 1 & $2,000(1)$ & 45 & $3 \times 10^{-2}$ \\
\hline 2 & 2,000 & 45 & $1 \times 10^{-1}$ \\
\hline 3 & 2,000 & 45 & $1 \times 10^{-1}$ \\
\hline 4 & 2,000 & 45 & $3 \times 10^{-1}$ \\
\hline 5 & 2,000 & 60 & $3 \times 10^{-2}$ \\
\hline 6 & 2,000 & 60 & $1 \times 10^{-1}$ \\
\hline 7 & 2,000 & 60 & $3 \times 10^{-1}$ \\
\hline 8 & 2,000 & 80 & $1 \times 10^{-1}$ \\
\hline 9 & 2,000 & 80 & $3 \times 10^{-1}$ \\
\hline 10 & 533 & 60 & $3 \times 10^{-2}$ \\
\hline 11 & 4,000 & 60 & $3 \times 10^{-2}$ \\
\hline 12 & $\begin{array}{c}533-944- \\
2,000-4,000 \\
\text { (Staged Test) }\end{array}$ & 45 & -- \\
\hline
\end{tabular}

(1) 1 psf $=47.8$ pascal 
Table 5.3

Cyclic Triaxial Tests with $\sigma_{3}^{\prime}=2,000 \mathrm{psf}^{(1)}$

\begin{tabular}{|c|c|c|c|}
\hline \multirow{2}{*}{$\begin{array}{c}\text { Relative } \\
\text { Density } \\
\text { D percent }\end{array}$} & $3 \times 10^{-2}$ & $1 \times 10^{-1}$ & $3 \times 10^{-1}$ \\
\cline { 2 - 4 } & Test 1 & Test 2 & - \\
\hline 45 & - & Test 3 & Test 4 \\
\hline 60 & Test 5 & Test 6 & Test 7 \\
\hline 80 & - & Test 8 & Test 9 \\
\hline
\end{tabular}

(1) 1 psf $=47.8$ pascal. 
d) Testing at $\gamma>\gamma_{t}$, (destructive testing). Strain-controlled cyclic testing was performed at the cyclic strain of the test, $\gamma$. This is the cyclic strain reported in tables 5.2 and 5.3. In most cases the test was carried to 100 cycles or to initial liquefaction $(\Delta u=\sigma \xi)$, whichever occurred first. However, tests 1, 10, and 11 were carried to 1,000 cycles. During each test the shear modulus, $G$, the damping ratio, $\lambda$, and the maximum pore water pressure, $\Delta u$, during the cycle were measured as a function of the number of cycles, $\mathrm{n}$. In addition, the test was stopped at selected numbers of cycles to allow for measurement of the residual pore water pressure, $\Delta u_{r}$, and then restarted without reconsolidation.

Of special concern during the planning of the testing program was the assumed nondestructive character of step (b). To further verify this assumption, tests 2 and 3 were conducted. These two tests are identical in all respects, except that step (b) was skipped in test 2, and step (a) was followed immediately by the destructive testing (step d). The results of the two tests 2 and 3 were essentially identical, thereby verifying the nondestructive character of step (b).

Test 12 was a staged test, with stages at $\sigma \xi=533$ psf, 994 psf, 2,000 psf, and 4,000 psf, respectively. Cyclic loading was performed undrained at each stage, and excess pore water pressures were dissipated by reconsolidation between stages. Except for the first stage at 533 psf, the results of this test were obviously affected by the reconsolidation process and associated curing period and are not included in the detailed presentation of results included in this chapter. Further research is definitely needed on the feasibility of staged cyclic tests for determining $\gamma_{t}$ and $\Delta u_{r}$.

\subsection{SHEAR MODULUS AND DAMPING RATIO}

Figures 5.3 through 5.10 present the experimental results for the shear modulus, $G$, and the damping ratio, $\lambda$. In all cases, $G$ was measured as the secant modulus between the compression and extension peaks within the same cycle.

Figures 5.3, 5.4, and 5.5 summarize the values of $G$ at $\sigma \xi=2,000$ psf, and for $D_{r}=45,60$, and 80 percent, respectively. In these figures, $G$ is plotted versus shear strain, $\gamma$, at $n=1$ cycle and $n=30$ cycles. The data points for strains below or about $10^{-2}$ percent were determined during the nondestructive very small strain measurements (step (a) in section 5.1.3), while the data points at larger strains were obtained during the destructive measurements in step (d).

Estimated values of $\mathrm{G}_{\max }$ were obtained using the Hardin and Drnevich (1972 [29]) equation for sands isotropically consolidated under a presure $\sigma\}$ :

$$
G_{\max }=1230 \frac{(2.973-e)^{2}}{1+e}\left(\sigma_{3}^{\prime}\right), 1 / 2
$$

where $G_{\max }, \sigma_{3}^{\prime}$ in psi

These $\mathrm{G}_{\max }$ estimates are included in table 5.4 and have been superimposed on figures 5.3 to 5.5. The comparisons in these figures indicate excellent agreement between the values of $G$ measured at very small strains $\left(\gamma \simeq 10^{-3}\right.$ percent $)$ 
Table 5.4. $G_{\max }$ at $\sigma_{3}^{\prime}=2,000 \mathrm{psf}^{(1)}$ for Monterey No. O Sand

\begin{tabular}{|c|c|c|}
\hline $\begin{array}{c}\mathrm{D}_{\mathrm{r}} \\
\text { percent }\end{array}$ & $\mathrm{e}$ & Hardin-Drnevich $\mathrm{G}_{\max }$ (2) \\
\hline 45 & 0.72 & $1,940 \mathrm{ksf}(1)$ \\
60 & 0.68 & 2,070 \\
80 & 0.63 & 2,230 \\
\hline
\end{tabular}

(1) 1 psf $=47.8$ pascal

$1 \mathrm{ksf}=47.8 \mathrm{kpa}$

(2) $G_{\max }=1230 \frac{(2.973-\mathrm{e})^{2}}{1+\mathrm{e}}\left(\sigma_{3}^{\prime}\right)^{1 / 2}$, with $G_{\max }$ and $\sigma \xi$ in psi from Hardin and Drnevich (1972) 
during the cyclic triaxial tests on Monterey No. 0 sand, and $G_{\text {max }}$ calculated using equation 5.1 .

The comparison between the curves for $n=1$ cycle and $n=30$ cycles in figures 5.3 through 5.5 confirm that $G$ at $\gamma \leq 10^{-2}$ percent is independent of number of cycles. For larger strains, the discrepancy between the two curves increases, indicating that modulus degradation occurs during cyclic loading, with the degradation increasing as $\gamma$ increases.

Figure 5.6 compares the three experimental curves of figures 5.3 through 5.5, without the data points and only for $\mathrm{n}=1$.

Figure 5.7 shows the results of measurements of the damping ratio, $\lambda$, during the destructive testing in step (d), for $\sigma 3=2,000$ psf and for all three relative densities tested. Since $\lambda$ could not be measured during the first cycle, the results presented in the figure are for $\mathrm{n}=2$ and $\mathrm{n}=30$ cycles. For $\gamma \simeq 3 \times 10^{-2}$ percent, $\lambda \simeq 7$ percent, with negligible influence of $\mathrm{n}$. For $\gamma \simeq 3 \times 10^{-1}$ percent, $\lambda=20$ to 30 percent, with a tendency to decrease with the number of cycles. The trend of increase of $\lambda$ with $\gamma$ and the numerical values plotted in figure 5.7 are in general agreement with the results reported for sands by other authors (e.g., see Seed and Idriss, 1970 [77]).

Figure 5.8 presents the influence of $\sigma\}$ on the measured values of $G$ versus $\gamma$, for $D_{r}=60$ percent and $n=1$ cycle. The corresponding values of $G_{\max }$ calculated using equation 5.1 have also been included in the figure, and again there is good agreement between $G$ at very small strains measured during the tests and Hardin and Drnevich's expression.

The comparisons in figures 5.3 through 5.8 between measured modulus reduction curves and $G_{\max }$ values estimated with eq. 5.1, are very encouraging. They suggest that cyclic triaxial tests can be used to measure $G_{\text {max }}$, if the improved testing techniques described herein are used. The band of experimental results for $G / G_{\max }$ versus $\gamma$ compiled by Seed and Idriss for sands, and included in figure 4.8 , indicates that, at $\gamma=10^{-3}$ percent, $G / G_{\max }=0.95$ to 0.98 . Therefore, $G_{\max }$ was estimated using equation 5.2:

$$
G_{\max }=\frac{(G)_{\gamma}=10^{-3} \%}{0.95 \text { to } 0.98}
$$

The values of $G_{\max }$ for $D_{r}=60$ percent and $\sigma \xi=533$ psf, 2,000 psf and 4,000 psf, were calculated from the values of $(G) y=10^{-3}$ percent in the experimental curves in figure 5.8 using equation 5.2. These values of $G_{\max }$ were plotted versus $\sigma \xi$ as data points in figure 5.9. Figure 5.9 also includes two other plots of $G_{\max }$ versus $\sigma_{3}$ for comparison. The dashed line was obtained from Hardin and Drenevich, equation 5.1. The solid lines were obtained from the Round Robin resonant column test program on Monterey No. O sand (Drnevich, 1979 [22]). In the Round Robin test program, $G_{\max }$ was measured by nine laboratories on specimens of dry Monterey No. 0 sand all using an identical sand placement procedure and testing technique. The two solid lines in figure 5.9 correspond to the range of values of $G_{\max }$ obtained by the nine laboratories (Drnevich, 1979 [22]). The comparison between $G_{\max }$ obtained herein and the results of of the Round 
Robin test program confirm that, with the improved testing techniques used here, cyclic triaxial test measurements at $\gamma \simeq 10^{-3}$ percent are feasible and can produce reliable values of $\mathrm{G}_{\max }$.

An additional check of the cyclic triaxial measurements of $G$ is presented in figure 5.10. The data points in figure 5.10 are the same as presented in figure 5.8 , for $D_{r}=60$ percent and $n=1$ cycle, except that in figure $5.10, K_{2}$ is plotted versus $\gamma_{\bullet} K_{2}$ is a normalized parameter, obtained from Seed and Idriss' (1970 [77]) equation for G:

$$
G=1,000 \mathrm{~K}_{2}\left(\sigma_{3}^{\prime}\right)^{1 / 2} \text { where } G, \sigma_{3}^{\prime} \text { in psf }
$$

Therefore, $\mathrm{K}_{2}=\mathrm{G} /\left(\sigma_{3}^{\prime}\right)^{1 / 2}$ if $\mathrm{G}$ is expressed in $\mathrm{ksf}$ and $\sigma_{3}^{\prime}$ in psf. In the Round Robin resonant column testing program, tests were performed at of $=1,040$ and 6,250 psf, respectively. The average values of $G_{\max }$ for the nine laboratories at these pressures, in conjunction with equation 5.3, gave values of $\mathrm{K}_{2 \max }$ of 50.4 and 47 , respectively. These values of $\mathrm{K}_{2 \max }$ were plotted in figure 5.10, together with the corresponding curves of $\mathrm{K}_{2}$ versus $\gamma$ predicted using :

$$
\left(\mathrm{K}_{2}\right)_{\gamma}=\mathrm{K}_{2 \max }\left(\frac{\mathrm{K}_{2}}{\mathrm{~K}_{2 \max }}\right)_{\gamma}
$$

where the curve of $\left(\mathrm{K}_{2} / \mathrm{K}_{2 \max }\right)_{\gamma}=\left(\mathrm{G} / \mathrm{G}_{\max }\right)$ versus $\gamma$ selected for the calculations is the average curve for sands suggested by Seed and Idriss (1971 [77]) (average of the experimental band in figure 4.8).

The agreement in figure 5.10 between the data points and the curves obtained combining the Round Robin's results with those of Seed and Idriss curve is excellent at both small and large strains. The only exceptions are the data points for $\sigma_{3}^{\prime}=4,000$ psf and $\gamma>10^{-2}$ percent, which plot somewhat higher than the curves and the rest of the data points, with increasing discrepancy at larger strains. This discrepancy would tend to confirm the tendency of $G / G_{\max }$ to be somewhat higher in solls at larger confining pressures, as discussed by Iwasaki et al., (1978 [33]), and Richart (1980 [66]). A similar effect was already discussed for the simple cubic array model in section 4.4. In any case, the comparison in figure 5.10 further validates the experimental values of $G$ obtained in this research with the cyclic triaxial technique.

\subsection{MODULUS DEGRADATION UNDER CYCLIC LOADING}

In the destructive part of the strain-controlled tests $\left(\gamma>\gamma_{t}\right)$, there was both pore water pressure buildup and degradation of the modulus with number of cycles, $n$. This modulus degradation effect is presented in figures 5.11 through 5.17 , as experimental curves of $G / G_{1}$ versus $n$. In all cases, $G_{1}$ is the secant modulus measured in the first cycle conducted at the cyclic strain of the test, $\gamma$. The influence of $\gamma$ on the curves of $G / G_{1}$ versus $n$ is presented in figures $5.11,5.12$, and 5.13 , for $D_{r}=45,60$ and 80 percent, respectively. These figures show that $G / G_{1}$ is significantly affected by both $n$ and $\gamma$, with $G / G_{1}$ decreasing rapidly as $\gamma$ increases above $10^{-2}$ percent. 
Figures 5.14, 5.15, and 5.16 illustrate the effect of $D_{\mathfrak{r}}$ on the curves of $G / G_{1}$ versus $\mathrm{n}$ for $\gamma=3 \times 10^{-2}, 1 \times 10^{-1}$, and $3 \times 10^{-1}$ percent, respectively. These figures show that $G / G_{1}$ is significantly affected by relative density, with modulus degradation being more pronounced at the lower relative densities. Figure 5.17 shows the influence of confining pressure, for $D_{r}=60$ percent and $\gamma=3 \times 10^{-2}$ percent. Other things being equal, this figure suggests that modulus degradation is more significant at lower values of 0$\}$.

\subsection{THRESHOLD STRAIN}

Figures 5.18 and 5.19 show the results of the threshold strain measurements in steps (a) and (b) of the tests (see section 5.1.3), while figure 5.20 presents relevant results on $\gamma_{t}$ for dry Monterey No. 0 sand obtained by Pyke (1973 [64]).

Figure 5.18 includes the values of the residual pore water pressure, $\Delta u_{r}$ after $\mathrm{n}=10$ cycles, for $\sigma \xi=2,000 \mathrm{psf}$ and for the three relative densities tested. Note that the values of $\Delta \mathrm{u}_{\mathrm{r}} / \sigma \xi$ in the figure are very low and smaller than 0.1 (a value of $\Delta u / \sigma\} \simeq 1.0$ would indicate initial liquefaction). Therefore, figure 5.18 permits determining the value of the threshold strain with a high degree of precision. Figure 5.18 demonstrates that:

a) For the sand tested and for $\sigma\}=2,000$ psf, the threshold strain is $\gamma_{t} \simeq$ $1.1 \times 10^{-2}$ percent. This value of $\gamma_{t}$ is independent of relative density in the range 45 percent $<D_{r}<80$ percent.

b) For values of strain slightly larger than $\gamma_{t}\left(1.1 \times 10^{-2}\right.$ percent $<<3 \times$ $10^{-2}$ percent, the residual pore water pressure, $\Delta u_{r}$, increases rapidly with strain, and the value of $\Delta \mathrm{u}_{\mathrm{r}}$ is again independent of relative density for the range studied.

Figure 5.19 shows the influence of confining pressure, of on $\gamma_{t}$ and $\Delta u_{r}$ at strains up to $\gamma \simeq 3 \times 10^{-2}$ percent. The curve for $\sigma_{3}^{\prime}=2,000$ psf from figure 5.18 has been superimposed for comparison. The data points in figure 5.19 corresponding to $\sigma\}=533$ psf were obtained from test 10 (open triangles, $D_{r}=60$ percent) and from the first step of test 12 (black triangles, $D_{r}=45$ percent). The data points for $\sigma \xi=4,000$ psf were obtained from test 11 . Figure 5.19 suggests that the value of $\gamma_{t} \simeq 1.1 \times 10^{-2}$ percent is valid for the range of pressures, 533 psf $<\sigma\}<4,000 \mathrm{psf}$, and that the same curve of $\left.\Delta u_{r} / \sigma\right\}$ versus $\gamma$ is valid for $\left.\sigma\right\}=533$ psf and $\sigma \xi=2,000$ psf, with this curve being independent of relative density. Although the evidence presented is not conclusive, figure 5.19 seems to suggest that $\left.\Delta \mathrm{u}_{\mathrm{r}} / \sigma\right\}$ at small strains above the threshold is somewhat smaller for of $=4,000$ psf than for 533 psf $\leq \sigma\} 2,000$ psf.

Figure 5.20 presents evidence on $\gamma_{t}$ from cyclic, strain-controlled simple shear tests on dry Monterey No. 0 sand, conducted by Pyke (1973 [64]). The tests were performed on specimens placed at relative densities, $D_{r}$, between 40 percent and 80 percent, and normally consolidated to vertical pressures, $\sigma_{\mathrm{v}}$, between 800 psf and 3600 psf. The plot shows the settlement in the first loading cycle, versus strain, $\gamma$. It can be seen that the settlement depends strongly on $\gamma$ and on $D_{r}$, but it does not depend on $\sigma_{v}$. This is consistent with the 
conclusion from similar tests on other sands discussed in section 3.2.2. In figure 5.20, the settlement in the first cycle becomes zero at $\gamma \simeq 0.01=10^{-2}$ percent, independent of $D_{r}$ and $\sigma_{v}$, thus, again suggesting $\gamma_{t} \simeq 10^{-2}$ percent. Therefore, based on the evidence presented in figures 5.18 through 5.20 , it can be concluded that $\gamma_{t} \simeq 10^{-2}$ percent for normally (isotropically and anisotropically) consolidated Monterey No. 0 sand, with this value being valid over a wide range of relative densities and confining pressures of practical interest, for both dry and saturated sand and for triaxial and simple shear cyclic loading conditions. This independence of $\gamma_{t} \approx 10^{-2}$ percent from variations in the confining pressure is unexpected, as the simple cubic array model predicts an increase in $\gamma_{t}$ as $\sigma \xi$ increases (see section 4.3 and figure 4.7).

\subsection{EXCESS PORE WATER PRESSURE}

Figures 5.21 through 5.33 present the experimental results for the excess pore water pressure, $\Delta u$, measured during the strain-controlled cyclic triaxial tests. Note that all these plots depict $\Delta u$, the maximum value measured for the corresponding cycle during cyclic loading, rather than $\Delta u_{r}$, the residual value measured after stopping the cyclic loading. Figure 5.34 attempts to relate $\Delta u$ and $\Delta \mathrm{u}_{\mathbf{r}}$.

Figures $5.21,5.22$ and 5.23 summarize the experimental results for $\sigma\}=2,000$ psf, as plots of $\Delta u / \sigma\}$ versus $n$ for $D_{r}=45,60$, and 80 percent, respectively. These figures show that $\Delta u$ increases significantly as both $\gamma$ and $n$ increase.

Figure 5.24, 5.25 and 5.26 illustrate the effect of $D_{\mathrm{r}}$ on the curves of $\left.\Delta \mathrm{u} / \sigma\right\}$ versus $n$, for $\gamma=3 \times 10^{-2}, 1 \times 10^{-1}$ and $3 \times 10^{-1}$ percent, respectively. As it could be expected, the pore water pressure increases as $\mathrm{D}_{\mathrm{r}}$ decreases. However, the effect is less marked than it could be expected from plots of densification of Monterey dry sand under cyclic loading, such as shown in figures 1.2 and 5.20. At a small number of cycles, $\mathrm{n} \leq 10, \Delta \mathrm{u}$ is not generally affected or is only moderately affected by $D_{r}$.

The reason why pore water pressure buildup in saturated sand is less affected by relative density than by densification of the same dry sand is not difficult to understand. If $(\Delta \mathrm{u})_{1}$ is the pore pressure increment for saturated sand corresponding to one cycle of cyclic strain, and $\left(\Delta \varepsilon_{\mathrm{vol}}\right)_{1}$, is the volumetric strain decrement corresponding to the same dry sand having the same relative density and subjected to the same cyclic strain, then $(\Delta u)$ and $\left(\Delta \varepsilon_{\mathrm{vol}}\right)$ are related approximately as follows:

$$
(\Delta \mathrm{u})_{1} \simeq \mathrm{E}_{\mathrm{r}}\left(\Delta \varepsilon_{\mathrm{vol}}\right)_{1}
$$

where $\overline{\mathrm{E}}_{\mathbf{r}}=$ drained tangent modulus of one-dimensional unloading curve of the sand (Martin et al., 1975 [49]). Although equation 5.5 was originally deve1oped for simple shear tests, it will be assumed here for the sake of this discussion, that the same expression, or a simflar one, also applies to triaxial tests. For the case of cyclic triaxial tests, $(\Delta u)_{1}$ should strictly be interpreted as the residual value, $\Delta u_{r}$, rather than the $\Delta u$ values included in the plots. However, the difference between $\Delta u$ and $\Delta u_{r}$ does not seem to be affected by $D_{r}$, and therefore, this should not affect the present discussion. The 
Important point about the theoretical equation 5.5 is that if $D_{r}$ increases, $\left(\Delta \varepsilon_{\mathrm{vol}}\right)_{1}$ decreases but $\overline{\mathrm{E}}_{\mathrm{r}}$ increases (a dense sand is stiffer than the same sand in a looser state). Therefore, $(\Delta u)_{1}$ is bound to be less affected by $D_{r}$ than $\left(\Delta \varepsilon_{\mathrm{vol}}\right)_{1}$, which is exactly what the experimental results show.

Figure 5.27 shows the influence of confining pressure, for $D_{r}=60$ percent and $\gamma=3 \times 10^{-2}$ percent. Other things being equal, normalized pore water pressure bulldup at this low $\gamma$ is faster at lower values of $\sigma\}$. The effect is not very significant at low numbers of cycles, but it becomes quite dramatic at $n=1,000$ cycles. An interesting corollary is that if figure 5.27 were denormalized (1.e., $\Delta \mathrm{u}$ were plotted versus $\mathrm{n}$ ), the difference would almost disappear, with the curves plotting very close to each other.

Figure 5.28, 5.29, and 5.30 summarize the results for $\sigma\}=2,000$, as plots of $\Delta u / \sigma\}$ versus $\gamma$ for different numbers of cycles, and for $D_{r}=45,60$, and 80 percent, respectively. The format of these figures is very useful for the purposes of the cyclic strain approach to liquefaction, and is the same used for other sands in figures 3.23 and 3.24 .

Figures 5.28 through 5.30 show again that the pore water pressure buildup for $\gamma<\gamma_{t} \simeq 10^{-2}$ percent is insignificant, and that this conclusion is independent of number of cycles and is valid for the three relative densities shown. $\Delta u$ is not exactly equal to zero for $\gamma<10^{-2}$ percent in the plots, due to the difference between $\Delta \mathrm{u}$ and $\Delta \mathrm{u}_{\mathrm{r}}$ (compare fig. 5.28 with fig. 5.18). Figures 5.28 through 5.30 show that $\Delta u$ increases significantly as both $\gamma$ and $n$ increase.

Figures 5.31 and 5.32 show the effect of $D_{r}$ on $\left.\Delta u / \sigma\right\}$ for of $=2,000$ psf and for $n=10$ and 30 cycles, respectively. As discussed before, there is a slight but not dramatic influence of $D_{r}$ on $\Delta u$. For some practical purposes, a representative band of results could well be taken from either figure and used irrespective of $D_{r}$. This is a very important practical conclusion. It is usually very difficult to estimate relative densities in the field and, therefore, the ability to predict pore pressure development without knowing the relative density can be very valuable.

It is of interest to compare the data on excess pore water pressures in Monterey No. 0 sand, presented here, with experimental data for other sands. Figure 3.24 complled results for various sands and placement techniques, obtained for $D_{r}=$ 60 percent and $n=10$ cycles during strain-controlled cyclic triaxial tests. All the data in figure 3.24 were for a range of $\sigma \xi=1,400$ to 2,800 psf. Figure 3.24 is reproduced in figure 5.33, where the data points for Monterey No. 0 sand have also been added. The data for Monterey No. 0 sand, obtained In this study and included in figure 5.33, are for $D_{r}=60$ percent and of = 2,000 psf. The agreement in figure 5.33 between the old curve and the new data points for Monterey No. 0 sand is outstanding. This reinforces the conclusion that the curve in figure 5.33 is valid for most clean, normally consolidated, saturated sands subjected to strain-controlled cyclic triaxial testing for of $=1,400$ to $2,800 \mathrm{psf}, \mathrm{D}_{\mathrm{r}} \simeq 60$ percent, and $\mathrm{n}=10$ cycles. It must be reemphasized that the data points in figure 5.33 correspond to three different sands, placed using three different methods, and that the tests were conducted Independently at two different laboratories. 


\subsubsection{Comparison Between $\Delta \mathrm{u}$ and $\Delta \mathbf{u}_{\mathrm{r}}$}

As discussed before, two different types of excess pore water pressure were measured during the cyclic triaxial tests reported here. They were: a) the peak cyclic pore water pressure during cyclic loading, $\Delta u$, and b) the residual pore water pressure, measured after cyclic loading had stopped, $\Delta u_{r}$ (see also section 5.1.3). In those cases where both $\Delta u$ and $\Delta u_{r}$ were avallable, 1nvariably $\Delta u \geq \Delta u_{r}$. In particular, for nondestructive testing at strains below the threshold, $\gamma\left\langle 10^{-2}\right.$ percent, $\Delta u_{r}=0$ while $\Delta u>0$.

It seems reasonable to assume that the difference between $\Delta u$ and $\Delta u_{r}$ corresponds to an "elastic" pore water pressure response, assoclated with the increase in volumetric stress generated by the cyclic loading. Therefore, as a first approximation, the following expression is assumed valid:

$$
\Delta \mathbf{u}=\Delta \mathbf{u}_{\mathrm{r}}+(\Delta \mathbf{u}) \text { elastic }
$$

If the soll skeleton is assumed to be both elastic and 1sotropic, $(\Delta u)$ elastic should be proportional to the cyclic deviator stress, $\Delta \sigma_{1}$ (Lambe and Whitman, 1969 [45]) or:

$$
(\Delta \mathrm{u})_{\text {elastic }}=\frac{1}{3} \Delta \sigma_{1}
$$

Combining equations 5.6 and 5.7 , the desired relation between $\Delta u$ and $\Delta u_{r}$ is obtained.

$$
\Delta u=\Delta u_{r}+\frac{1}{3} \Delta \sigma_{1}
$$

In particular, at strains lower than $10^{-2}$ percent, where $\Delta u_{r}=0$ and the behavior of the soll could be expected to be close to being elastic and isotropic, $\Delta \mathbf{u}=\frac{1}{3} \Delta \sigma_{1}$ is predicted.

The expression $\left(\Delta u-\Delta u_{r}\right) /\left(1 / 3 \Delta \sigma_{1}\right)$ was computed for tests 1 through 11 , for all cyclic strains and numbers of cycles for which both $\Delta u$ and $\Delta u_{r}$ were avallable. It was found that, at small strains, above and below the threshold, $\gamma \leq$ $3 \times 10^{-2}$ percent, and for moderate pore pressure buildup, $0.01 \leq \Delta \mathrm{u} / \sigma_{3}^{1} \leq 0.20$, the expression has a falrly constant value, which is $\left(\Delta u-\Delta u_{r}\right) /\left(\overline{1} / 3 \Delta \sigma_{1}\right)=0.42$ \pm 0.07 , as shown in figure 5.34. For values of $\Delta u / \sigma\}$ outside this range the values are more erratic. Therefore, for small strain, testing $\left(\gamma \leq 3 \times 10^{-2}\right.$ percent), above and below the threshold, and for $\Delta u / \sigma_{3} \lesssim 0.20$, the plots of $\Delta \mathrm{u} / \sigma \xi$ presented in this section could be approximately converted into plots of $\left.\Delta u_{r} / \sigma\right\}$ by means of equation 5.9 :

$$
\frac{\Delta u_{r}}{\sigma_{3}^{\prime}}=\frac{\Delta u}{\sigma_{3}^{\prime}}-\frac{0.14 \Delta \sigma_{1}}{\sigma_{3}^{\prime}}
$$

where $\pm \Delta \sigma_{1}$ is the cyclic deviator stress. The fact that $\left(\Delta \mathrm{u}-\Delta \mathrm{u}_{\mathrm{r}}\right) /\left(1 / 3 \Delta \sigma_{1}\right)$ is not equal to 1.0 , as predicted by equation 5.8 , but instead is equal to 0.42 , is probably due to the membrane compliance effect (Martin et al., 1978 [50]). 


\subsection{PORE WATER PRESSURE AND MODULUS DEGRADATION}

Sections 5.3 and 5.5 discussed the modulus degradation and the development of excess pore water pressure during cyclic loading, respectively. Modulus degradation was studied using the normalized parameter $G / G_{1}$, which is 1.0 at the beginning of the destructive cyclic loading and subsequently decreases to values between 0 and 1. Excess pore water pressure buildup was studied by means of the normalized parameter, $\Delta \mathrm{u} / \sigma\}$, which is zero at the beginning and subsequently increases to values between 0 to 1 . Both modulus degradation and pore water pressure increase are affected significantly by $\gamma$ and $n$, and to a lesser degree by $D_{r}$ and $\left.\sigma\right\}$, and the effect of all these factors is very similar for both $G / G_{1}$ and $\left.\Delta u / \sigma\right\}$, $1 . e .$, the factors which decrease $G / G_{1}$ increase $\left.\Delta u / \sigma\right\}$ and vice versa. Furthermore, at strains below the threshold, $\gamma<10^{-2}$ percent, $G / G_{1} \simeq 1$ and $\left.\Delta u / \sigma\right\} \simeq 0,1 . e$. , they both stay constant, independently of $n$, $\mathrm{D}_{\mathrm{r}}$ and $\left.\sigma\right\}$.

It seems reasonable from the above discussion to assume that $G / G_{1}$ and $\left.\Delta u / \sigma\right\}$ are directly related. To test this hypothesis, the two parameters were plotted together as shown in figure 5.35. Figure 5.35 is reasonably consistent, considering the diversity of test conditions. A single curve could be fitted to the data points as shown in the figure. This relation between $\Delta \mathrm{u} / \sigma\}$ and $\mathrm{G}_{/} / \mathrm{G}_{1}$ for Monterey No. 0 sand under cyclic triaxial conditions is of considerable theoretical and practical interest. It suggests that for pore water pressure buildup and liquefaction analyses, the modulus $G$, can also be calculated using a relation such as that shown in the figure if the pore water pressure, $\Delta u$, is known at any time during cyclic loading.

The largest amount of scatter in figure 5.35 occurs near the middle of the plot, for $(1-(\Delta \mathrm{u} / \sigma \xi)) \simeq 0.4$ to 0.7 . There, the lowest data points, having somewhat lower modulus degradation for a given pore pressure buildup, correspond to tests $1,5,10$, and 11 , all run with a low cyclic strain, $\gamma=3 \times 10^{-2}$ percent. Conversely, the highest point corresponds to test 4 , run with a high cyclic strain, $\gamma=3 \times 10^{-1}$ percent. If needed, this influence of $\gamma$ could be used to refine the correlation of figure 5.35 and decrease its present scatter. 


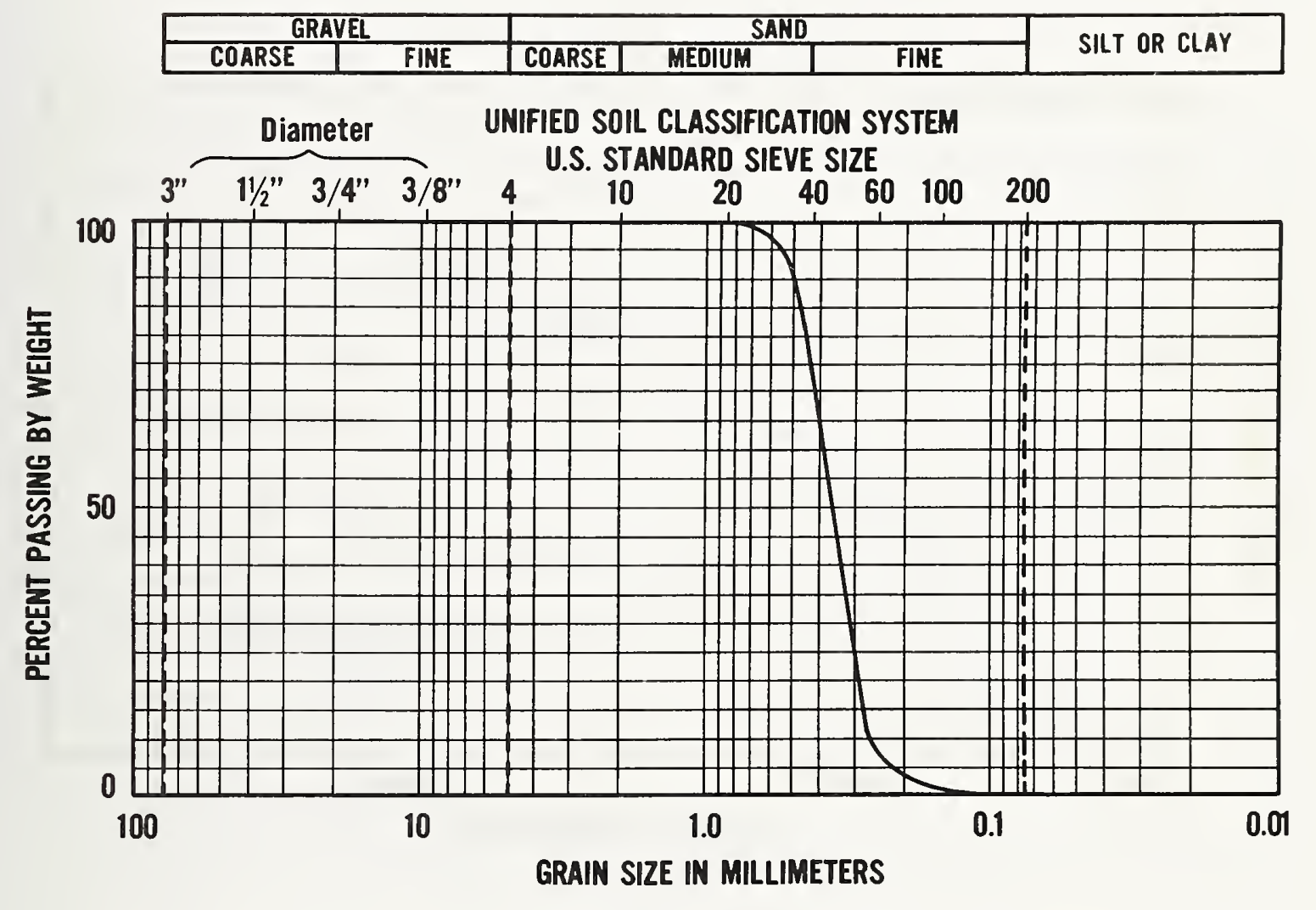

Figure 5.1 Grain size distribution of Monterey No. 0 sand 


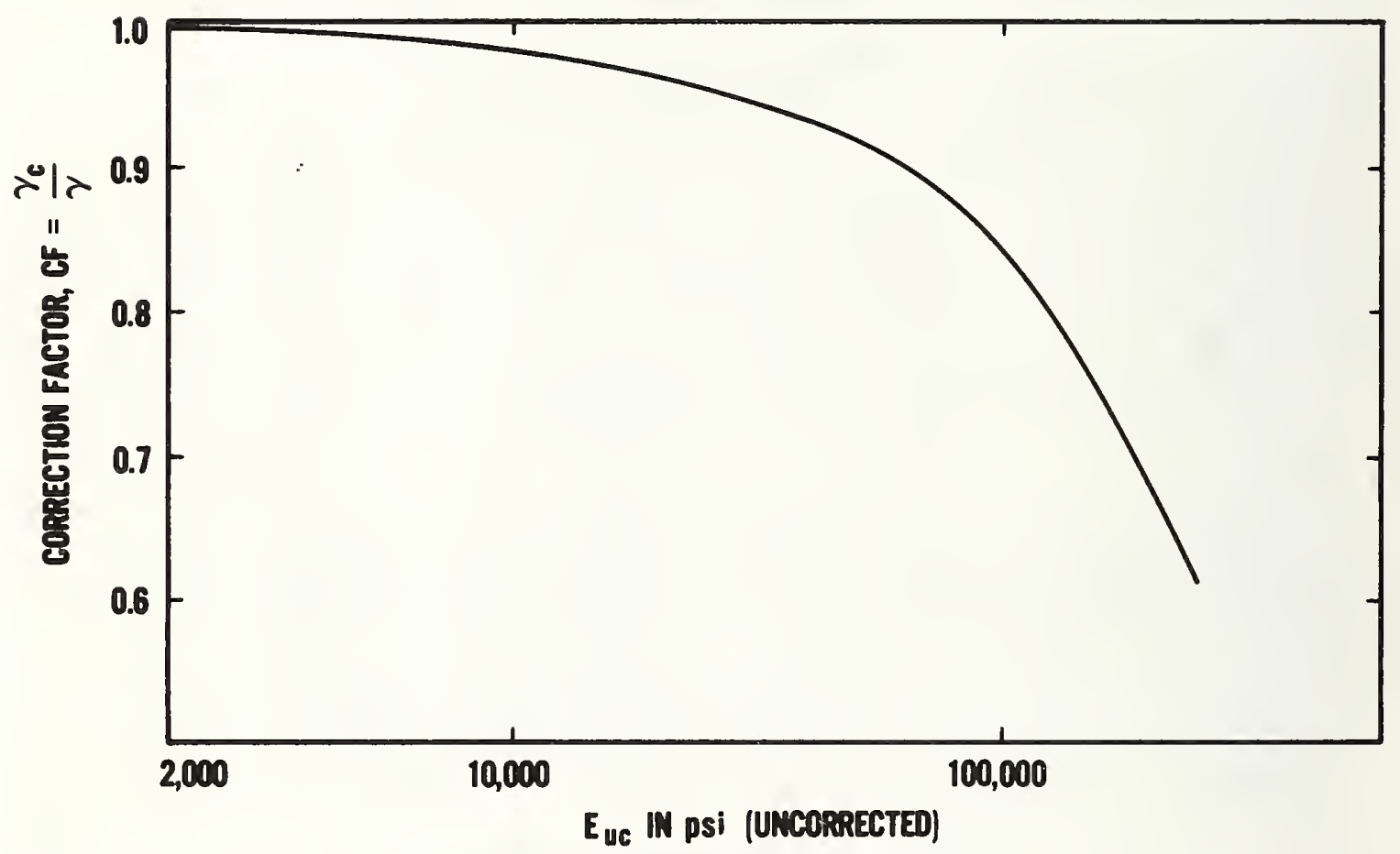

Figure 5.2 Typical correction factor for equipment compliance, cyclic triaxial tests 


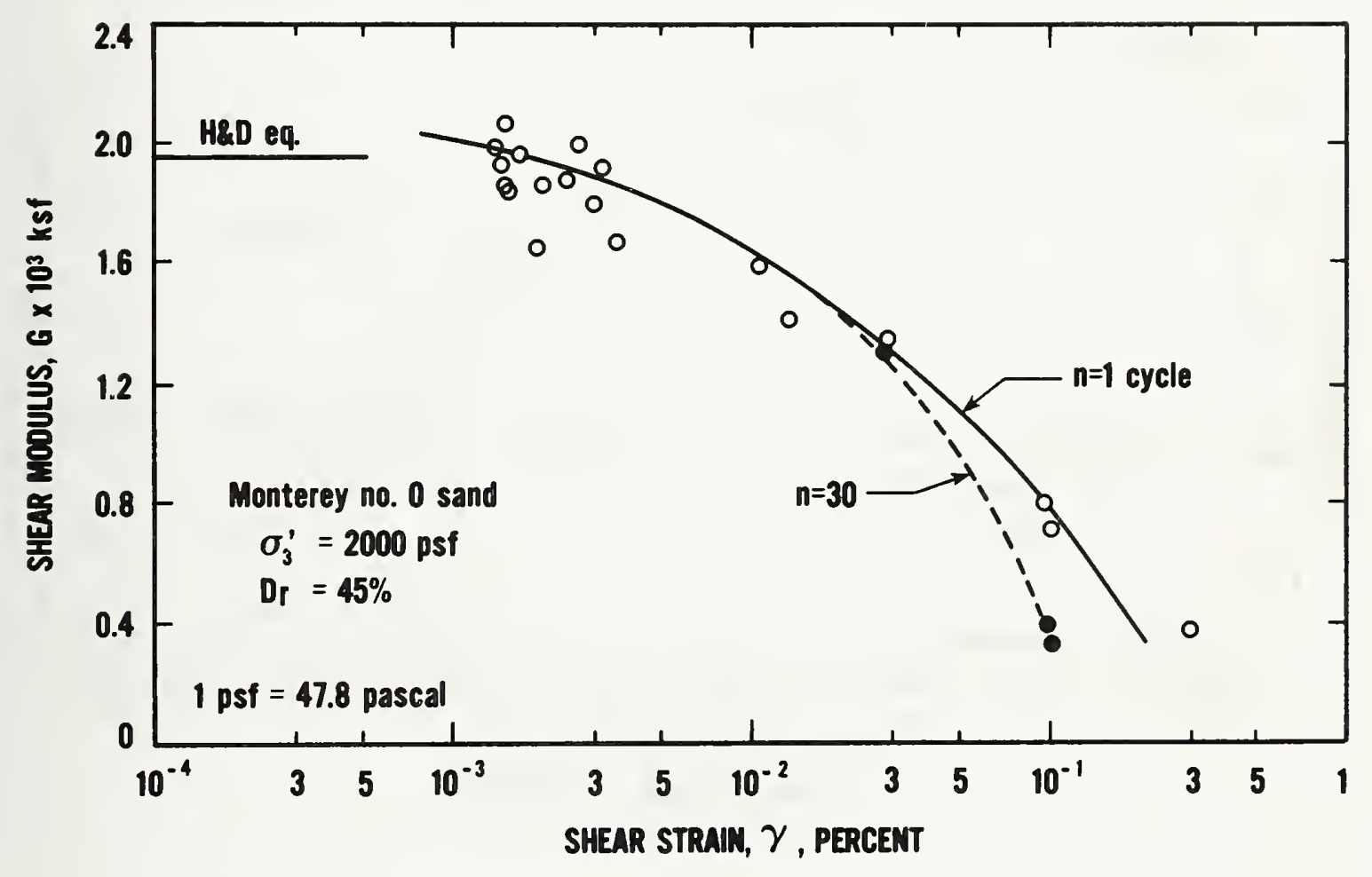

Figure 5.3 Reduction of shear modulus as a function of cyclic shear strain for Monterey No. 0 sand at of $=2000$ psf and $D_{r}=45$ percent 


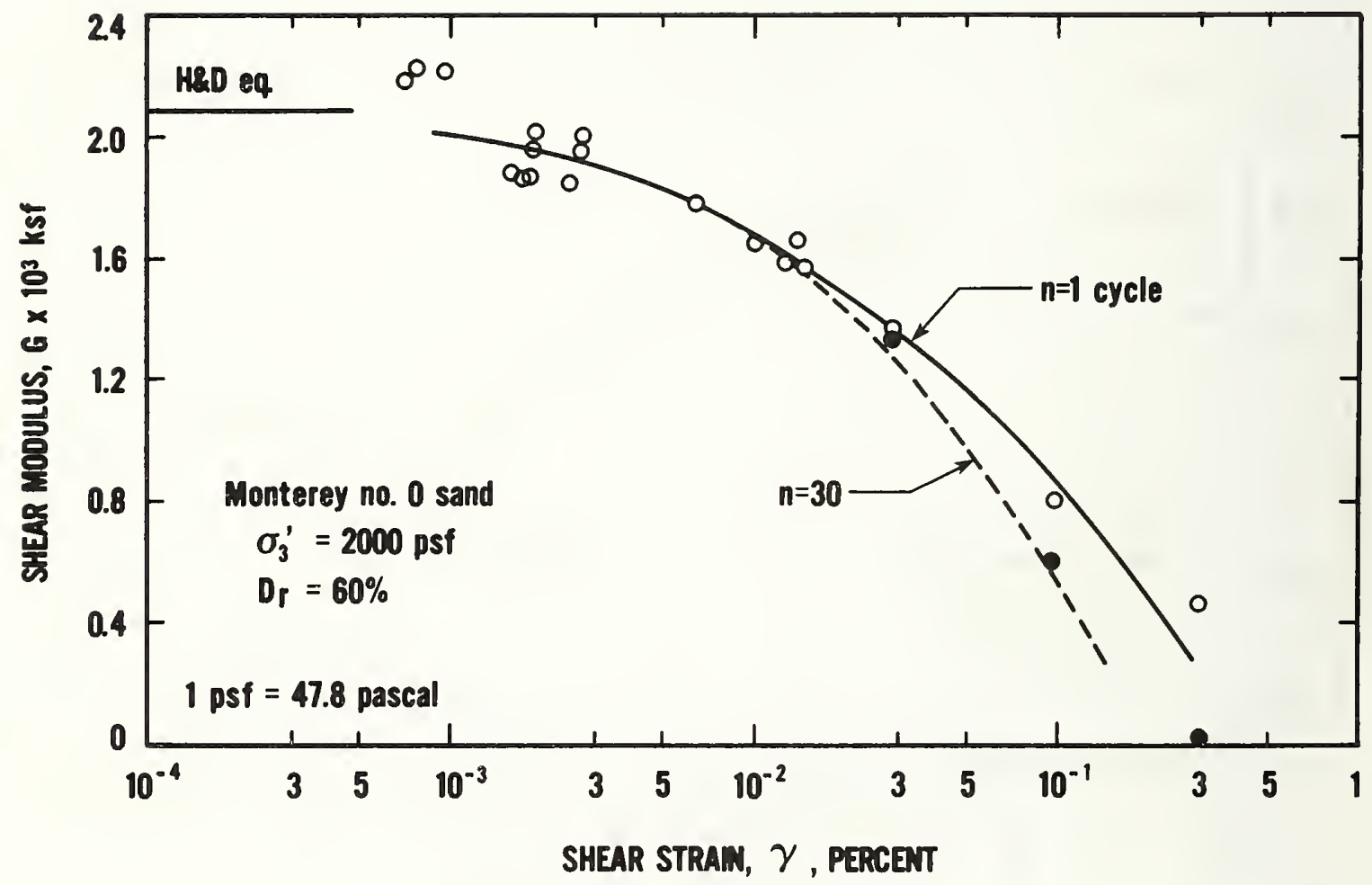

Figure 5.4 Reduction of shear modulus as a function of cyclic shear strain for Monterey No. 0 sand at $\sigma \xi=2000$ psf and $D_{r}=60$ percent 


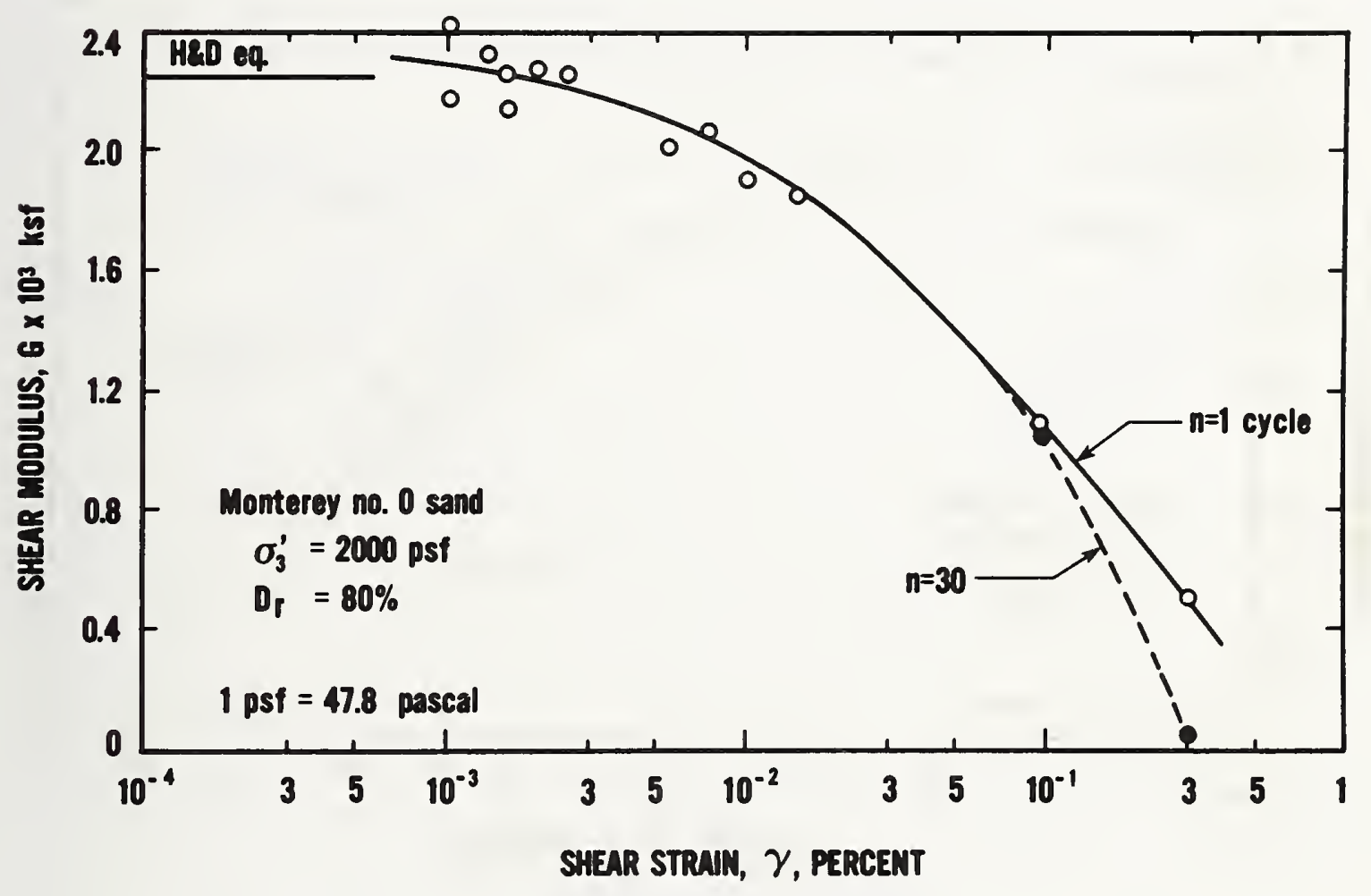

Figure 5.5 Reduction of shear modulus as a function of cyclic shear strain for Monterey No. 0 sand at $\sigma\}=2000$ psf and $D_{r}=80$ percent 


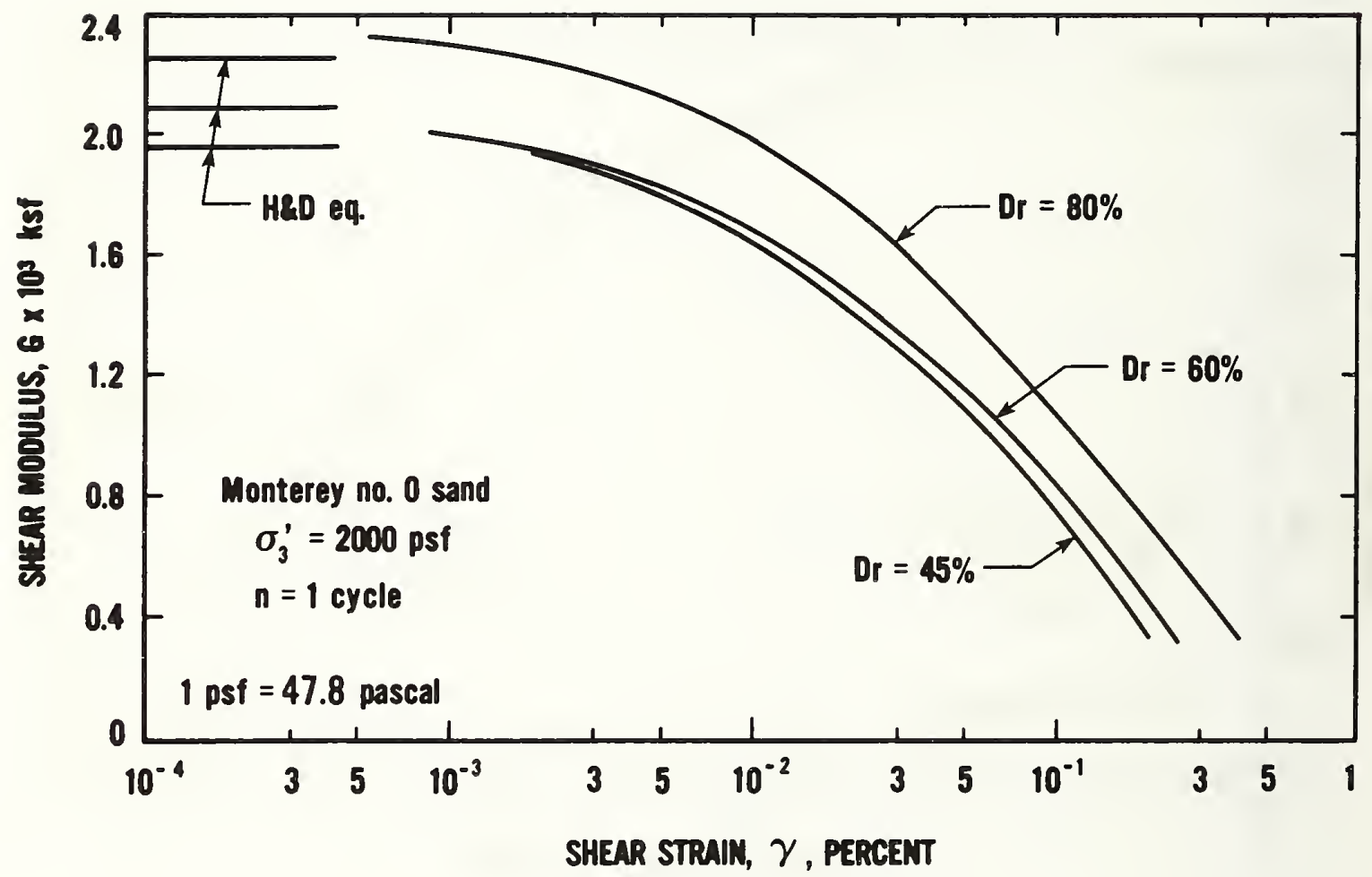

Figure 5.6 Reduction of shear modulus as a function of cyclic shear strain for Monterey No. 0 sand at of $=2000$ psf and $D_{r}=45,60$, and
80 percent 


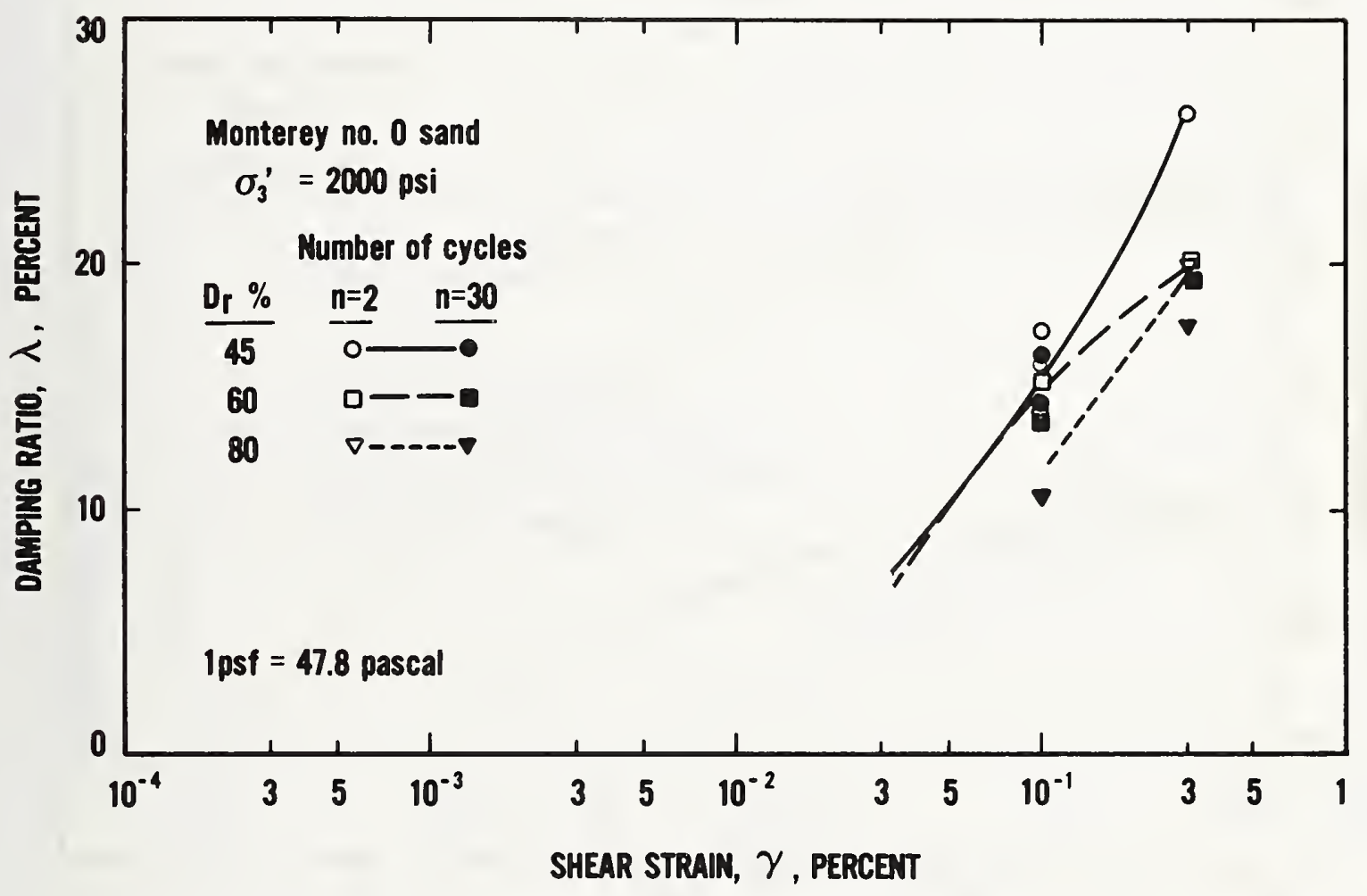

Figure 5.7 Damping ratio as a function of cyclic shear strain for Monterey No. 0 sand at of $=2000$ psf and $D_{r}=45,60$, and 80 percent 


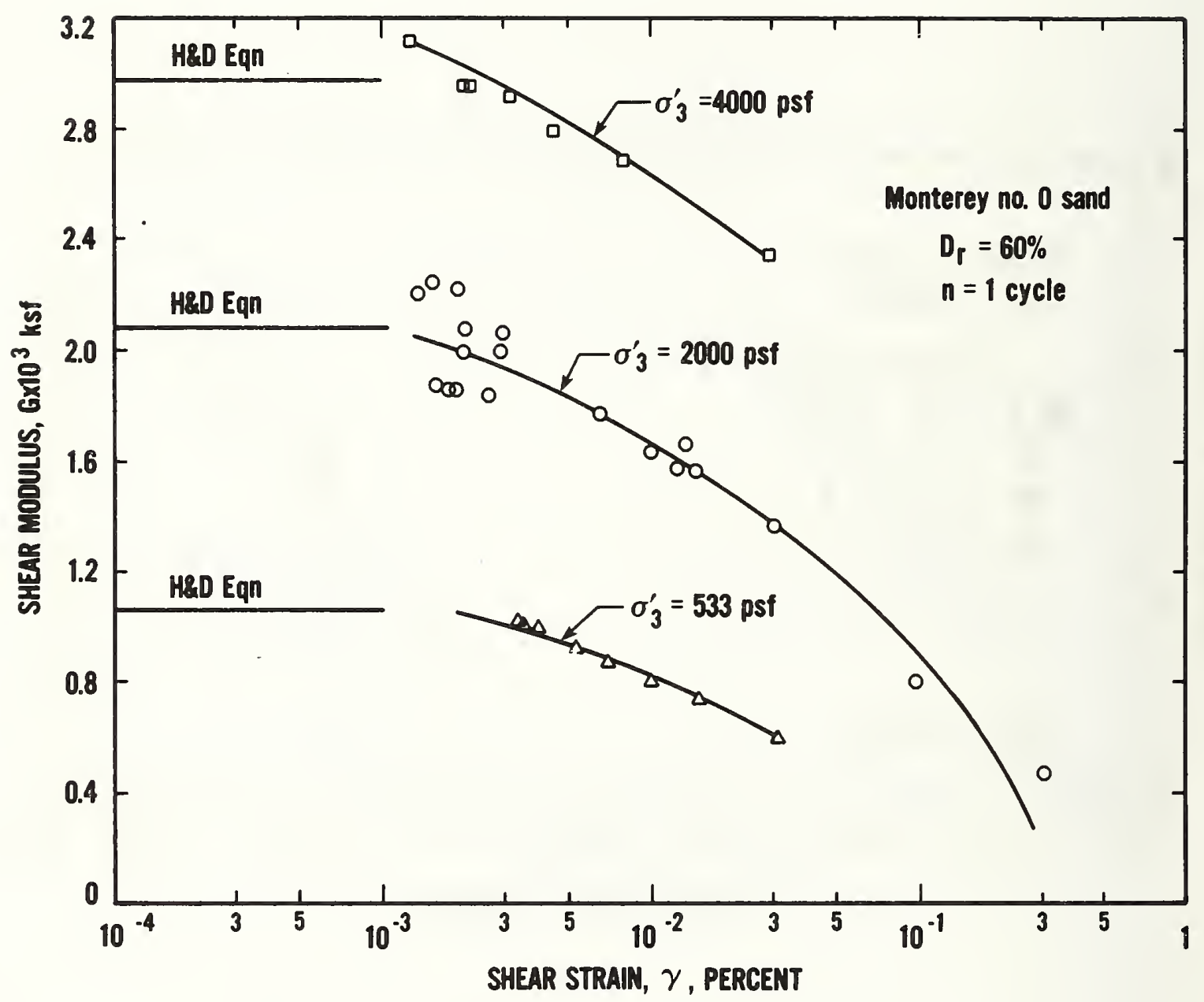

Figure 5.8 Reduction of shear modulus as a function of cyclic shear strain for Monterey No. 0 sand at $D_{r}=60$ percent and $\left.o\right\}=533,2000$, and 4000 psf 


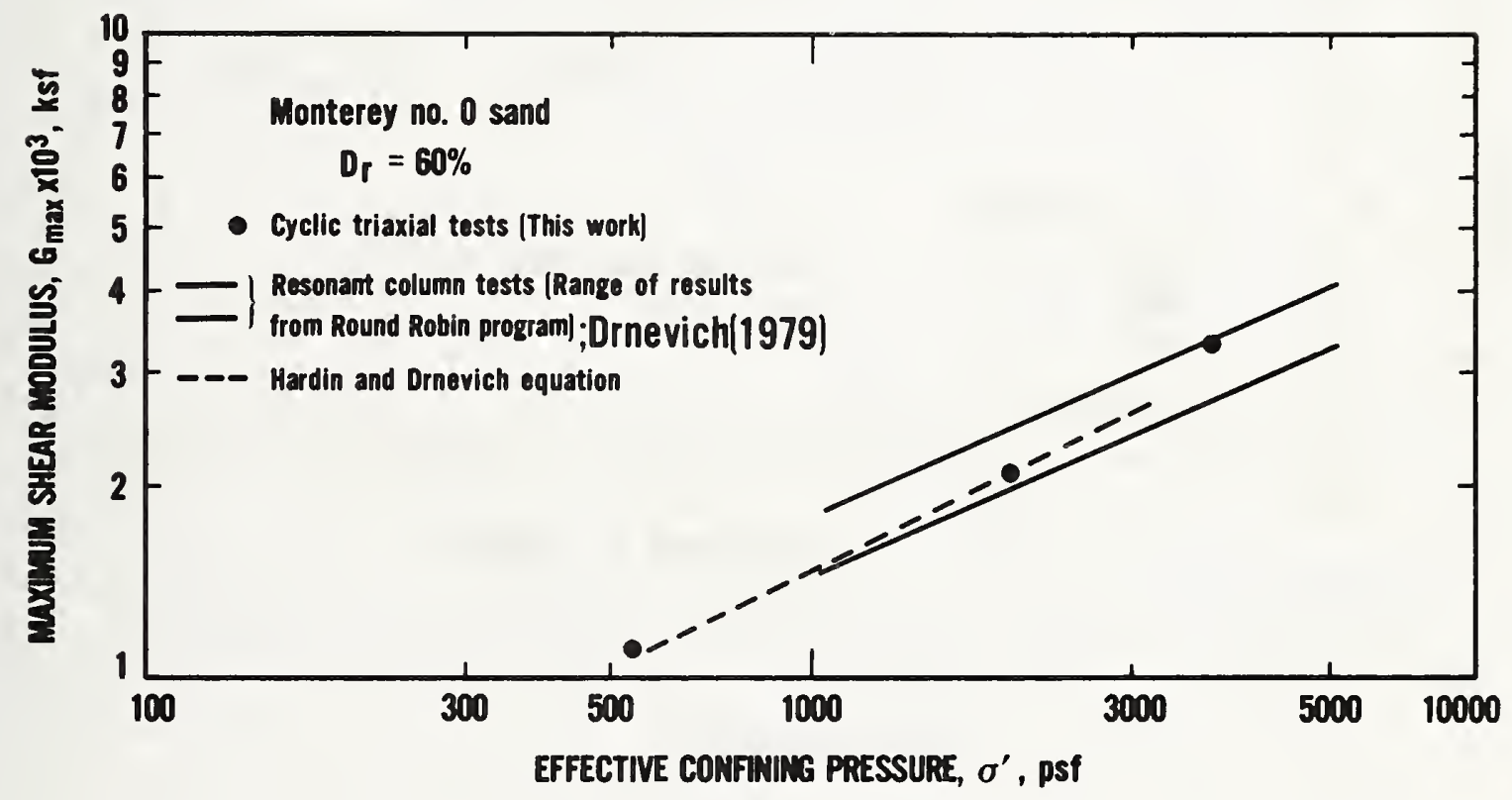

Figure 5.9 Shear modulus of very small shear strains ( $G_{\max }$ ) as a function of effective confining pressure $(\sigma \xi)$ for Monterey No. 0 sand and $\mathrm{D}_{\mathrm{r}}=60$ percent 


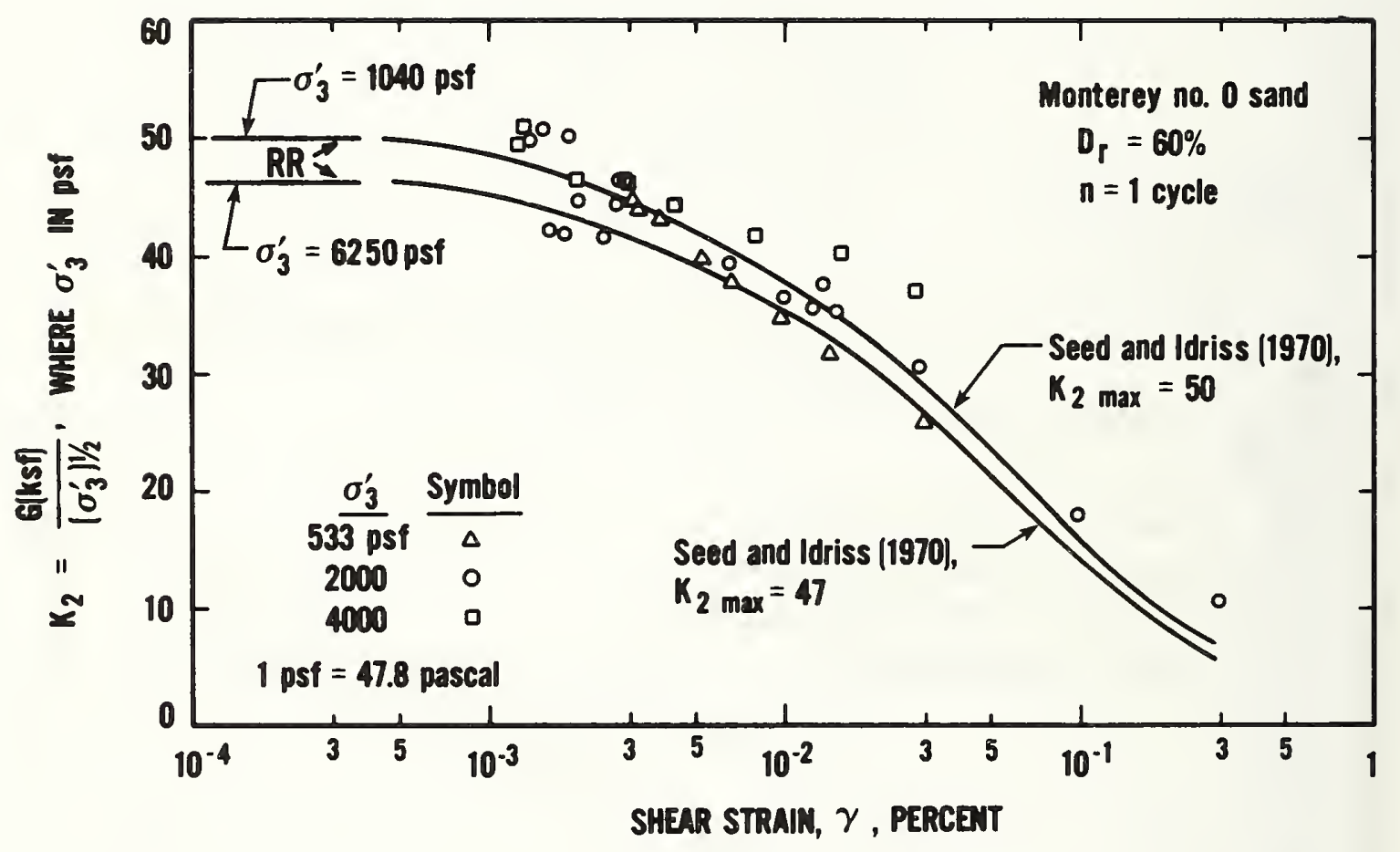

RR ROUND ROBIN RESONANT COLUMN TESTING PROGRAM (Drnevich, 1979 [22]

Figure 5.10 Normalized stiffness parameter as a function of cyclic shear strain for Monterey No. 0 sand at $D_{r}=60$ percent, $\sigma \xi=2000$ psf and various effective confining pressures 


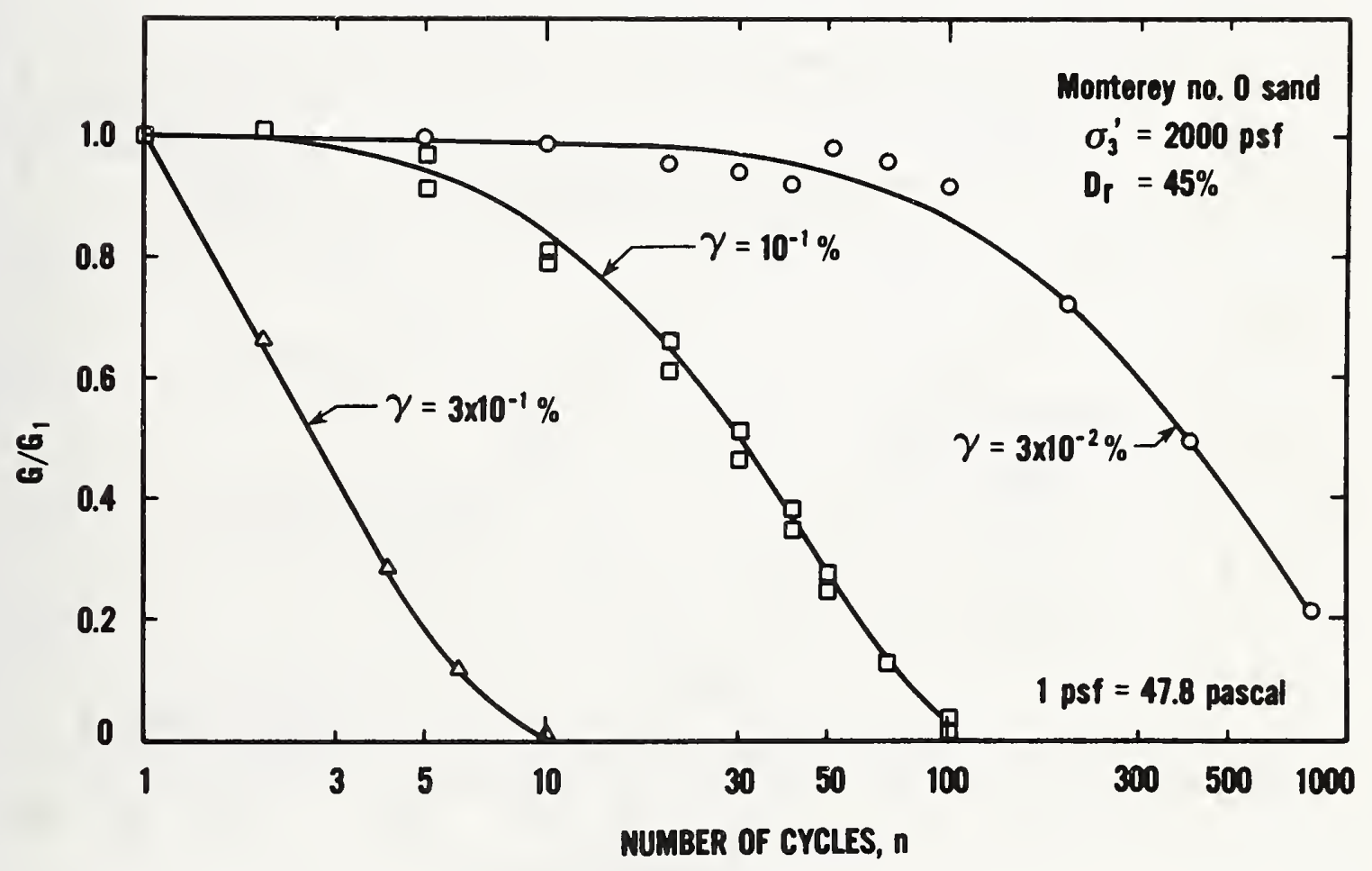

Figure 5.11 Degradation of shear modulus as a function of number of cycles for Monterey No. 0 sand at $D_{r}=45$ percent, of $=2000$ psf and varlous cyclic shear strains 


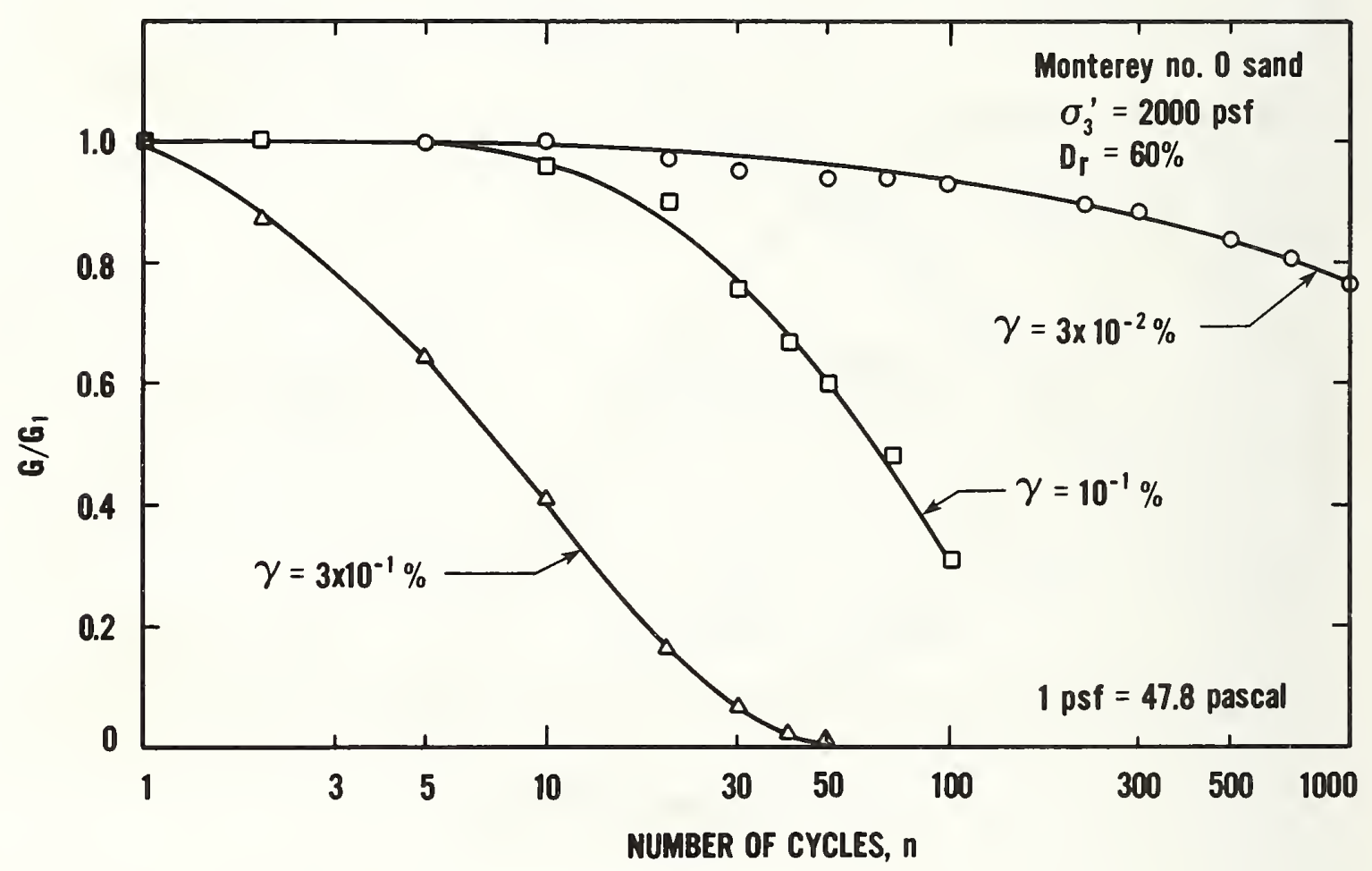

Figure 5.12 Degradation of shear modulus as a function of number of cycles for Monterey No. 0 sand at $\mathrm{D}_{\mathrm{r}}=60$ percent, of $=$ 2000 psf and various cyclic shear strains 


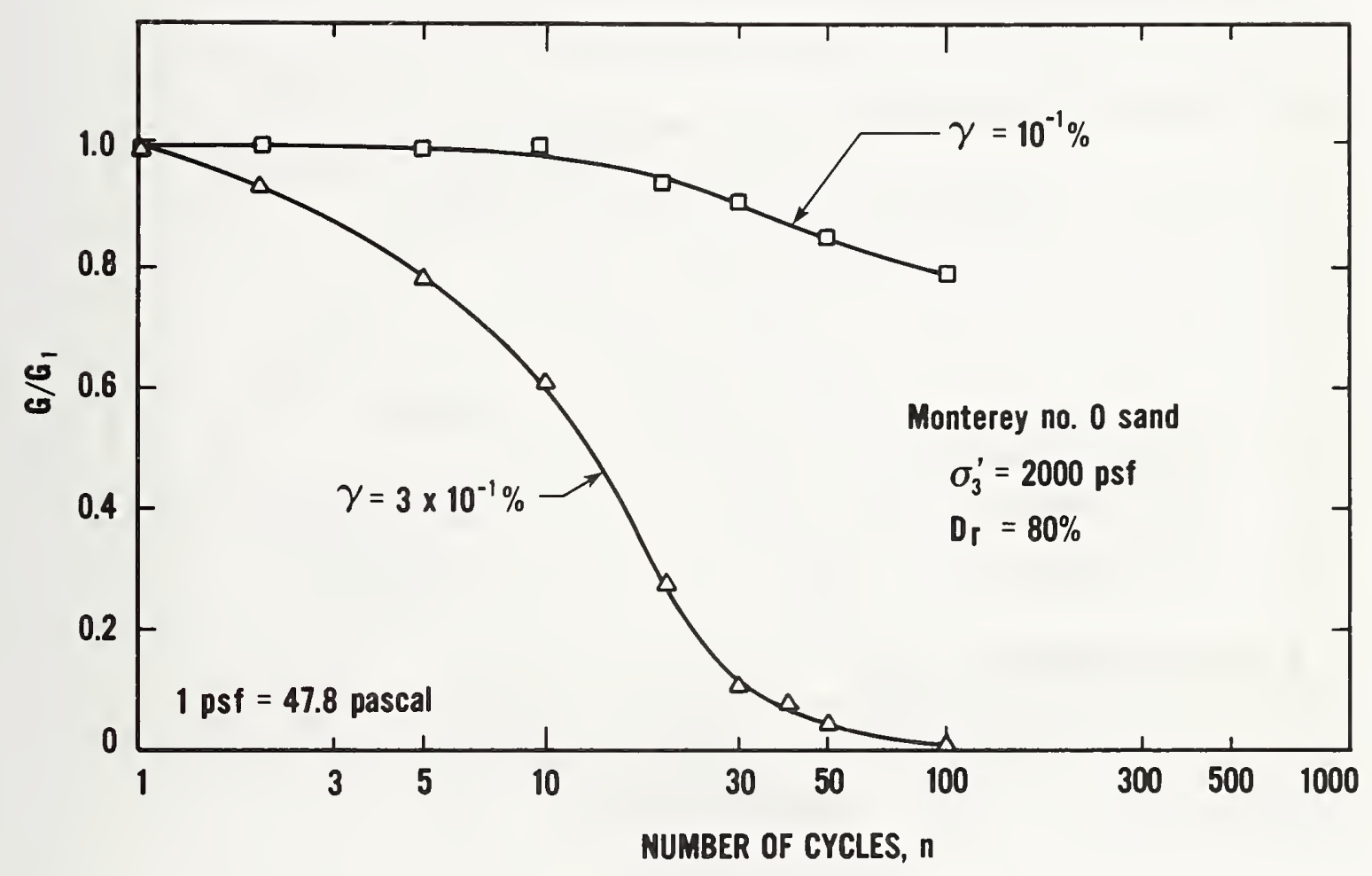

Figure 5.13 Degradation of shear modulus as a function of number of cycles for Monterey No. 0 sand at $D_{r}=80$ percent, of $=$ 2000 psf and various cyclic shear strains 


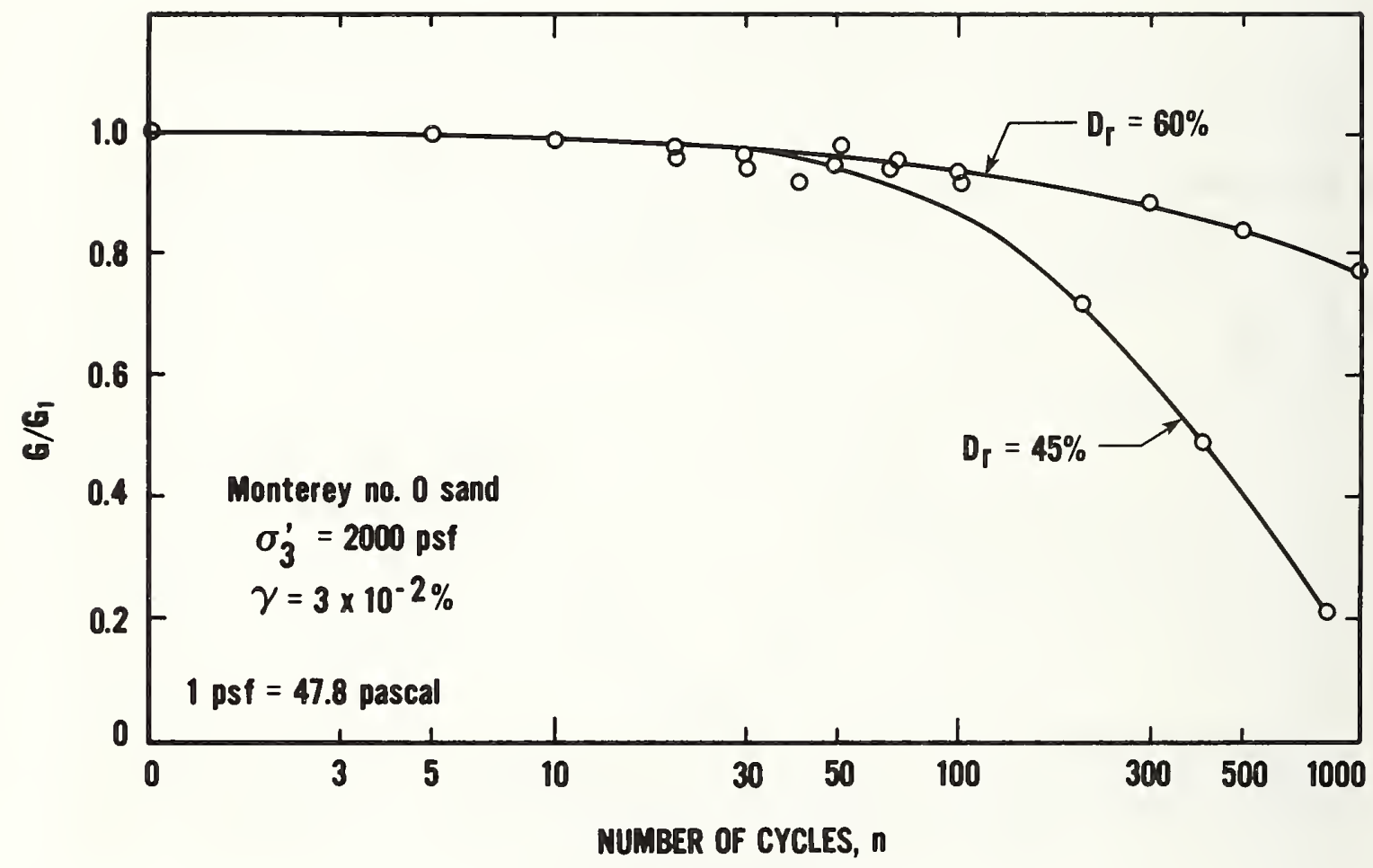

Figure 5.14 Degradation of shear modulus as a function of number of cycles for Monterey No. 0 sand at $\sigma_{3}^{\prime}=2000 \mathrm{psf}, \gamma=3 \times 10^{-2}$ percent and $D_{r}=45$ and 60 percent 


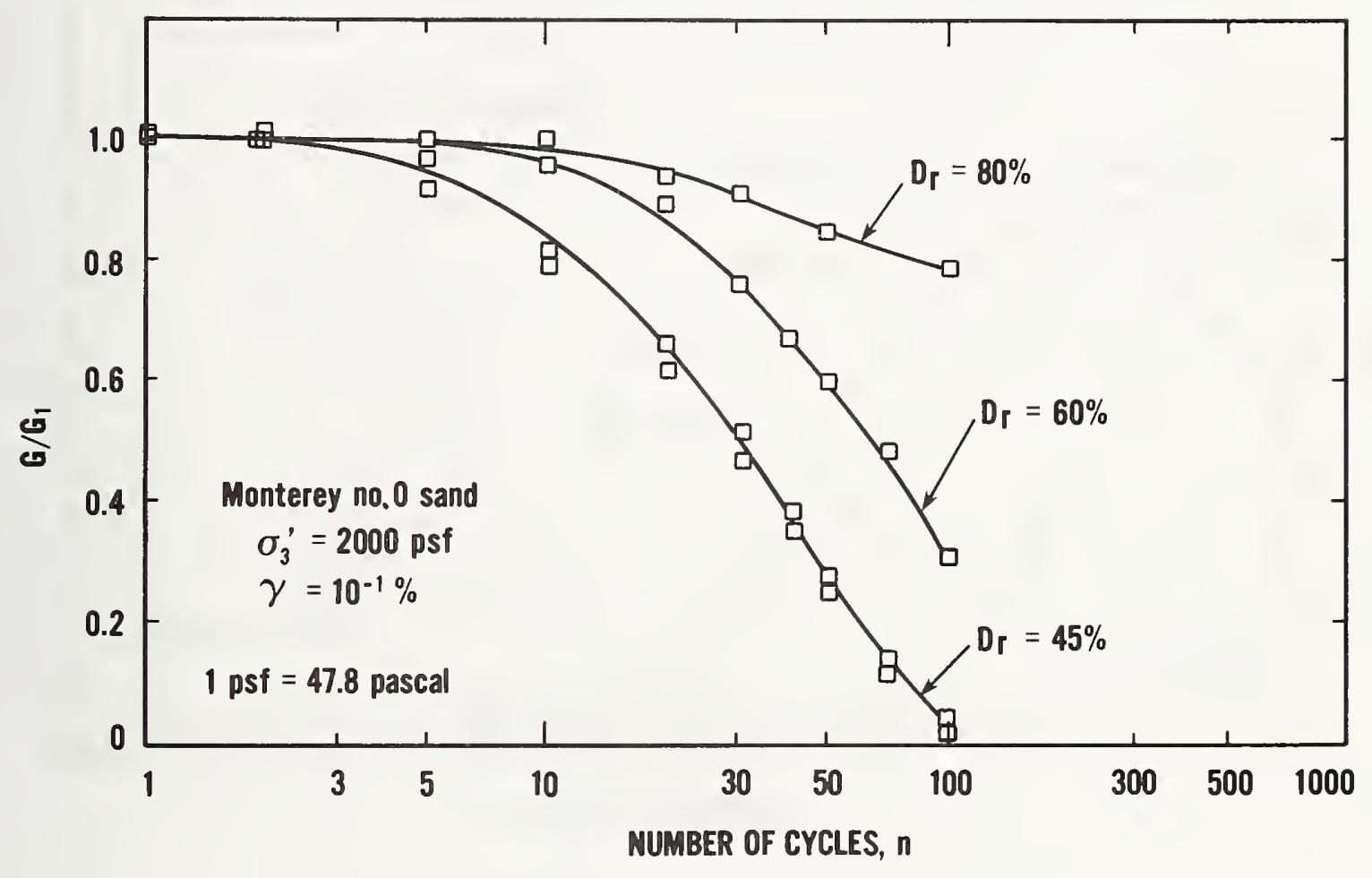

Figure 5.15 Degradation of shear modulus as a function of number of cycles for Monterey No. 0 sand at $\sigma_{3}^{\prime}=2000 \mathrm{psf}, \gamma=1 \times 10^{-1}$ percent and $D_{r}=45,60$, and 80 percent 


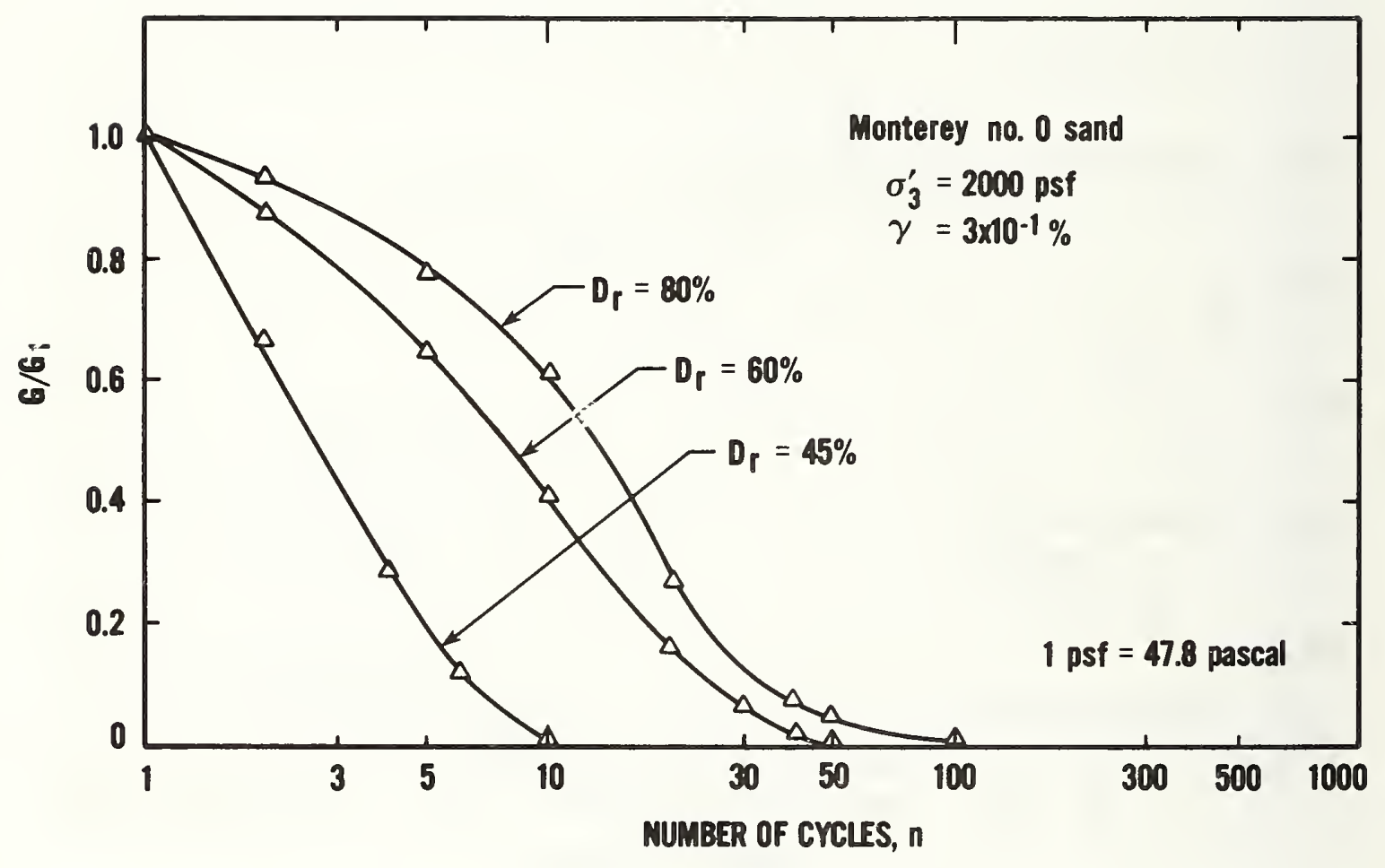

Figure 5.16 Degradation of shear modulus as a function of number of cycles for Monterey No. 0 sand at $\sigma_{3}^{\prime}=2000$ psf, $\gamma=3 \times 10^{-1}$ percent and $\mathrm{D}_{\mathrm{r}}=45,60$, and 80 percent 


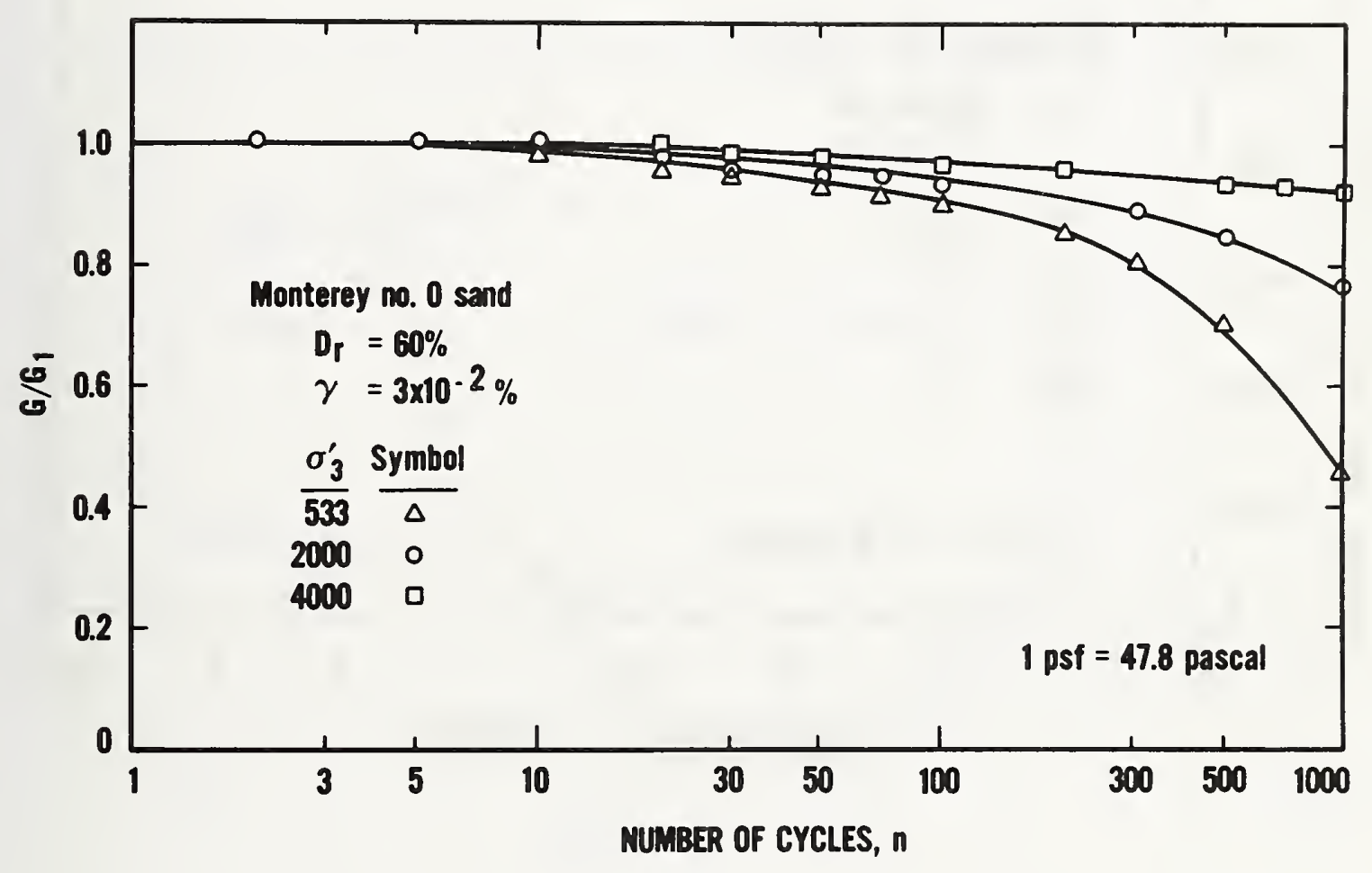

Figure 5.17 Degradation of shear modulus as a function of number of cycles for Monterey No. 0 sand at $D_{r}=60$ percent, $\gamma=3 \times 10^{-2}$ percent, and $\sigma\}=533,2000$, and 4000 psf 


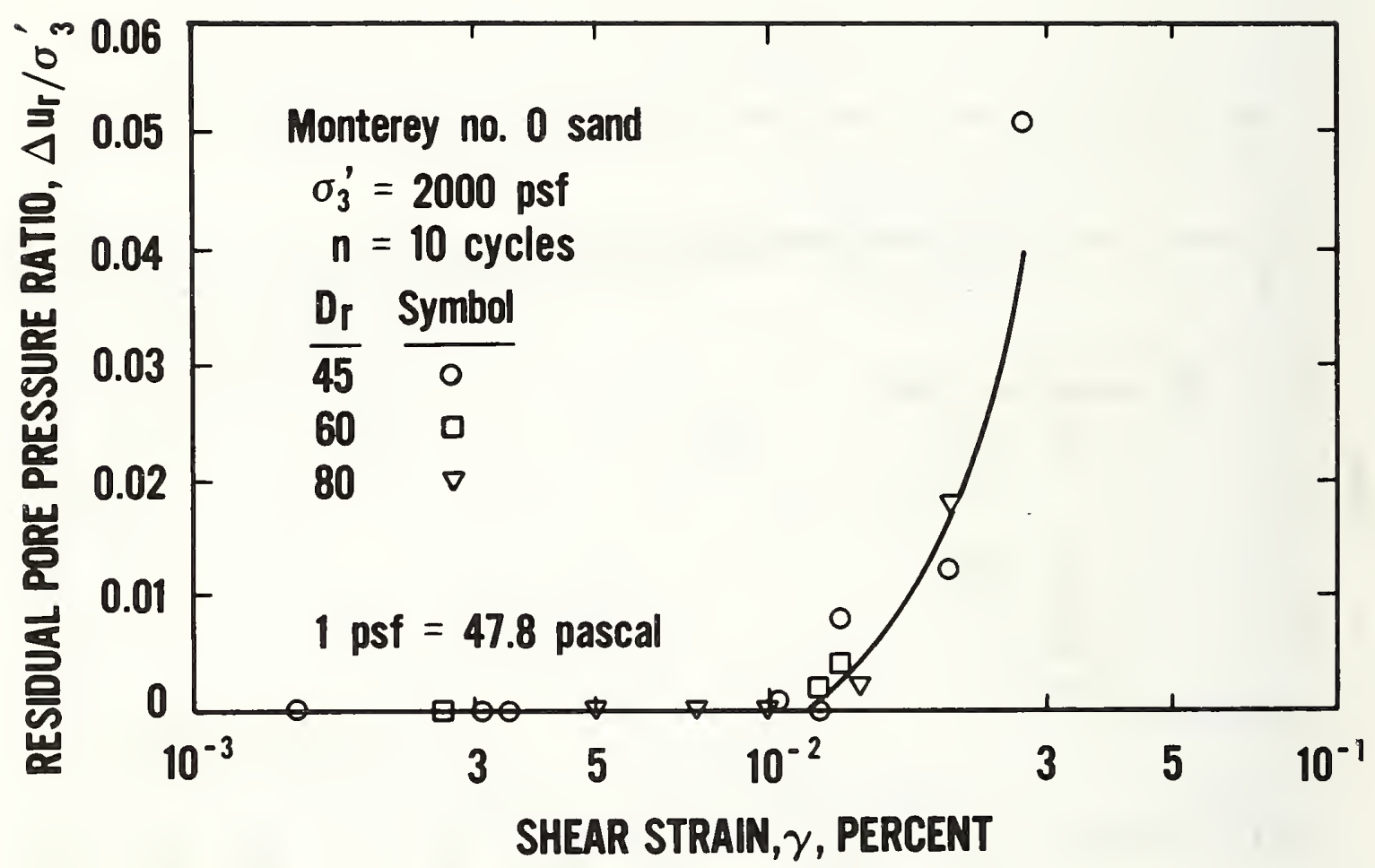

Figure 5.18 Residual pore water pressure bulldup after ten loading cycles, as a function of cyclic shear strain for Monterey No. 0 sand at of $=$ 2000 psf and $D_{r}=45,60$, and 80 percent 


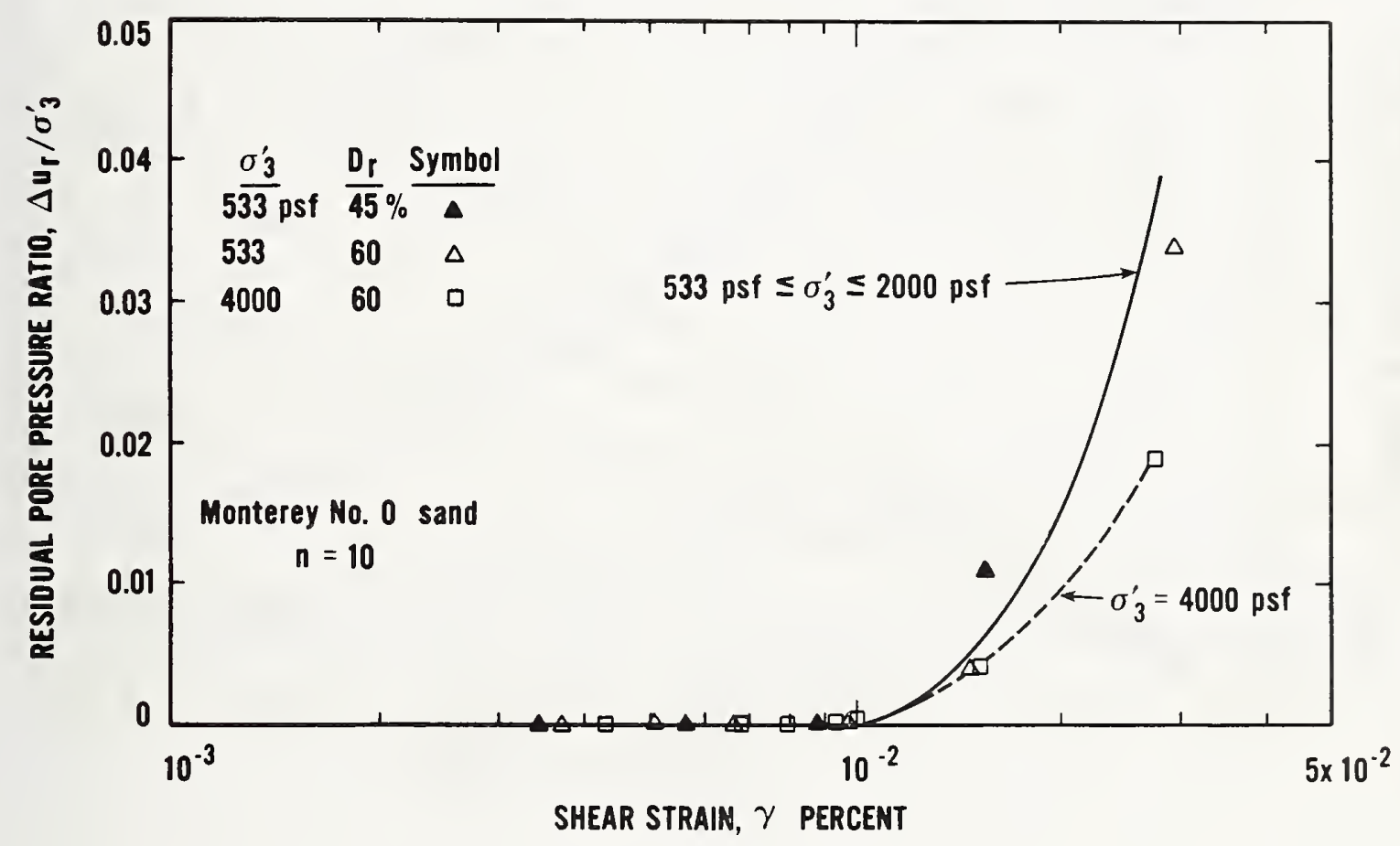

Figure 5.19 Residual pore water pressure buildup after ten loading cycles, as a function of cyclic shear strain for Monterey No. 0 sand at $\sigma\}=533,2000$, and 4000 psf and $D_{r}=45,60$, and 80 percent 


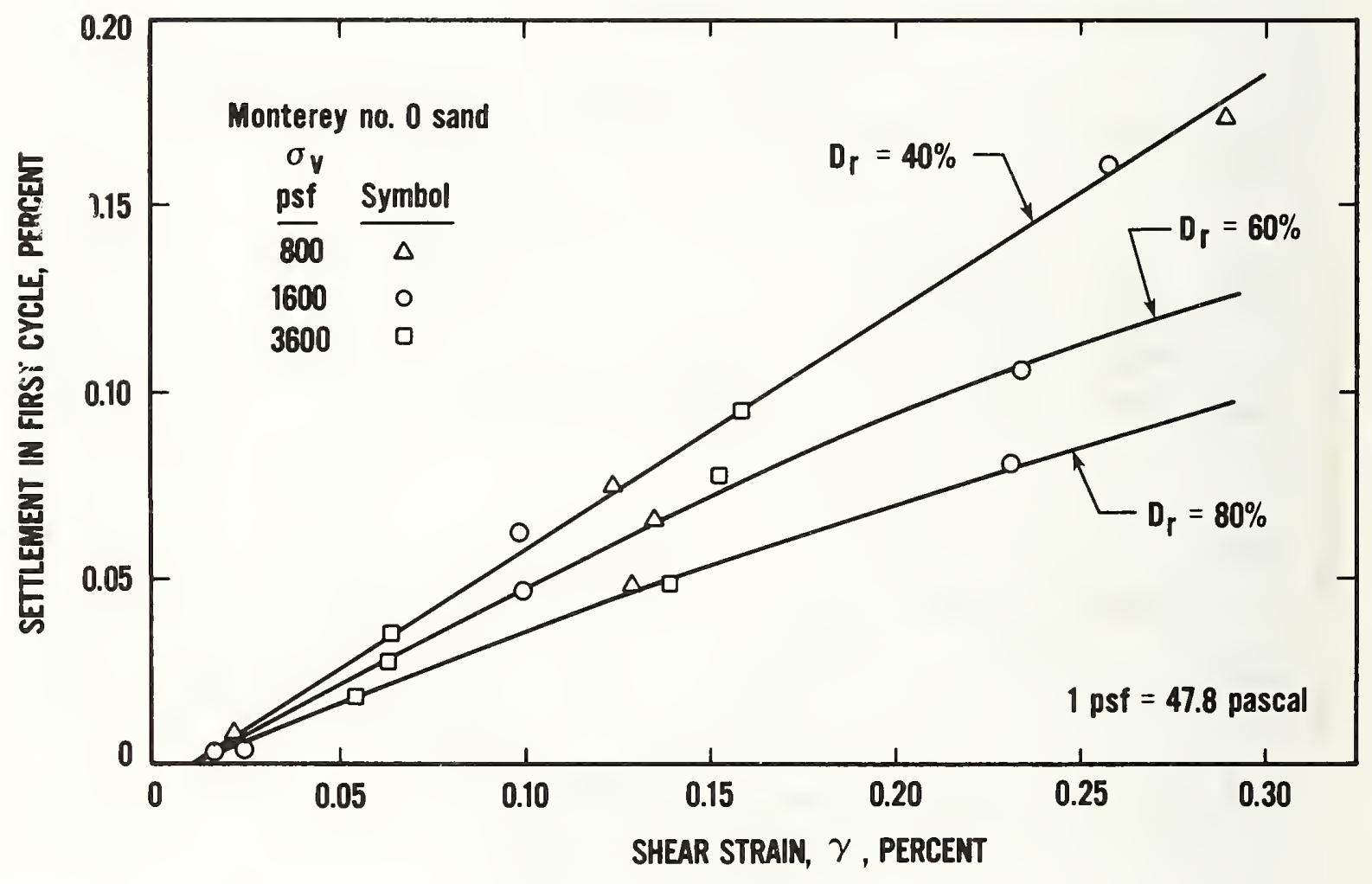

Figure 5.20 Settlement in the first loading cycle as a function of cyclic shear strain for dry Monterey No. 0 sand at various relative densities and confining pressures, simple shear tests (Pyke, 1973) 


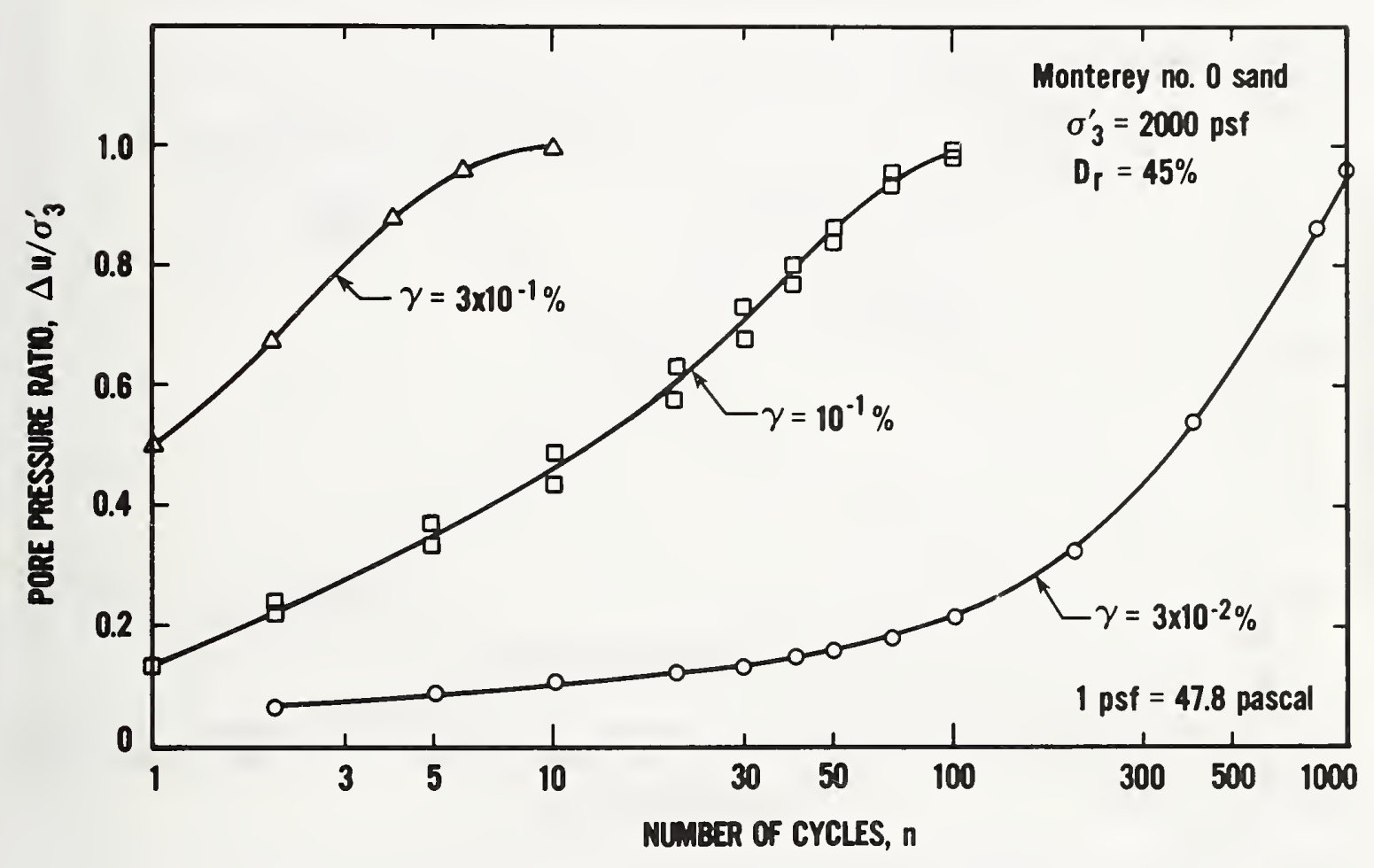

Figure 5.21 Pore water pressure buildup as a function of number of cycles for Monterey No. 0 sand at $\sigma\}=2000 \mathrm{ps} f, D_{r}=45$ percent and various cyclic shear strains 


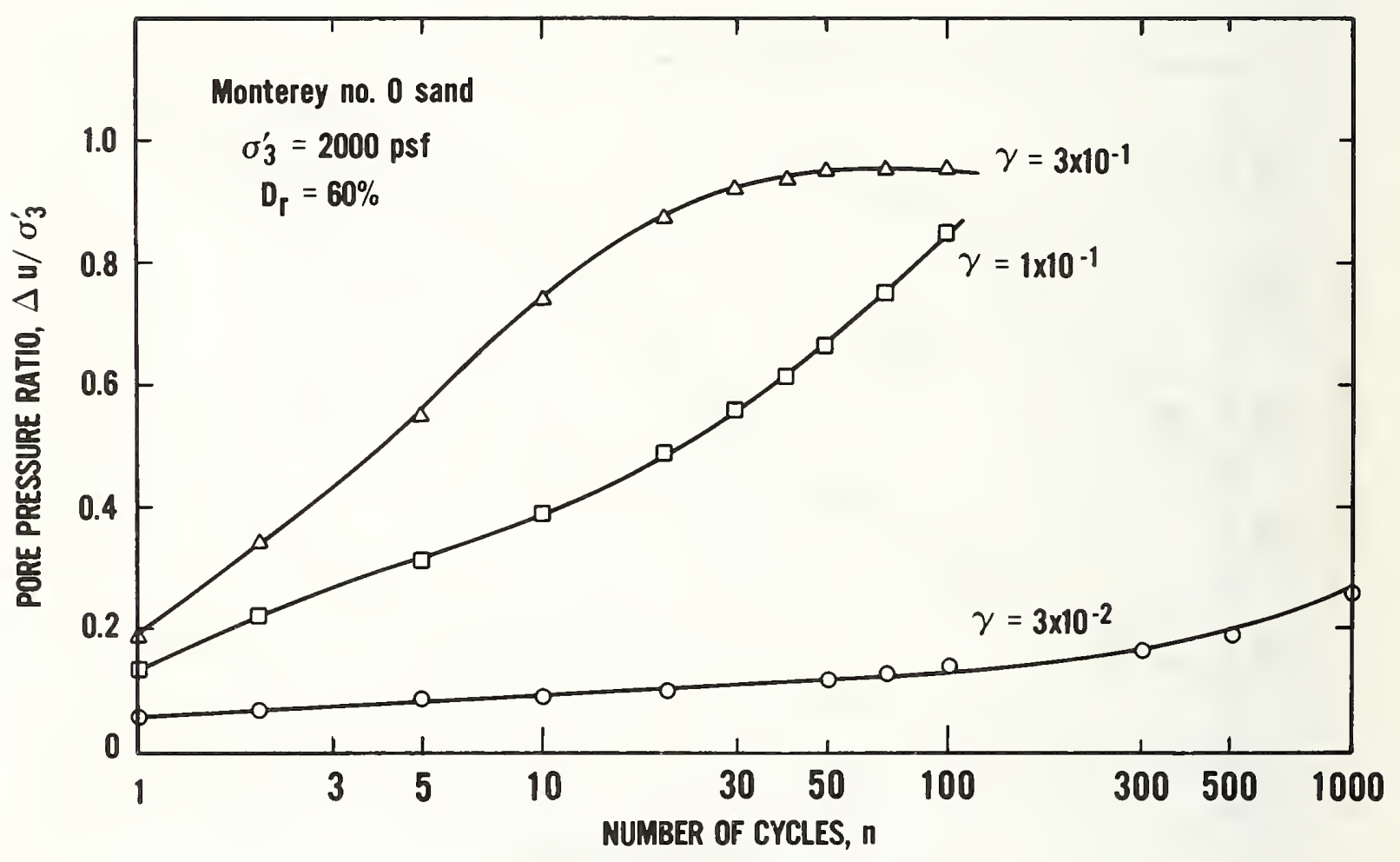

Figure 5.22 Pore water pressure buildup as a function of number of cycles for Monterey No. 0 sand at $\sigma \xi=2000 \mathrm{psf}, D_{\mathrm{r}}=60$ percent and various cyclic shear strains 


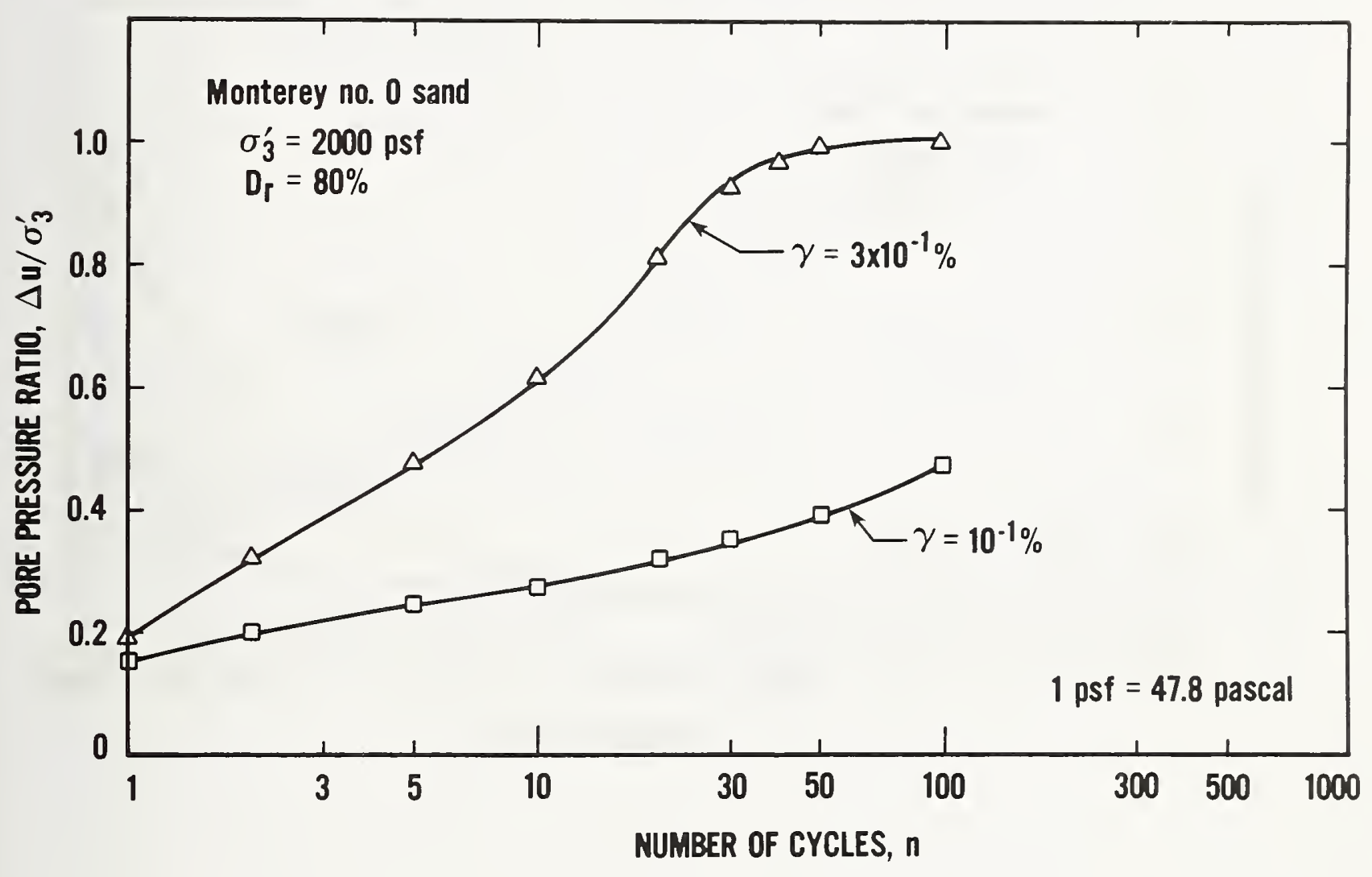

Figure 5.23 Pore water pressure buildup as a function of number of cycles for Monterey No. 0 sand at $\sigma\}=2000$ psf, $D_{r}=80$ percent and various cyclic shear strains 


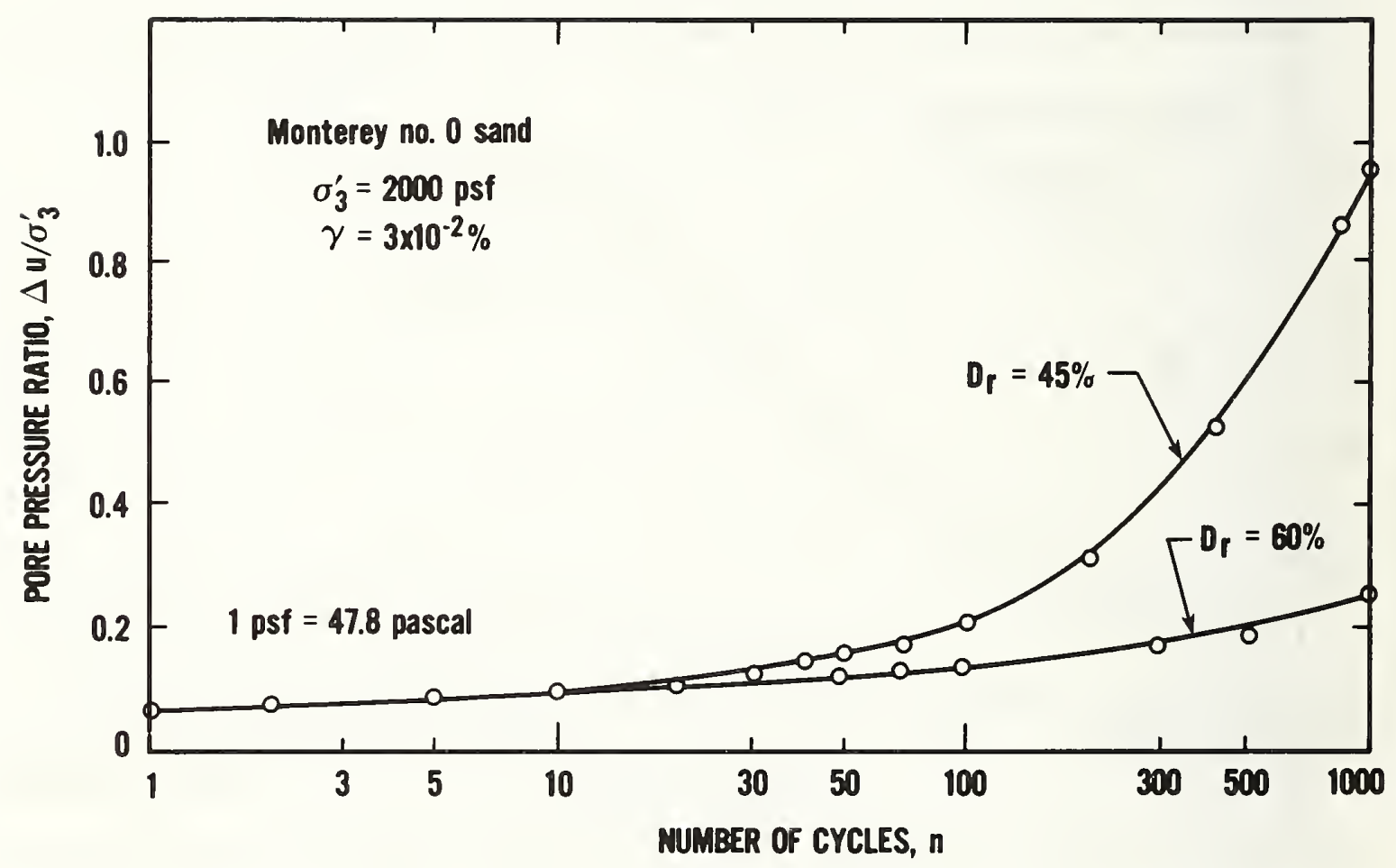

Figure 5.24 Pore water pressure buildup as a function of number of cycles for Monterey No. 0 sand at $\sigma_{3}^{\prime}=2000 \mathrm{psf}, \gamma=3 \times 10^{-2}$ percent, and $D_{r}=45$ and 60 percent 


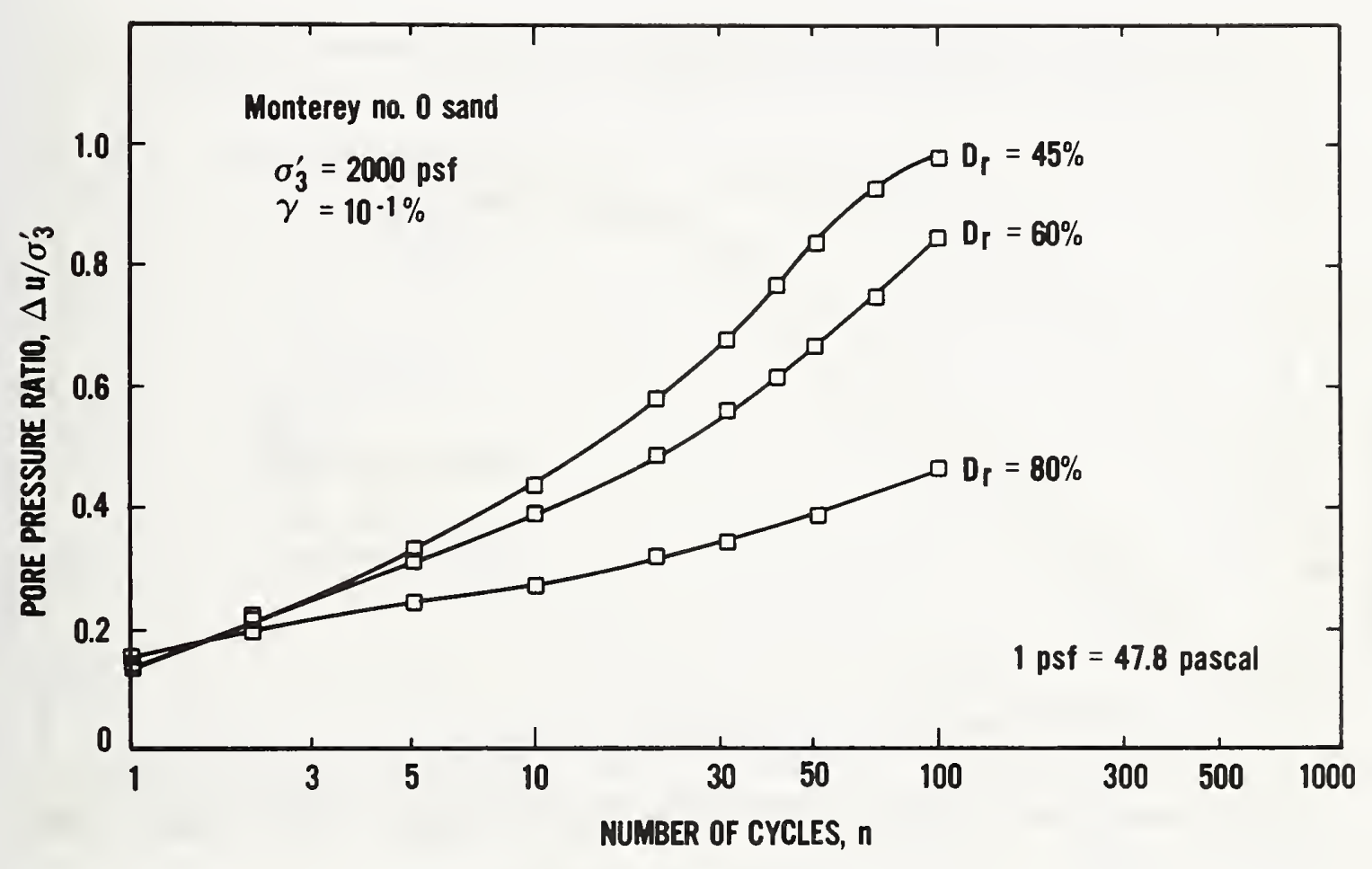

Figure 5.25 Pore water pressure buildup as a function of number of cycles for Monterey No. 0 sand at $\sigma_{3}^{\prime}=2000 \mathrm{psf}, \gamma=1 \times 10^{-1}$ percent, and $D_{r}=45,60$, and 80 percent 


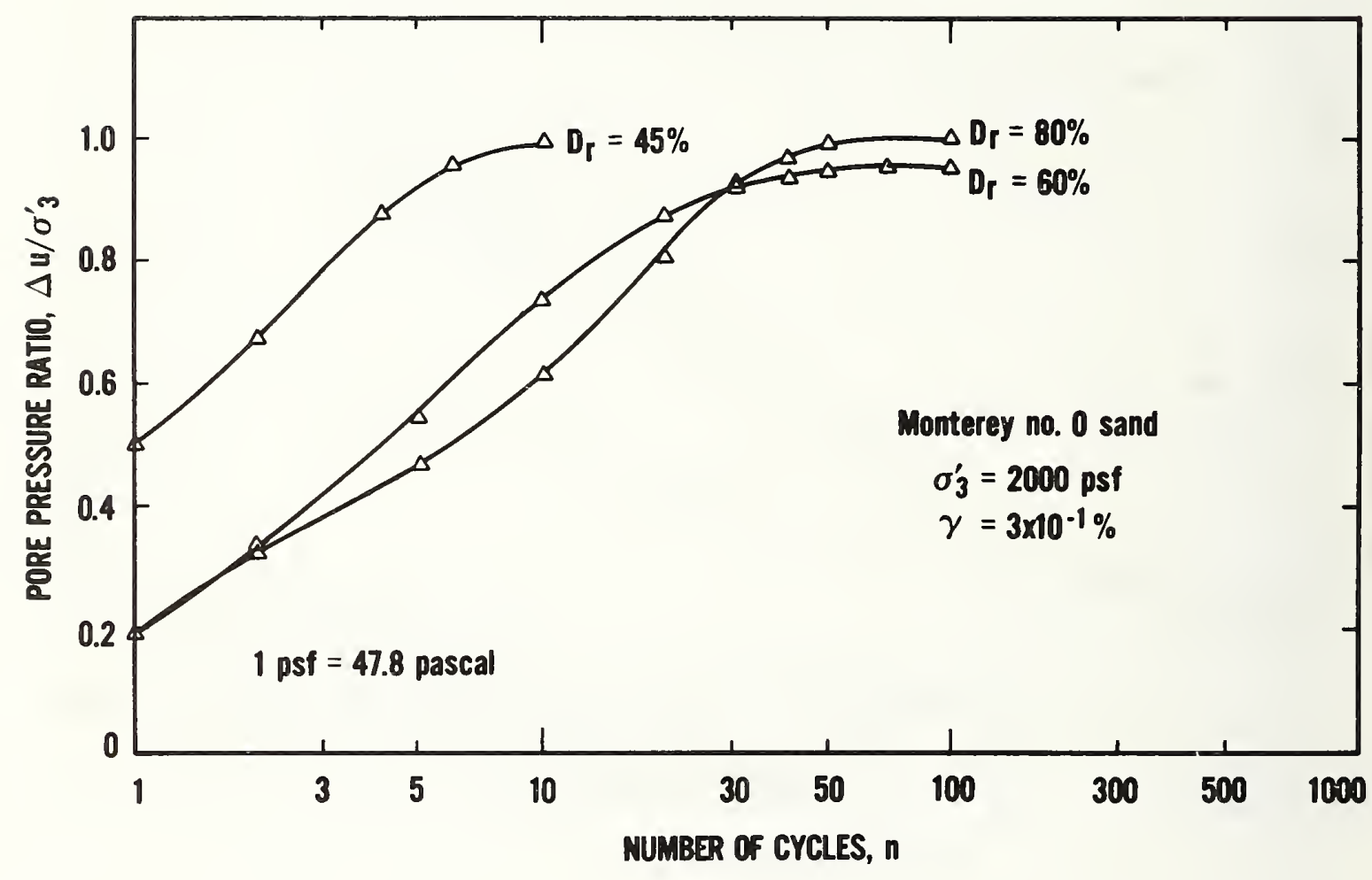

Figure 5.26 Pore water pressure bulldup as a function of number of cycles for Monterey No. 0 sand at $\sigma_{3}^{\prime}=2000$ psf, $\gamma=3 \times 10^{-1}$ percent, and $\mathrm{D}_{\mathrm{r}}=45,60$, and 80 percent 


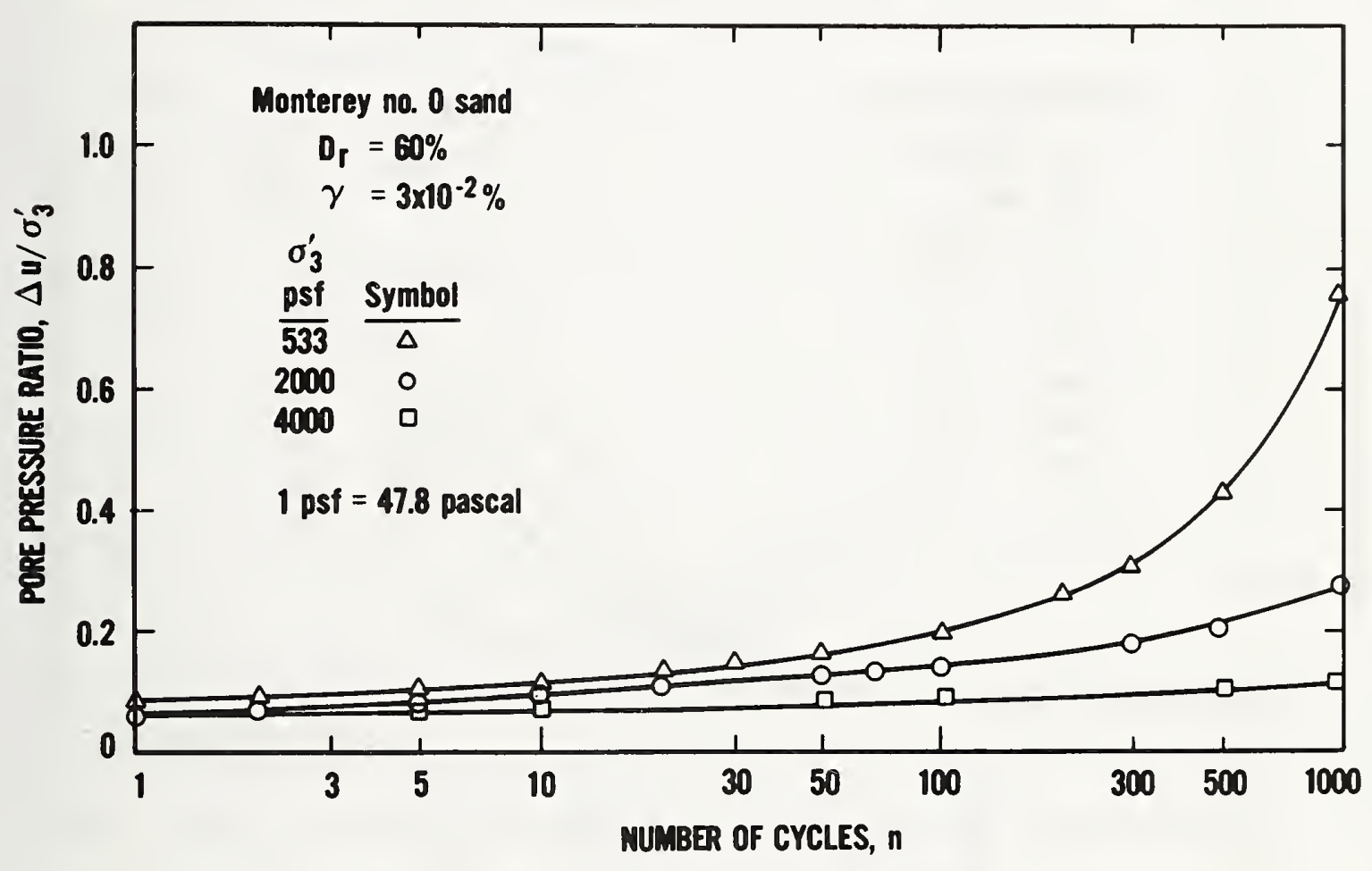

Figure 5.27 Pore water pressure buildup as a function of number of cycles
for Monterey No. 0 sand at $D_{r}=60$ percent, $\gamma=3 \times 10^{-2}$ percent and various effective confining pressures 


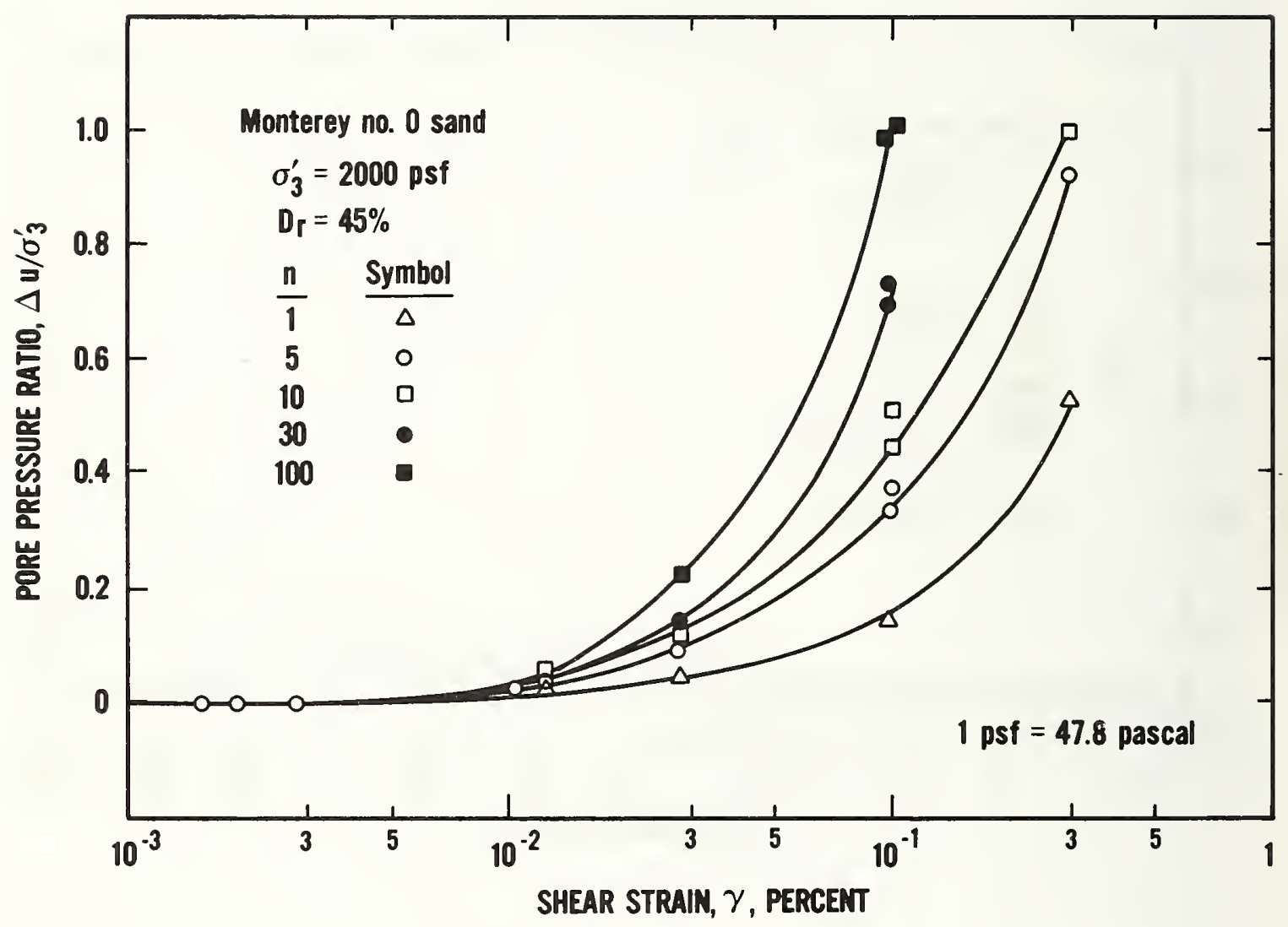

Figure 5.28 Pore water pressure buildup as a function of cyclic shear strain for Monterey No. 0 sand at $D_{r}=45$ percent, of $=2000$ psf and various numbers of cycles 


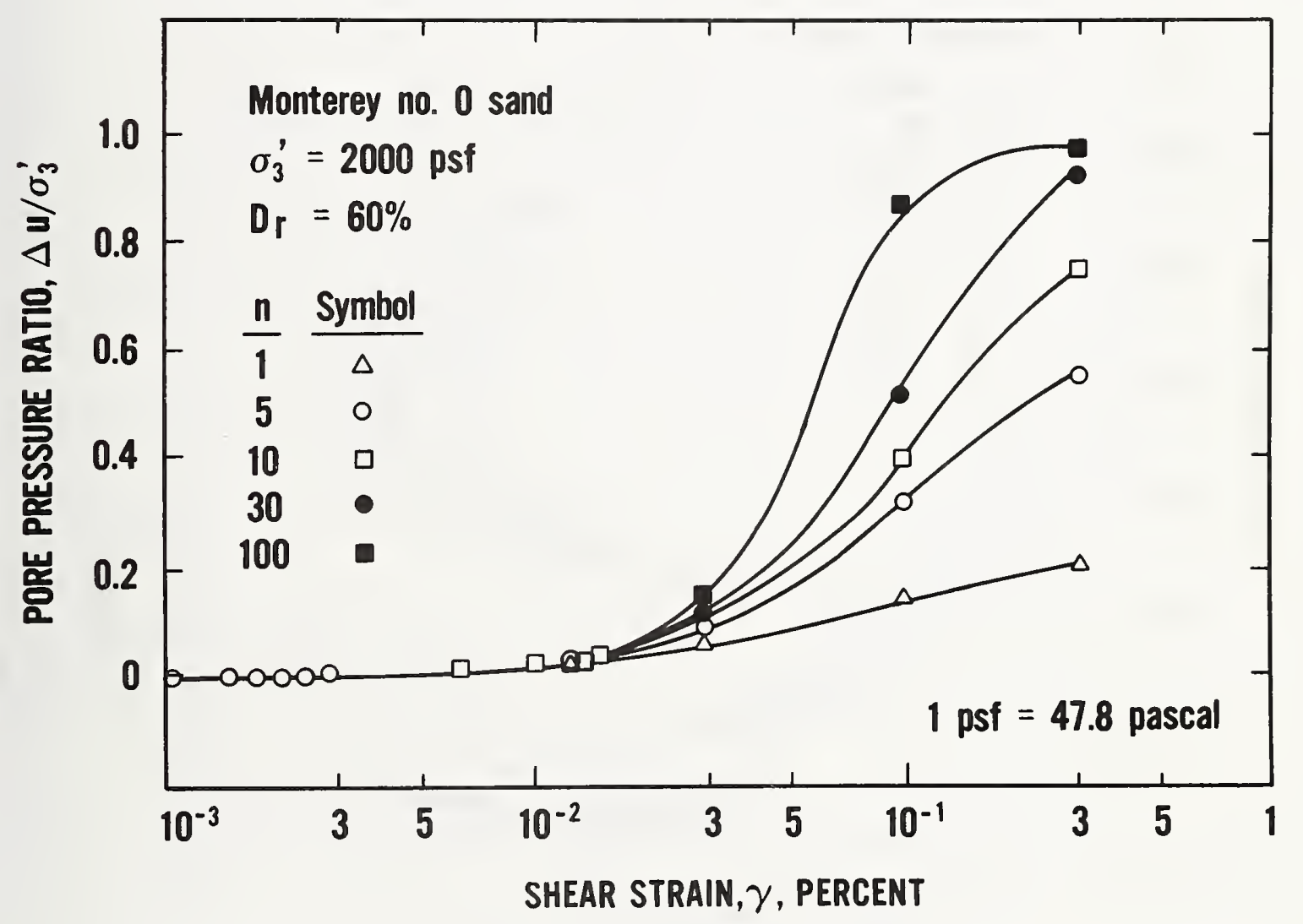

Figure 5.29 Pore water pressure buildup as a function of cyclic shear strain for Monterey No. 0 sand at $D_{r}=60$ percent, of $=2000$ psf and various numbers of cycles 


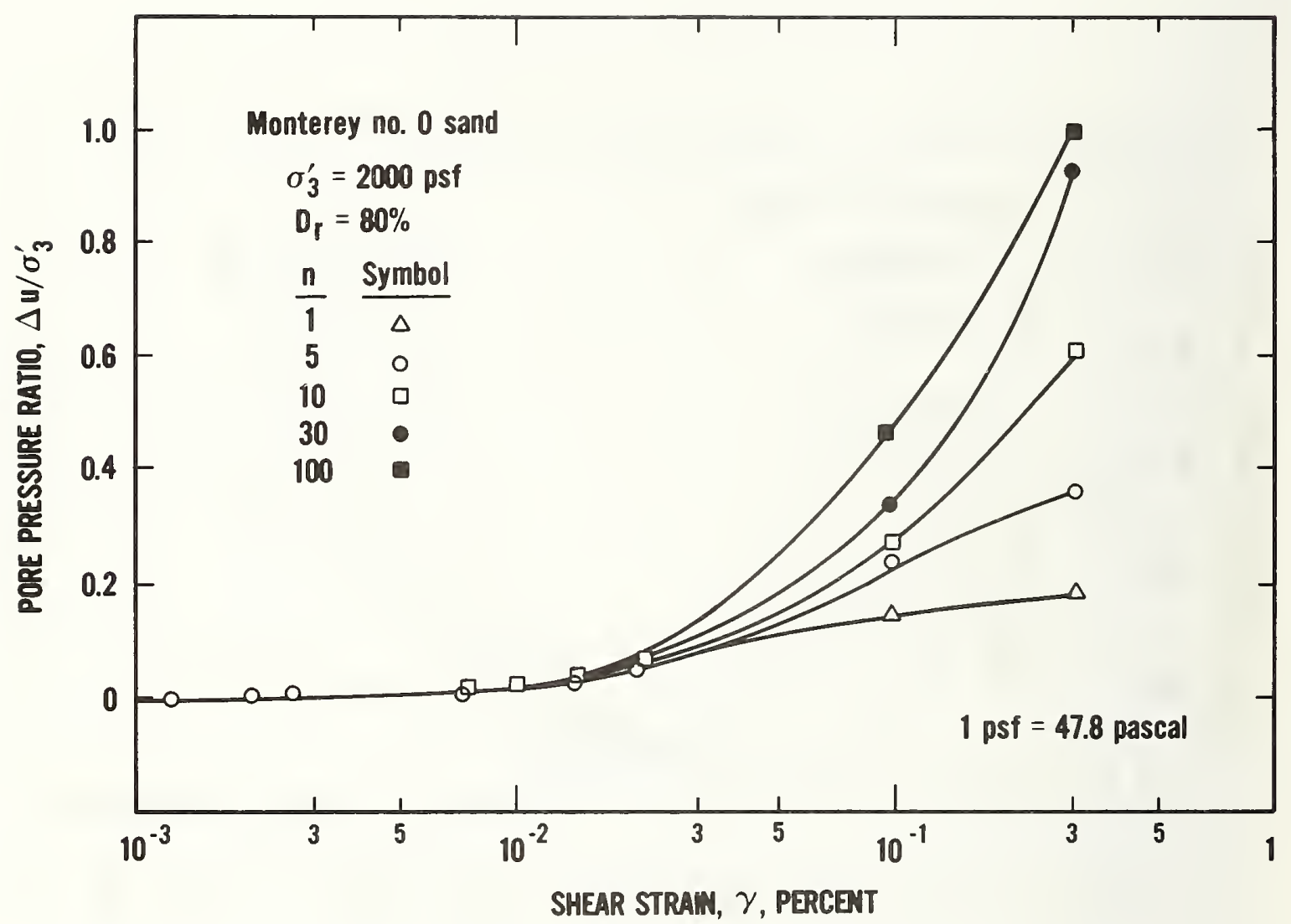

Figure 5.30 Pore water pressure buildup as a function of cyclic shear strain for Monterey No. 0 sand at $\mathrm{D}_{\mathrm{r}}=80$ percent, of $=2000$ psf and various numbers of cycles 


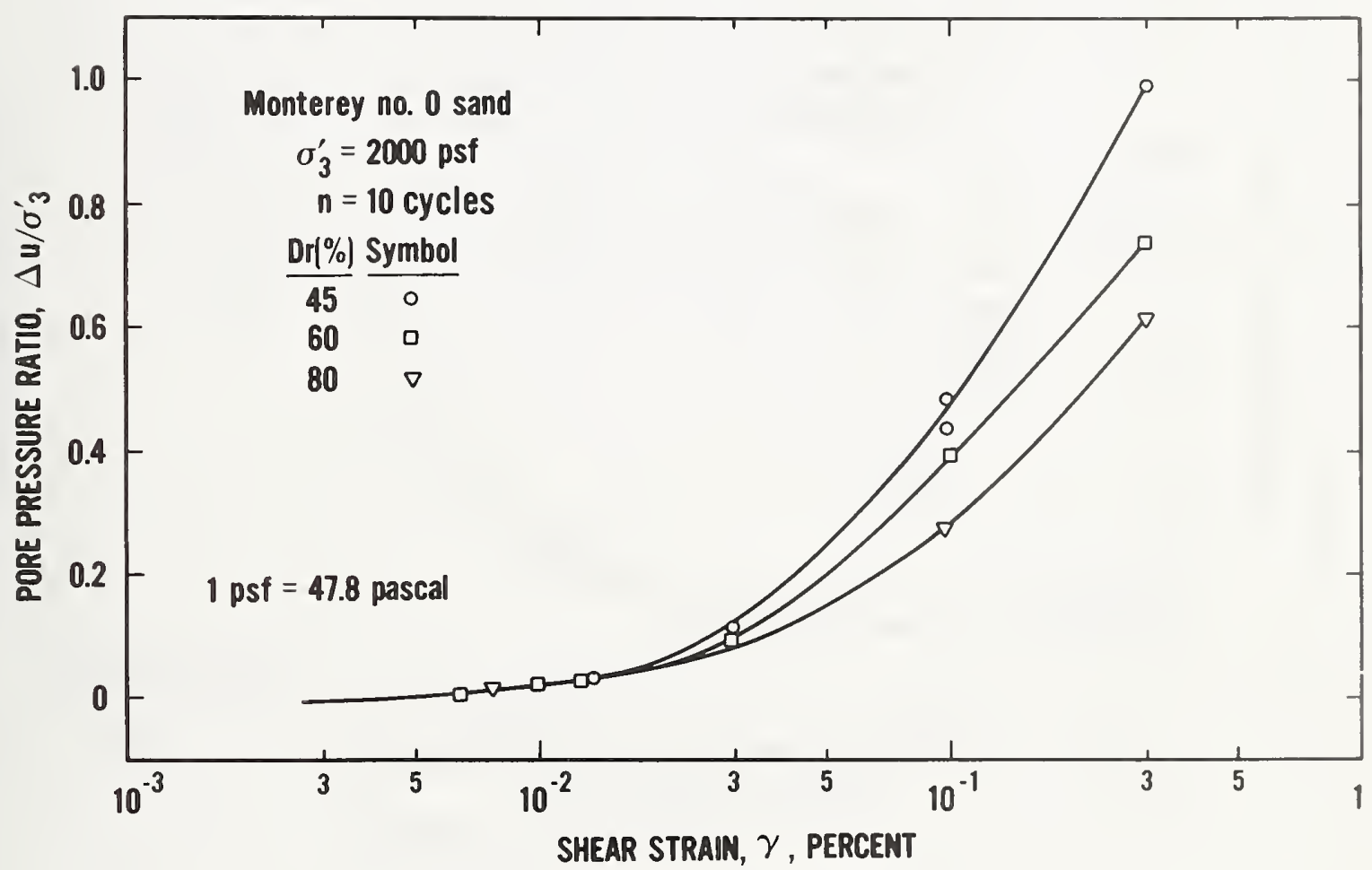

Figure 5.31 Pore water pressure buildup after ten loading cycles, as a function of cyclic shear strain for Monterey No. 0 sand at $\sigma\}=2000$ psf and $D_{r}=45,60$, and 80 percent 


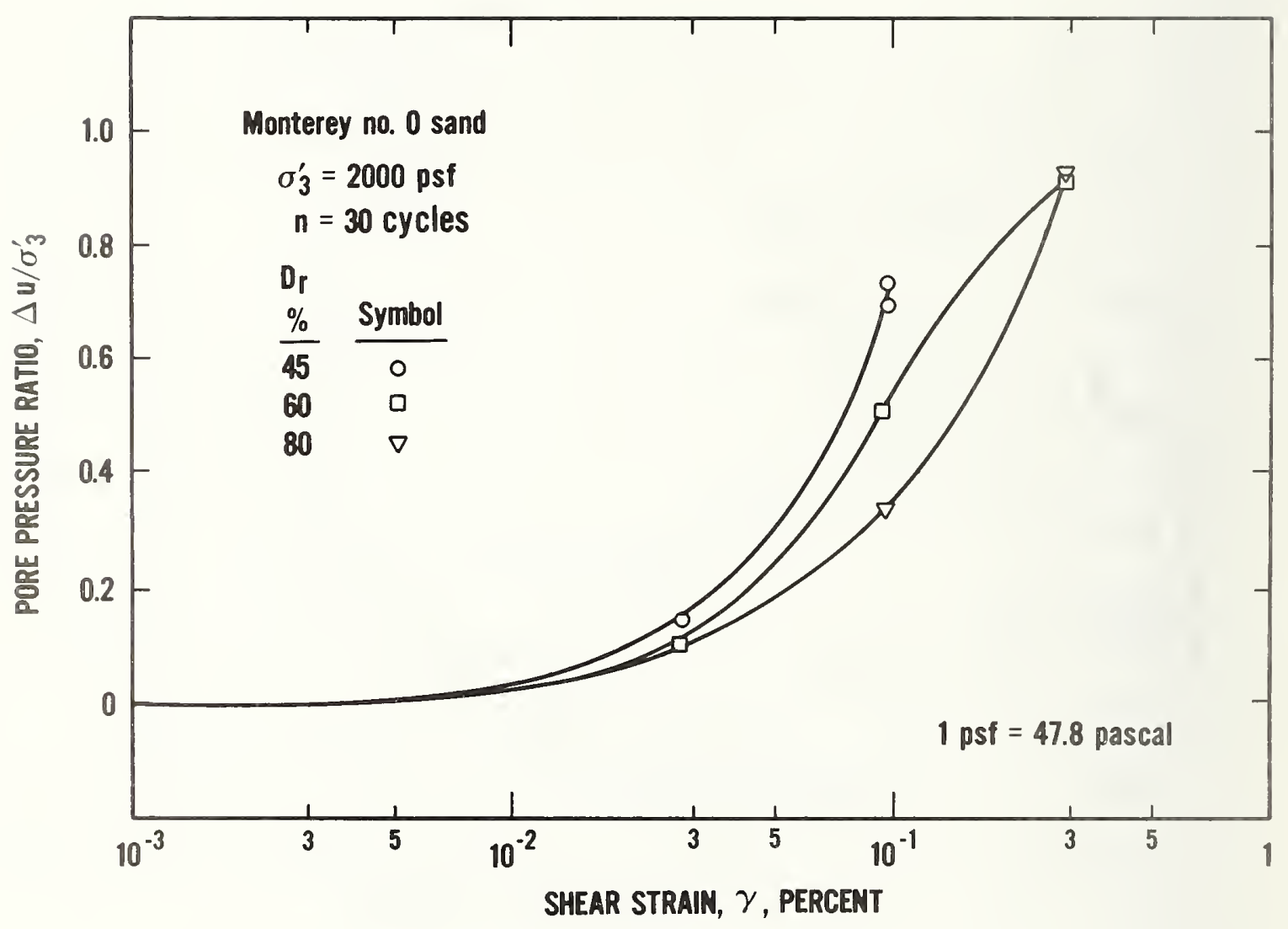

Figure 5.32 Pore water pressure buildup after thirty loading cycles, as a function of cyclic shear strain for Monterey No. 0 sand at $\sigma\}=2000$ psf and $D_{r}=45,60$, and 80 percent 


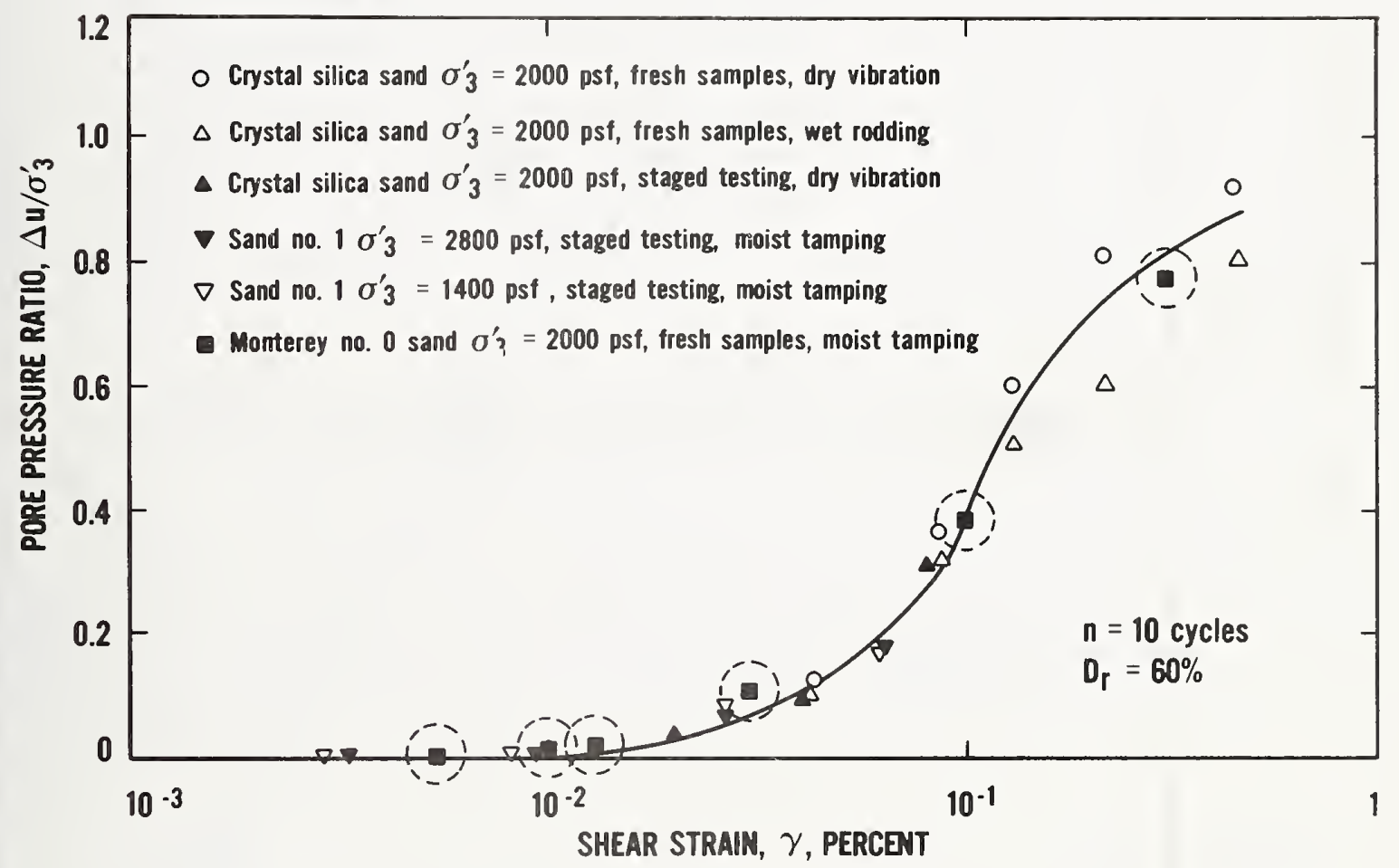

Figure 5.33 Pore water pressure buildup in cyclic triaxial strain-controlled tests after ten loading cycles, as a function of cyclic shear strain, for various NC saturated sands at $D_{r}=60$ percent and for various confining pressures 


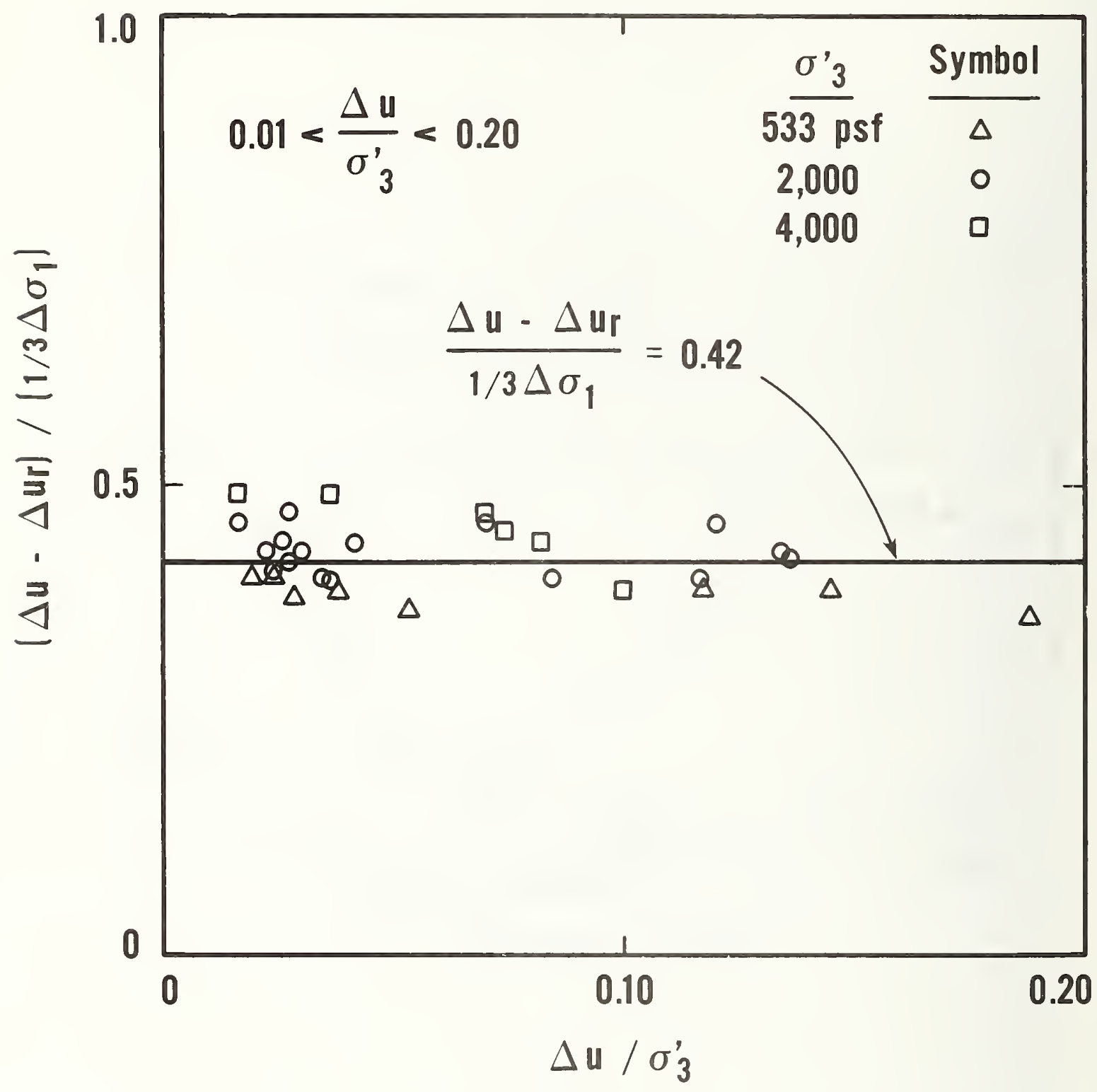

Figure 5.34 Comparison between $\Delta \mathrm{u}$ and $\Delta \mathrm{u}_{\mathrm{r}}$ as a function of pore water pressure ratio for Monterey No. 0 sand at $D_{r}=45,60$ and 80 percent and of $=533,2000$, and 4000 psf 


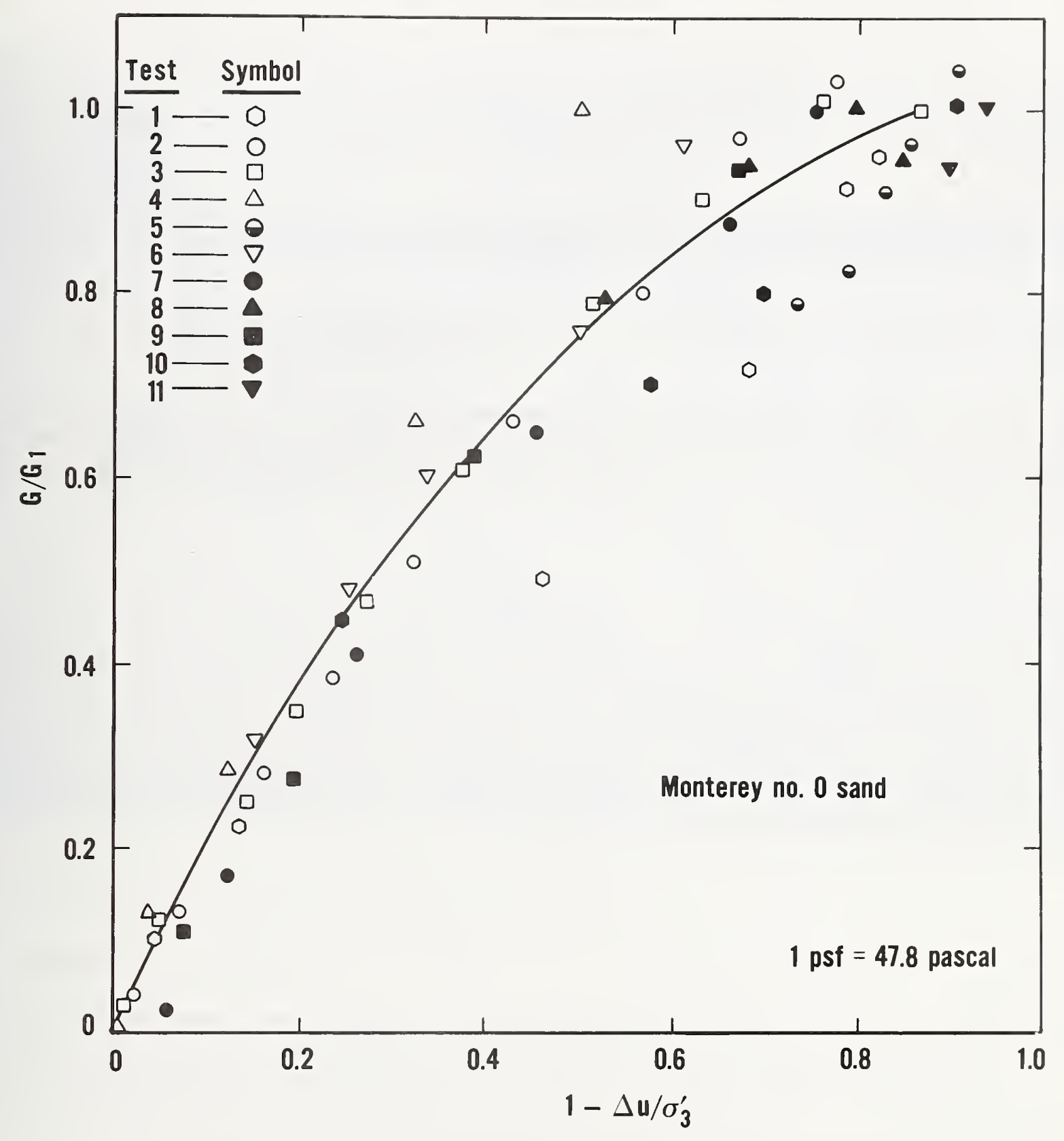

Figure 5.35 Degradation of shear modulus as a function of pore water pressure buildup for Monterey No. 0 sand at $\sigma\}=2000$ psf 
FACING PAGE: Landslide on the shore of Lake Merced induced by the liquefaction of loose saturated sand during the $1957 \mathrm{San}$ Francisco, CA, earthquake. 


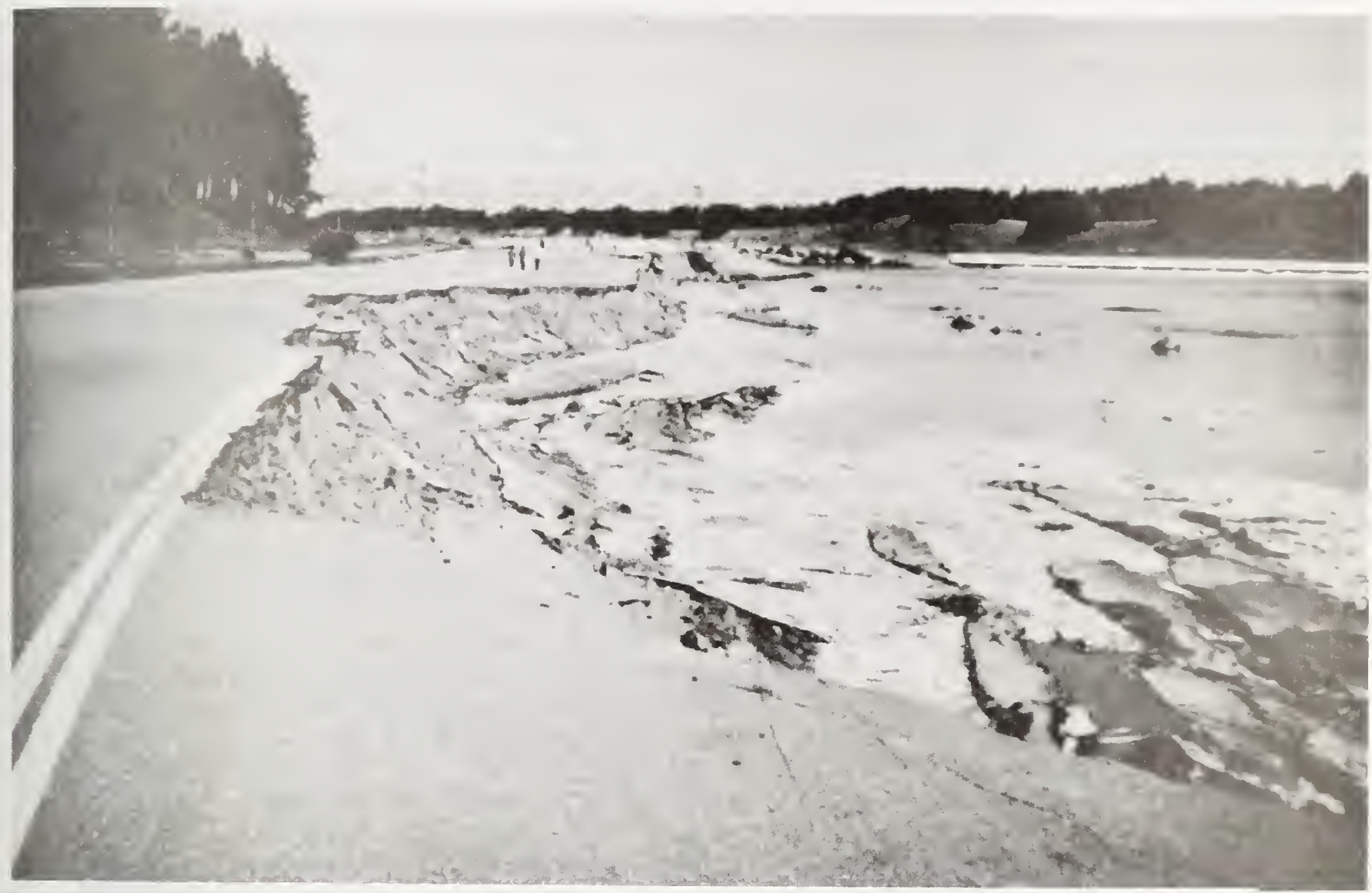

6. EARTHQUAKE ACCELERATION AND THRESHOLD STRAIN

\subsection{GENERAL}

Laboratory and analytical results have been presented, thus far, to support the use of a cyclic strain approach for predicting liquefaction potential. The basic equation of the proposed method is equation 3.5 as restated below:

$$
\gamma_{c}=0.65 \frac{a_{p}}{g} \frac{\sigma_{v} r_{d}}{G_{\max }\left(\frac{G}{G_{\max }}\right) \gamma_{c}}
$$

where the symbol $\sigma_{\mathrm{V}}$ is used instead of $\sigma_{\mathrm{o}}$ (used in section 3.2) to denote total vertical pressure. The rest of the symbols in equation 3.5 are the same as defined for equation 3.5 originally. 
Equation 3.5 can be used in principle to compute the equivalent seismic cyclic shear strain, $\gamma_{c}$, acting on a layer of sand located below the groundwater table. An element of this sand layer is sketched in figure 6.1. The soil is subjected to a peak ground surface horizontal acceleration, $a_{p}$, which induces the seismic strain $\gamma_{c}$ at depth $z$.

When using equation $3.5, a_{p}$ is assumed known, and $\sigma_{v}$ can be obtained from the unit weights of the layers between the ground surface and depth $\mathrm{z}$, if the depth to groundwater level, $z_{W}$, is also known. The value of $r_{d}$ can be obtained from a plot such as figure 3.4. The other two factors in equation 3.5 are $G_{\max }$ and $\left(G / G_{\max }\right) Y_{c}$. The shear modulus at small strains, $G_{\text {max }}$, can be measured in the field by means of geophysical techniques. The measuring in situ of $G_{\max }$ is one of the key aspects of the proposed cyclic strain method, and one of its main advantages. The main source of uncertainty in equation 3.5 is $\left(G / G_{\max }\right) \gamma_{c}$ which will be discussed in detail in the following paragraphs. ( $\left(G / G_{\max }\right) \gamma_{c}$ is a function or curve giving $G / G_{\max }$ once $\gamma_{c}$ is known. Typical measured curves of $\left(G / G_{\max }\right)$ versus $\gamma_{c}$ for sands are given in figure 6.2. Therefore, the determination of $\gamma_{c}$ using equation 3.5 will, in general, involve iterating.

Two different cases may arise when using equation 3.5 to compute $\gamma_{c}$ :

(a) The computed value is smaller than or about equal to the threshold strain, i.e., $\gamma_{c} \lesssim \gamma_{t} \simeq 10^{-2}$ percent $=10^{-4}$. This will occur for a "stiff" sand $\left(G_{\max } \mathrm{high}\right)$ and/or a small acceleration, $\mathrm{a}_{\mathrm{p}}$. In this case, the use of equation 3.5 is straightforward. At these small strains $\left(\gamma_{c} \lesssim 10^{-2}\right.$ percent), $\left(G / G_{\max }\right) \gamma_{c}$ is not far for unity (see $f i g .6 .2$ ) and $G_{\max }$ is a very reliable predictor of the secant shear modulus, $G$, at the strain $\gamma_{c}$. In addition, there is no pore water pressure buildup in the sand layer during shaking, and neither $G$ nor $\left(G / G_{\max }\right) \gamma_{c}$ change during cyclic loading. This is illustrated by the test results for $\gamma_{C}<10^{-2}$ in figures 5.3, 5.4, and 5.5 .

(b) The computed value is significantly larger than the threshold, i.e., $\gamma_{c}>\gamma_{t} \simeq 10^{-2}$ percent. This condition will occur for a "flexible" sand $\left(G_{\max }\right.$ low) and/or a large acceleration, $a_{p}$. In this case, the use of equation 3.5 involves additional uncertainties due to the increased uncertainty in the value of $\left(G / G_{\max }\right) \gamma_{c}$. One of the reasons for this is the reduction of $G / G_{\max }$ to values significantly less than unity at large strains (see fig. 6.2), with the corresponding increase in the uncertainty of the calculated $\left(G_{\max }\right) \gamma_{c}$. In other words $G_{\max }$ is a less reliable predictor of the secant modulus $G$, at large values of $\gamma_{C}$, than at small values of $\gamma_{c}$. A second source of uncertainty for $\left(G / G_{\max }\right) \gamma_{c}$ is that for $\gamma_{c}>\gamma_{t}$, there is a pore water pressure buildup, and due to that the values of $G$ and $\left(G / G_{\max }\right)$ \& are reduced with duration of cyclic loading (see results in figs. 5.3, 5.4, and 5.5). Both $G$ and $\left(G / G_{\max }\right) \gamma_{c}$ are now a function of the number of cycles, and hence, of the duration of shaking, thus, further complicating the use of equation 3.5 and adding to the uncertainty of the calculated $\gamma_{c}$. These problems, arising from the use of expressions such as equations 3.5 for strains above the threshold, have also been recently discussed by Seed (1980 [75]). 
The rest of this chapter focuses on case (a), and specifically on the conditions under which the seismic strain is equal to the threshold value, $\gamma_{c} \simeq \gamma_{t}$. Case (b) requires further research, and is not further discussed herein.

The available evidence for the existence and value of the threshold strain, $\gamma_{t}$, is discussed elsewhere in this report and includes experimental results reported by several authors, analytical results using a model of spheres in chapter 4 , and a very precise measurements of $\gamma_{t}$ in Monterey No. 0 sand presented in figures 5.18 and 5.19. All these results are remarkably consistent, and suggest that $\gamma_{t} \simeq 10^{-2}$ percent is a realistic estimate of the threshold for normally consolidated sands over a wide range of confining pressures and relative densities. For this reason, a value of $\gamma_{t}=10^{-2}$ percent $=10^{-4}$ will be used for the calculations in the rest of this chapter.

If the value $\gamma_{c}=\gamma_{t}=10^{-4}$ is placed in equation 3.5 , the peak ground surface acceleration which induces the threshold strain in the sand layer can be computed. We call this acceleration the "threshold peak ground surface acceleration" and label it " $\left(a_{p}\right)_{t}$ ":

$$
\frac{\left(a_{p}\right)_{t}}{g}=1.538 \times 10^{-4} \frac{G_{\max }\left(G / G_{\max }\right) \gamma_{t}}{\sigma_{v} r_{d}}
$$

If $\left(a_{p}\right)_{t}$ is measured in $g^{\prime} s$, equation 6.1 can be rewritten:

$$
\left(a_{p}\right)_{t}=1.538 \times 10^{-4} \frac{G_{\max }\left(G / G_{\max }\right) \gamma_{t}}{\sigma_{v} r_{d}} \quad\left(g^{\prime} s\right) \quad 6.2
$$

Throughout the rest of this chapter, equation 6.2 is used to compute $\left(a_{p}\right)_{t}$. Section 6.2 reviews available values of $G_{\max }$ for sands measured in the laboratory and in situ, and the modulus reduction curve, $\left(G / G_{\max }\right) \gamma$ versus $\gamma$, is discussed in section 6.3. In section 6.4, equation 6.2 is used as the basis for a parametric study of the value of $\left(a_{p}\right)_{t}$ for different sand stiffnesses and depths, as well as for different water table elevations in the field.

\subsection{THE MODULUS AT SMALL STRAINS, $\mathrm{G}_{\max }$}

\subsubsection{Laboratory Results}

Hardin and Drnevich (1972 [29]) performed an extensive study of $G_{\max }$ in the laboratory, using the resonant column technique, and they proposed the expression for $G_{\max }$ shown in equation 5.1, which was used in chapter 5 to evaluate the triaxial measurements of $G$ at small strains in Monterey No. 0 sand. Seed and Idriss (1970 [77]) modified equation 5.1, and suggested the use of the expression:

$$
G_{\max }=1,000 \mathrm{~K}_{2 \max }\left(\sigma_{\mathrm{m}}^{\prime}\right)^{1 / 2} \quad G_{\max }, \sigma_{m}^{\prime} \text { in psf }
$$


where $\sigma_{m}^{\prime}=\frac{1}{3}\left(\sigma_{1}^{\prime}+\sigma_{2}^{\prime}+\sigma_{3}^{\prime}\right)$ is the average effective normal stress, and $\mathrm{K}_{2 \max }$ is a function of the relative density of the sand, $\mathrm{D}_{\mathrm{r}}$. Equation 6.3 is certainly valid for isotropically consolidated sands, in which $\sigma_{\mathrm{m}}^{\prime}=\sigma \mid=$ $\sigma\}=\sigma\}$. There is also evidence suggesting its applicability to the case of anisotropically consolidated sands, and to sands subjected to a static compressive deviator stress in cyclic triaxial tests (Hardin and Black, 1968 [28]; Tatsuoka, et al., 1979 [85]).

Figure 6.3 shows the function $\mathrm{K}_{2 \max }$ versus $\mathrm{D}_{\mathrm{r}}$, proposed by Seed and Idriss. For a loose sand with a relative density, $D_{r} \simeq 30$ percent, $K_{2 \max } \approx 35$, and for a very dense sand with $D_{r} \simeq 90$ percent, $K_{2 \max } \approx 70$. Therefore, figure 6.3 predicts that, for a given state of stresses, $G_{\max }$ will approximately double for dense sand as compared with loose sand.

\subsubsection{In Situ Measurements}

Several geophysical (seismic) techniques have been used to measure $G_{\max }$ of soils in situ. In all these techniques, the shear wave velocity, $V_{S}$, at small strains is measured in the field and $G_{\max }$ is obtained from the expression:

$$
G_{\max }=\rho V_{S}^{2}
$$

where $\rho=$ mass density of soil layer = total unit weight/acceleration due to gravity. The geophysical techniques used for this purpose include the crosshole method, the downhole method, the refraction method and the Rayleigh wave method (Anderson and Espan̄a, 1978 [2]; Woods, 1978 [87]). Of these, the most reliable one is the crosshole technique sketched in figure 6.4. In this method, a vertically polarized shear wave impulse propagates horizontally, and the travel time of the impulse between drillholes is measured to compute $V_{S}$.

Powell (1979 [63]) performed a literature review of available in situ measurements of $G_{\max }$ in sands which had been obtained using these geophysical methods. As these measurements were made at depths varying between 10 and $130 \mathrm{ft}$ at sites having different groundwater elevations, the values of effective vertical overburden pressure, $\sigma_{v}^{\prime}$ and of average effective stress, $\sigma_{m}^{\prime}$ varied widely. It would have been useful to normalize these measured $G_{\max }$ values by means of equation 6.3 , thus, obtaining $K_{2 \max }$ :

$$
\mathrm{K}_{2 \max }=\frac{G_{\max }}{1,000\left(\sigma_{\mathrm{m}}^{\prime}\right)^{1 / 2}}
$$

In field conditions, $\sigma_{\mathrm{m}}^{\prime}=\frac{1}{3} \sigma_{\mathrm{v}}^{\prime}\left(1+2 \mathrm{~K}_{\mathrm{o}}\right)$; nevertheless, $\mathrm{K}_{\mathrm{o}}$ was generally not measured at those sites. Therefore, Powell normalized $G_{\max }$ by $\left(\sigma_{v}^{\prime}\right) 1 / 2$, as the value of $\sigma_{\dot{v}}^{\prime}$ could be easily estimated in all cases and a coefficient A was defined instead of $\mathrm{K}_{2 \max }$ :

$$
A=\frac{G_{\max }}{816.5\left(\sigma_{v}^{\prime}\right)^{1 / 2}}
$$


In equation 6.5 , both $G_{\max }$ and $\sigma_{v}^{\prime}$ are in psf and the units of $A$ are the same as these of $\mathrm{K}_{2 \text { max; }}$ i.e., $\left(1 \mathrm{~b}^{1 / 2} / \mathrm{ft}\right)$. The numerical coefficient 816.5 in equation 6.5 was selected so that, for $\mathrm{K}_{\mathrm{o}}=0.5, \sigma_{\mathrm{m}}^{\prime}=\left(\frac{1}{3}\right) \sigma_{\mathrm{v}}^{\prime}[1+(2)(0.5)]$, $\mathrm{A}=\mathrm{K}_{2 \max }$ and equations 6.4 and 6.5 become one and the same. A value of $\mathrm{K}_{0}=$ 0.5 is a reasonable estimate for normally consolidated, freshly deposited, noncompacted sand deposits.

Figure 6.5 shows the data compiled by Powe11, as a plot of A versus depth $\mathrm{z}$, for 10 sandy sites consisting of clean sand and silty sand deposits without gravel or clay. The values of A range from 35 to 240 with most of them between 35 and 150 .

It is interesting to compare the values of A from the field in figure 6.5 with the values of $\mathrm{K}_{2 \mathrm{max}}$ from the laboratory in figure 6.3. The lower bound of $A \simeq 35$, coincides well with the lower bound of $\mathrm{K}_{2 \mathrm{max}} \simeq 35$, corresponding to loose sands. This observation is reasonable, as it could be expected that the lower values of $G_{\max }$ (and of $A$ ) in the field should correspond to loose, normally consolidated sands having a low value of $\mathrm{K}_{\mathrm{O}}(\approx 0.5)$. On the other hand, the upper bound of the $A$ values in figure 6.5, which is at least 150 and may be as high as 240 , is much above the highest value, $\mathrm{K}_{2 \mathrm{max}}=70$ in figure 6.3. Therefore, while the laboratory results might suggest that, for a given state of stress, sands may have values of $G_{\max }$ differing by a factor of only about two, the field results suggest that this ratio may be as high as four or seven.

From the viewpoint of the proposed strain approach to liquefaction, this wide variation of the A value from field results is of great importance. A value of $A \simeq 35$ would define a "flexible" sand, while a value of $A \simeq 150$ or 200 would define a "very stiff" sand. The practical implications for liquefaction of a sand being "flexible" or "stiff" will be demonstrated in section 6.4. For the purpose of this study, a range of values of A between 35 and 150 is used.

The possible reasons for this discrepancy between the highest measured values of $\mathrm{K}_{2 \mathrm{max}}$ and $\mathrm{A}$ will now be examined.

One possibility for the discrepancy is that the actual range of $\mathrm{K}_{2 \mathrm{max}}$ for different sands is larger than the ratio of 2 suggested by figure 6.3. In fact, equation 6.3 and figure 6.3 are somewhat simplified versions of Hardin-Drnevich equation 5.1. $G_{\max }$ is really a function of the void ratio e, rather than a function of relative density, $D_{r}$. Therefore, different sands having different grain size distributions and silt contents, such as those summarized in figure 6.5, may have quite different values of $e$, and thus may, as a group, cover a wider range of $G_{\max }$ than that suggested by figure 6.3 .

Another possible explanation is that $\mathrm{K}_{0}>0.5$ in the field due to overconsolidation or other factors, in which case $A \neq K_{2 m a x}$. From equations 6.4 and 6.5 , the relation between $K_{2 \max }$ and $A$ for any value of $K_{0}$ is

$$
\frac{\mathrm{K}_{2 \max }}{\mathrm{A}}=\left(\frac{2}{1+2 \mathrm{~K}_{\mathrm{O}}}\right)^{1 / 2}
$$


For an overconsolidated sand, $\mathrm{K}_{0}$ is a function of the overconsolidation ratio, OCR. As shown by the typical data in figure 6.6 , for $\mathrm{OCR}=1, \mathrm{~K}_{\mathrm{O}} \simeq 0.4$, which is close to $K_{O}=0.5$ assumed here. For $O C R \simeq 7, K_{0} \simeq 1$, while for much large values of OCR, $K_{0}$ can even approach 1.6 or 1.8 . Equation 6.6 is plotted in figure 6.7 for the range of $K_{0}$ between 0.4 and 1.6 . It can be seen that for a sand with $\mathrm{OCR} \simeq 7$ and $\mathrm{K}_{0} \simeq 1, \mathrm{~K}_{2} \max \simeq 0.8 \mathrm{~A}$. Therefore, if some of the sands having $A \simeq 150$ in figure 6.3 were consolidated with $K_{0} \simeq 1, K_{2 \max } \simeq(0.8)(150)$ $=120$, and the factor between maximum and minimum $K_{2 m a x}$ in the field would be 3.4 instead of 4 obtained before.

The variation discussed above for the void ratio, e, and for $k_{0}$ of sands in the field may serve as a partial explanation of the difference in ranges between figures 6.3 and 6.5. However, they do not explain all the differences since other factors also seem to play an important role. These other factors, which have been shown to increase $G_{\max }$ of sands in the laboratory and yet were not considered, neither in the original Hardin-Drnevich equation (eq. 5.1) nor in the modified Seed-Idriss version (eq. 6.3), include: (i) seismic prestraining, and (ii) time under pressure.

The seismic prestraining effect was originally discussed by Drnevich and Richart (1970 [23]), when performing resonant column tests on dry sand. They found that a large number of cycles of high amplitude shear straining could cause a large increase in the value of $G_{\max }$ if the amplitude is above the threshold strain, $\gamma>\gamma_{t} \simeq 10^{-2}$ percent. The increase in $G_{\text {max }}$ was significant for a few thousands of cycles (an increase of about 30 percent) while for one million cycles $G_{\max }$ was increased by a factor of two or three. This large increase in $G_{\max }$ could not be explained by changes in void ratio, and was attributed by Drnevich and Richart to wear and stiffening of the contacts between the sand grains. Another possible explanation of the effect of prestraining in sand has been suggested by Youd (1977a [95]). In his hypothesis, cyclic straining produces changes in the packing of the sand by means of the collapse of the more unstable grain arrangements. These collapses have a negligible or small influence on the overall relative density or void ratio of the sand, but they do produce a more stable and stiffer structure or fabric of the soil. A large number of high amplitude oscillations of the soil may occur in situ because of man-made operations, e.g., compaction of sand with vibrating equipment, vibrations due to nearby operating machinery, traffic, etc., or in geologically old natural soil deposits located in active seismic areas.

The effect of time under pressure on $G_{\max }$ of soils has been studied systematically by Afifi and Richart (1973 [1]) and Anderson and Stokoe (1977 [3]). The test results discussed by these authors show that $G_{\max }$ increases with time of secondary consolidation in all soils. The increase for $G_{\max }$ in sands in the laboratory is typically of the order of one percent per log cycle of time after 1,000 minutes. An extrapolation of this rate of increase would suggest a significant increase in $G_{\max }$ for geologically old sand deposits. 


\subsection{THE MODULUS REDUCTION FACTOR, G/G}

The modulus reduction curve $\left(G / G_{\max }\right) \gamma$ versus cyclic shear strain, $\gamma$, is critical for the application of the proposed strain approach. Of special interest is the value of $\left(\mathrm{G} / \mathrm{G}_{\max }\right) \gamma_{t}$ at the threshold strain, $\gamma_{t}=10^{-2}$ percent. Hardin and Drnevich (1972 [29]) and Seed and Idriss (1970 [77]) discussed the curve of $\left(G / G_{\max }\right)_{\gamma}$ versus $\gamma$ for sands. After reviewing the experimental evidence ava11able at the time, Seed and Idriss proposed the curve shown in figure 6.2 , with an experimental band to take into account the scatter of the results. This band was previously shown in figure 4.8. Both the curve in figure 6.2 and the band in figure 4.8 are independent of the relative density of the sand and of confining pressure. At the threshold strain, $\gamma_{t} \simeq 10^{-2}$ percent, $\left(\mathrm{G} / \mathrm{G}_{\mathrm{max}}\right) \gamma_{\mathrm{t}} \approx 0.75$ with the band giving a dispersion range between 0.65 and 0.85 .

More recent results have confirmed these values reported by Seed and Idriss. Figure 6.2 includes a comparison of ( $G / G_{\max }$ ) curves obtained by different investigations, which was compiled and originally published by Iwasaki et al., (1978 [33]). At $\gamma_{t}=10^{-2}$ percent, ( $\left.G / G_{\max }\right) \gamma_{t}$ in figure 6.2 ranges from 0.75 to 0.90 . Figure 6.8 , which was also published by Iwasaki et al., (1978 [33]), includes results for 13 sands having different grain size distributions. The factor $B$ in the figure is a constant characteristic of each sand. Of special interest in figure 6.8 is the value of $\left(G / G_{\max }\right) \gamma_{t}$ for $\gamma_{t}=10^{-2}$ percent which is notably constant and equal to 0.75 for the 13 sands used. It should be noted that these 13 sands were tested by Iwasaki et al. in a dry state by a combination of the resonant column and torsional shear techniques, and for a confining prèssure of $2,000 \mathrm{psf}\left(\simeq 1 \mathrm{~kg} / \mathrm{cm}^{2}\right)$. Iwasaki et al. also performed tests at other confining pressures in the range from 550 to 4,000 psf and found similar results to those presented in figure 6.2. They noticed a tendency for $\left(G / G_{\max }\right) \gamma$ to increase with confining pressure; however, all $\left(G / G_{\max }\right) \gamma_{t}$ values were in the range from 0.70 to 0.85 . This influence of confining pressure on $\left(G / G_{\max }\right) \gamma_{t}$ is consistent with the discussion by Richart ( 1980 [66]) and with the results for Monterey No. 0 sand summarized in figure 5.10 .

The results discussed above strongly suggest that $\left(G / G_{\max }\right) \gamma_{t} \simeq 0.75$ for $\gamma_{t}=$ $10^{-2}$ percent, with an experimental scatter between about 0.65 and 0.85 . These numbers seem to be independent of relative density and to be generally representative for the range of confining pressures of practical interest. Tatsuoka et al. (1979 [85]) showed that these conclusions for $\left(G / G_{\max }\right) \gamma_{t}$ are valid for both isotropically $(K=1)$ and anisotropically consolidated in the range $0.33 \leqslant K$ \$1) sand specimens. Very recently, Canales (1980 [8]) presented results showing that, although $G_{\max }$ is strongly affected by prestraining, the curve $\left(G / G_{\max }\right) \gamma$ and the value $\left(G / G_{\max }\right) \gamma_{t}$ at the threshold are about the same before and after prestraining. With respect to the influence of time under pressure on $G / G_{\max }$, Anderson and Stokoe (1977 [3]) have suggested that $G / G_{\max }$ may increase somewhat due to this effect. Specifically, at the threshold, $\left(G / G_{\text {max }}\right) \gamma_{t}$ may increase from about 0.75 without the time effect, to 0.80 or 0.90 after long time under pressure.

For the purposes of this study, a representative value of $\left(G / G_{\max }\right) \gamma_{t}=0.75$ is adopted for sands at $\gamma_{t}=10^{-2}$ percent, with lower and upper bounds of 0.65 and 0.85 , respectively. 


\subsection{PARAMETRIC STUDY}

This section presents the results of a parametric study of the threshold peak surface acceleration, $\left(a_{p}\right)_{t}$, based on equation 6.2 and on the results discussed in sections 6.2 and 6.3 . For simplicity, in equation $6.2, G_{\max }$ is replaced by $A$ as defined by equation 6.5, and a total unit weight $=1151 \mathrm{~b} / \mathrm{ft}^{3}$ is assumed for the soil both above and below the groundwater table. For the field condition sketched in figure $6.1, \sigma_{\mathrm{v}}=115 \mathrm{z}\left(1 \mathrm{~b} / \mathrm{ft}^{2}\right)$, and $\sigma_{\mathrm{v}}^{\mathrm{i}}=115 \mathrm{z}_{\mathrm{w}}+(115-62.4)$ $\left(z-z_{W}\right)$. Finally, and for $\left(G / G_{\max }\right) \gamma_{t}=0.75$, equation 6.2 becomes

$$
\frac{\left(a_{p}\right)_{t}}{A}=8.2 \times 10^{-4} \frac{\left(62.4 z_{w}+52.6 z\right)^{1 / 2}}{z r_{d}} \quad\left(a_{p}\right)_{t} \text { in } g^{\prime} s
$$

Equation 6.7 was used for the parametric study. In the calculations, the following values of $r_{d}$, obtained from figure 3.4 were used.

$\begin{array}{ll}\underline{z} \text { (feet) } & \underline{\mathrm{r}_{\mathrm{d}}} \\ 10 & 0.98 \\ 20 & 0.96 \\ 30 & 0.92\end{array}$

The calculations were performed for values of $z$ below the water table, $z>z_{W}$. Equation 6.7 has been plotted in figure 6.9 as a function of $z_{W}$ and for depths $z=10,20$, and 30 feet, which covers the range of depths where liquefaction most frequently occurs.

Equation 6.7 is also plotted as $\left(a_{p}\right)_{t}$ versus $z_{W}$ in figure 6.10 for the depth, $z=20 \mathrm{ft}$ and for $A=35,100$, and 150 .

Figures 6.9 and 6.10 clearly show the influence of the parameters $z, z_{W}$, and $A$ in determining the value of $\left(a_{p}\right)_{t}$. In figure 6.9 , for the same stiffness, $A$, there is a large decrease in $\left(a_{p}\right)_{t}$ between $z=10 \mathrm{ft}$ and $z=20 \mathrm{ft}$ while the decrease is much smaller from 20 to $30 \mathrm{ft}$. As expected, $\left(a_{p}\right)_{t}$ increases when the depth to groundwater, $z_{W}$, increases.

The effect of the stiffness parameter, $A$, on $\left(a_{p}\right)_{t}$ is very dramatic. As $\left(a_{p}\right)_{t}$ is directly proportional to $A$, the value of ( $\left.a_{p}\right)_{t}$ should more than quadruple when going from a "flexible" $(A=35)$ sand to a "stiff" $(A=150)$ sand, other conditions being equal. This is illustrated by figure 6.10. In a sand layer having a measured $A=35$ and located at $20 \mathrm{ft}$, and for shallow groundwater, $z_{w}=0$, the threshold is $\left(a_{p}\right)_{t} \simeq 0.05 \mathrm{~g}$. If the sand is very stiff with $A=150$, then $\left(a_{p}\right)_{t} \simeq 0.21 g$. This difference is very significant since a peak surface ground acceleration of $0.20 \mathrm{~g}$ is quite strong and can even be higher than the design acceleration in many low selsmicity areas. As shown by figure 6.10, for $z=20 \mathrm{ft},\left(a_{p}\right)_{t}$ can be substantially larger than $0.20 \mathrm{~g}$ if $A>150$ and/or the groundwater is located at some depth. 
For an example of application using figures 6.9 and 6.10 , let us assume that we have two adjacent soll profiles, both with the groundwater level at $z_{\mathrm{W}}=10 \mathrm{ft}$ and potentially liquefiable sand layers at $z=20 \mathrm{ft}$. The design surface acceleration is also the same, $a_{p}=0.15 \mathrm{~g}$ which corresponds to a magnitude 8 (long duration) earthquake. In site 1 , the sand layer has a value of $A=35$, measured using the crosshole technique. Therefore, $\left(a_{p}\right)_{t} \simeq 0.06 \mathrm{~g}$ and this layer wil1 most probably 1iquefy. In site 2, the sand layer has a measured $A=150$. Therefore, $\left(a_{p}\right)_{t}=0.26 \mathrm{~g}$. The sand layer in site 2 will not even start developing an excess pore water pressure, let alone liquefy during the design earthquake.

Figures 6.9 and 6.10 also suggest that sand deposits will not liquefy for peak ground accelerations less than about $0.05 \mathrm{~g}$, even for the worst soil conditions, shallow water table, and for large earthquake magnitudes causing the longest durations of shaking. Seed et al., (1975 [81]) compiled a list of thirty-eight 1iquefaction case histories. According to that 11st, the smallest value of $a_{p}$ to cause liquefaction is $0.08 \mathrm{~g}$ wich occurred during the 1933 Tohnanka1 earthquake in Japan, which had a magnitude 8.3 and a long duration of shaking. Based on a review of about 100 liquefaction fallures in Japan during the last century, Kuribayashi and Tatsuoka (1975 [42]) concluded that the minimum intensity in the Japanese Intensity Scale, JMA for which liquefaction has occurred is five, which corresponds to a range of peak acceleration between $0.08 \mathrm{~g}$ and $0.25 \mathrm{~g}$. Finally, 1iquefaction is usually associated with earthquakes having Modified Mercalli Intensities MMI of VI or larger. The MMI of VI corresponds approximately to a ground acceleration of $0.05 \mathrm{~g}$. Therefore, the avallable evidence indicates that the results of the parametric study present herein are generally consistent with reported cases of liquefaction during earthquakes.

In order to evaluate the uncertainty in $\left(a_{p}\right)_{t}$ introduced by the scatter of values of $r_{d}$ and $\left(G / G_{\max }\right) \gamma_{t}$, the chart of figure 6.10 was recalculated to obtain lower bound and upper bound curves, as follows.

$\begin{array}{lccc} & \frac{r_{d}}{0.98} & \frac{\left(G / G_{\max }\right) \gamma_{t}}{0.65} \\ \text { Lower Bound Curve } & 0.96 & 0.75 \\ \text { Average Curve (figure 6.10) } & 0.94 & 0.85\end{array}$

The corresponding values of $\left(a_{p}\right)_{t}$, calculated using modified versions of equation 6.7, are plotted in figure 6.11 for $z=20 \mathrm{ft}$, and for $A=35$ and $A=$ 150. Although the numerical values of $\left(a_{p}\right)_{t}$ change somewhat when the variations in $r_{d}$ and $\left(G / G_{\max }\right) \gamma_{t}$ are considered, the main conclusions reached above on the influence of stiffness on $\left(a_{p}\right)_{t}$ do not change. For $z_{W}=0$, if $A=35$, $\left(a_{p}\right)_{t}$ varies between 0.04 and $0.06 \mathrm{~g}$, while if $A=150,\left(a_{p}\right)_{t}$ varies between $0.18 \mathrm{~g}$ and $0.24 \mathrm{~g}$. For the example of sites 1 and 2 discussed above, with $z_{W}=$ $10 \mathrm{ft}$ and $z=20 \mathrm{ft}$, the ranges of $\left(a_{\mathrm{p}}\right)_{\mathrm{t}}$ are 0.05 to $0.07 \mathrm{~g}$ and 0.22 to $0.30 \mathrm{~g}$ for sites 1 and 2, respectively. Therefore, for a design acceleration of $0.15 \mathrm{~g}$ and a long duration earthquake, site 1 may 1 iquefy and site 2 will not, as concluded previously using average values of $r_{d}$ and $\left(G / G_{\max }\right) \gamma_{t}$. 


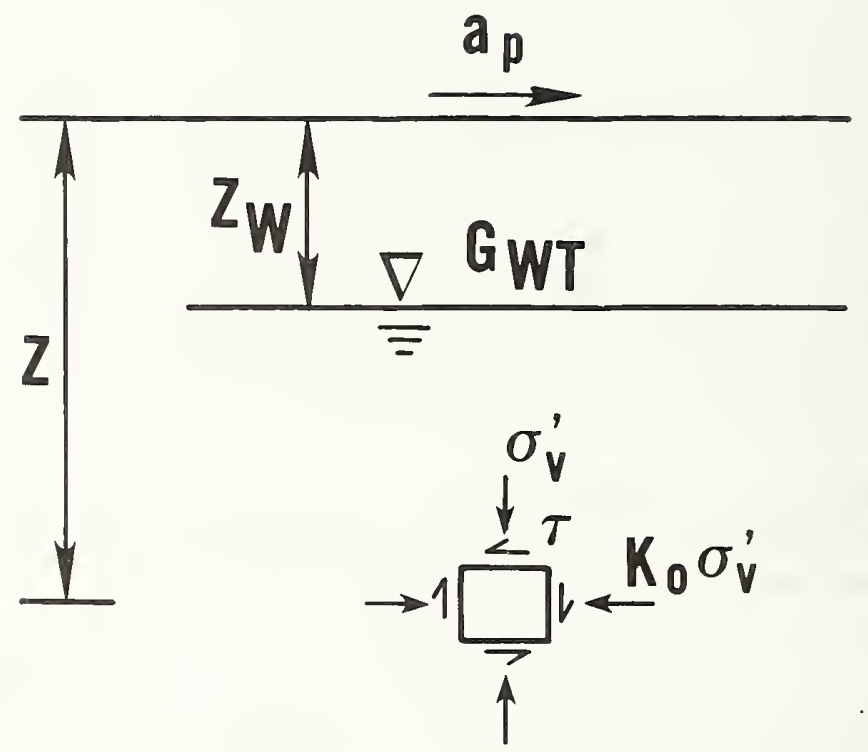

Figure 6.1 Simplified soil profile 


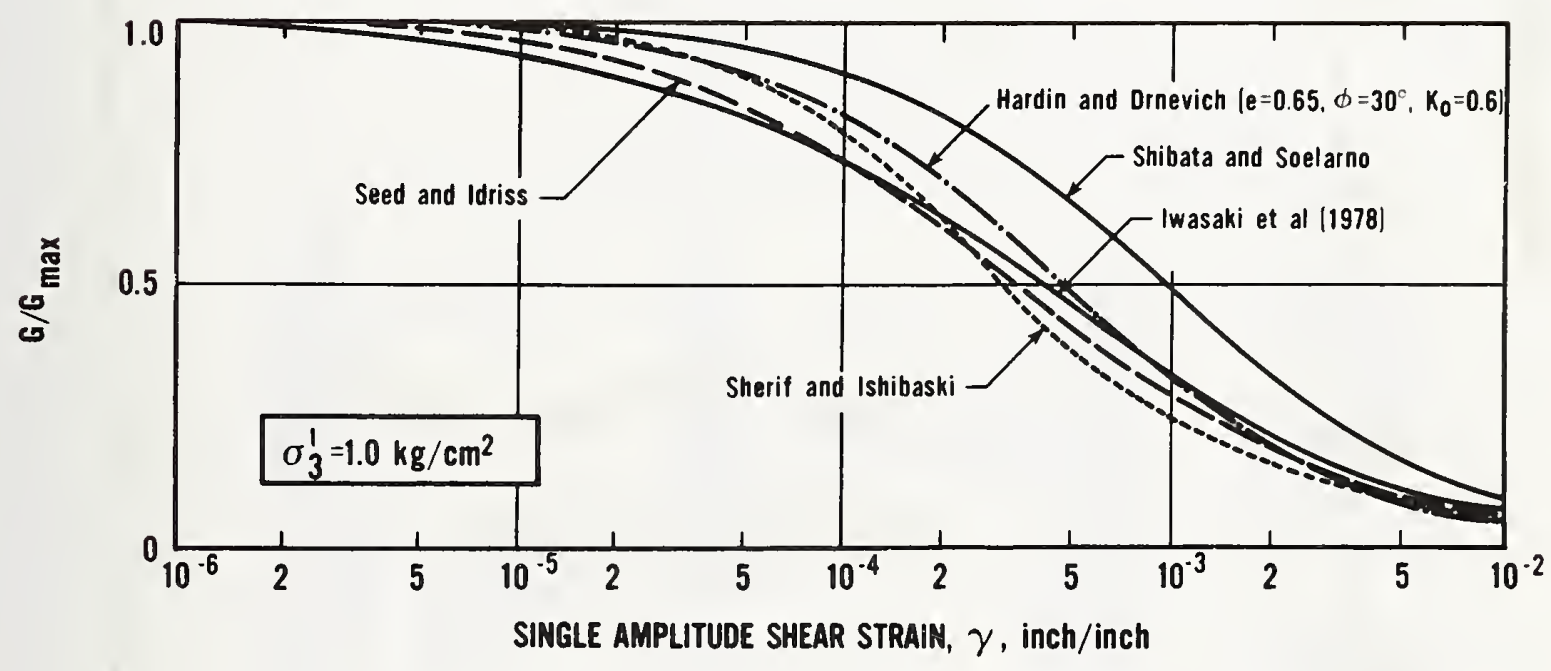

Figure 6.2 Modulus reduction curves for sands (Iwasaki et al., 1978) 


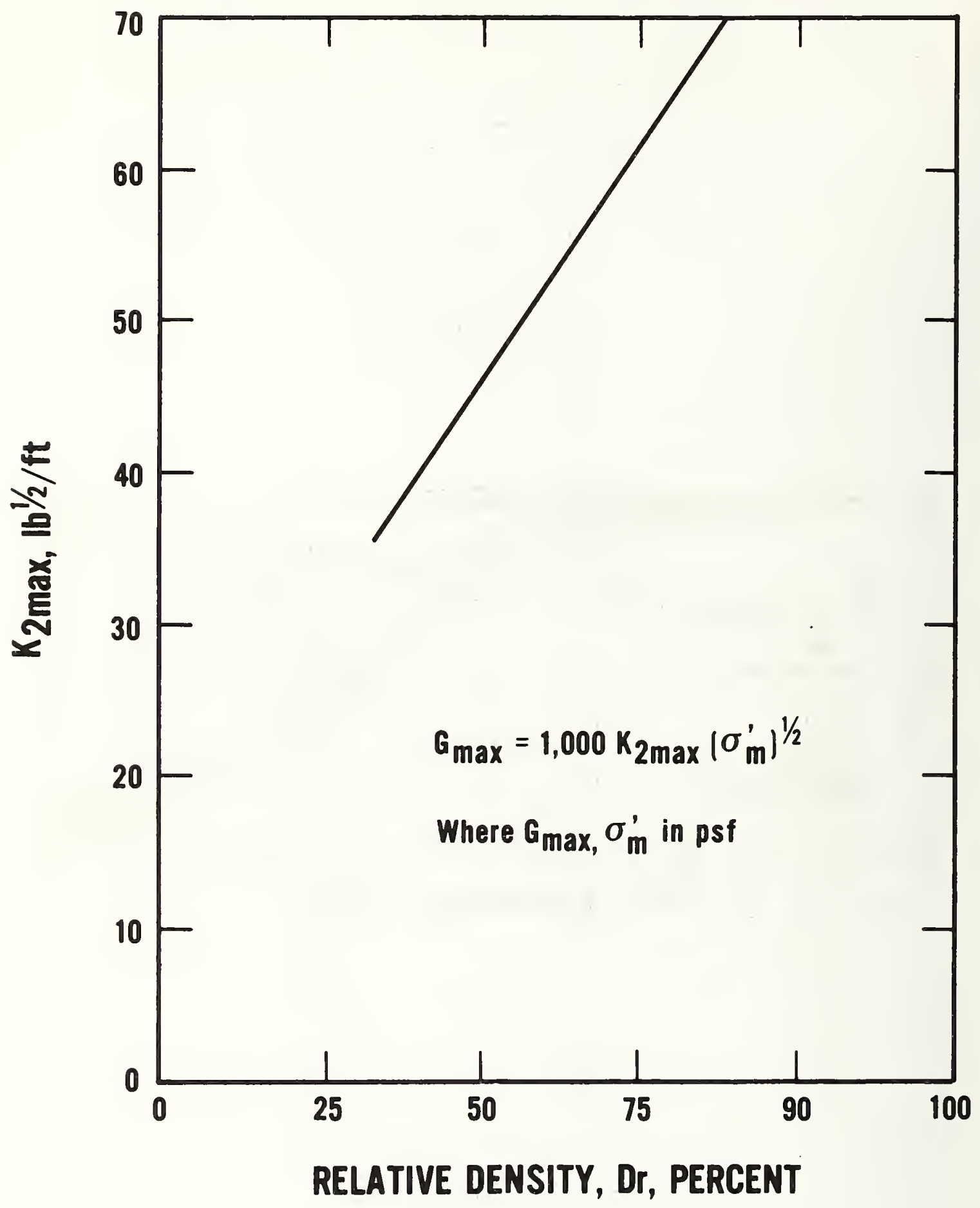

Figure 6.3 Relation between normalized stiffness parameter, $\mathrm{K}_{2 \max }$, and relative density (modified from Seed and Idriss, 1970) 
Receiver Boreholes

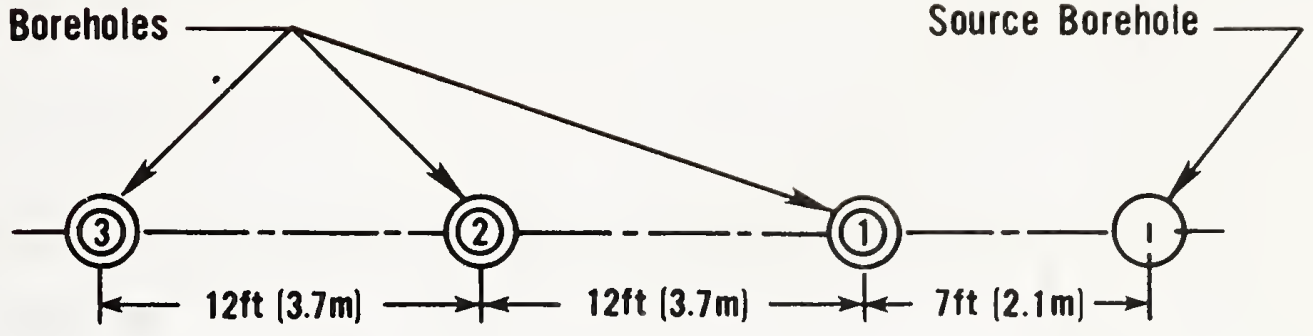

\section{a.-PLAN VIEW}

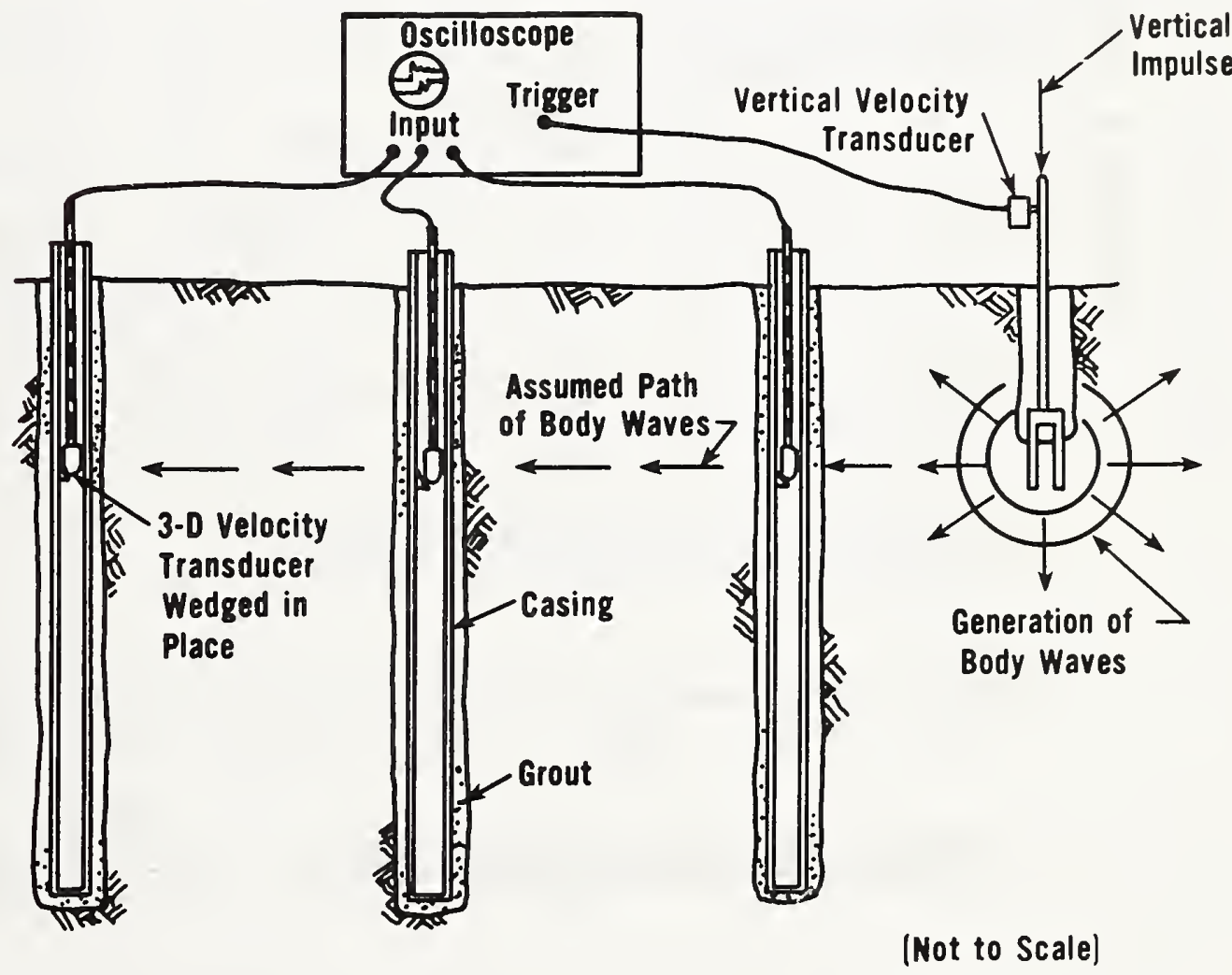

b.-CROSS-SECTIONAL VIEW

Figure 6.4 Crosshole geophysical method (Hoar and Stokoe, 1977) 


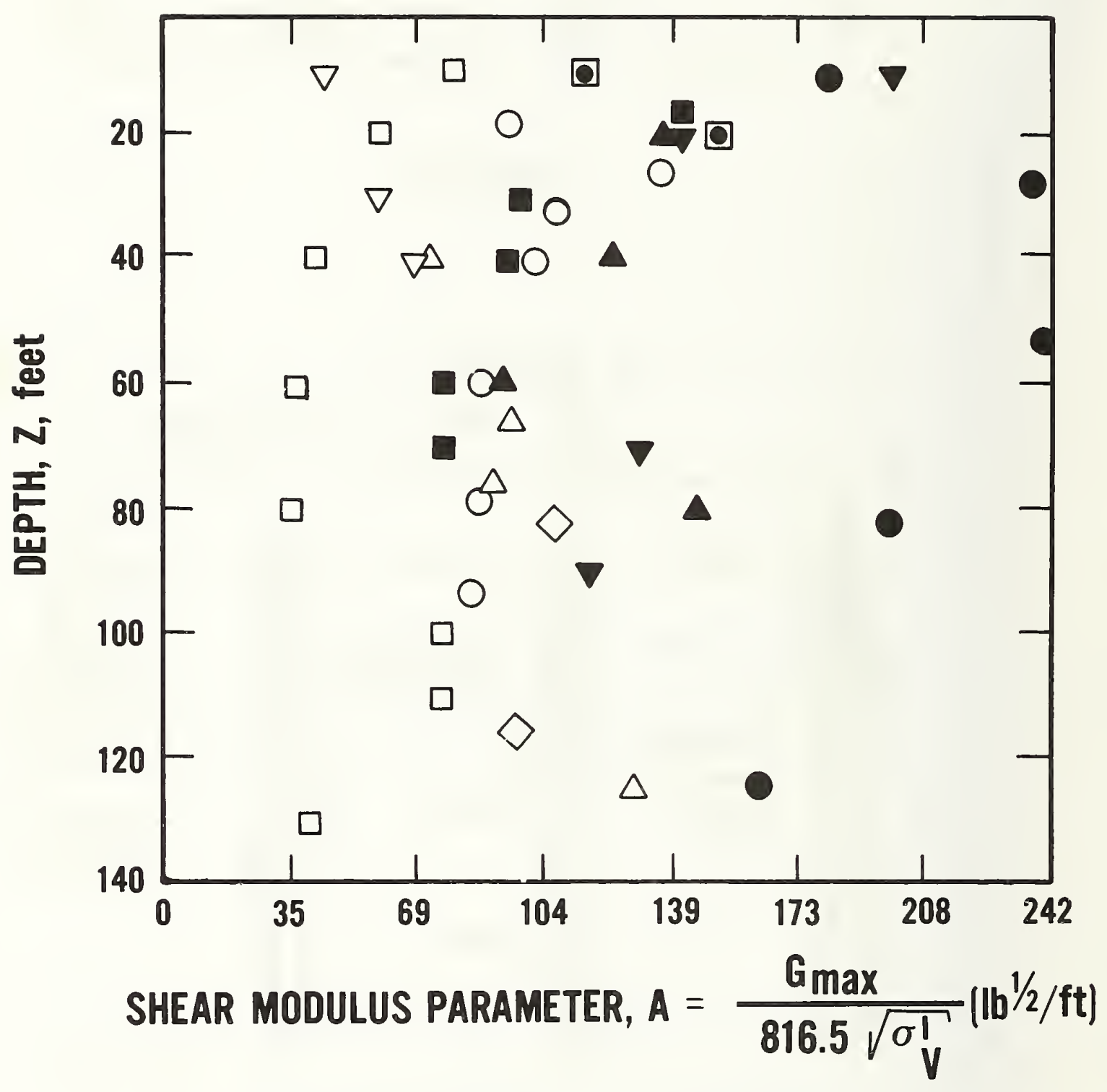

Figure 6.5 Normalized shear modulus parameter, A, measured for sands in the field using geophysical techniques (Powell, 1979) 


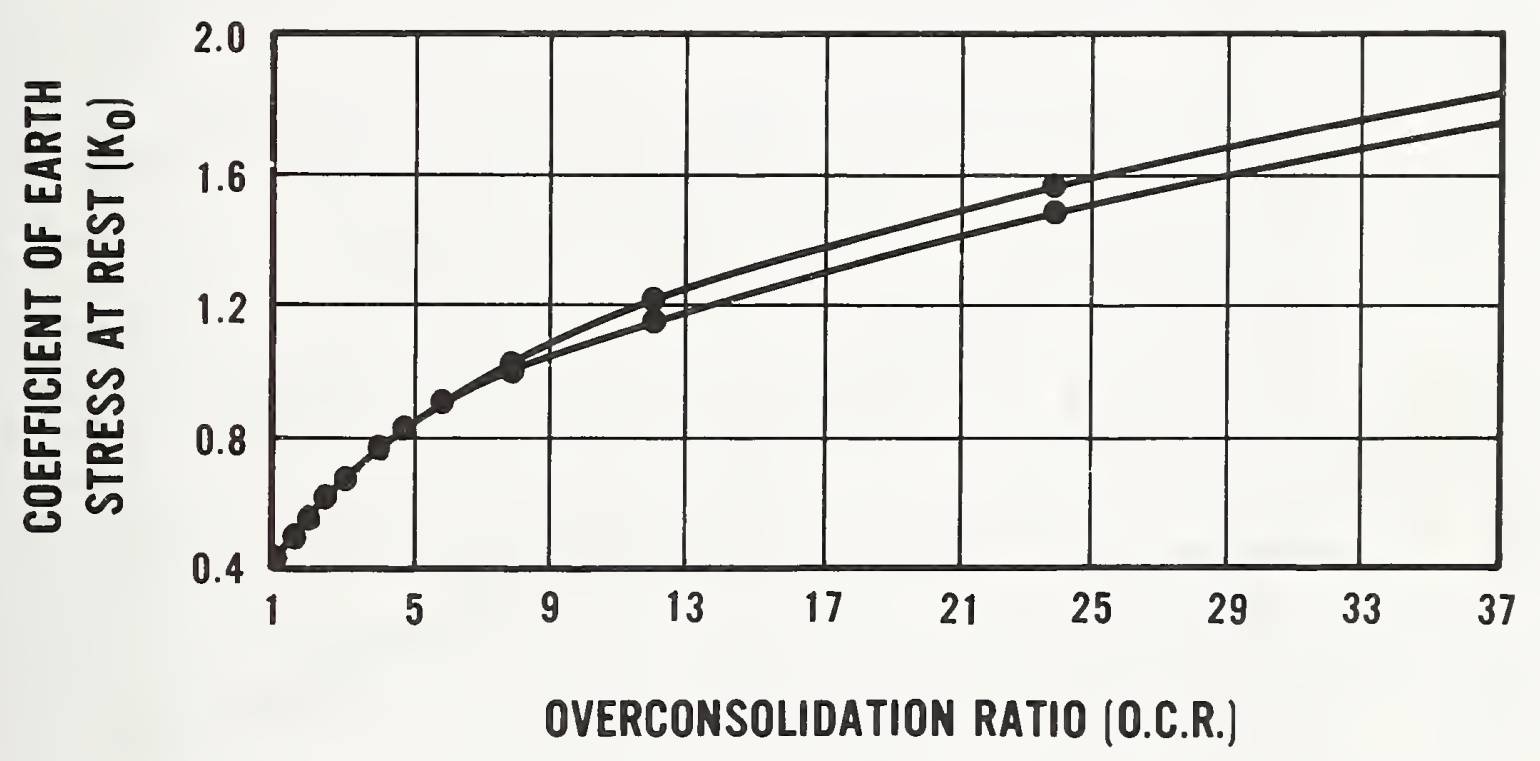

Figure 6.6 Coefficient of earth pressure at rest, $\mathrm{K}_{\mathrm{O}}$, as a function of overconsolidation ratio, OCR (Hendron, 1963) 


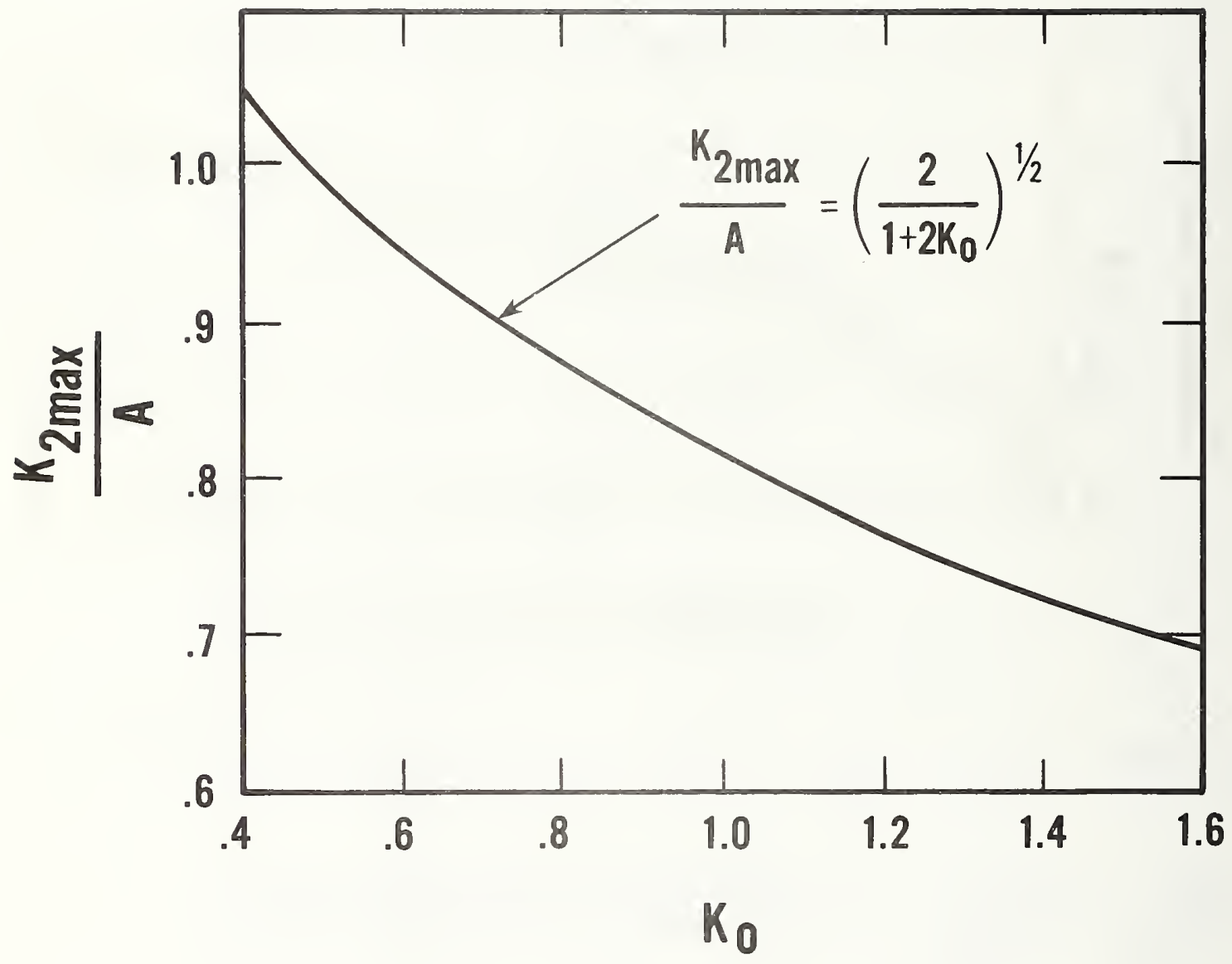

Figure 6.7 Influence of the coefficient of earth pressure at rest, $K_{0}$, on the normalized shear modulus parameter, A 


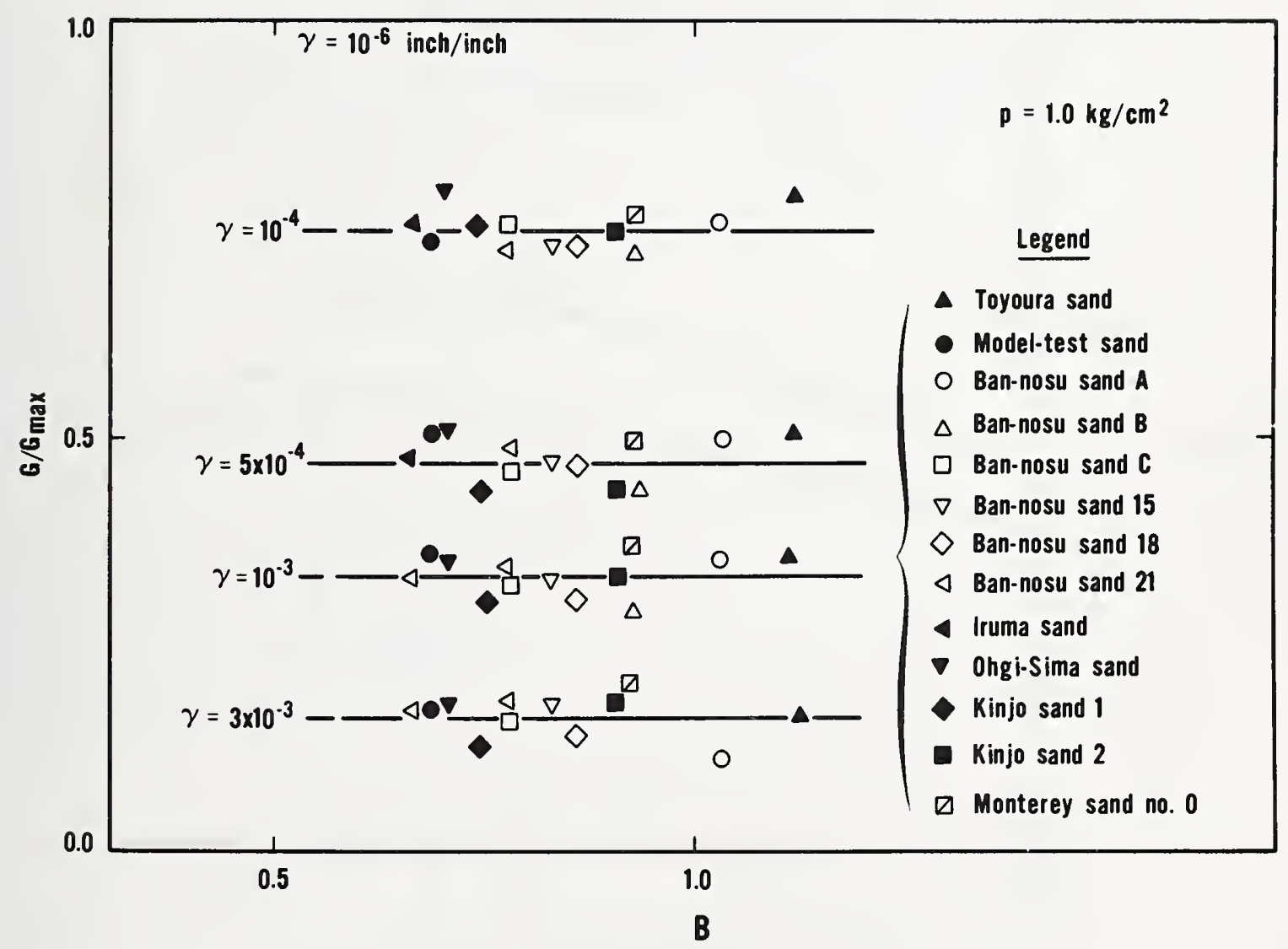

Figure 6.8 Reduction of shear modulus at different cyclic shear strains, $\gamma$, for sands (data from Iwasaki et al., 1978; B is a coefficient characteristic of each sand tested) 


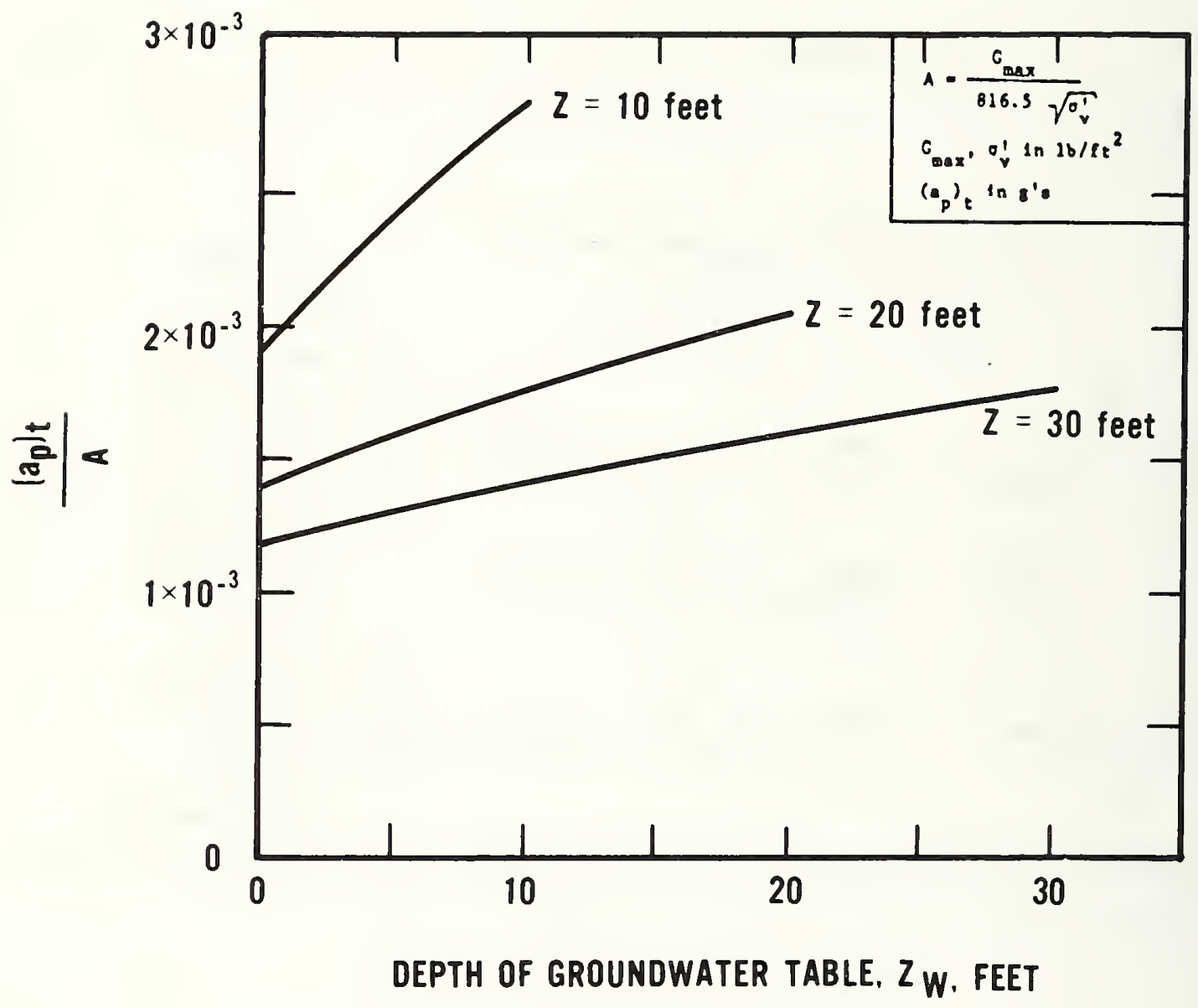

Figure 6.9 Liquefaction chart for threshold peak ground surface acceleration, $\left(a_{p}\right)_{t}$ 


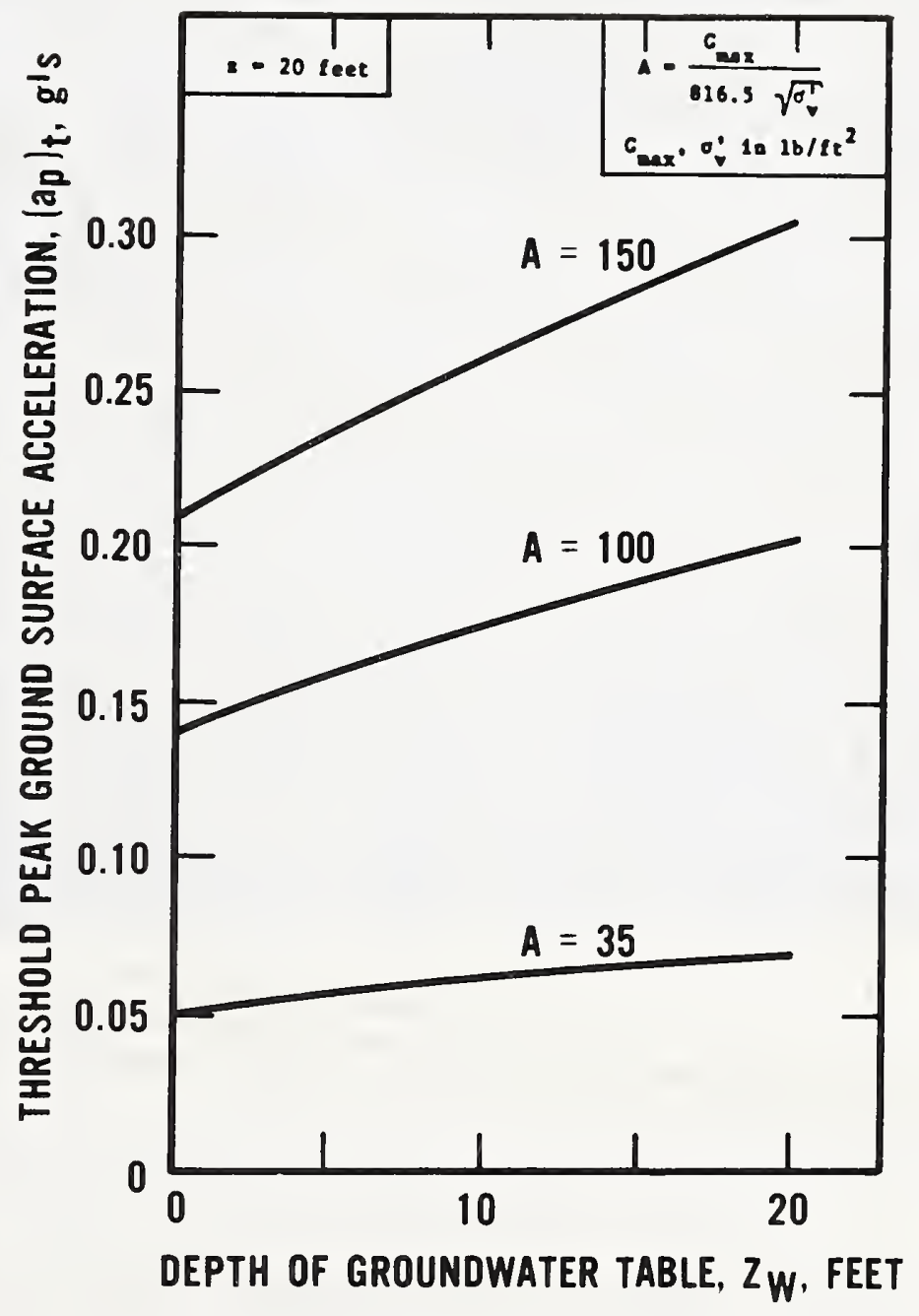

Figure 6.10 Liquefaction chart for threshold peak ground surface acceleration $\left(a_{p}\right)_{t}$, at $z=20$ feet 
FACING PAGE: Sand boils in rice field near old Kitakami River. The sand boils were caused by liquefaction during the Miyagi-ken-oki, Japan, June 12, 1978, earthquake.

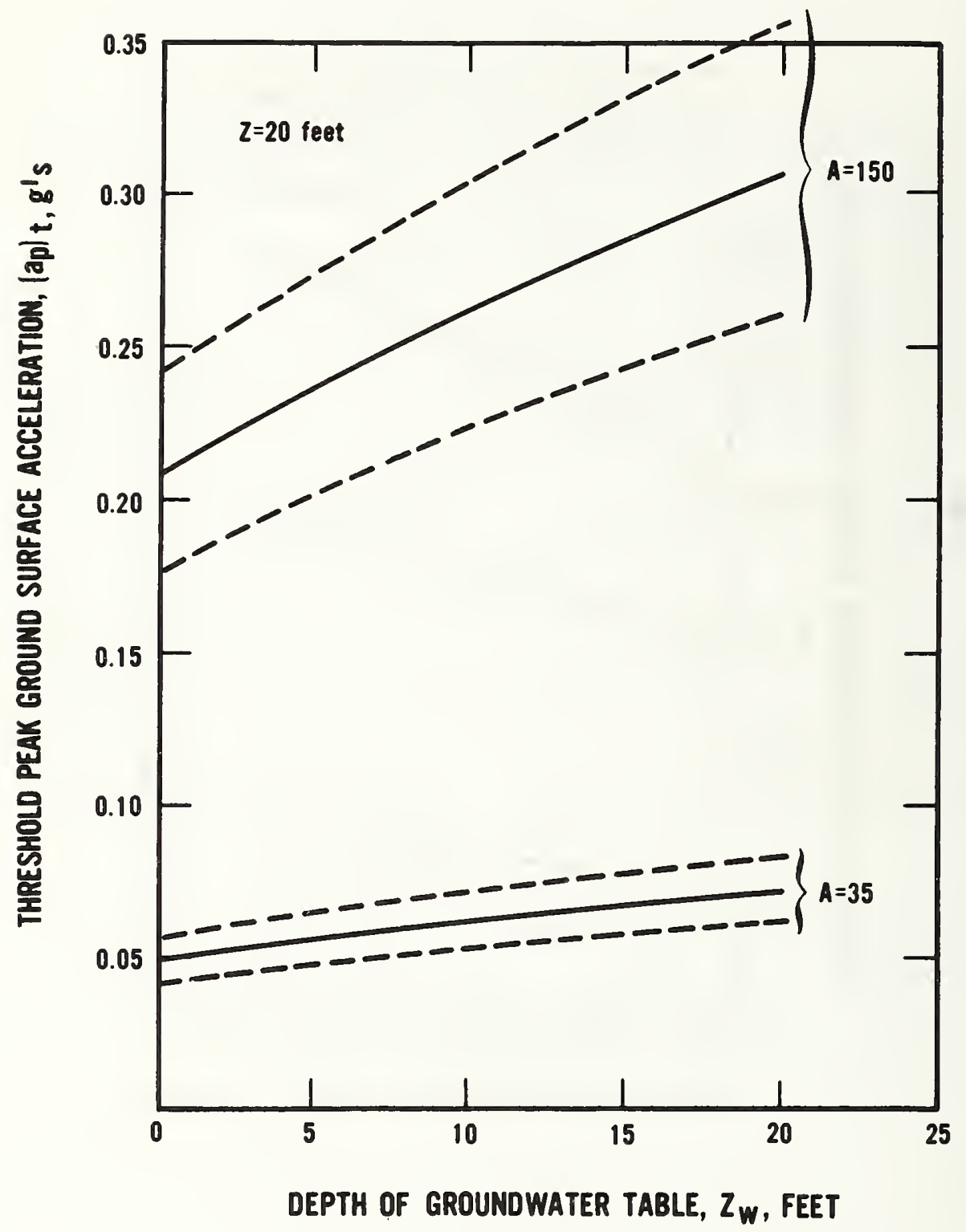

Figure 6.11 Lower and upper values of $\left(a_{p}\right)_{t}$ to account for scatter in $\left(G / G_{\max }\right) \gamma_{t}$ and $r_{d}$ at $z=20 \mathrm{ft}$ 


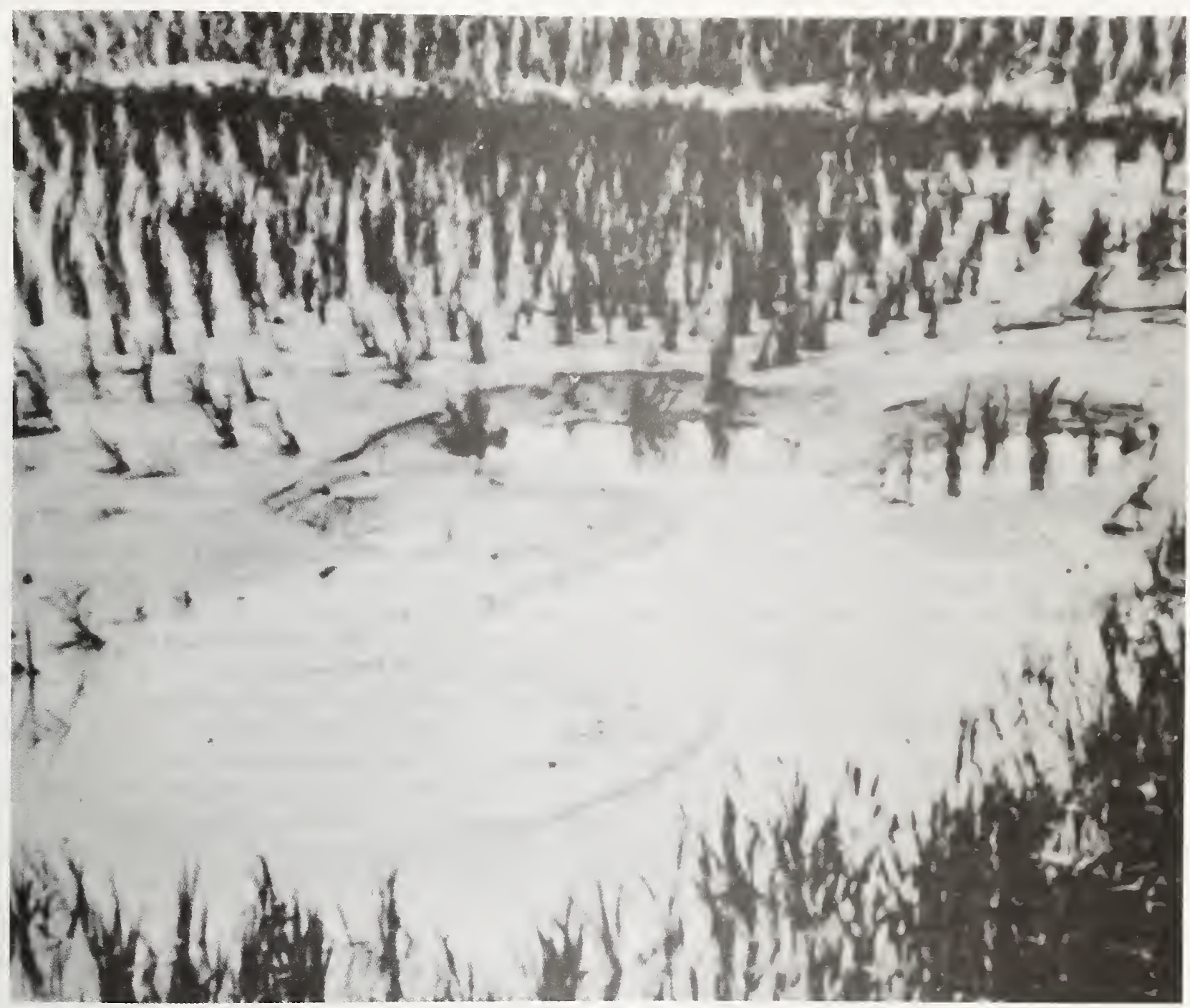

\section{SUMMARY AND FINDINGS}

We have reached the following conclusions from the work presented in this report, on methods for predicting pore pressure buildup and liquefaction potential of saturated sands at level sites during earthquake:

1) Data from cyclic stress-controlled tests on sands accumulated in the last few years demonstrate that a number of factors besides relative density influence the value of the cyclic strength. These factors include fabric, overconsolidation, prior seismic straining and time under pressure. The findings raise serious doubts about the present practice of using stresscontrolled cyclic tests on disturbed samples reconstituted to the estimated field density. 
2) Cyclic test results have demonstrated that there is a predictable correlation between cyclic shear strain and the pore water pressure buildup of saturated sands. An example of this correlation is presented in figure 5.33. Also, more consistent results are obtained if strain-controlled rather than stress-controlled tests are conducted. In particular, fabric, which has a large influence on cyclic strength, does not influence significantly the pore water pressure developed during strain-controlled tests. It is suggested that the influence of relative density and of the other factors listed in point (1), on the cyclic strength, is due to a large extent to differences in stiffness between specimens in both compression and extension, which, in turn, induce very different shear strains during stress-controlled tests. This would explain why strain-controlled tests give more consistent results that stress-controlled tests.

3) Results of strain-controlled tests on norma11y consolidated dry and saturated sands by several investigations, using a number of testing techniques, have consistently suggested the existence of a threshold cyclic shear strain, $\gamma_{t} \simeq 10^{-2}$ percent. For strains below this threshold, there is neither densification nor prestraining of dry sands and there is no pore water pressure buildup in saturated sands. An analytical model of the sand constituted by a simple cubic array of quartz spheres predicts similar values of $\gamma_{t}\left(\gamma_{t}=1 \times 10^{-2}\right.$ to $4 \times 10^{-2}$ percent for the range of confining pressures of practical interest). A series of undrained cyclic straincontrolled triaxial tests on saturated Monterey No. 0 sand reported herein measured a value $\gamma_{t}=1.1 \times 10^{-2}$ percent. The experimental data in figures 5.18 and 5.19 indicate that this value of $\gamma_{t}$ for the sand tested is independent of relative density and of confining pressure for the range between about 500 psf and 2,000 psf. This proof of the existence of $\gamma_{t}$, as well as its constant value are powerful arguments in favor of a strain approach to liquefaction.

4) Based on the conclusions above, a cyclic strain approach to liquefaction is proposed. The basic equation of the suggested method (eq. 3.5) requires estimating both the seismic strain induced in the sand layer and the effective shear modulus of the layer during the earthquake. The proposed method is based on measuring the shear modulus in situ at small strains, $G_{\max }$, using geophysical techniques, and on performing cyclic strain-controlled tests in the laboratory to determine: (1) the modulus reduction values, $G / G_{\max }$, (1i) the value of $\gamma_{t}$, and (iii) the pore water pressure buildup $\Delta u$, versus cyclic strain $\gamma$ and number of cycles $n$.

5) A series of 12 undrained strain-controlled cyclic triaxial tests on saturated Monterey No. 0 sand specimens was performed. The tests included nondestructive, high precision measurements at very small strains $\left(\gamma \simeq 10^{-3}\right.$ percent) using an improved technique recently developed by the second author (Ladd), which allowed the measurement of $G_{\max }$ and $\gamma_{t}$ for the sand specimens. In addition to $G_{\max }$ and $\gamma_{t}$, the values of $G / G_{\max }$ and $\Delta u$ needed for the cyclic strain approach were also measured. The results of this test program are presented in chapter 5 where the influence of relative density and confining pressure on $G_{\max }$ and $\gamma_{t}$, and of cyclic strain and number of straining cycles on $G / G_{\max }$ and $\Delta u$ are presented and discussed in detail. 
The results are also compared with similar data obtained by other researchers on Monterey No. 0 sand and other sands, with good agreement.

6) Two outcomes are possible when applying the proposed strain approach to a specific site under a given design peak surface acceleration, $a_{p}$. In the first outcome, which will occur for a low value of $a_{p}$ and/or a stiff sand layer ( $G_{\max }$ large), $\gamma_{c} \lesssim \gamma_{t} \simeq 10^{-2}$ percent, the application of the method is stralghtforward with very small uncertainty, and the method predicts that the risk of liquefaction is negligible. In the second outcome, which will occur for a high value of $a_{p}$ and/or a flexible sand layer ( $G_{\max }$ small), the seismic strain, $\gamma_{c}>\gamma_{t} \simeq 10^{-2}$ percent, and there is risk of liquefaction. In this case, the uncertainty in the application of the method will increase as $\gamma_{c}$ increases above $\gamma_{t}$, due to the uncertainty in the value of $G / G_{\max }$ •

7) Finally, a simplified cyclic strain approach to liquefaction is proposed, almed at determining, for a given site and depth of the sand, the value of the surface peak acceleration inducing the threshold strain in the layer. This is called the threshold peak ground surface acceleration $\left(a_{p}\right)_{t}$. If the design acceleration, $a_{p} \leqslant\left(a_{p}\right)_{t}$, the danger of 1iquefaction can be discarded. If $a_{p}>\left(a_{p}\right)_{t}$, further studies are needed. Simplified charts were developed and are presented in chapter 6 to compute $\left(a_{p}\right)_{t}$ for a given site. The use of these charts require knowing $G_{\max }$, the depth of the layer, the overburden pressure and the depth to groundwater table. These charts are consistent with the historic experience of selsmic liquefaction, and are recomended for preliminary site-specific evaluations. These charts, shown in figures 6.9 through 6.11 , indicate that $\left(a_{p}\right)_{t}$ may be as low as $0.04 \mathrm{~g}$ for a site with low $G_{\max }$ and shallow water table, and as high as $0.20 \mathrm{~g}$ or $0.30 \mathrm{~g}$ for a stiff site having a high measured $G_{\max }$ and a deep water table. 



\section{ACKNOWLEDGMENT}

The authors gratefully acknowledge the contributions by Mr. Paul Dutko and his associates at Woodward-Clyde Consultants, Clifton, NJ, in carrying out the laboratory testing program presented in this report. The contribution of Mr. Gregory Thomas at Rensselaer Polytechnic Institute, who plotted the laboratory results shown in chapter 5, is also gratefully acknowledged. The authors also want to thank Dr. Rune Dyvik and Captain William Plerce at Rensselaer Institute, who reviewed the manuscript and made useful suggestions. A special note of thanks to Mrs. Brenda Thompson and Ms. Ulesia Gray of the Word Processing Center of CBT for the typing and performing the many revisions of this manuscript. 



\section{REFERENCES}

1. Afifi, S. S. and Richart, F. E., Jr., (1973) "Stress-History Effects on Shear Modulus of Solls," Solls and Foundations, Vol. 13, No. 1, March, pp. 77-95.

2. Anderson, D. G. and España, C., (1978) "Evaluation of In Situ Testing Methods for High-Amplitude, Dynamic Property Determination," Report by FUGRO to EPRI, NP-920, November.

3. Anderson, D. G. and Stokoe, K. H., II, (1977) "Shear Modulus: A TimeDependent Material Property," Sym. on Dynamic Soll and Rock Testing, STP 654, ASTM, Denver, June, pp. 66-90.

4. ASCE, (1976) "Liquefaction Problems in Geotechnical Engineering," Preprint 2752, Annual Convention and Exposition, Philadelphia, PA, September 27 October 1 .

5. Auld, B., (1977) "Crosshole and Downhole Vs by Mechanical Impulse," Journal of the Geotechnical Engineering Division, ASCE, No. GT12, December, pp. 1381-1398.

6. Brusch1, A., (1978) "The Earthquake of 23 November 1977 in Caucete, San Juan, Argentina," Newsletter, Earthquake Engineering Research Institute, Vol. 12, No. 2, March, pp. 123-126.

7. BSSA, (1963) Volume 53, with papers on the 1960 Southern Chile Earthquake, Vo1. 53, No. 6, December .

8. Canales, A. R., (1980) "Measurement Techniques and Test Related Variables in Resonant Column Testing," Master Thesis, University of Texas at Austin.

9. Castro, G., (1975) "Liquefaction and Cyclic Mobility of Saturated Sands," Journal of the Geotechnical Engineering Division, ASCE, Vol. 101, No. GT6, June, pp. 551-569.

10. Castro, G. and Poulos, S. J., (1977) "Factors Affecting Liquefaction and Cyclic Mobility," Journal of the Geotechnical Engineering Division, ASCE, Vo1. 103, GT6, June, pp. 501-516.

11. Castro, G. and Poulos, S. J., (1980), Closure to Castro and Poulos (1977), JGED, ASCE, Vo1. 106, No. GT2, February, pp. 211-214.

12. Christian, J. T. and Swiger, W. F., (1975) "Statistics of Liquefaction and SPT Results," Journal of the Geotechnical Engineering Division, ASCE, Vol. 101, No. GT11, November, pp. 1135-1150.

13. Cluff, L. S., (1973) Oral Communication to H.B. Seed, cited by Seed et al., (1975). 
14. DeAlba, P., Chan, C. K. and Seed, H. B., (1975) "Determination of Soil LIquefaction Characteristics by Large Scale Laboratory Tests," Report No. 75-14, Earthquake Engineering Research Center, University of California, Berkeley, May.

15. DeMe11o, V. F. B., (1971) "The Standard Penetration Test," Proceedings, Fourth Pan American Conference on Soll Mechanics and Foundation Engineering, San Juan, Puerto Rico, Vol. 1, pp. 1-86.

16. Deresiewicz, (1973) "Bodies in Contact with Applications to Granular Media," Included in R. D. Mindlin and Applied Mechanics, G. Herrman, Editor, Pergamon Press, NY.

17. Diaz de Cossio, R., (1960) "Foundation Failures During the Coatzacoalcos, Mexico, Earthquake of 26 August 1959," Proc. Second World Conference Earthquake Engineering, Tokyo, Vol.1, Pp. 473-486.

18. Dixon, S. J. and Burke, J. W., (1973) "Liquefaction Case History," Journal of the Soll Mechanics and Foundations Division, ASCE, Vol. 99, No. SM11, pp. 921-937.

19. Dobry, R. and Grivas, Athanasiou D., (1978) "Stress-Strain Relation for Solls Under Earthquake Loading - Technical Background," Report No. 78-2, Department of Civil Englneering, Rensselaer Polytechnic Institute, Troy, NY, July, 77 pages.

20. Dobry, R. and Ladd, R., (1980) Discussion to "Soll Liquefaction and Cyclic Mobility Evaluation for Level Ground During Earthquakes," by H. B. Seed and "Liquefaction Potential: Science versus Practice," by R. B. Peck, Journal of the Geotechnical Engineering Division, ASCE, Vol. 106, GT. 6, June, pp. 720-724.

21. Dobry, R. and Swiger, W. F., (1979) "Threshold Strain and Cyclic Behavior of Cohesionless Solls," Proceedings, Third ASCE/EMDE Specialty Conference, Austin, TX, September 17-19, pp. 521-525.

22. Drnevich, V. P., (1979), "Results of Resonant Column Round Robin Testing Program," (draft), ASTM Subcommittee D18.09, January.

23. Drnevich, V. P. and Richart, F. E., Jr., (1970) "Dynamic Prestraining of Dry Sand," Journal of the SMFD, ASCE, 96, SM2, March, pp. 453-469.

24. Finn, W. D., Liam, (1979) "Role of Foundation Solls in Selsmic Damage Potential," Proceedings, Third Canadian Conference of Earthquake Englneering, Vol. 1, pp. 77-114, June 4-6, Montreal.

25. Geological Survey of India, (1939) "The Bihar-Nepal Earthquake of 1934," Geol. Survey India Mem., Vol. 73, 391 p. 
26. Gibbs, H. J. and Holtz, W. G., (1957) "Research on Determining the Denslty of Sands by Spoon Penetration Testing," Proceedings, Fourth International Conference on Soil Mechanics and Foundation Engineering, London, England.

27. Goodman, L. E. and Brown, (1962) "Energy Dissipation in Contact Friction: Constant Normal and Cyclic Tangential Loading," J. App. Mech., Paper No. 61-WA-29.

28. Hardin, B. O. and Black, W. L., (1968) "Vibration Modulus of Normally Consolidated Clay," Journal of Soll Mechanics and Foundation Division, ASCE, March.

29. Hardin, B. 0. and Drnevich, V. P., (1972) "Shear Modulus and Damping in Solls: Measurements and Parameter Effects," Proceedings, ASCE, 98, No. SM 6, June 1972, pp. 603-624.

30. Hendron, A. J., Jr., (1963) "The Behavior of Sand in One-Dimensional Compression," Ph.D. Thesis, Dept. of Civil Engineering, University of Illinois at Urbana.

31. Hoar, R. J. and Stokoe, K. H., II., (1977) "Generation and Measurement of Shear Waves In Situ," Dynamic Geotechnical Testing, ASTM STP 654, June, pp. 3-29.

32. Hoose, S. N., (1976) Oral Communication to T. L. Youd, cited by Youd (1977).

33. Iwasak1, T., Tatsuoka, F., and Y. Takag1, (1978) "Shear Modul1 of Sands Under Cyclic Torsional Shear Loading," Solls and Foundations, Vo1. 18, No. 1, March, pp. 39-50

34. Johnson, K. L., (1955) "Surface Interaction Between Elastically Loaded Bodies Under Tangential Forces," Proceedings Roy. Soc. A230, pp. 531548.

35. Johnson, K. L., (1961) "Energy Dissipation of Spherical Surfaces in Contact Transmitting 0sc1llating Forces," J. Mechanical Engineering, Sc1.3, pp. 362-368.

36. Kishida, H., (1966) "Damage to Reinforced Concrete Bulldings in Nilgata City with Special Reference to Foundation Engineering," Solls and Foundations, Tokyo, Japan, Vol. VII, No. 1.

37. Kobayash1, H., Seo, K., Midorikawa, S., Yoshimi, Y., Tokno, I., Tokimatsu, K., Katayama, T., and Shibata, H., (1978) "A Report on the Miyagiken-Ok1, Japan Earthquake of June 12, 1978," Proceeding8, Second International Conference on Microzonation, Vol. I, pp. 587-614, San Francisco, November 26 - December 1. 
38. Kolzumi, Y., (1966) "Change in Density of Sand Subsoll Caused by the Nilgata Earthquake", Soils and Foundations, Tokyo, Japan, Vol. VIII, No. 2, pp. 38-44.

39. Kolbuszewsk1, (1948), "General Investigation of the Fundamental Factors Controlling Loose Packing of Sands," Proc. Second Int. Conf. Soil Mech. and Found. Eng., Rotterdam, Vol. 7, pp. 47-49.

40. Kovacs, W. D., (1975) "Discussion of 'On Dynamic Shear Moduli and Poisson's Ratios of Soils Deposits', by Y. Ohsaki and R. Iwasaki," Solls and Foundations, Vol. 15, No. 1, March, pp. 93-96.

41. Kovacs, W. D., Salomone, L. S., and Yoke1, F. Y., (1981) "Energy Measurement in the Standard Penetration Test," National Bureau of Standards, Building Science Series 135, August.

42. Kuribayashi, E. and Tatsuoka, F., (1975) "Brief Review of Liquefaction During Earthquakes in Japan," Solls and Foundations, Vol. 15, No. 4, December.

43. Ladd, R. S., (1977) "Specimen Preparation and Cyclic Stability of Sands," Journal of the Geotechnical Engineering Division, ASCE, Vol. 103, No. GT6, June, pp. 535-547.

44. Ladd, R. S., (1978) "Preparing Test Specimens Using Under Compaction," Geotechnical Testing Journal, ASTM, Vol. 1, No. 1, March, pp. 16-23.

45. Lambe, T. W., and Whitman, R. V., (1969) Soil Mechanics, John Wiley and Sons, New York, NY, 553 pages.

46. Lawson, A. C. and others, (1908) "The California Earthquake of Apri1 18, 1906," Carnegie Institute.

47. Lee, K. L,, and Seed, H. B., (1967) "Cyclic Stress Conditions Causing Liquefaction of Sand," Journal of the Soil Mechanics and Foundations Division, ASCE, Vo1. 93, No. SM1, January, pp. 47-70.

48. Marcuson, W. F., III, Ballard, R. F., Jr., and Cooper, S. S., (1978) "Comparison of Penetration Resistance Values to In Situ Shear Wave Velocities," Proceedings, Second Microzonation Conf., San Francisco, CA, November.

49. Martin, G. R., Finn, W. D. L., and Seed, H. B., (1975) "Fundamentals of Liquefaction under Cyclic Loading," Journal of the Geotechnical Engineering Division, ASCE, Vol. 101, No. GT5, Proceedings Paper 11284 , May, pp. 423-483.

50. Martin, G. R., Finn, W. D. L., and Seed, H. B. (1978) "Effects of System Compliance on Liquefaction Tests," Journal of the Geotechnical Engineering Division, ASCE, Vol. 104, No. GT4, April, pp. 463-479. 
51. Mindlin, R. D., (1949) "Compliance of Elastic Bodies in Contact," Journal of Applied Mechanics, September, pp. 259-268.

52. Mindlin, R. D., Mason, W. P., Osmer, T. F., and Deresiewicz, H., (1951) "Effects of an Oscillating Tangential Force on the Contact Surface of Elastic Spheres," Proceedings, 1st U.S. National Congress of Applied Mechanics, ASME, pp. 203-208.

53. Mindlin, R. D. and Deresiewicz, H., (1953) "Elastic Spheres in Contact Under Varying Oblique Forces," Journal Applied Mechanics, Trans. ASME, pp. 203-208, September.

54. Mulilis, J. P., Chan, C. K., and Seed, H. B. (1975) "The Effects of Method of Sample Preparation on the Cyclic Stress-Strain Behavior of Sands," Report No. EERC 75-18, Earthquake Engineering Research Center, University of California, Berkeley, July.

55. Newmark, N. M. (1967), "Problems in Wave Propagation in Soil and Rock," Proc. Int. Symposium on Wave Propagation and Dynamic Properties of Earth Materials, Albuquerque, New Mexico, pp. 7-26.

56. Ohsaki, Y., (1966) "Niigata Earthquakes, 1964, Building Damage and Soil Conditions," Soils and Foundations, Vol. VI, No. 2, pp. 14-37.

57. Ohsaki, Y., (1969) "Effects of Local Soil Conditions Upon Earthquake Damage," Proceedings, Soil Dynamics Specialty Session, Mexico City, pp. 3-32.

58. Ohsaki, Y. and Iwasaki, R., (1973) "On Dynamic Shear Moduli and Poisson's Ratios of Soil Deposits," Soils and Foundations, Vol. 13, No. 4, December.

59. Park, T. and Silver, M. L., (1975) "Dynamic Soll Properties Required to Predict the Dynamic Behavior of Elevated Transportation Structures," U.S. Dept. of Transportation Report DOT-TST-75-44, May.

60. Peacock, W. H. and Seed, H. B., (1967) "Liquefaction of Saturated Sand Under Cyclic Loading Simple Shear Conditions," Report TE-67-1, Dept. of Civil Engineering, University of California, Berkeley, July.

61. Peck, R. B., (1979) "Liquefaction Potential: Science Versus Practice," Journal of the Geotechnical Engineering Division, ASCE, Vol. 105, No. GT3, March, pp. 393-398.

62. Peck, R. B., (1980) Closure to Peck (1979), JGED, ASCE, Vol. 106, No. GT6, June, pp. 729-730.

63. Powel1, D., (1979) "A Cyclic Strain Approach to Liquefaction of Level Sand Sites," Master Thesis, Dept. of Civil Engineering, Rensselaer Polytechnic Institute. 
64. Pyke, R. M., (1973) "Settlement and Liquefaction of Sands under MultiDirectional Loading," Ph.D. Dissertation, University of California, Berkeley.

65. Pyke, R. M., Chan, C. K. and Seed, H. B., (1974) "Settlement and Liquefaction of Sands under Multi-Directional Shaking," Report No. EERC 74-2, Earthquake Engineering Research Center, University of California, Berkeley, February.

66. Richart, F. E., Jr., (1980) "Influence of Soil Properties on Wave Propagation During Earthquakes," included in State-of-the-Art Report on Dynamic Properties and Behavior of Soils, by Ozaydin, Richart, Dobry, Ishihara, and Marcuson, Proc. Seventh World Conference on Earthquake Engineering, Istanbul, Turkey.

67. Ross, Grant A., (1968) "Case Studies of Soil Stability Problems Resulting from Earthquakes," Ph.D. Dissertation, University of California, Berkeley.

68. Ross, Grant A., Seed, Bolton H., and Migliaccio, Ralph R., (1969) "Bridge Foundations in Alaska Earthquake," Journal of the Soil Mechanics and Foundations Division, ASCE, Vo1. 95, No. SM4, pp. 1007-1036.

69. Schmertmann, J. H., (1977) "Use the SPT to Measure Dynamic Soil Properties? - Yes, But...!," ASTM STP 654 on Dynamic Geotechnical Testing, pp. 341-355.

70. Schmertmann, J. H. and Palacios, A., (1979) "Energy Dynamics of SPT", Journal of the Geotechnical Engineering Division, ASCE, Vo1. 105, No. GT8, August, pp. 909-926.

71. Schnabel, P. B., Lysmer, J., and Seed, H. B., (1972) "SHAKE - A Computer Program for Earthquake Response Analysis of Horizontally Layered Sites," Earthquake Engineering Research Center, Report No. EERC 72-12, University of California, Berkeley.

72. Seed, H. B., (1968) "Landslides During Earthquakes Due to Liquefaction," Journal of the Soil Mechanics and Foundations Division, ASCE, Vol. 94, No. SM5, Proceedings Paper 6110, September, pp. 1053-1122.

73. Seed, H. B., (1976) "Some Aspects of Sand Liquefaction Under Cyclic Loading," Proceedings, Conference on Behavior of offshore Structures (BOSS), The Norwegian Institute of Technology.

74. Seed, H. B., (1979) "Soil Liquefaction and Cyclic Mobility Evaluation for Level Ground During Earthquakes," Journal of the Geotechnical Engineering Division, ASCE, Vo1. 105, No. GT2, February, pp. 201-255.

75. Seed, H. B., (1980) Closure to "Soil Liquefaction and Cyclic Mobility Evaluation for Level Ground During Earthquakes," Journal of the Geotechnical Engineering Division, ASCE, Vol. 106, GT6, June, p. 724. 
6. Seed, H. B. and Idriss, I. M., (1967) "Analysis of Soil Liquefaction: Nilgata Earthquake," Journal of the Soll Mechanics and Foundations Division, ASCE, Vo1. 93, No. SM3, Proceedings Paper 5233, May, pp. 83-108.

7. Seed, H. B. and Idriss, I. M., (1970) "Soil Modull and Damping Factors for Dynamic Response Analyses," Earthquake Engineering Research Center Report No. EERC 70-10, University of California, Berkeley, December.

18. Seed, H. B. and Idriss, I. M., (1971) "Simplified Procedure for Evaluating Sol1 Liquefaction Potential," Journal of the Soll Mechanics and Foundations Division, ASCE, Vo1. 97, No. SM9, September, pp. 1249-1274.

79. Seed, H. B. and Lee, K. L., (1965) "Studies of Liquefaction of Sands Under Cyclic Loading Conditions," Report No. TE-65-65, Dept. of Civil Engineering, University of California, Berkeley.

80. Seed, H. B., Arango, I., and Chan, C. K., (1975) "Evaluation of Soll Liquefaction Potent1al During Earthquakes," Report No. EERC 75-28, Earthquake Engineering Research Center, University of California, Berkeley, October.

81. Seed, H. B., Idriss, I. M., Makdis1, F., and Banerjee, N., (1975a) "Representation of Irregular Stress Time Histories by Equivalent Uniform Stress Series in Liquefaction Analyses," Report No. EERC 75-29, Earthquake Engineering Research Center, University of California, Berkeley, October.

82. Silver, M. L., (1975) "Laboratory Triaxial Testing Procedures to Determine the Cyclic Strength of Sol1s," Report No. NUREG-31, U.S. Nuclear Regulatory Commission, Washington, DC.

83. Silver, M. L. and Seed, H. B., (1971) "Volume Changes in Sands During Cyclic Loading," Journal Soil Mechanics and Foundations Division, ASCE, Vo1. 97, No. SM9, p. 1171, September.

84. Stokoe, K. H., II. and Woods, R. D., (1972) "In Situ Shear Wave Velocity by Crosshole Method," Journal of the Soil Mechanics and Foundations Division, ASCE, Vo1. 98, No. SM5, May, pp. 443-460.

85. Tatsuoka, F., Iwasak1, T., Fukushima, S., and Sudo, H., (1979) "Stress Conditions and Stress Histories Affecting Shear Modulus and Damping of Sand Under Cyclic Loading," Sol1s and Foundations, Vo1. 19, No.2, June, pp. 29-43.

86. Whitman, R. V., (1971) "Resistance of Soll to Liquefaction and Settlement," Solls and Foundations, Japanese Society of Soll Mechanies and Foundation Engineering, Vo1. 11, No. 4, December, pp. 59-68.

87. Woods, R. D., (1978) "Measurement of Dynamic Soll Properties," Proceedings of the Earthquake Engineering and Sol1 Dynamics Conference, Geotechnical Engineering Division, ASCE, Pasadena, CA, June, pp. 91-178. 
88. Xie Junfei, (1979) "Empirical Criteria of Sand Liquefaction," Special Session on Earthquake Engineering in China, Second U.S. National Conference on Earthquake Engineering, pp. 10-22, Stanford University, August 22-24.

89. Yamamura, K., Iwasaki, T., Sasaki, Y•, Koga, Y., Taniguchi, E., and Tokida, K., (1979) "Ground Failures and Damages to Soil Structures From the MiyagiKen-Ok1, Japan Earthquake of June 12, 1978," Publication, Public Work Research Institute, Ministry of Construction, Japan.

90. Yegian, M. K., (1976) "Risk Analysis for Earthquake-Induced Ground Failure By Liquefaction," Report No. R76-22, Dept. of Civil Engineering, M.I.T., Cambridge, MA, May.

91. Yegian, M. K. and Whitman, R. V., (1978) "Risk Analysis for Ground Failure by Liquefaction," Journal of the Geotechnical Engineering Division, ASCE, Vol. 104, No. GT7, July, pp. 921-938.

92. Youd, T. L., (1972) "Compaction of Sands by Repeated Shear Straining," Journal of the SMFD, ASCE, 98, SM7, July, pp. 709-725.

93. Youd, T. L., (1975) "Liquefaction, Flow and Associated Ground Failure," Proceedings, U. S. National Conference on Earthquake Engineering, Ann Arbor, MI, June.

94. Youd, T. L., (1977) "Discussion of 'Brief Review of Liquefaction During Earthquakes in Japan' by E. Kuribayashi and F. Tatsuoka," Soils and Foundations, Vol. 17, No. 1, March, pp. 82-84.

95. Youd, T. L., (1977a), "Packing Changes and Liquefaction Susceptibility," Journal of the Geotechnical Engineering Division, ASCE, Vo1. 103, No. GT8, August, pp. 918-922.

96. Youd, T. L. and Castle, R. O., (1970) "Borrego Mountain Earthquake of April 8, 1968," American Society of Civil Engineering, Journal of Soil Mechanics and Foundations Division, Vol. 96, No. SM4, pp. 1201-1219.

97. Youd, T. L. and Hoose, S. N., (1976) "Liquefaction During 1906 San Francisco Earthquake," American Society of Civil Engineering, Journal of the Geotechnical Engineering Division, Vol. 102, No. GT5, pp. 425-439.

98. Youd, T. L., Tinsley, J. C., Perkins, D. M., King, E. J., and Preston, R. F., (1978) "Liquefaction Potential Map of San Fernando Valley, California," Proceedings Second International Conference on Microzonation, San Francisco, November 26 - December 1, Vol. I, pp. 267-278. 


\section{APPENDIX}

Calculations of Cyclic Triaxial Tests Results

From the measured peak axial loads and axial deformations within a given cycle, cyclic deviator stresses and axial strains are computed using the specimen dimensions after consolidation. No corrections were made for the affect of the rubber membrane.

The shear strain amplitude is calculated from the axial strain amplitude using the following equation:

$$
\pm \gamma= \pm \varepsilon(1+\nu)=\frac{\Delta \mathrm{L} p \mathrm{pp}}{2 \mathrm{H}_{\mathrm{c}}} \times(1+\nu)= \pm 1.5 \varepsilon
$$

where:

$$
\begin{aligned}
+\gamma & =\text { shear strain amplitude (in/in) } \\
\underline{+\varepsilon} & =\text { axial strain amplitude (in/in) } \\
\Delta \mathrm{L}_{\mathrm{pp}}= & \text { peak-to-peak axial deformation measured within a given } \\
& \text { loading cycle using the oscillograph recorder } \\
\mathrm{H}_{\mathrm{c}} & =\text { height of specimen after consolidation } \\
\nu & =\text { Poisson's ratio; a value of } 0.5 \text { was used in all tests. }
\end{aligned}
$$

The shear modulus is calculated using the following equation:

$$
G=\frac{E}{2(1+\nu)}=\frac{p_{p p} \times H_{c}}{3 A_{c} \times L_{p p}}
$$

where:

$\mathrm{G}=$ shear modulus

$E=$ Young's modulus

$\mathrm{p}_{\mathrm{pp}}=$ peak-to-peak axial load measured within a given loading cycle using the oscillograph recorder

$A_{c}=$ area of specimen after consolidation

Calculated values of shear strain amplitude and shear modulus were also corrected for sample setup compliance using the following equations:

$$
\begin{aligned}
\pm \gamma_{c} & = \pm \gamma \times C F \\
G_{c} & =G / C F
\end{aligned}
$$

where:

$$
\begin{aligned}
\pm \gamma_{c}= & \text { shear strain amplitude corrected for equipment compliance } \\
\mathrm{G}_{\mathrm{c}}= & \text { shear modulus corrected for equipment compliance } \\
\mathrm{CF}= & \text { correction factor for equipment compliance obtained from a } \\
& \text { curve such as that presented in figure } 5.2 \text {. }
\end{aligned}
$$


The data presented in figure 5.2 represent the results of a series of special tests in which each test was individually corrected for equipment compressibility. This correction consisted of correcting each recorded value of $\Delta \mathrm{L}_{\mathrm{pp}}$ by subtracting away the peak-to-peak axial deformation of a steel cylinder grouted into the cell in the same manner as the text specimens and at a confining pressure and peak-to-peak axial load similar to that which was recorded when $\Delta \mathrm{L}_{\mathrm{pp}}$ was determined.

During the cell calibration and from test to test, the same stones, platens, etc., are used. In addition, these items were indexed in such a manner that they are in the same position from test-to-test. 
BIBLIOGRAPHIC DATA

SHEET (See instructions)

4. TITLE AND SUBTITLE

Prediction of Pore Water Pressure Buildup and Liquefaction of Sands

During Earthquakes by the Cyclic Strain Method

5. $A U T H O R(S)$

R. Dobry, R.S. Ladd, F.Y. Yokel, R,M. Chung, and D. Powell

6. PERFORMING ORGANIZATION (If joint or other than NBS, see in structions)

NATIONAL BUREAU OF STANDARDS

DEPARTMENT OF COMMERCE

WASHINGTON, D.C. 20234

9. SPONSORING ORGANIZATION NAME AND COMPLETE ADDRESS (Street. City, State, ZIP)

7. Contract/Grant No.

8. Type of Report \& Period Covered

Final

Same as 6.

10. SUPPLEMENTARY NOTES

Library of Congress Catalog Card Number: 82-600561

Document describes a computer program; SF-185, FIPS Software Summary, is attached.

11. ABSTRACT (A 200-word or less factual summary of most significant information. If tocument includes a significant bibliography or literature survey, mention it here)

A cyclic strain approach for evaluating the buildup of excess pore water pressures and the potential for liquefaction of level sandy sites during earthquakes is proposed in this report. This strain approach is based on the premise that, for undrained loading of sand, there is a predictable correlation between cyclic shear strain and excess pore water pressure; also, that there is a threshold shear strain below which there is no sliding at the contacts between sand particles and no pore water pressure buildup can occur. As the result, a sand deposit will not develop excess pore pressures if the induced seismic shear strain is less than the threshold strain. Both theoretical evidence and experimental verification supporting the cyclic strain approach and the existence of the threshold, are presented in the report. Based on all these findings, a specific design method is proposed for predicting if excess pore pressures will develop at a specific site during a design earthquake.

12. KEY WORDS (Six to twelve entries; alphabetical order; capitalize only proper names; and separate key words by semicolons) cyclic strain; damping ratio; earthquake engineering; laboratory testing; 1iquefaction; particulate mechanics; particulate model; pore water pressure; sand; seismic loading; shear modulus; shear strain; site stability.

13. AVAILABILITY

$\mathrm{X}$ Unlimited

$\square$ For Official Distribution. Do Not Release to NTIS

[ $\mathrm{X}$. Order From Superintendent of Documents, U.S. Government Printing Office, Washington, D.C. 20402.

14. NO. OF PRINTED PAGES

168

[] Order From National Technical Information Service (NTIS), Springfield, VA. 2216I 





\section{NBS TECHNICAL PUBLICATIONS}

\section{PERIODICALS}

JOURNAL OF RESEARCH-The Journal of Research of the National Bureau of Standards reports NBS research and development in those disciplines of the physical and engineering sciences in which the Bureau is active. These include physics, chemistry, engineering, mathematics, and computer sciences. Papers cover a broad range of subjects, with major emphasis on measurement methodology and the basic technology underlying standardization. Also included from time to time are survey articles on topics closely related to the Bureau's technical and scientific programs. As a special service to subscribers each issue contains complete citations to all recent Bureau publications in both NBS and nonNBS media. Issued six times a year. Annual subscription: domestic $\$ 18$; foreign $\$ 22.50$. Single copy, $\$ 4.25$ domestic; $\$ 5.35$ foreign

\section{NONPERIODICALS}

Monographs-Major contributions to the technical literature on various subjects related to the Bureau's scientific and technical activities.

Handbooks-Recommended codes of engineering and industrial practice (including safety codes) developed in cosperation with interested industries, professional organizations, and regulatory bodies.

Special Publics -lnclude proceedings of conferences sponsored by NBS, , annual reports, and other special publications appropriate to this grouping such as wall charts, pocket cards, and bibliographies.

Applied Mathematics Series-Mathematical tables, manuals, and studies of special interest to physicists, engineers, chemists, biologists, mathematicians, computer programmers, and others engaged in scientific and technical work.

National Standard Reference Data Series-Provides quantitative data on the physical and chemical properties of materials, compiled from the world's literature and critically evaluated. Developed under a worldwide program coordinated by NBS under the authority of the National Standard Data Act (Public Law 90-396).

NOTE: The principal publication outlet for the foregoing data is the Journal of Physical and Chemical Reference Data (JPCRD) published quarterly for NBS by the American Chemical Society (ACS) and the American Institute of Physics (AIP). Subscriptions, reprints, and supplements available from ACS, 1155 Sixteenth St., NW, Washington, DC 20056.
Building Science Series-Disseminates technical informatıon developed at the Bureau on building materials, components, systems, and whole structures. The series presents research results, test methods, and performance criteria related to the structural and environmental functions and the durability and safety characteristics of building elements and systems.

Technical Notes-Studies or reports which are complete in themselves but restrictive in their treatment of a subject. Analogous to monographs but not so comprehensive in scope or definitive in treatment of the subject area. Often serve as a vehicle for final reports of work performed at NBS under the sponsorship of other government agencies.

Voluntary Product Standards-Developed under procedures published by the Department of Commerce in Part 10, Title 15, of the Code of Federal Regulations. The standards establish nationally recognized requirements for products, and provide all concerned interests with a basis for common understanding of the characteristics of the products. NBS administers this program as a supplement to the activities of the private sector standardizing organizations.

Consumer Information Series-Practical information, based on NBS research and experience, covering areas of interest to the consumer. Easily understandable language and illustrations provide useful background knowledge for shopping in today's technological marketplace.

Order the above NBS publications from: Superintendent of Documents, Government Printing Office, Washington, DC 20402.

Order the following NBS publications-FIPS and NBSIR's-from the National Technical Information Services, Springfield, VA 22161.

Federal Information Processing Standards Publications (FIPS PUB)-Publications in this series collectively constitute the Federal Information Processing Standards Register. The Register serves as the official source of information in the Federal Government regarding standards issued by NBS pursuant to the Federal Property and Administrative Services Act of 1949 as amended, Public Law 89-306 (79 Stat. 1127), and as implemented by Executive Order 11717 (38 FR 12315, dated May 11. 1973) and Part 6 of Title 15 CFR (Code of Federal Regulations).

NBS Interagency Reports (NBSIR) - A special series of interim or final reports on work performed by NBS for outside sponsors (both government and non-government). In general, initial distribution is handled by the sponsor; public distribution is by the National Technical Information Services, Springfield, VA 22161. in paper copy or microfiche form. 
U.S. DEPARTMENT OF COMMERCE

National Bureau of Standards

Washington, DC 20234

OFFICIAL BUSINESS

Penalty for Private Use, $\$ 300$
POSTAGE AND FEES PAID COM-215
CDENT OF CDMMERCE

THIRD CLASS 